\title{
Canada and the Cultural Trade Quandary: \\ Rethinking National Identity, Economic Liberalization, and \\ Policy Capacity
}

\author{
By \\ Jason Bristow
}

\author{
A thesis submitted to the \\ Faculty of Graduate Studies \\ in partial fulfillment of \\ the requirements for the degree of \\ Doctor of Philosophy Mass Communication
}

Carleton University

Ottawa, Ontario

c 2003 


\author{
National Library \\ of Canada \\ Acquisitions and \\ Bibliographic Services \\ 395 Wellington Street \\ Ottawa ON K1A ON4 \\ Canada
}

Bibliothèque nationale

du Canada

Acquisisitons et services bibliographiques

395 , rue Wellington Ottawa ON K1A 0N4 Canada
Your file Votre référence ISBN: 0-612-89884-9 Our file Notre référence ISBN: 0-612-89884-9
The author has granted a nonexclusive licence allowing the National Library of Canada to reproduce, loan, distribute or sell copies of this thesis in microform, paper or electronic formats.

The author retains ownership of the copyright in this thesis. Neither the thesis nor substantial extracts from it may be printed or otherwise reproduced without the author's permission.
L'auteur a accordé une licence non exclusive permettant à la Bibliothèque nationale du Canada de reproduire, prêter, distribuer ou vendre des copies de cette thèse sous la forme de microfiche/film, de reproduction sur papier ou sur format électronique.

L'auteur conserve la propriété du droit d'auteur qui protège cette thèse. $\mathrm{Ni}$ la thèse ni des extraits substantiels de celle-ci ne doivent être imprimés ou aturement reproduits sans son autorisation.
In compliance with the Canadian Privacy Act some supporting forms may have been removed from this dissertation.

While these forms may be included in the document page count, their removal does not represent any loss of content from the dissertation.
Conformément à la loi canadienne sur la protection de la vie privée, quelques formulaires secondaires ont été enlevés de ce manuscrit.

Bien que ces formulaires aient inclus dans la pagination, il n'y aura aucun contenu manquant. 


\begin{abstract}
Twin themes inspire this study: Canadian concern over the import of American entertainment, which pre-dates Confederation and is part of the reason for cultural policy; and suspicion over cultural globalization, the contemporary notion that national cultures are being diluted and homogenized. The issue - the quandary - becomes focussed at two levels: for policy, over how to reconcile cultural measures with trade liberalization; for mass communication theory, over the idea that cultural products (motion pictures, TV programming, books, magazines, and sound recording) have a role beyond entertainment to reflect domestic culture and foster national identity. The question of how, exactly, foreign entertainment content influences domestic culture and identity has been a scholarly blindspot.

It is my thesis that through a consideration of the theories, and review of the literature, on cross-cultural influence we will be able to better reconcile Canadian cultural policy with trade liberalization. To demonstrate that the International Instrument on Cultural Diversity (IICD) merits serious attention, the first part of the study surveys how different trade systems treat cultural products, then goes on to analyze the proposed texts and the two-level politics of implementation. The theoretical part of the study follows two avenues. Looking for a direct answer, it reviews the theoretical development and empirical experiments of several approaches to the cross-cultural influence question. Indirectly, the concepts of national identity and culture are examined in order to determine valid limits for claims of influence and change.

It will be argued that the new approach of seeking rules-based recognition is superior to the older route of pursuing an exemption. The policy portion concludes in favour of cautious optimism: that the IICD, looking like it will be adopted by 2005 , will soften trade dispute norms in the cultural sector despite the uncertain relationship between the IICD and institutions of international trade and politics. The conceptual portion will synthesize several points that should be foundational for any policy prescription: while trade of cultural products is global, interpretation remains local; interpretation is shaped by numerous factors of socialization, which lead away from concluding for direct influence; and that philosophical and methodological challenges inherent in national identity and culture impose formidable limits to any claim of change.
\end{abstract}




\section{Acknowledgments}

More people than one might guess support, openly cheer, silently suffer, and run . alongside any thesis as it wends its way down a very long path, from birth of the idea to the day of the oral defence. My process has been no different from any other Ph.D student's, though my honour role has.

Professionally, I would like to gratefully acknowledge the role my supervisor, Michael Dorland, played, from the time I approached him about serving in this capacity, in September 1999 , to his agreement to continue to participate when he otherwise would not have had to, during his sabbatical in Paris, in the Fall of 2003. Michael was steady, positive, and saw himself as part sherpa, part coach to the marathon. Paul Attallah and Karim Karim, Mass Communication faculty members who round out my internal examining committee, also deserve a doff of the hat, Karim for his support and valuable advice, and Paul for his relentless enthusiasm, close reading of the first draft, and for assuming an informal supervisory role during the end-game and defence itself.

Widening the circle, Dennis Browne, Emeritus Executive Director of Carleton's Center for Trade Policy and Law read my original cultural trade paper, the seed for this thesis, in the Spring of 1999, invited me to his house for a good-natured and thorough critique, then suggested two university courses that contributed immeasurably to the development of my thinking. Christopher Sands, Director of the Canada Project at the Center for Strategic and International Studies, in Washington, D.C., and himself a Ph.D. candidate (at Johns Hopkins), gave a detailed and unflinching reaction to a paper written in 2001, the next step in the development of ideas that became this thesis, and has been encouraging, especially when the lights of academic opportunity appeared to dim. Christopher Maule, Distinguished Professor in Economics and International Affairs at Carleton University, gave generously of his time and his deeply informed advice, both during the research and writing phase and again at the conclusion, by participating as an external examiner in the oral defence. Nancy Peden, Carleton University Reference Librarian extraodinaire was wonderfully helpful as I rounded every corner, orienting my database searches, streamlining my literature reviews, ordering books, and helping to track down and retrieve archival material (some of it fifty years old and classified by the U.S. State Department). 
Widening the circle once more, Michael Hawes, Mark Kasoff, Rostam Neuwirth, and Greg Donaghy, have each helped, contributing insight on the subject matter, providing an opportunity to publically test the ideas, reading and commenting on particular chapters, and locating and providing GATT documents buried deep in storage. Finally, I would like to thank Reginald Stuart, Professor of History and Political Studies at Mount Saint Vincent University, whose response has and will continue to shape these arguments and this research as I attempt the transformation from thesis to book.

The personal side of the ledger is no less important, and I do have many friends, acquaintances, and family, scattered in Ottawa, Winnipeg, and Calgary, to thank. Darrel Houlahan, Regan Khan, Carla Ventin, Marie-Andree Poupart, Josee Villeneuve, Brent Clute, Heather De Santis, Dennis Price, Taylor Hladik, and Sonya Thissen deserve mention by name. Two notches above the rest, my girlfriend, Marta Stelmaschuk, who lived with this thesis every bit as much as I did, deserves my sincerest thanks for her encouragement, patience, and proofreading skills. My parents, Gerry and Carol, also are deeply deserving of gratitude, for their emotional, spiritual, material, and financial support, without which this thesis would never have seen print. 


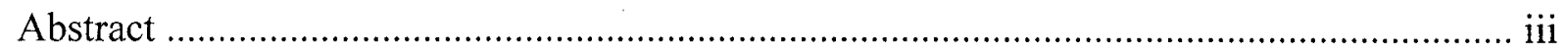

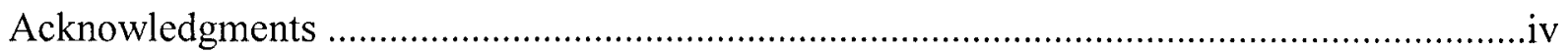

Introduction: Understanding the Cultural Trade Quandary ............................................... 1

Chapter 1: The Treatment of Cultural Products within the Trading System ........................ 26

Chapter 2: The Two-Level Policy Chessboard ...................................................................... 58

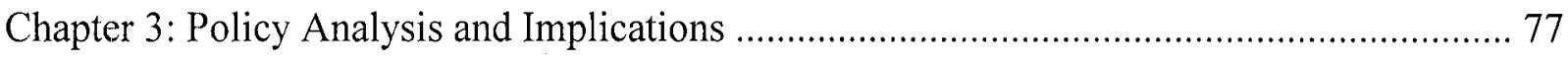

Chapter 4: The Influence of Media Content on Culture ................................................ 116

Chapter 5: Formidable Limits: Perspectives on National Identity and Culture ..................... 144

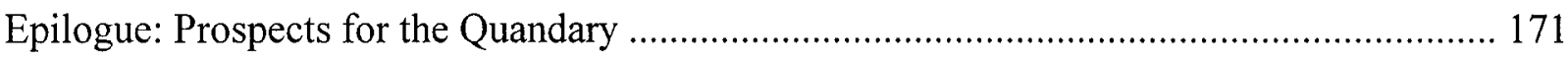

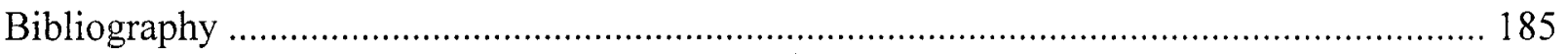




\section{Introduction:}

\section{Understanding the Cultural Trade Quandary}

"Throughout the period since the end of the Second World War until recent changes in both the political culture and intellectual orientation that may be associated with the Free Trade Agreement and the North American Free Trade Agreement, 'identity' was the key term through which the will to maintain, or develop, an independent Canada was expressed." Ian Angus (1997)

On July $1^{\text {st }}, 2002$ - Canada Day - the Globe and Mail ran an article under the headline, "Dominant U.S. culture worries Canadians." According to the piece, $61 \%$ of Canadians "defined the threat [of American culture] as very or somewhat important." On January $27^{\text {th }}, 1997$, approximately 51/2 years earlier, then-International Trade Minister Art Eggleton spoke at Osgoode Hall Law School, under the title: "Can Canada Maintain its Cultural Identity in the Face of Globalization?" He acknowledged "[o]ur need to remain open to the world while continuing to champion Canadian culture has long proved a tricky balancing act," (5) referring to the permeable line that distinguishes acceptable from unacceptable cultural policy measures. A minute before in his speech, he had placed a higher wager: "The survival of the strong, distinctive Canadian voice is closely linked to the survival of a strong and distinctive Canada," (2) and "The global economy will have an impact on national cultures at least as great as its impact on national economies." $(3)^{1}$

The connection between cultural survival and political existence, and concerns about imported foreign entertainment, extend back to Canada's Confederation. Thomas D'Arcy McGee was aware of the role culture "helped play in defining, building, and consolidating a community" (Smith 8). U.S. magazines had attained very wide circulation in late $19^{\text {th }}$ Century Canada, to the consternation of elites who lamented the displacement of British periodicals. U.S. motion pictures dominated Canadian movie screens by the 1920 s, and by 1925 , U.S. radio stations ruled

\footnotetext{
1 "Dominant U.S. Culture Worries Canadians, poll shows" Globe and Mail July 1, 2002: A6. Art Eggleton's speech quoted from Notes for an Address by the Honourable Art Eggleton, Minister for International Trade, on the Occasion of a Panel Discussion: "Can Canada Maintain its Cultural Identity in the Face of Globalization."
} 
the airwaves in Canada - of 96 available frequencies on the electromagnetic spectrum, Canadian stations occupied 8 and shared 11 with American stations. By mid-century, the Massey Commission (1951) would assert a direct link between political independence and cultural autonomy. Motion pictures, books and periodicals, radio and television broadcasting were not simply entertainment, but culturally powerful media and content, possessing the ability to cultivate tastes and morals, shape the self-image of a people, nurture or erode the critical faculties necessary for democracy, foster a national spirit, and ultimately define and consolidate a nation. In a once often-quoted remark, John K. Galbraith said (in 1968) about the political ramifications of foreign ownership and control of cultural institutions: "If I were still a practicing, as distinct from an advisory Canadian, I would be much more concerned about maintaining the cultural integrity of the broadcasting system and of making sure that Canada has an active independent theatre, book publishing industry, newspapers, magazines and schools of poets and painters" $(89) .^{2}$

In the effort to fortify national culture, Canadian cultural policy has incorporated an array of measures: foreign investment restrictions, tariffs and content quotas, subsidies and grants, tax incentives, and miscellaneous others, some of which, like the different commercial postal rates for foreign and domestic magazines, had been in place since 1857. Beginning in the 1960s, the acceptability of some of these cultural policy measures were called into question, because the progressive liberalization of trade had drawn more of the measures within its scope and subjected them to increasing scrutiny. The increasing interface - and dissonance - between international trade agreements and domestic cultural policy, like ripples in a reflecting pool, has led to an escalating number of irritants, disputes, and dire predictions about cultural policy in an era of economic liberalization. In 1977, Roger Swanson wrote that "U.S. tolerance levels [of Canadian cultural measures] are not as high as they were a few years ago" (63). In 1994, with such tension

\footnotetext{
${ }^{2}$ Quote from Allan Smith (1990) "Canadian Culture, the Canadian State, and the New Continentalism," Canadian-American Public Policy (October, 3), Orono, ME: U Maine P. Assertion of early penetration of U.S. periodicals from Allan Smith (1976) "The Continental Dimension in the Evolution of the English-Canadian Mind" International Journal (31): 442-469; and John Charles Weaver (1973) Imperilled Dreams: Canadian Opposition to American Empire, 1918-1930, unpublished Ph.D. dissertation, Duke University, particularly Chapter 7, "Americanization in Full Stride" (pp. 298-333). Galbraith quote in Richard Bowles (1973) Canada and the US: Continental Partners or Wary Neighbours?, Scarborough, ON: Prentice-Hall.
} 
on the rise, Joyce Zemans wrote that "the cultural domain...shows every sign of becoming increasingly complicated over the next months and years" (512). A crescendo was reached, in 2000 , in Ivan Bernier's statement that "Unless something is done in the coming years to solve the problem, chances are that the existing tension between trade and culture will increase rather than decrease" (3). ${ }^{3}$

These issues are the subject matter of this thesis: the presumed link between national culture and entertainment, and the quest to reconcile cultural policy with open trade. What is the relationship between entertainment - or cultural - products and the underlying national culture? Do motion pictures, printed material, and television programming contribute to national identity, or strengthen national bonds, in any tangible way? And do the policies themselves promote expressions of national culture, or are they disguised trade restrictions that foster uninspiring entertainment? Swirling amid these questions are others. What is the difference between culture and entertainment? Is there any self-evident line of demarcation, any principle independent of taste, that can be used to distinguish between cultural products and entertainment? Is there a definite cultural connection between ownership and content? (For instance, Does a Canadian production automatically result in Canadian content?) The research question that animates the thesis is, What influence does foreign entertainment have on national culture and identity; and given this influence and its limits, what policy will best reconcile open trade with the promotion of national culture? Abstract and general, this question will be rooted in Canadian thinking because no other country has more experience with, and a richer literature devoted to understanding, the cultural trade quandary. In the Canadian setting, therefore, we can begin to find answers that are concrete and specific.

To understand the cultural trade quandary, one needs to appreciate Canadian thinking on

\footnotetext{
${ }^{3}$ Postal rate difference from a lecture by William Fizet, Director (Periodical Publishing Policy \& Programs), Canadian Heritage, March $5^{\text {th }}$, 2003. Roger Frank Swanson (1977) "Canadian Cultural Nationalism and the U.S. Public Interest" Janice L. Murray (ed.), Canadian Cultural Nationalism (pp. 55-84), NY: NYUP; Joyce Zemans (1994) "And the Lion Shall Lie Down with the Lamb: U.S.-Canada Cultural Relations in a Free Trade Environment" American Review of Canadian Studies 24(4): 509-536; and Ivan Bernier (2000) "The World Trading System and Culture: Looking at the Problem from a Cultural Perspective" Speech given at Culture in a World of Trade Conference, March $3^{\text {rd }}, 2000$, New York University. Allan Smith (1990), op cit. note \#2, characterizes cultural policy as having two broad periods: first, from 1860 s until the 1950 s, cultural policy meant the creation of institutions, and second, from the 1950s onwards, cultural policy meant the creation of policy itself.
} 
the "national question," which is a focal point where ideas about political existence, survival, economic development and destiny have come together to shape the Canadian psyche. And to appreciate the nature of the national question, one must understand the historical development of the Canada-U.S. relationship. The Canada-U.S. relationship is the interior monologue of the quandary, omnipresent yet not always apparent: sometimes a stream of consciousness that flows from the background of myths, history, doubts, and circumstance; occasionally a dialogue, when it gets channeled into debating Canada-U.S. free trade, as it did during the 1988 federal election. But views about the long-run Canada-U.S. relationship have always permeated the background of Canadian thinking. Canada-U.S. relations comprise the material conditions, and as interior monologue are also the existential motivations, that frame and animate my research question. The terms in the sub-title - national identity, economic liberalization, and policy capacity extrude from the monologue, and are shaped specifically by the quandary, so that discussion of these co-ordinating ideas will lend depth of perspective to the thesis arguments and answers that follow.

The first idea to develop is economic liberalization, because the quandary has arisen in response to economic and trade liberalization. The relaxing or elimination of barriers to commercial exchange across borders leads to economic integration, where two or more political jursidictions begin to approximate a common market. Liberalization is the common denominator to both North American economic integration and globalization, the difference simply a matter of scale - continental or global. As George Hoberg (2002) writes "North American integration is one part of the more general phenomenon of globalization" (4). The purpose of this section is to outline the trend of economic integration, and to grasp with some precision the degree of integration. The embedded idea is whether a more open, and closer, economic relationship between Canada and the United States would strengthen Canada politically by generating economic prosperity, or whether, by erasing the border for commercial purposes, it would dissolve political difference and reawaken $19^{\text {th }}$-century demands for political union. The title of Jack Granatstein's article (1985), “The Issue That Will Not Go Away,” captures the primordial 
and lasting place of this question in Canadian history. ${ }^{4}$

For the majority of the $19^{\text {th }}$ century, the economic and political relationship of Canada and the United States was about the existence of Canada. From the abolition of British Corn Laws, in 1846, which gave preferential treatment of Canadian grains and timber, Canada sought improved U.S. market access. Access moved along a spectrum, from restricted reciprocity, on one end, to political union, on the other. The abolition of British preferences prompted the failed Annexation Movement in Montreal in 1849, and the successful ratification of the Elgin-Marcy Reciprocity Treaty in 1854 . After the treaty was abrogated by the U.S. Senate in 1866 , due to anti-British feeling and need for tariff revenue to pay Civil War costs, there were three more attempts to renegotiate reciprocity made between Confederation, in 1867, and the implementation of the National Policy, in 1879. This demonstrates that greater U.S. market access, a form of integration or continentalism, was preferred to economic nationalism or protection. The early national period, from 1867 until 1900, was a 33-year-long economic dark age for Canada. Coinciding with another unsuccessful attempt to negotiate reciprocity in 1891, the liberal-continentalist Goldwin Smith penned Canada and the Canadian Question, casting doubt on the future of a sovereign existence for Canada by advocating political union based on geography, commerce, and demography. ${ }^{5}$

${ }^{4}$ George Hoberg (2002). Capacity for Choice, Toronto, UTP. Jack Granatstein (1985), "The Issue That Will Not Go Away" in Denis Stairs and Gilbert Winham (Eds.), The Politics of Canada's Economic Relationship with the United States, (pp. 1 1-54). Toronto: UTP. See also Allan Smith (2000) "Doing the Continental: Conceptualizations of the Canadian-American Relationship in the Long Twentieth Century" Canadian-American Public Policy 44 (December); and Kim Richard Nossal (1985) "Economic Nationalism and Contintental Integration: Assumptions, Arguments and Advocacies," in The Politics of Canada's Economic Relationship with the United States (pp. 55-94); John H. Thompson and Stephen J. Randall (2002) Canada and the United States: Ambivalent Allies, $3^{\text {rd }}$ ed. especially Chapter 11, “A North American Trajectory? 1994-2001" (pp. 297-317), Athens, GA.: U Georgia P.

${ }^{5}$ Gordon Stewart (1992) The American Response to Canada Since 1776, East Lansing: MSUP, especcially pps. 78-9 for U.S. Senate abrogation; and Michael Hart (2002) A Trading Nation: Canadian Trade Policy From Colonialism to Globalization, Vancouver, BC: UBC P, especially pp. 51-52. Description of futile Canadian attempts to re-negotiate reciprocity in Hart and also Stephen J. Randall (2000) "Integrating Canada and the U.S.: The Historical Framework" Canadian Journal of Policy Research 1(1): 32-38, but especially p. 34 . The early national period was economically bleak due to a small national market, undeveloped industrial sector, and inadequate access to capital (Hart [2002] p. 61-62). See Allan Smith (2000), op cit. note \#4 for corroboration of Goldwin Smith's prescription. Donald F. Warner (1960) The Idea of Continental Union: Agitation for the Annexation of Canada to the United States, 1849-1893 provides a book-length treatment of the topic of this paragraph. For the first 50 years of the $19^{\text {th }}$ Century, the relationship was characterized by belligerence, territorial 
The empirical evidence from Confederation to the Second World War reveals the shifting triangular pattern of economic integration. The direction and volume of trade shifted between the U.K. and the U.S., the U.S. rising steadily as, first, the leading importer, then the leading export destination. By 1883, U.S. imports had displaced U.K. imports in Canada. The U.S. and U.K. alternated as leading export destinations throughout the 1920s and 1930s (the U.S. leading from 1921-1931, the U.K. from 1932-1938 and again from 1940-1942), but through Canada's first 75 years, trade overall tilted away from the U.K. and toward the U.S., like a slow-swinging pendulum. Investment was different. U.K. loans and bonds provided the necessary capital for colonial and early national projects like canal- and railway-building. U.S. investment was minimal before the $1890 \mathrm{~s}$, but a trickle soon became a stream soon became a torrent, for several reasons. One, the high tariffs of the National Policy led to tariff-jumping investment, where U.S. companies established Canadian branch-plants to serve the Canadian market. Two, the U.S. generated a lot of wealth during its post-Civil War industrial revolution, and Canada's proximity made it a natural location to seek foreign returns. Three, the First World War demanded that British savings be used for domestic reconstruction instead of foreign investment. This domestic reconstruction coincided with, and partly contributed to, the switch of centers of international finance from London to New York. Between 1920 and 1922, the U.S. overtook the U.K. as the leading foreign investor in Canada. The years between 1883 and 1920-1922 stand as a threshold moment when the balance tipped toward Canada-U.S. economic integration. By the 1920s, integration was the recognizable antecedent of today. The U.S. had become, by far, the leading importer and leading foreign investor, into Canada, and American branch-plants had become ubiquitous. While branch-plants began appearing after the National Policy, they surged around the turn of the century and again through the 1920s. Estimates varied, but reports put the number between 350 and 500 in Canada by 1919, and one report claimed 1,150 were operating by 1930 . They were so ubiquitous a feature of Canada by 1930, that "one-sixth of manufacturing workers of Canada were employed by United States branch plants which paid out one-fifth of the total

negotiation and dispute. 
manufacturing wages and produced nearly one-quarter of all goods manufactured in Canada."

The Second World War irrevocably tipped Canada's trade flows toward the U.S. Before the war, Canadian trade was triangular: Canada imported the lion's share from the U.S., and exported a majority to the U.K., subject to the flip-flopping of the 1920s and 1930s. The war forced the U.K. to radically curtail Canadian imports. Similar to the First World War, British income was required to reconstruct, not purchase from abroad - a condition the government ensured by imposing post-war import controls. The immediate post-war trade-flow redirection was dramatic. In the five years after the Second World War, from 1946-1951, Canadian exports to the U.S. increased by $260 \%$, while Canadian exports to the U.K. increased by $6 \%$. By the 1950s, relative Canadian export parity to the U.S. and U.K. would never exist again: the gap would only widen throughout the $20^{\text {th }}$ century. The Royal Commission on Canada's Economic Prospects reported, in 1957, that "our trade is now concentrated so preponderantly on the U.S. that for most purposes it has ceased to be useful to think of it as being triangular" (37). This statement was prophetic, and it could appear as easily in a contemporary press account as it did in a Royal Commission almost 60 years ago. ${ }^{7}$

Geography has played an overwhelming role in economic integration. While the casual observer might understand the powerful role geography exerts on the process, he or she will likely under-appreciate the true extent of geographic factors for integration. The Canada-U.S. border is 8,100 kilometers long, a staggering distance approximately equal to that of a flight between Toronto and Frankfurt or New York and Buenos Aires. While the U.S. has a population and economy unevenly distributed throughout its territory, Canada's population and economy (Edmonton excepted) lies entirely within 160 kilometers of the international border. Despite a

${ }^{6}$ Claim of 1883 as tipping-point year from John Weaver (1973), op cit. note \#2, p. 196; and supported by Michael Hart (2002), op cit. note \#5, p. 68. Investment information from John Weaver (1973), op cit. note \#2, chapter 5, "The Continental Economy" (pp. 194-242). Estimates of American branch-plants in Canada from Weaver, p. 228, op cit. note \#2. Quote from Weaver (1973), op cit. note \#2, pp. 237-38. The claim of leading export destination rivalry drawn from Historical Statistics of Canada, $2^{\text {nd }}$ ed. (1983), Series G389-395 and G401-407.

${ }^{7}$ Bruce Muirhead (1989) "Trials and Tribulations: The Decline of Anglo-Canadian Trade, 1945-1950" Journal of Canadian Studies 24(1): 50-65; Robert Bothwell and John English (1977) "Canadian Trade Policy in the Age of American Dominance and British Decline, 1943-1947" Canadian Review of American Studies 18(1): 52-65. Post-war trade increases calculated from Historical Statistics of Canada, op. cit. note \#6. 
vast national territory, Canada, in commercial terms, is a thin country that sits like a horizontal sliver along the northern U.S. border. Foreign-affairs correspondent Robert Kaplan (1998) paints this vivid picture: "Though Canada is the largest country in the Western Hemisphere, stretching to the polar ice cap, the habitable part of it looks like Chile laid on its side" (50 emphasis added). This disparity between geographic Canada and economic Canada is exactly what Paul Krugman had in mind when he wrote (1991): "Canada is essentially closer to the United States than it is to itself" (2). The Maritimes trade with the New England states more naturally than they do with the Canadian west, a pattern that repeats itself for every economic region in Canada. ${ }^{8}$

In the last 20 years, economic integration has been driven legally and institutionally, by free trade agreements, by corporate reorganization, and general prosperity. Prior to the CanadaU.S. FTA (1989), Canadian provinces traded 20 times as much with neighbouring provinces as they did with adjacent states. By 1996, the province-to-province trade advantage dropped to 12 times more than province-to-state trade. This evidence is important, because it demonstrates (firstly) the overwhelming national orientation retained by the Canadian economy - 12 times larger is an order of magnitude - yet (secondly) the consequential impact on trade re-orientation by free trade. Engel and Rogers (1996) found further evidence of the border effect: prices did not equalize as they would have in the absence of a border. Belying the continuing preference for Canadians to trade along latitudinal, rather than longitudinal, lines, the level of exports to, and imports from, the U.S. increased sharply in the 1990s, a direct effect of freer trade. In 1988, 73\% of all Canadian exports went to the US, which rose to $86 \%$ by 1999 . In $1988,69 \%$ of all Canadian imports came from the US, which rose to $75 \%$ by 1999 . Moreover, $43 \%$ of Canadian

\footnotetext{
${ }^{8}$ Robert Kaplan's “Travels Into America's Future" appeared in the August 1998 Atlantic Monthly, pp. 3761. For comparisons used to illustrate the length of the Canada-U.S. border, see Robin Winks (1998) The Civil War Years: Canada and the United States, $4^{\text {th }}$ ed., McGill-Queen's Press, especially "Preface to the First Edition" (xv): "For a distance as great as that between London and Cape Town or between New York and Buenos Aires, Canada and the United States share a frontier line noted for its lack of fortifications." Krugman quote from Geography and Trade, Cambridge, MA: MIT Press. A precursor of Krugman's thinking comes from William Yandell Elliot, as reported in Gordon Stewart (1992), op cit. note \#5, pp. 145-147. In Harvard's Department of Political Science, Elliot viewed Canada as complementary, rather than competitive, for American industrial growth needs, because Canada was contiguous and rich in minerals and energy. Another source is Hugh G.J. Aitken (1961) American Capital and Canadian Resources, Cambridge, MA: Harvard UP for comprehensive treatment of this trend.
} 
GDP is earned through trade, making it the most trade dependent nation in the G7.'

The rise of transnational companies (TNCs), and continental corporate re-organization is the final element, an institutional element, to understanding contemporary Canada-U.S. economic integration. The older model of industrial organization had companies that were based nationally, focused on the domestic market, and exchanging goods in inter-industry trade from behind borders. The newer organization of TNCs is characterized by companies whose sourcing, production, distribution, and supply processes straddle borders and trade goods and service inputs primarily intra-industry or intra-firm. They rationalize production and distribution across large areas, taking advantage of localized factor endowments and lowered costs. The evolution from older to newer models of industrial organization is one dramatic difference between the earlier era of internationalization (1870-1914) and the present. Within Canada and the U.S., contemporary TNCs span the border, enmesh the economies, and view Canada and the U.S. as a unified commercial space, rationalizing production, distribution, supply, delivery, and support functions across the continent. This has happened to a startling degree in North America: twothirds (67\%) of Canada-U.S. trade is intra-firm, and the majority of investment activity is mergers and acquisitions, which reflect corporate consolidation and rationalization. ${ }^{10}$

${ }^{9}$ Original determination of 20-times-greater ratio in John McCallum (1995) "National Borders Matter: Canada-U.S. Regional Trade Patterns" American Economic Review (June): 615-623. And, yes, this is John McCallum, Minister of National Defence, in 2003. McCallum's conclusion was confirmed in John F. Helliwell (1996) "Do National Borders Matter?" Canadian Journal of Economics (29): 507-522. While McCallum used data for the last pre-FTA year, 1988, Helliwell expanded the data set, using data for 1988, 89, and 90. See also John F. Helliwell and John McCallum (1995) "National Borders Still Matter for Trade" Policy Options (July-August): 4448. Charles Engel and John Rogers (1996) "How Wide is the Border?" American Economic Review (December): 1112-1125. See John F. Helliwell, Frank C. Lee, and Hans Messinger (2002) "Effects of the FTA on Interprovincial Trade" in Hoberg (Ed.), Capacity for Choice, (pp. 17-60), UTP. Export- and import-percentages over time come from page 7 of Maureen Molot and Fen Hampson (2000) "Does the $49^{\text {th }}$ Parallel Matter Anymore?" in Maureen Molot \& Fen O. Hampson (Eds.) Vanishing Borders: Canada Among Nations (pp. 1-26), Toronto, UTP.

${ }^{10}$ For discussion of older and newer TNC organization, see Michael Hart \& William Dymond (2002) "NAFTA Chapter 11: Precedents, Principles, and Prospects" in Laura Ritchie-Dawson (Ed.), Whose Rights? The NAFTA Chapter 11 Debate (pp. 129-170), Ottawa: Center for Trade Policy and Law. See Earl Fry (2003) "CanadaUS Economic Relations: A Window for Opportunity" Policy Options (February): 33-38 for difference between preWorld War I and contemporary phases of globalization. This logic, according to Hart and Dymond, has been incorporated into the increasing coverage and complexity of trade agreements. While older agreements specified government conduct, usually for at-the-border measures like tariffs and quotas, and where treaties bind states-tostates in a relationship, newer agreements specify behind-the-border conduct such as regulations, private investor rights, government procurement, and service provision, and give private actors standing to challenge foreign 
Empirical evidence shows that integration has occurred, whether measured in absolute year-by-year trade increases, relative shares of international trade to GDP, trade direction, sources of foreign investment, or the rise of trans-border firms that straddle the $49^{\text {th }}$ parallel. Determined by geography, this pattern is and has been subsequently legally underwritten by free trade agreements. Economic integration has benefited Canada, as its proponents prophesied, but ambiguously: since the FTA (1989), Canada has sustained strong job growth but not productivity growth, which has resulted in a devalued Canadian dollar and a declining standard of living compared to the U.S; ; and in the new century, Canadian yearly growth remains at or near the top of the G7-countries, yet this growth is entirely dependent on export growth to the U.S. While "the Canadian economy retains a strong national structure" (Helliwell, Messinger, Lee 47), the $19^{\text {th }}$-Century compass heading on industrial development has been re-oriented from east-west to north-south. For Canadian nationalist scholarship, the compass direction has long been thought to dovetail with national destiny, so contemporary accounts of "fearful asymmetry," or external dependence, is consistent with a venerable trend to forecast doom on the horizon. Despite the economic integration, however, contemporary Canada shows no sign of re-awaking $19^{\text {th }}$-century thoughts of political union. The emergence of a national identity militates against this."

The second co-ordinating idea is national identity. Nations, like individuals, have identities, perceptions of themselves and beliefs about how others view them. Again like individuals, nations claim to have a purpose, based in history and perpetuated in myth. The U.S. defines its purpose as the guardian of freedom. In the Victorian era, the English viewed themselves as bearing the burden of civilizing distant lands, while classically the Greeks looked upon themselves as the cradle of Western culture. Other nations regard themselves as having a

governments.

${ }^{11}$ Sidney Weintraub (1994) "Current State of U.S.-Canada Economic Relations" American Review of Canadian Studies, 24(4), 473-488. For an exemplar of nationalist doomsaying, see Philip Resnick (2002, October) "Can Canada Survive Free Trade?" Literary Review of Canada, 10(8), 12-13; Stephen Clarkson (1998) "Fearful Asymmetries: The Challenge of Analyzing Continental Systems in a Globalizing World" Canadian-American Public Policy (35), Orono, ME. U Maine P. See Earl Fry, op cit. note \#10, for comparative assessments of benefits under NAFTA. For an even more pointed statement, claiming Canada as the primary beneficiary of trade liberalization, see his (2003) "Prospects for Further North American Integration: A U.S. Perspective" paper presented at the CPSA Conference, Halifax, NS., June 1, 2003. 
special purpose. The Canadian "purpose" has often been identified as survival, political unity within and political independence without, the national question from both ends. The CanadaU.S. relationship provides the existential grist of Canadian national identity, the underground stream that feeds our cultural policy and the even-deeper need to set cultural policy. To posit national identity as one of our co-ordinating ideas is to listen to the murmur of our interior monologue at the most free-associative level, not on the material level of economic integration, or the practical level of policy capacity, but on the purely psychological level. This section will add to that depth by analyzing how strong the need is for Canada to pursue cultural policy in the face of open trade. ${ }^{12}$

National identity, because it is metaphysical, existential, and psychological cannot be argued, only pondered. And pondering Canadian national identity is, at best, a history of ideas, or in a more pedestrian way, a history of sentiment, akin to what used to be called a parlour game -like debating the greatest movie ever made, an exercise in answering unanswerable questions. Reflections on national identity easily slide into related areas, nationalism, Loyalism, antiAmericanism, regionalism, and sociological and statistical attempts to ascertain value and attitude difference. It soon becomes clear that the pursuit of the descriptive content of Canadian national identity involves negative definition and deferral, defining Canada by what it is not, and defining it through substitution of related ideas, sentiments, and properties. ${ }^{13}$

Early Canadian national identity wasn't Canadian at all, but rather British (and French) colonial, fed by the United Empire Loyalists (1783) and post-Loyalists (from 1791-1812). Historians have assigned various motivations, material and ideal, to explain loyalty: expropriated property, lost homes, disrupted family connections, the suffering of indignities at the hands of colonial elites, and suspicion and hatred of revolutionary republican ideas. Though nationalist historians have made much of the emotional basis - the anti-Americanism - of the Loyalists

\footnotetext{
12 Inspiration for this paragraph comes from an exceptionally good editorial, published by the Globe and Mail, on Canada Day, 1997, entitled "On Being Canadian, Forever."

${ }^{13}$ William Morton's (1961) The Canadian Identity, Madison, WI.: University of Wisconsin Press, attempts to grasp identity whole, while Michael Dorland and Maurice Charland (2002) Low, Rhetoric, and Irony in the Formation of Canadian Civic Culture, Toronto: U Toronto $\mathrm{P}$ focuses on civic culture in relation to the constitutional orderings of national identity.
} 
and post-Loyalists, it is likely that anti-Americanism was post facto and codified during the early attempts to construct a Loyalist mythology in the 1880s. Interesting as an invented tradition, or usable past, the Loyalist tradition would become one aspect of Canadian identity. Jane Errington and George Rawlyk (1984) record another interesting phenomenon. The Loyalists' critique of the fledgling American Republic - a nation that was anathema to order, deference, and societal stability - was transcribed from the Federalist critique of early national America; that is, incipient Canadian anti-Americanism was really a form of American anti-Americanism. This habit of appropriating American outrage to suit Canadian purposes will re-appear with surprising regularly over the subsequent two centuries. ${ }^{14}$

From Confederation throughout the rest of the $19^{\text {th }}$ century, the Canada-U.S. relationship was the tectonic plate on which national identity was constructed. Robin Winks (1998) noted bursts of nationalism, expressed as anti-Americanism and motivated by fear, surrounding the U.S. Civil War. Aspects of Canadian identity involved a fear of U.S. invasion, immediately after the Civil War; a contempt of Republican government, which over time would soften into a general moral superiority; and simple class snobbery. Despite the appearance of nationalism, and its anti-American orchestration, early national identity remained British, expressed with crystal clarity in Sir John A. Macdonald's election cri-de-coeur (1891): “A British subject I was born, a British subject I will die." 15

${ }^{14}$ A succinct overview of this period of history comes from John H. Thompson and Stephen J. Randall (1997) Canada and the United States: Ambivalent Allies, $2^{\text {nd }}$ ed., Athens, GA: U Georgia P, particularly pp. 14-19. The list of Loyalist motivations is drawn from Sidney Wise (1962) "The Origins of Anti-Americanism in Canada" in Fourth Seminar on Canadian-American Relations (pp. 297-306). Windsor, ON. U Windsor. See Allan Smith (1990), op cit. note \#2, for corroboration of claim that pre-Confederation Canada possessed only a colonial identity. Jane Errington and George Rawlyk (1984) "The Loyalist-Federalist Alliance of Upper Canada" American Review of Canadian Studies, 14(2), 157-176 argues persuasively for the Canadian adoption of American self-criticism, and identify the 1880 s as time when Loyalist mythology was created. See also George Rawlyk (1976) "The FederalistLoyalist Alliance in New Brunswick, 1784-1815" Humanities Association Review, 27(2), 142-161; Neil MacKinnon (1973) "The Changing Attitudes of the Nova Scotia Loyalists towards the United States, 1783-1791" Acadiensis 2(2), 43-54; and Murray Barkley (1975) "The Loyalist Tradition in New Brunswick: the Growth and Evolution of an Historical Myth, 1825-1914" Acadiensis 4(2), 3-45. This is only the tip of the ice-berg, as the literature on "loyalism" is well established.

${ }^{15}$ See Robin Winks (1998) The Civil War: Canada and the United States, $4^{\text {th }}$ ed., particularly chapter 11 , "Public Opinion in British North America on the Civil War" (pp. 206-243), Montreal: McGill-Queen's UP. The claims of other aspects of $19^{\text {th }}$ Century Canadian identity come from Sidney Wise and Robert Brown (1967) Canada Views the United States: $19^{\text {th }}$ Century Political Attitudes, Seattle, WA.: U Washington P; and Reginald Stuart 
A Canadian national identity emerged between 1900 and 1945, triangulated between the British tie and American influence. Canada of this era was materially and geographically North American but spiritually and traditionally British, and it is easy from a contemporary vantage point to under-estimate how profound the cherished tie still was. The Empire Club of Canada was founded in 1903; the Imperial Order of Daughters of the Empire began; Empire Day (now Victoria Day) was founded as a national holiday in 1897. The Empire was the organizing idea for economic relations, with the Imperial trade preferences of 1896 the basis for quixotic ideas such as an Imperial common currency. There were even discussions of an Imperial foreign policy, which would have been decided upon by an Imperial parliament. Canada's participation in World War One simultaneously renewed the British tie and produced anti-Americanism, over U.S. isolationism and late entry into hostilities. Consequently, the 1920s witnessed assertions of British, and by extension Canadian, moral superiority mixed with invective directed at American opportunism: "Sir Robert Falconer [the President of the University of Toronto], the unswerving believer in British fortitude and moral superiority, also became vocal in his condemnation of American influence" (Weaver 350). Moral superiority further sedimented as another feature of Canadian identity. One generation later, in 1962, Claude Bissell, also a University of Toronto President, mentioned the "assumption of a quiet moral superiority" that permeated Canadians' literary themes and self-perceptions. ${ }^{16}$

The complexion of national identity becomes more Canadian, less British, after 1945 and largely as a result of the Second World War. If the state makes war, and war makes the state, the victory of the Allies - and Canada's disproportionately large role - enlivened national identity, like a sleepwalker jolted by electricity. Though the Imperial Conference of 1926, and the Statute

provides a portrait of $19^{\text {th }}$-Century anti-Americanism in (1997) "Anti-Americanism in Canadian History" American Review of Canadian Studies, 27(2), 293-310. Ramsey Cook (1977) "Cultural Nationalism in Canada: An Historical Perspective" in Janice Murray (Ed.), Canadian Cultural Nationalism (pp. 15-44), New York: NYUP also notes stirrings of Canadian nationalism during this time.

${ }^{16}$ Ramsey Cook (1977), op cit. note \#15. John Charles Weaver's dissertation (1973), op cit. note \#2, is a rich and textured source for apprehending Canadian society in the 1920s. In addition to the quote, see particularly, pp. 30, 71, and 131 for mention of Empire-related activities and for further quotes about "moral superiority" and "moral rectitude." A supplemental source for common currency and Empire federation from Mark Lovewell (2002) "In Search of Canada's Character" Literary Review of Canada, 10(10), 10-13. Bissell quote comes from Seymour Lipset (1979) The First New Nation: The U.S. in Historical and Comparative Perspective, NY: Norton, p. 257. 
of Westminster of 1932, formally de-coupled Canadian law and policy-making from England, the climate of ideas and sentiment, fostered by the Second World War, now proved fertile to nurturing an independent Canadian identity. In 1947, Canadian citizenship was created, becoming the common denominator of a new identity. In 1949, Vincent Massey chaired the Royal Commission on National Arts, Sciences, and Letters, which entrenched the Aird Commission's (1931) recommendations of state involvement with national culture, widening and deepening involvement into many artistic sectors as well as university life. It had been 57 years since John A. Macdonald's cri-de-coeur, but the title of Vincent Massey's On Being Canadian (1948) resoundingly signaled the existential change in Canadian identity. ${ }^{17}$

Canada has often been positioned in a triangular trading or diplomatic relationship between Britain and the United States. The liminal, betwixt and between, nature extends to national identity and is captured superbly in this formerly classified State Department dispatch, from 1949:

The cultural and economic attraction of the former [U.S.] together with the military cooperation are, for the time being, neatly balanced by the traditional and emotional ties with the latter [U.K.], leaving Canada suspended as a separate entity between the two. Many Canadians are acutely conscious of this situation and believe that it enables them to choose and adopt the best features of both societies. They have borrowed a British parliamentary system and have combined with it the American feature of decentralized governing power. Similarly, Canadians customarily think they possess the most laudable features of British national character, such as moderation and modesty, and, at the same time, have chosen from their neighbors the initiative and friendliness usually attributed to them. A large proportion of Canadians feel that by this means they may be able to create a society here which is an improvement over either the United States or Great Britain. (Harrington 3)

${ }^{17}$ Dates for Imperial Conference and Statute of Westminister come from Cook (1977), op cit. note. \#15. Vincent Massey (1948) On Being Canadian, Toronto: Dent \& Sons. Regarding the creation of Canadian citizenship, until 1948, in formal, legal terms Canadians were residents of Canada but subjects of the United Kingdom, which was the designation carried in passports issued to Canadians. In 1947, the Canadian Supreme Court replaced the British Privy Council as Canada's highest court. Jack Granatstein also argued, in Canada's War (1975), that Canada moved psychologically from semi-autonomy to genuine nationhood as a result of World War Two. 
Canada's principal external relationships were transformed between the World Wars. Reacting to the movement out from under the secure mantle of British empire into the economic and military orbit of the United States, Harold Innis wrote of opportunity lost (1948): "in one generation, Canada went from colony to nation to colony" (405). These two quotes reveal the internal dynamics of identity construction: as a response to the changing balance of external relationships. $^{18}$

The distinguished American historian David Potter commented (1967) that the Canadian response to the U.S., and Canada's search for identity, should be understood as the collective psychological expressions of self-recognition, self-congratulation, and the narcissism of minor difference. With Canadian achievement and success came congratulation, with the World Wars as a rite de passage came recognition, yet with continental defence and economic integration came diminishing differences: and as the distinctions diminished, the need to insist upon them intensified. According to Allan Smith (2000) there has been a shift in conceptualizing the Canada-U.S. relationship from presuming similarity to presuming difference. The presumption of difference, which has been sustained by arid statistical attempts to quantify national values and attitudes, should itself be seen as evidence of this underlying need. ${ }^{19}$

\footnotetext{
${ }^{18}$ Extended quotation from Julian Harrington (1949) "Development and Character of Canadian Nationalism," letter of July 5 to Secretary of State, Washington, DC. Decimal File 842.00/7-549, Record Group 59, National Archives at College Park, Maryland. The letter was originally designated "restricted." Harold Innis quotation was originally delivered to a British audience in 1948, and cited in Harold Innis (1956) Essays in Canadian Economic History, p. 405. The title of another Jack Granatstein book (1989) parallels Innis' observation, How Britain's Weakness Forced Canada into the Arms of the United States.

${ }^{19}$ David M. Potter (1967) "Canadian Views of the United States as a Reflex of Canadian Values: A Commentary" in Robert Brown and Sidney Wise (Eds.), Canada Views the United States: $19^{\text {th }}$ Century Political Attitudes, (pp. 121-130), Seattle: U Washington P. Allan Smith (2000), op cit. note \#4. The statistical attempts refer to Seymour Martin Lipset's oevre, and reaction to it. The recent book (1990) Continental Divide: The Values and Institutions of Canada and the United States, London: Routledge is a synthesis of much earlier work. Reacting to an article in 1986 by Lipset, see Doug Baer, Edward Grabb, and William Johnston (1990) "The Values of Canadians and Americans: A Critical Analysis and Reassessment" Social Forces, 68, 693-713; Lipset (1990) "A Reply" Social Forces, 69, 267-272; and finally, Baer, Grabb, and Johnston (1990) “A Rejoinder" Social Forces, 69, 273-277. On the contrary, Jon Alston, Theresa Morris, and Arnold Vedlitz (1990) "Comparing Canadian and American Values: New Evidence from National Surveys" American Review of Canadian Studies, 26(3), 301-314 agree with Lipset's conclusions. For the views for and against a new flowering of Canadian identity, expressed through advertising, see Gregory Millard, Sarah Riegel, and John Wright (2002) "Here's Where We Get Canadian: English-Canadian Nationalism and Popular Culture" American Review of Canadian Studies, 32(1), 11-34. The same issue contains a reply, by Stephen Brooks, a rejoinder by the authors, and another article on the same topic.
} 
This highly telescoped survey shows how Canadian identity is contingent on history and psychology, so that the reflection in the mirror has changed along with historical circumstance. Anti-Americanism is present to a greater degree in contemporary identity because that relationship has much larger implications for Canada than does the British tie. Implied by this overview are notions about identity itself: national identity is free-floating; and is spontaneous and reactionary and not a stable entity, with inherent or immutable features. This discussion of national identity also deepens our understanding of the cultural trade quandary. National identity, as a wellspring for the cultural trade quandary, is contingent entirely on self-perception and collective psychology. While economic integration can be rooted in empirical reality, and so have a basis in material reality, national identity reflects history, long-terms trends, Canada's changing external relationships, and galvanizing moments - but ultimately national identity is disembodied. This raises a formidable challenge for cultural policy, because the aim is one of attempting to foster a sense of collective identity.

The third co-ordinating idea is policy capacity, which is where the cultural trade quandary assumes a definite shape. Capacity refers to the degree of constraint, or freedom, policy formulators have to design and implement policy. Capacity ranges from narrow to wide, highly constrained to completely unfettered, and policy autonomy describes conditions relatively free of constraints. The study of policy capacity, and concern over convergence, has risen on the research agenda over the last two decades. Numerous academic studies examine capacity as a dependent variable, often within the framework of declining state authority, and capacity and convergence occupy a featured spot in the federal government's research agenda. ${ }^{20}$

Cultural policy, in particular, has come under increased scrutiny and pressure from economic liberalization. As Hoberg puts it: "cultural policy is one area where economic

${ }^{20}$ For a recent study, see George Hoberg, ed. (2002) Capacity for Choice: Canada in a New North America Toronto: U Toronto P. Political studies and policy studies, understandably, have the leading disciplinary interest. Hoberg's just-cited book follows up on Keith Banting, George Hoberg, and Richard Simeon, Eds. (1997), Degrees of Freedom: Canada and the United States in a Changing World, Montreal: McGill-Queen's. Two related books are David Cameron and Janice Stein, Eds. (2002) Street Protests and Fantasy Parks: Globalization, Culture, and the State, Vancouver, BC: UBC Press; and David Held, Anthony McGrew, David Goldblatt, and Jonathan Perraton, Eds. (1999) Global Transformations: Politics, Economics, and Culture, Stanford, CA.: Stanford UP. These two, while focussing on globalization, examine the impact on domestic policy autonomy. 
integration, and trade agreements in particular, have placed undeniable constraints on Canadian domestic policy" (304). And Ivan Bernier (1997) writes in even more stark terms: "The real issue in the debate on the place of cultural products in international trade agreements is the state's ability to make cultural development policy" (87). For the Canadian cultural sector, the challenge is several-fold: attempting to overcome the inherent advantage of American producers; trying to escape, in many cases, their own reputation for mediocrity; struggling to build on recent successes without employing some of the older policy measures used to achieve those successes (that is, moving from a national to an open view); and adapting to changing technology, such as the digitalization of content, compression of bandwidth, and the Internet as a distribution medium, all of which pose substantial challenges to traditional cultural policy. ${ }^{21}$

In October 1999, the Government of Canada committed to pursuing a different strategy to reconcile the cultural trade quandary. The original Canada-U.S. FTA "cultural industries exemption," while politically expedient and a marginal improvement over the pre-existing void, never delivered on the goal of an exemption in ordinary, plain-language terms. Carried into NAFTA (1994), the non-reality of the exemption was soon exposed by the U.S. challenge to Canadian magazine policy in 1997 . The exemption was soon characterized as leading to "anarchy," due to the disparity between what the word conveyed to the sector and cultural policy formulators and what it didn't allow in the commercial realm. By the late 1990's, several commentators expressed a desire to abandon the pursuit of an exemption as unworkable from a realist perspective of international trade agreements. At a panel entitled "Trade and Cultural Policy in a North American Context," the chair - a senior researcher at Canadian Heritage encouraged the panelists to propose a new solution beyond the exemption approach. And at a conference held at the JFK School of Government, a similar panel also stated that it was time to consider an instrument that was anchored in the rules-based trading system, not an exemption outside of it. ${ }^{22}$

\footnotetext{
${ }^{21}$ Quote from Hoberg (2002), "Conclusion: Capacity for Choice," op cit. note \#20, (pp. 299-313). Bernier quote from (1997) "Opening Markets and Protecting Culture: A Challenging Equation" FORCES 117: 84-87.

${ }^{22}$ Characterization of the exemption as anarchic comes from Richard Stursberg keynote address to the Canadian Institute of International Affairs, Montreal, November $25^{\text {th }} 2000$, as reported in Christopher Maule (2001)
} 
We need a basic framework to analyze policy capacity, to detect whether the prevailing trend is convergence, divergence, or neither, and more importantly, to explain the continuity or change. Banting, Hoberg, and Simeon (1997) identify three forces that promote convergence. The first is parallel domestic pressure. This describes a situation where independent causes in two jurisdictions provoke a similarity of response. The second force for convergence is emulation. While there was no transfer of ideas between different countries in the first explanation, the transmission of ideas and adoption of similar ideas is the defining characteristic of the second. This process often occurs between Canada and the U.S., with the ideas flowing from the U.S. to Canada. The third force is international constraint, which plays a powerful role in conditioning cultural policy. One type of constraint is international treaties, which may establish rules that positively and negatively prescribe what countries can and can not do, or they may also create supra-national institutions that possess legislative, executive, or judicial functions. A second type of constraint is that imposed by economic integration. Economic integration results from openness to the external financial world, which leads to a greater level of dependence on, and enmeshment within, the international economy. A key difference between the two constraints is that treaties are formal and legal — sometimes called "top down," while economic integration is informal and simply emerges as a condition of participation in global capital flows and currency markets - "bottom up." Paradoxically, the informal constraint of the international economy is more powerful than the formal, legal constraints of treaties, because if a country has some choice in abiding by the terms of the treaty - they have wiggle room - it also stands to suffer punitive economic returns for imposing measures considered unorthodox. ${ }^{23}$

To foreshadow chapters two and three, the forces that determine the range of options for cultural policy are overwhelmingly of the third category. While trade agreements, as international

\footnotetext{
"Globalization, Culture, and the WTO" paper presented at conference on Globalization and the Knowledge Economy, Kuala Lumpur, Malaysia, January 30-31, 2001. First panel comes from Rethinking the Line: The CanadaU.S. Border conference held at University of British Columbia, October 22-25, 2000, p. 53. Second panel "New Wine in Old Bottles? Cultural Policy in France and Italy" at Integration Pressures: Lessons from around the World, held at Harvard University's JFK School, March 29-30, 2001, p. 19.

${ }^{23}$ For detailed elaboration on forces for convergence, see Banting, Hoberg, and Simeon (1997), op cit. note \#20, chapter one, and Hoberg (2002), op cit. note \#20, chapter nine.
} 
treaties, prevent governments from setting certain cultural policy, the high degree of Canadian openness and integration in the global and, especially, the North American economy tend to persuade the Canadian government against pursuing other policies. As such, economic integration and trade liberalization, the confluence of international constraints, are not just coordinating ideas but controlling assumptions for a study on cultural trade. The powerful, gravitational nature of informal integration is captured vividly when economist Lester Thurow said, in 1984, referring to continental integration, "Canadians and Americans are like copassengers on the same aircraft. You can decide whether you want to be in first class, which is where the Americans are now sitting, or you can decide to sit in steerage, which is where Canadians are sitting today. The one decision you can not make is to get off the plane" (Gwyn 233). In a similar vein, New York Times columnist Thomas Friedman uses the phrase "golden straightjacket" to describe the inextricable inter-connections of globalization. The process, for Friedman, controversially, is a beneficial one. ${ }^{24}$

A striking instance of the interplay between identity, economic liberalization, and policy autonomy can be seen, curiously, in post-World War II Canadian monetary policy. The Bretton Woods System (BWS) of a fixed-exchange-rate regime was implemented in 1947, to correct the breakdown and anarchy that arose in the international economy from 1914 to 1944. Canada immediately faced a difficult choice after full convertibility was established between the Canadian and U.S. dollars, in 1945. The enormous flows of American capital into Canada, coupled with the fixed exchange rate, prescribed by the BWS, compromised the Bank of Canada's monetary policy, in a relationship known as the "open-economy trilemma." Countries can choose only two out of three optimal positions of unrestricted capital flow (opposed to capital controls), flexible exchange rate (opposed to fixed rates), and an independent (not dependent) monetary policy. The Bank was neutered, having no freedom to fight the business cycle through interest rate increases or reductions, and automatically having American recessions transmitted north of the border. With two positions locked in, any interest-rate movements opposite the U.S. Federal Reserve would have provoked an exodus of American capital, so

\footnotetext{
${ }^{24}$ Lester Thurow quote from Richard Gwyn (1985) The $49^{\text {th }}$ Paradox: Canada in North America, Toronto: McCLelland \& Stewart. See Thomas Friedman (1999) The Lexus and the Olive Tree, NY: Farrar, Straus \& Giroux.
} 
between 1945 and 1950, the Bank of Canada effectively became a ward of the U.S. Federal Reserve. In October 1950, Canadian policy-makers made the unprecedented move to let the Canadian dollar float against the U.S. dollar, to regain a measure of autonomy in targeting domestic economic conditions. (Canada would again fix the exchange rate in 1963, before returning permanently to a float in 1970.) Viewed in an age when floating currencies are common, this decision might seem unexceptional. On the contrary, Paul Krugman (1999) puts it in perspective: "These days, high capital mobility and a fluctuating exchange rate are the norm, but in those days they seemed outrageous - or would have seemed outrageous, if anyone but the Canadians had been involved" (3). Canadian statecraft preserved autonomy and identity under powerful centripetal forces to synchronize the North American economy. ${ }^{25}$

The co-ordinating ideas of economic liberalization, national identity, and policy capacity fit naturally together. Economic liberalization describes, as a condition and process, the motor force, the cause of the study, while national identity, as a shadowy concept, describes the aim, and policy capacity is where specific measures are put in place to buffer the cause and enhance the aim. Where the rubber hits the road, policy capacity is logically the final term in the sub-title, the outcome of the first two. Policy capacity, as mentioned above, is where the quandary assumes a definite shape. There's nothing metaphorical, symbolic, or historic about the connection from policy capacity to the cultural trade quandary, as will be seen from the first three chapters.

And finally, one can't adequately situate the cultural trade quandary without briefly discussing globalization. Globalization, to echo one authority, is an idea whose time has come. While economists, political scientists, historians, and others debate definitions, we are concerned with cultural globalization, the notion that predominantly economic forces that build bridges, and erodes walls, between nations will also homogenize or dilute national cultures. If the Canada-

${ }^{25}$ Paul R. Krugman (1999) "O Canada" The New Republic 18 October 1999. www. slate.msn.com/ dismal/99-10-18. The story of the Canadian dollar, and Canadian monetary policy, is told from an expert point of view in Paul Wonnacott (1965) The Canadian Dollar, 1948-1962, Toronto: U Toronto P. The understanding of the relationship between exchange rate, capital, and monetary policy was first formulated in Robert Mundell (1963) "Capital Mobility and Stabilization Policy Under Fixed and Floating Exchange Rates" Canadian Journal of Economics and Political Science 29(4): 475-485. "A Reply: Capital Mobility and Size," Canadian Journal of Economics and Political Science, 30(3), 421-431. Hoberg (2002), op cit. note \#20, p. 257. The "open-economy trilemma" is that countries can only have two out of three: (1) unrestricted capital movement, (2) independent monetary policy, and (3) a floating exchange rate. 
U.S. historical relationship constitutes the interior monologue of the quandary, then the discourse of cultural globalization is an adjacent conversation that takes as its focus the continued existence of Canadian culture and national identity. ${ }^{26}$

The idea of cultural globalization is easily observable yet devoid of rigourous definition. As Held (1999) writes: "[T]here can be little doubt that one of the most directly perceived and experienced forms of globalization is the cultural form," and "[f]ew expressions of globalization are so visible, widespread and pervasive as the world-wide proliferation of internationally traded consumer brands, the global ascendancy of popular cultural icons and artefacts, and the simultaneous communication of events by satellite broadcasts to hundreds of millions of people at a time on all continents" (327). A closer look, contrary to these facile observations, seems to demonstrate that dilution or homogenization is happening only at the most superficial of levels - the emergence of globally available products, for instance - but that underneath local, regional identities, anchored by language, ethnicity, religion, and ties to a specific place, exert a powerful sense of a particular identity against a universalizing consumer trend. "Though no one can deny the power or reach of American mass culture, there is little evidence that globalization is killing off local identities" (Globe \& Mail, April 18, 2001: A15). ${ }^{27}$

The salience of cultural globalization to this study resides in the conferring or transferring of anxiety between discourses, an adjacent conversation fraught with jangled nerves. And there have been several developments that have lent urgency, not empirical evidence, to the homogenization idea. The rise of ethnic and religious nationalism since 1990, the popular backlash against globalization that targets agents and institutions, and the emergence of terrorism that many attribute to a fundamental cultural clash all contribute to the appearance of a

${ }^{26}$ Echoed quote comes from David Held (1999), op cit. note \#20, p. 1. The debate over definitions, and whether in fact the term even applies to contemporary reality has been hotly contested, with participants falling into, to use Held and colleagues as references, those skeptical of a new condition, those hyperglobalizers who believe globalization is an accurate term, and transformationalists who implicitly accept that things have changed but who aren't sure globalization is the correct description.

${ }^{27}$ First quote from Held (1999), op cit. note \#20, p. 327. Paragraph-end quote from "The Myths of Globalization (6)" Globe \& Mail, 18 April 2001, A15. For another claim about the resiliency of local identities, see Francis Fukuyama "Economic Globalization and Culture" at www.ml.com/woml/forum/global. Accessed on February $22,2001$. 
phenomenon of cultural globalization. Former Clinton Administration Under Secretary for Commerce and International Trade, Jeffrey Garten (1998) titled a piece, “'Cultural Imperialism' Is No Joke." Former Director-General of the WTO, Renato Ruggerio, directly mentioned culture in two addresses, including his influential out-going speech. He said "But while the WTO is an essential part of the answer to globalization, it is not sufficient. More and more, we are facing issues and concerns which go beyond the parameters of trade," and went on to ask "Can we preserve cultural identities in [an] age of borderless communications?"28

The final part of my Introduction must address the apparatus that supports the thesis, the organization, flow, and also how the idea of communication is embedded in my specific thesis question, and the questions that hover nearby (all on page three), which take as their key term "culture": cultural products, national culture, and cultural policy. In danger of being pushed to the margins, the idea of communication, implicitly connected to culture, shadowing it throughout the thesis, needs to be explicitly drawn out. John Thompson (1995) characterizes communication as "a distinctive kind of social activity which involves the production, transmission, and reception of symbolic forms" (18). Both the processes named - production, transmission, and reception — and the matter - the symbolic forms - are of sovereign importance, because it is through communication that culture is constituted (and maintained, eroded, or transformed). Culture presupposes communication. David Held and colleagues (1999), drawing on Thompson to explicate the relationship between culture and communication, write "[w]e can probably hold that culture refers to the social construction, articulation, and reception of meaning" (328) and "[c]ommunication, in this context, refers to the ways in which these artifacts, beliefs, and messages are moved through space and time" (329). The focal length of the lens in this thesis places "culture" in view, but we need to be aware that "communication" is the parallel idea that

\footnotetext{
${ }^{28}$ Jeffrey Garten (1998) “'Cultural Imperialism' Is No Joke" Business Week, 30 November, 26. Renato Ruggerio (1998) "Address by the Director-General Mr. Renato Ruggerio" Geneva WTO Ministerial Statement; and Ruggerio (1999) "Beyond the Multilateral Trading System" WTO News. Both found at www.wto.org/english/news. Accessed February 2, 2001.
} 
could, should another student choose, be the focus of a similar study. The difference is slight. ${ }^{29}$

The thesis proceeds according to the following chapter objectives. Chapter One details the treatment of cultural products within the international (multi-lateral) and regional (CanadaU.S. FTA, then NAFTA) trading systems. When describing the treatment afforded under various trade agreements, the chapter will rely on the legal texts. Also analytical, the chapter constitutes a negotiating history, exploration of particular episodes, issues, or disputes, and it concludes by elaborating on challenging problems for any resolution of the cultural trade quandary: agreement coherence, goods and services overlap, and the general absence of direct treatment for cultural products. It is important to note that the treatment of cultural products is not actual trade of products, so noting that Article IV of GATT permits screen quotas (and understanding how this provision was achieved) is different from reporting foreign market share occupied by Hollywood films. The understanding of treatment, and the system itself, not current trade volumes, will allow for an informed contribution to what is possible through negotiation. Chapter One constitutes the trade-agreement framework for my policy analysis.

Chapter Two contributes the policy framework. Because the policy under consideration requires domestic and international consensus, the framework must have a two-level approach. The chapter draws on Robert Putnam's influential article, "Diplomacy and Domestic Politics: The Logic of Two-Level Games" to establish the criteria that need to be worked up in an integrative approach, where both an international negotiation phase and domestic ratification phase exert powerful and simultaneous constraints on the other level. The chapter relies on Howlett and Ramesh's five-stage subcycle model to highlight criteria relevant to the domestic policy process: from agenda setting, policy formulation, decision making, implementation, and assessment. Given the ability of external forces to shape policy outcomes, John Kingdon's idea of "streams" is introduced to expand the discussion to allow for a-rationality, unknowns, and wild cards to the process. Chapter Two is more of a guideline than a blueprint, an analysis of

\footnotetext{
${ }^{29}$ See John B. Thompson (1995) The Media and Modernity, Stanford, CA: Stanford UP for a definition of "communication," appearing on page 26. The first chapter, entitled "Communication and the Social Context" (pp. $10-43$ ) is a superb discussion, deep and deeply informed about the nature and characteristics of communication. For the unabridged inter-relationship between communication and culture, see David Held, Anthony McGrew, Jonathon Perraton, and David Goldblatt (1999), op. cit. note \#20, pp. 328-29.
} 
two-level policy making by working up criteria, rather than prediction.

Chapter Three scrutinizes the International Instrument on Cultural Diversity (IICD) and the International Agreement on Cultural Diversity (IACD), the official versions of the major initiative proposed to reconcile the cultural trade quandary, as well as two un-official proposals. While Chapter Two constituted a generic analysis of key decisions such as location, nature, and capacity to resolve disputes, Chapter Three applies these criteria to the actual proposals. As such, this chapter is a close reading and textual analysis of several proposals. Chapter Three will also outline the history, brief as it may be, of the IICD's development. One challenge is that the Instrument, as of 2003, exists in a liminal state, neither a hypothetical construction without any real-world existence, nor policy already completed and in operation. It is under-going construction, painstakingly slowly, which makes it a target of policy analysis occupying a shadowy and fleeting existence.

With Chapter Four, the thesis shifts from policy analysis to theoretical considerations. Chapter Four examines what influence foreign entertainment content has on domestic culture. Primarily a literature review, the chapter distills the literature on effects and cross-cultural influence in order to draw conclusions. Findings haven't yielded a unified theory of change, but an otherwise diverse range of literature points in some common directions: that meaning is made, not found; that interpretation is always shaped by local (cultural, religious, gender, and socioeconomic) factors; and that influence has been repeatedly found on peripheral attitudes and behaviours (for example, in shaping consumer preferences), but influence on deeper levels like identity tends to range from negligible to minimal, not the image portrayed by a surprisingly large scholarship of alarmist persuasion. Precisely pinpointing, or circumscribing, influence might best be understood as successive approximations towards a bull's-eye we'll never hit, an answer we'll never reach. Although this chapter is organized around assembling an answer to the research question that motivates the entire thesis, it will also serve as an intellectual history, due to its chronological organization, of the idea of influence, in both general context and specific application.

Chapter Five, "Formidable Limits: Perspectives on National Identity and Culture," tackles the concepts that linger in the background of this study. If "national identity" and "culture" 
(including "national culture") are the reasons for seeking special trade treatment of cultural products, then we're obliged to make sense of these ideas. The chapter reviews both concepts, which are surprisingly distinct from one another, interrogates their ontological nature, their epistemological pitfalls (of which there are many), and exposes their methodological dilemmas, to strive to say as much as can be said about some very mysterious parts of the woods. The key objective of this chapter is to determine limits of the connection between the ideas of national identity and culture and the process of foreign entertainment influence.

The epilogue, as the final chapter of the thesis, serves as a conclusion and impressionistic coda. After balancing arguments for and against foreign entertainment influence, the epilogue concludes by taking sides, judging the argument against influence as more convincing. It vividly underscores the premises and logic employed by refuting the argument contained in a wellknown article on global cultural homogenization. The epilogue then finishes on a note of ambivalent optimism, by synthesizing several trends that are propitious for some solution to the cultural trade quandary, though maybe only a partial solution. The existential nature of Canadian thinking, rooted in the Canada-U.S. historical relationship, will, despite any policy success, prevent any fundamental change in assuaging the long-standing feeling of American cultural encroachment and threat. 


\section{Chapter One:}

\section{The Treatment of Cultural Products within The Trading System}

"What is truly frightening to the U.S. is the idea of a cultural exception. To make culture untouchable is to enable people to protect anything because no one has a universal definition of culture. Such general provisions would raise serious problems of legal validity and enforceability." Richard Self, U.S. Negotiator, Uruguay Round (1993)

This chapter addresses the treatment of cultural products within the trading system. Cultural products are defined here to include motion pictures, TV programming and broadcasting, sound recording, books and magazines. The central aspect of their trade treatment is the domestic competitive conditions they face, which include conditions of entry, internal regulations, and foreign investment provisions. Intellectual property rights (IPR) and the impact of technology are not included in this examination. Although IPR weave their way alongside the products themselves, a double helix that determines how the product is treated inside national borders, IPR is very much a realm unto itself, very complex, and "a highly specialized topic" (Maule 3). IPR encompasses the creation of ownership rights, payment received for that ownership, and leasing rights. These rights are legislated domestically, but states belong to international organizations that provide protection for each other's content. IPR has emerged as a result of changing technology - digitalization - and the impact of this change potentially undermines, and renders irrelevant, cultural policy. ${ }^{1}$

\footnotetext{
${ }^{1}$ The central aspect of the trading systems under consideration will be an assessment of competitive conditions between domestic and foreign products. The principle of non-discrimination is codified in two central GATT (1947) articles: Most-Favoured Nation (Article I) and National Treatment (Article III). It is difficult to overstate their importance. IPR quote and summation come from Christopher Maule (2002) "Overview of Trade and Culture" Canadian Foreign Policy (9, Winter): 1-14. Pertinent international organizations alluded to are the World Intellectual Property Organization (WIPO), the Universal Copyright Convention, and the Berne Convention and TRIPs of the WTO. The actual definition of "cultural industries," and thus the precise areas covered by the exemption, are "(a) the publication, distribution, or sale of books, magazines, periodicals, or newsprint in print or machine readable form but not including the sole activity of printing or typesetting any of the foregoing; (b) the production, distribution, sale or exhibition of film or video recordings; (c) the production, distribution, sale or exhibition of audio or video music recordings; (d) the publication, distribution or sale of music in print or machine readable form; or (e) radiocommunications in which the transmissions are intended for direct reception by the general public, and radio, television and cable broadcasting undertakings and all satellite programming and broadcast network services" (NAFTA Article 2107, "Definitions"). On the subject of the impact of technology, for
} 
The scope of the chapter includes the multilateral and preferential, or regional, trade systems to which Canada belongs, principally the Canada-U.S. FTA (FTA), which began in 1989, and now the North American Free Trade Agreement (NAFTA), in effect since 1994. The multilateral system is based on the General Agreement on Tariffs and Trade 1947 (GATT), which has been expanded incrementally and since 1995 housed and administered by the World Trade Organization (WTO). These agreements incorporate the principles of non-discrimination, progressive liberalization, reciprocity (or reciprocal concessions), and transparency. As of January 2003, Canada had bi-lateral agreements with Israel, Chile, and Costa Rica, in addition to NAFTA. "Culture" was a highly visible, and controversial, piece of the FTA and NAFTA, treated in a ground-breaking way still considered problematic by some observers. Culture was treated in an unconditional way in the subsequent agreements involving Israel, Chile, and Costa Rica. The emphasis here will be on understanding the treatment of cultural products within the WTO and NAFTA (an emphasis dictated by a realist view to international affairs). ${ }^{2}$

Beyond these terms and scope, the chapter is both descriptive and explanatory in purpose. Descriptive means setting out what, exactly, is covered and the extent to which it is covered by the trade agreements. This entails relying on the legal text of the agreements themselves. Moreover, I also explain how culture came to be treated in such a way in the different cases. Explaining the terms included and excluded in trade regimes tends to be difficult, because of the dispersed nature of decision making and subtle contextual factors, but a sufficient account should

instance, the dramatically increased capacity of broadcasting bandwidth has rendered TV quotas irrelevant, as a way to ensure substantial market share showcasing Canadian content. See section in Maule article, listed above, for more examples and explanation.

${ }^{2}$ Graham Carr (1991) "Trade Liberalization and the Political Economy of Culture: An International Perspective on the FTA" Canadian-American Public Policy (6, June), Orono, ME: U Maine, summarizes the treatment cultural products receive within the European Free Trade Association, Ireland-UK Free Trade Area, and the Australia-New Zealand Trade Agreement. Hernan Galperin (2000) "Cultural Industries Policy in Regional Trade Agreements: the Cases of NAFTA, the European Union, and Mercosur" Media, Culture, and Society 21(5): 627-648 covers one Latin American PTA. To clarify terminology, preferential trading systems - or PTAs - are defined as agreements between two or more members that exclude at least some other members of the multilateral system. Preferential agreements are often called regional systems. "Realism" identifies a framework, and set of assumptions, for understanding international relations. I use it in a general way, consistent with its specialist meaning, to suggest what is reasonably possible in terms of negotiating outcomes within the trading system. See specific usages, in footnote \#14, page 183 of the Epilogue. 
address these considerations: international political economy; trade relations between negotiating countries; circumstances of domestic industry; domestic politics, and government-industry linkages; actual trade volumes; and negotiating objectives. These forces and factors change over time, and they often vary substantially between the multilateral and regional fora. And new technology may place as much pressure on cultural measures as trade liberalization. The explanatory section will rely on the secondary literature that is abundantly available. It is important to note a couple of caveats. One, the purpose here is different from presenting the actual trade volumes, patterns, flows, and trends that obtain for cultural products. In other words, trade treatment is not the same as actual trade. The second purpose here is to provide a sufficiently compelling explanation of how the system came to be as it is. It is a matter of judgement about what constitutes a satisfactory explanation of a particular outcome, and while this analysis strives to account for several factors, specialists interested in a particular multilateral round, negotiating issue, contextual factor, or outcome will want to consult the appropriate literature on negotiating history. ${ }^{3}$

The chapter is organized chronologically. It begins with the cinema exemption of the GATT (1947), then considers the Pre-Kennedy Round Working Party to include TV programming, in 1961-62, touches on American complaints against film industry subsidization within the Tokyo Round (1973-79), then examines the audiovisual dispute of the Uruguay Round (1986-94). The focus shifts to the negotiation and outcome of culture within the FTA and the NAFTA. The treatment of culture within the trading system lends itself naturally to a historical

\footnotetext{
${ }^{3}$ Several other overviews exist. Excellent ones include Ivan Bernier (1998) "Cultural Goods and Services in International Trade Law" in D. Browne (Ed.), The Culture/Trade Quandary (pp. 108-154), Ottawa: Centre for Trade Law and Policy; Keith Acheson \& Christopher Maule (1998) "International Agreements and the Cultural Industries" North American Outlook 6(4): 7-24; and W. Ming Shao (1995) "Is There No Business Like Show Business?" Yale Journal of International Law (20): 105-150. Good overviews include Hernan Galperin (1999) "Cultural Industries in the Age of Free-Trade Agreements" Canadian Journal of Communication 24 (1): 49-77; Mary Footer \& Christoph Graber (2000) "Trade Liberalization and Cultural Policy" Journal of International Economic Law (December): 115-144; Chi Carmody (1999) "When 'Cultural Identity Was Not At Issue': Thinking About Canada - Certain Measures Concerning Periodicals" Law and Policy in International Business 30(2): 231 320; Gottselig, Glenn A. 2000. "Canada and Culture: Can Current Cultural Politics Be Sustained in the Global Trade Regime?" International Journal of Communications Law and Policy 5:1-44; and Oliver Goodenough (1998) "Defending the Imaginary to Death? Free Trade, National Identity, and Canada's Cultural Preoccupation" Arizona Journal of International \& Comparative Law, 15, 203-253. As mentioned in the paragraph, numerous accounts of particular episodes or issues exist, which will be included at the appropriate time.
} 
organization because contemporary trade agreements modify, build on, and sometimes simply incorporate, earlier agreements and understandings, while trying to account for technological innovation, transnational corporate restructuring, and other elements that lie outside of the letter of the agreements.

I.

Motion pictures, or cinematograph films as they were then called, were treated explicitly in the original GATT. The preamble to Article IV establishes the permissibility of limits to the import of foreign films: "If any contracting party establishes or maintains internal quantitative regulations relating to exposed cinematograph films, such regulations shall take the form of screen quotas which shall conform to the following requirements." Four qualifying clauses then specified the terms and conditions. In ordinary language, a screen quota allows a country to designate a portion of screen time for domestic films, usually expressed as screen time per theatre per year. Motion pictures received a double exemption, from Article XI (against Quantitative Restrictions) and from Article III:10 (National Treatment). This has been described as exempting "motion pictures from the general principle of nondiscrimination" (Shao 111); an "express exception to the basic rule of national treatment...[and] an implicit exception to Article XI's prohibition of the use of quotas" (Filipek 339); and as "recognizing the specificity of cultural products...without subtracting them from the disciplines of the agreement" (Bernier 109). ${ }^{4}$

How does one explain the presence of the screen quota, an article that explicitly contradicts the principle of nondiscrimination? John H. Jackson, a distinguished American trade lawyer, attributed its existence as "more related to domestic cultural policies than to economics and trade" (293). Importing motion pictures has been a contentious trade issue for 75 years, and

\footnotetext{
${ }^{4}$ Article IV quote from GATT legal text. Article IV (a) specifies that minimum proportion of screen time devoted to national films be computed on the basis of screen time per theatre per year; (b) ensures that notwithstanding films of national origin, MFN will apply; (c) grandfathers the quotas as effective on April 10, 1947; and (d) requires that the quotas be subject to future negotiation for their limitation, liberalization, and elimination. For characterizations, see Jon Filipek (1992) "“Culture Quotas': The Trade Controversy over the European Community's Broadcasting Directive" Stanford Journal of International Law (28): 324-370; Shao (1995), op cit. note \#3; and Bernier (1998), op cit. note \#3.
} 
the difficulties that arose from the First World War to the Second set the stage for the central inclusion of Article IV within the general agreement on trade. ${ }^{5}$

In the earliest beginnings, from 1895 until the early teens, the French and to a lesser extent, the Italian, film industries were dominant. Although other factors helped tip the balance in America's favour, such as a larger domestic market, better reach of overseas distributors, and early patent rulings, World War I was decisive. The U.S. went from a net importer to a net exporter of films between 1914-1918. European film industries didn't recover a significant portion of their own domestic market share in the immediate postwar years, so Germany in 1925 enacted a contingency plan that required one German movie be distributed for every American movie distributed. France, Italy, and the UK implemented similar restrictions soon thereafter, using different mechanisms: a numerical limit on imports for France, and domestic quotas for Italy and the UK. In response to rising protection, the Motion Picture Producer and Distributors Association (MPPDA) - the forerunner to today's MPAA — developed strong governmentindustry relations. The Foreign Department of the MPPDA throughout the late 1920s and 1930s exerted direct influence on government negotiating positions and cultivated relations with foreign embassies, for the purpose of monitoring film policy. The context for GATT negotiations, then, was marked by a stark contrast: the American industry pushing hard for better access for its films, compared to European countries desperately trying to resuscitate their domestic film industry, but reliant on American financial assistance, which was itself conditional on removing barriers to U.S. imports. ${ }^{6}$

${ }^{5}$ Quote from John H. Jackson (1969) World Trade and the Law of GATT, Charlottesville, VA.: Michie, p. 293. Chi Carmody (1999), op cit. note \#3, pp. 254-55, notes the significance of the central location of Article IV, right after the two general nondiscrimination articles, MFN (I) and National Treatment (III). A former student of Jackson's, Carmody invests the location with significance, noting that the screen quota wasn't designated with a much higher numeral, say XIV or XXII, or addressed by annex or ancillary agreement. Claim of seventy-five-yearold contention attributed to Thomas Guback (1985) "Hollywood's International Market" in Tino Balio, (Ed.), The American Film Industry (pp. 463-486), Madison, WI.: U. Wisconsin P.

${ }^{6}$ This paragraphs condenses a longer, intricate story that is best described in Kristin Thompson (1985) Exporting Entertainment, London: BFI; Thomas Guback (1985) "Non-Market Factors in the International Distribution of American Films" in Bruce A. Austin (Ed.) Current Research in Films, (pp. 111-126), Norwood, NJ: Ablex; and Guback (1985), op cit. note \#5. Ian Jarvie (1992) Hollywood's Overseas Campaign: The North Atlantic Movie Trade, 1920-1950, Cambridge: Cambridge UP is also excellent. Guback emphasizes structural factors must not be overlooked in explaining the rise of American dominance: (1) the consolidation of the domestic American 
The post-World War II Franco-American film dispute offers the best country-specific case with which to crystallize the film-specific, and general contextual, factors of GATT negotiations. The Washington Agreement, signed in May 1946, obtained coal, wheat, and a reconstruction loan of $\$ 650$ million for France. Attached was the Blum-Byrnes Agreement, two pages that specified new levels of film quotas. Gone was the Accord Marchandeau (1936), which licensed up to 150 American films per year. Blum-Byrnes reserved four weeks per quarter for French films, to begin in July 1946. These terms were re-negotiated upward to five weeks per quarter and codified as the Paris Agreements in September 1948. Despite a desperate national situation, in which Charles De Gaulle's provisional government struggled to "recreate an army, feed the population, [and] restore communications" (Jeancolas 48), the terms for motion pictures proved difficult to negotiate. As Irwin Wall (1991) wrote "The often bitter and protracted negotiations over what appeared to be a minor matter, the motion picture industry, defy explanation in simple terms of economics" (56). Given the prevailing deprivations, the singular commitment to films had to be based on non-economic reasons. Only culture, and the domestic politics behind culture, can explain why so minor an issue became such a major contention.?

The central place of Article IV within GATT is a fascinating instance of the trade-offs between specific negotiating objectives, the economics of industry, and contextual factors present at the outset of the Cold War. The Americans originally pushed for the removal of all barriers to film imports, yet agreed to a screen quota. The Europeans pursued some form of safeguard. Facilitating the consensus was the American recognition that local exhibitors would exert

industry into the studio system, (2) the advantage conferred by a domestic market at least three times as large as any European competitor, and (3) early success at establishing European distribution networks. Historians of American foreign relations sometimes refer to this cozy alliance between industry and foreign policy as "corporatism," which is the view presented in this paragraph. There is sharp disagreement, among these historians, however, over the validity of these claims. Antagonistic positions are exemplified in John Lewis Gaddis (1986) "The Corporatist Synthesis: A Skeptical View" Diplomatic History 10(4): 357-362; and Michael J. Hogan (1986) "Corporatism: A Positive Appraisal" Diplomatic History 10(4): 363-372. The debate continues in subsequent issues of Diplomatic History.

${ }^{7}$ Details of the Blum-Byrnes and Washington Agreements from Jean-Pierre Jeancolas (1998) "From the Blum-Byrnes Agreement to the GATT Affair" in Geoffrey Nowell-Smith \& Steven Ricci (Eds.) Hollywood and Europe: Economics, Culture, and National Identity, 1945-1995 (pp. 47-62), London: BFI. Irwin Wall (1991) The United States and the Making of Postwar France, 1945-54, Cambridge, MA.: Cambridge UP will give the reader a full account of France in the European Recovery Program. 
domestic pressure on their governments to lower, or not implement, quotas because American films meant higher revenues. At the level of grand strategy, a new international order was emerging, and the U.S. wanted a multilateral trading system to bring prosperity, stability, and ultimately security to the region. On balance, Article IV represents the awareness of internalizing the pressure for minimal quotas within France and the higher geo-political goal of achieving a liberalized trade framework with limited areas of discrimination, a small sacrifice for the greater good. ${ }^{8}$

The next episode involving cultural products occurred in the early 1960s. In November 1961, the U.S. requested that a Working Party study fair-market access for TV programming. Because the medium was in its infancy during the original negotiations, TV programming and broadcasting were not addressed. The technology itself and television broadcasting systems developed substantially, and the number to television sets worldwide had proliferated, throughout the 1950 s, so by 1960 , the U.S. viewed the public ownership of television as a barrier to the export of programming. TV programming had "become an important article of commerce" (L/1646 1). Unlike motion pictures, which could rely on the profit motive of private entrepreneurs to ensure continuing trade, television's public nature had no similar natural incentive. Consequently, the U.S. alleged the sector would remain highly protected unless subject to explicit rules governing trade. ${ }^{9}$

${ }^{8}$ In my opinion, Article IV deserves more research than has actually occurred. For now, the claim that the U.S. originally pushed for removal of all barriers comes from Jarvie (1992), op cit. note \#6, p. 251. Attribution of American awareness that foreign exhibitors may be their own best ally, due to their financial incentive to screen American films, comes from Shao (1995), op cit. note \#3, p. 111, which in turn comes from GATT document series L/1741, Application of GATT to International Trade in Television Programmes: Report of the Working Party (March 13, 1962); and L/1646, Statement Made by the United States Representative (November 21, 1963). The final claims are generally known enough not to need sourcing. Furthermore, the American government considered films to have salutary ideological effects, in addition to commercial benefits. Viewing American films, which portrayed liberal democracy in glowing terms, was thought to help congeal sentiment favourable to capitalism and democracy in post-war countries like France and Italy, which had a highly fluid post-war political climate.

${ }^{9}$ The original submission of American intention is in L/1615, (no subtitle), Application of GATT to International Trade in Television Programmes. Request for establishment of Working Party examination in L/1646, Statement Made by the United States Representative (November 24, 1961). Terms of Reference articulated in Working Party on Application of GATT to International Trade in Television Programmes, L/1686 (December 18, 1961). It is important to note that the U.S. recognized substantial differences between countries on the openness to the purchasing of foreign TV programming. Excellent secondary sources to complement this historical snapshot are Shao (1995), op cit. note \#3, pp. 111-112; and Filipek (1992), op cit. note \#4, pp. 340-342. 
Ten member countries were involved in the negotiations, with three members holding observer status. The Final Report, tabled in March, 1962, contained three views. For the U.S., the internal regulation that affected the use of imports (of TV programming, in this case) fell within the meaning of Article III:4, yet they acknowledged television's "importance as a cultural and informational medium" (L/1741 2). They proposed, therefore, that the international sale of TV programming be governed under Article III with the provision that countries may reserve air time for domestic programs while ensuring "a reasonable proportion of viewing time" (L/1741 6) for imported programs. A second group of members, not identified by country, proposed that TV programming could be brought within GATT, although they rejected the American position of reasonable market access. The third view, articulated by France, stated the TV programming resembled a service more than a good, and they questioned the competency of the Working Party to address TV programming and broadcasting systems in the first place. They noted the rapid technological developments of satellite and terrestrial broadcast systems, as well as changes in bandwidth and spectrum delivery capacity, and proposed to reconvene the Working Party after the new technological developments had been implemented. Each of the three draft positions was contained entirely within square brackets, indicating a lack of consensus. Although the U.S. presented a revised proposal in November 1962, and again in March 1964, no consensus was ever reached, no report was ever issued. The issue of TV programming and broadcasting was dropped, not to resurface for twenty years. ${ }^{10}$

The question of whether TV programming constituted a good or a service was at the heart of the disagreement over 40 years ago. This pre-Kennedy Round negotiating episode serves as a prologue to the U.S.-EU contention over the European Directive popularly known as "Television Without Frontiers" in the late 1980s. Likewise, it foreshadowed the disagreement over audiovisual products during the Uruguay Round, and the WTO Canada Periodicals decision (1997). One argument held that TV programs were goods because motion pictures were goods, and

\footnotetext{
${ }^{10}$ Ten members, or Contracting Parties as they were then known, included Australia, Austria, Brazil, Canada, France, Germany, Japan, Sweden, the UK, and the U.S. Belgium, Italy, and Switzerland participated as observers. The Report of the Working Party (L/1741) contains the positions, and arguments, in detail. The two U.S. proposals subsequent to the March 1962 Report simply revised the levels of reasonable market access, thereby holding to the conception of TV programming as a good within the meaning of GATT.
} 
motion pictures were goods because of their inclusion in the original GATT. This was an argument that motion pictures were goods by default because tradable services weren't understood or classified in the 1940s, so the GATT had to have dealt with goods. Furthermore, the connection between TV programs and motion pictures was based on their presumed similarity. Contrary to this, the means of display served as the basis to conclude programming was a service. While motion pictures were images fixed on celluloid, which were then physically transported across frontiers in canisters, programming was displayed on a select bandwidth of the electromagnetic spectrum. The status of TV programming has yet to be resolved as of January 2003, although the U.S. communicates its intention to view programming as a good, while the Europeans and Canadians intend to view it as a service. I will return to the question of programming status, audiovisual products, and the related issue of co-existing overlap between goods and services later in the chapter. ${ }^{11}$

The next episode, the third presented, is more of a blip on the cultural-trade radar screen than an episode. In the Tokyo Round (1973-79), the U.S. complained about domestic film and television subsidy practices in 21 countries. No challenge was ever launched. ${ }^{12}$

The Uruguay Round (1986-1994) was the setting for the highly publicized disagreement over audiovisual (A/V) services. The round set an ambitious negotiating agenda for itself, to cover trade in services, aspects of IPR and investment, to establish a dispute-settlement forum and procedure, to encompass all elements into a "single undertaking," and importantly to establish the institution of the World Trade Organization itself. By the time the round was formally concluded on 15 April 1994, A/Vs would prove themselves to be one of the most contentious areas. As Karl Falkenberg (1995) wrote: "The decline of the European audiovisual

${ }^{11}$ See Christopher Maule (2002) "Trade and Culture: Rhetoric and Reality" Policy Options (March): 39-44 for general observation of the goods-services overlap. Comment of pre-Kennedy negotiations serving as prologue from Filipek (1992), op cit. note \# 4, p. 340; and argument in favour of TV as a good from Shao (1995), op cit. note $\# 3$, p. 112. Straightforward statement of continued division of U.S. and EU (and Canadian) view of TV as good or service comes from Sandrine Cahn \& Daniel Schimmel (1997) "The Cultural Exception: Does it Exist in GATT and GATS Frameworks? How Does it Affect or is it Affected by the Agreement on TRIPs?" Cardozo Arts and Entertainment Journal 15(2): 281-314.

${ }^{12}$ The blip is reported in Footer \& Graber (2000), op cit. note \#3, p. 118; and Bernier (1998), op cit. note $\# 3$, p. 109. Primary source documentation comes from GATT doc. MTN/3B1. 
sector and the success of the U.S. sector are [sic] the background for the EU-U.S. battle in the Uruguay Round" (430). In 1992, the transition year for Europe, while the U.S. exported \$3.6 billion (U.S.) in A/Vs to Europe, Europe exported a paltry $\$ 290$ million in return - a deficit of twelve fold. Behind the enormous balance-of-trade disparity lay the abiding concern that A/Vs play an important, if difficult to define, role in shaping and maintaining national consciousness. Additionally, the Canada-U.S. free trade negotiations (1986-87) introduced the concept of "cultural exemption" onto the multilateral negotiating menu. ${ }^{13}$

The original negotiating positions will by now be familiar. Due to their dramatic competitive sectoral advantage, the U.S. strongly pushed for fully liberalized trade, and so by implication strongly opposed any tariff or non-tariff barrier to $\mathrm{A} / \mathrm{V}$ products. Canada tabled language calling for a total exclusion of the sector. The EU did not even support this. They believed this would precipitate a cascade of withdrawls from other service sectors, and they felt such a stance would also undermine the position of many EU-based firms that relied on exports in films, books, and sound recording. By the mid-term Montreal Ministerial meeting, in December 1988, the idea of a "cultural exception" had replaced a total exclusion. ${ }^{14}$

The European Commission (EC), as the institution that represents the EU multilaterally, at the behest of both industry and national government representatives, awoke to the possibility that trade liberalization and obligations would likely affect cultural policy much more than they originally had thought. (Unlike for goods, where the Commission had an unrestricted negotiating mandate, the Commission had restrictions placed on its negotiating prerogative for the services

${ }^{13}$ Quote from Karl Falkenberg (1995) “The Audiovisual Sector” in Jacques H.J. Bourgeois, Frederique Berrod, and Eric Gippini Fournier (Eds.) The Uruguay Round Results (pp. 429-434), Brussels: European Interuniversity Press. A/V sector trade data comes from European Commission's White Paper on Growth, Competitive, Employment: The Challenges and Ways Forward into the $21^{s t}$ Century, part B, II, Chapter V, especially C, para. 5.11; as reported in Mary Footer (1995) "The Future for a Cultural Exception in the World Trade Organization," paper presented at the International Law Association (ILA) Meeting, Geneva, 22-23 June. Paper provided courtesy of the author. The subject of the rise of American A/V export coupled with the decline of European domestic market share for its own products is treated thorougly. See Guback (1985), op cit. note \#5, and Jeancolas (1998), op cit. note \#7, for details. 1992 is Europe's transition year because the Maastricht Treaty was signed, which created the European Monetary Union and a common market.

${ }^{14}$ Original negotiating positions come from Falkenberg (1995), op cit. note \#13, pp. 429-30; also Eric Morgan De Rivery (1995) in The Uruguay Round Results (pp. 435-443), op cit. note \#13. A third good secondary source is Footer \& Graber (2000), op cit. note \#3, pp. 119-122. 
area.) The EC introduced the so-called "cultural exception." Canada had obtained a "cultural exemption" in the Canada-U.S. FTA, and this "cultural carve out" as the EC liked to refer to it, spurred on the Commission. Within the Uruguay Round working text, the exception had two variations. The first was an exception written into GATS article XIV (General Exceptions) that would provide a genuine exemption from scheduled disciplines, to be written in parallel to the bis exception for security. When the U.S. strongly protested such an inclusion, the second variation, that of a scheduled annex, was proposed. Similar in objective to an article XIV exception, the annex would specify a portion of the $\mathrm{A} / \mathrm{V}$ sector for permanent, non-negotiable exception rather than safeguarding the whole sector. ${ }^{15}$

In 1989-90, A/V negotiations became yet more difficult as a result of the EU implementation of the "Television Without Frontiers" (TWF) Broadcasting Directive. This initiative was consistent with the so-called "common policies" introduced to help achieve harmonization of different national policies. TWF required that $50 \%$ or more TV programming be of EU origin. As before, the US immediately condemned the directive, because the wave of broadcasting deregulation and privatization begun in the 1980s had stimulated demand for American content. The Group of Negotiations on Services created the Audio-Visual Sector Working Group, in 1990, to address the emergent tangle of issues. Aside from American opposition, the cultural exception faced two major difficulties. One, culture would need to be defined in an acceptable, which is to say narrow and concrete, way. Article XIV of GATS was modelled after Article XX of GATT, which had adopted precisely circumscribed conditions for exemptions. Two, any exception that was challenged would face double conditionality, having to demonstrate that such a measure wouldn't constitute "a means of arbitrary or unjustifiable discrimination" (once) or a "disguised restriction on trade in services" (twice). This double burden was thought to set the bar close to impossible to clear in a dispute. This episode in the Uruguay Round was akin to the fundamental difference that impeded progress for the 1961-62 Working Party: basic divisions again appeared to be insurmountable, so the Working Group met

${ }^{15}$ This history comes primarily from Falkenberg (1995), op cit. note \#13, pp. 429-30; Footer (1995), op cit. note \#13, pp. 1-2; portions of which are verified by Filipek (1992), op cit. note \#4, pp. 343-45. "Exemption" and "exception" are interchangible, exemption usually referring to goods, exception to services. 
only a few times and was disbanded until near the end of negotiations. ${ }^{16}$

In July 1993, Sir Leon Brittan, EU External Affairs Commissioner, encouraged the European Parliament to replace the cultural exception with "cultural specificity." Remaining within GATS, "specificity" proposed to modify Article XIX (Negotiation of Specific Commitments - Progressive Liberalization), and incorporate similar language on Article XV (Subsidies) and into the Annex on Article II Exemptions. The objective would be to achieve a genuine exemption: the $\mathrm{A} / \mathrm{V}$ sector would not be subject to the general disciplines on liberalizing in the future. What distinguished cultural specificity from the exception was that it would address the continuing friction over TWF's content quotas by translating market access for TV programming into a set of specific commitments. This was a crucial item linkage: for the EC, codification of Article XIX, and for the U.S., scheduling of market access. Energized by activists, artists, and content creators who rallied in support of cultural specificity, the EC pressed its position, only to fail by a narrow margin in garnering support in negotiations that proceeded right until the December $15^{\text {th }}$ deadline. Without reaching consensus, Sir Leon Brittan and Mickey Kantor famously agreed to disagree over the inclusion and terms of treatment of the $\mathrm{A} / \mathrm{V}$ sector. ${ }^{17}$

The time that has passed since the Uruguay Round provides perspective for assessing the $\mathrm{A} / \mathrm{V}$ outcome. The result is often described as a victory for the EU, and Canada, a victory because neither scheduled any positive commitments. This is only a relative, not an absolute victory — some might say a pyrrhic victory — because Members are obliged under the built-in agenda to negotiate on services. Not only has this formally begun, within the Doha Round (having commenced in November 2001), discussion over subsidies are currently underway

\footnotetext{
${ }^{16}$ Although TWF is a separate issue from the Uruguay Round A/V negotiations, the two mutually influenced each other. I am not aware of a scholarly study devoted to comprehensively explaining this crosspollination. Until one appears, Filipek (1992), op cit. note \#4 remains an excellent commentary on TWF specifically. However, since his article appears in 1992, it couldn't have traced the interaction of TWF through to the end of the Uruguay Round, in December 1993, or April 1994. The problems besetting the "cultural exception" approach come from Falkenberg (1995), op cit. note \#13; Morgan De Rivery (1995), op cit. note \#14; and Footer \& Graber (2000), op cit. \#3.

${ }^{17}$ The timing and specificity details comes from Morgan De Rivery, op cit. note \#14, p. 437; and Footer \& Graber (2000), op cit. note \#3, p. 121. The assertion over the importance of issue linkage comes from Falkenberg (1995), op cit. note \#13, p. 432. Shao (1995), op cit. note \#3, p. 113-14 provides excellent point-by-point negotiating history. Those interested in the detail should consult this work. The characterization of the KantorBrittan difference from the Manchester Guardian 15 December 1993: 1.
} 
within the Trade in Council of Services. All of this marches under the command of progressive liberalization, the same principle from which it was the goal to exempt the sector. It is difficult to see how a standstill is the same as a permanent exception. The subtitle of a law journal article reflects such an understanding: "The United States May Have Lost the Battle But Not the War" (Chao). Perhaps the most reasonably generous interpretation comes from Donald MacDonald, who wrote (1994) "Canada played a supporting role to the European community in those negotiations doing its best, to borrow a phrase from our national game, to keep its stick in $\mathrm{Mr}$. Kantor's skates, and with some success. At the final siren, Mr. Kantor had to leave the ice without success but muttering threats of 'wait until next time"" (262). ${ }^{18}$

Commentaries, especially those of European observers, convey the notion that a real opportunity was squandered, that $\mathrm{A} / \mathrm{V}$ services could have been addressed substantively in Articles XIV, XIX, or a sectoral annex. Eric Morgan De Rivery attributed the failure to "the almost inexplicable lack of preparation which characterized the negotiations on both the European and American sides" (439), and claimed that the absence of staff work gave way to hyperbole and histrionics in the waning days of 1993. Karl Falkenberg notes more laconically that the failure was "certainly due to the fact the Community presented its position late in the negotiations" (432). The lack of staff work, the failure to table realistic proposals, and the poor timing are inexcusable reasons given the conceptual complexity and political sensitivity of the audiovisual sector, and cultural matters in general. At the conclusion of the round, only the U.S. and the Central African Republic scheduled full commitments for the A/V sector, with 17 other members scheduling partial commitments. ${ }^{19}$

${ }^{18}$ Full citation for quoted subtitle, T.W. Chao (1996) "GATT"s Cultural Exemption of Audiovisual Trade: The United States May Have Lost the Battle But Not the War" University of Pennsylvania Journal of International Economic Law 17(4): 1127-xxxx. MacDonald quote from Donald S. MacDonald (1994) "The Canadian Cultural Industries Exemption Under Canada-U.S. Trade Law" Canada-United States Law Journal (20): 253-262. John Gero, ADM (International Business and Chief Trade Commissioner), at DFAIT, in conversation with author, 27 October 2000, for claim that US "lost" the Uruguay Round A/V negotiation.

${ }^{19}$ Morgan De Rivery (1995) quote, op cit. note \#14; and Falkenberg (1995) quote, op cit. note \#13. 
II.

Turning to regional agreements, cultural sector negotiations within the Canada-U.S. free trade negotiations (1986-87) were challenging. Difficult negotiations reflect the sensitive and frequently problematic nature of Canada-U.S. cultural relations. Dennis Browne (1999) wrote: "Culture trade issues have been a burr under the saddle of Canada-United States trade relations for well over a decade" (363). Two trade negotiators - first American, then Canadian elaborate: "of all the bilateral irritants, those disputes involving culture tend to be the most contentious and intractable" (Merkin 1); and "while wheat and softwood lumber are generally confined to their constituencies, cultural issues generate waves of national feeling, which make them especially tricky to handle" (Dymond 114). The difficulty of negotiations, sensitivity of the sector, and persistence of problems can be distilled into two fundamental reasons: market dominance and the presumed properties of cultural products. First, each of the cultural sectors in Canada is dominated by foreign, often American, products. Second, there is a presumed link between content and culture, with this national expression having long been thought to help ensure the political viability of an independent country. ${ }^{20}$

One can not adequately understand and appreciate the delicacy of cultural-sector negotiations until it is recognized that these two reasons embody the commercial and cultural, the tangible and intangible, the physical and meta-physical. Concern over the existence, survival, distinctiveness, and vitality of Canadian culture is a feature of the Canadian psyche, with roots stretching back before Confederation and encompassing the related ideas of nationalism, sovereignty, destiny, and the Canada-U.S. relationship, itself the reservoir of historical fears over invasion, annexation, and absorption. Deep and pervasive, this collective unconsciousness inflects Canadian thinking toward the United States with a defensive, reactionary posture. In anticipation of these primordial fears, the Mulroney Government sought to assure Canadians that, to use the operative phrase, "culture was off the table" during negotiations. Then, External

${ }^{20}$ Quotations from Dennis Browne (1999) "Canada's Cultural Trade Quandary" International Journal (Summer): 363-374; William Merkin (1999) "U.S. Trade Policy and Canadian Culture: What Can Be Accomplished Through Trade Negotiation?" Working paper presented at U.S. Trade Strategy and Canadian Culture Workshop, Washington D.C.: Center for Strategic and International Studies (CSIS), April 23; and William Dymond (2000) "Cultural Issues" in Mordechai Kreinin (ed.), Building A Partnership (pp. 113-115), Calgary - East Lansing: Michigan State U \& U Calgary Presses. 
Affairs Minister Joe Clark asserted this at a talk to the New York chapter of the Foreign Policy Association, in the Fall 1985. Prime Minister Brian Mulroney told those gathered at the University of Chicago, on December 4, 1985: "When it comes to discussing better trade rules for cultural industries, you will have to understand that what we call culture sovereignty is as vital to our national life as political sovereignty...In the United States, you cast the net of national security over more areas than we; in Canada, we cast the net of cultural sovereignty more widely than you." $" 21$

As a result of protectionist Canadian cultural policy, rooted in the above mindset, it is little wonder the United States "entered the negotiations with a long list of irritants in the cultural sector" (Hart 384). The two sides agreed not to negotiate on culture: culture would be exempted by way of derogation. Paragraph 1 of Article 2005 stipulated "Cultural industries are exempt from the provisions of this agreement except as specifically provided," and paragraph two stipulated "Notwithstanding any other provision of the Agreement, a party may take measures of equivalent commercial effect in response to action that would have been inconsistent with this Agreement but for paragraph one.,"22

The cultural industries exemption is a conditional, or retaliatory, exemption, which has a definite meaning for specialists but is vague, confusing, and appears contradictory under a

${ }^{21}$ Joe Clark's speech, as reported by Michael Hart, with Bill Dymond and Colin Robertson (1994), Decision at Midnight, Vancouver, BC: UBC Press, p. 111. Prime Minister Mulroney's quote from "Notes for an address to the University of Chicago," December 4, 1995. The subject of the Canadian mindset is a vast labyrinth and receives treatment indirectly in half a dozen fields. An excellent starting point is Allan Smith (1994) Canada-An American Nation?, Montreal, QC: McGill-Queen's P. In this collection of mostly previously published essays and occasional papers, Smith describes the historical development of the Canadian sensitivity about Canada's relation to, and co-existence alongside, the United States.

${ }^{22}$ Article 2005(1)(2) from legal text of the Canada-US Free Trade Agreement. The so-called "cultural industries exemption" contained four exceptions. One, Article 2005 doesn't apply to the tariff reduction on cultural products (Article 401). Two, forced divestiture requires Canada to purchase at fair open-market value from an American investor an investment should Canada demand such a divestment. Three, Article 2005 doesn't apply to Article 2006 in respect of copyright provisions. A fourth exception nullifies the obligations under the Income Tax Act (section 19) that requires a periodical be typeset and printed in Canada in order to qualify for the tax rebate. The terms "exemption" and "derogation" mean different things to a trade specialist. While an exemption includes an item under negotiations only to exempt it from the terms of liberalization, a derogation excludes an item from negotiations altogether. What makes this example confusing is that a derogation was dressed in the language of exemption. Explanation of the words come from Emery Simon, p. 384, in E. McAnany \& K. Wilkinson (1996) Mass Media and Free Trade: NAFTA and the Cultural Industries, Austin, TX.: U Texas P. 
reading of the ordinary meaning of the terms. The bipartite article means that (1) one country may act contrary to the agreement (2) if it is willing to be retaliated against. Article 2005 represented an improvement over the prevailing situation because retaliation would now be limited to "equivalent commercial effect." For instance, if an American producer incurred $\$ 200$ million in lost revenue due to discriminatory treatment, the U.S. would be entitled to retaliatory measures worth $\$ 200$ million, not more. The article introduced the rule of law, instead of an exercise of power, as the basis to resolve cultural sector disputes. The absence of this basis and structure contributed to the high number of irritants which had festered into disputes over the years. ${ }^{23}$

Much criticism has been levelled against the exemption, principally because the exemption is not an exemption within the ordinary meaning of the word. However, Article 2005 does indeed represent an improvement over the vacuum that had previously prevailed. Moreover, the exemption illustrates the concept of constructive ambiguity that is used to achieve consensus over politically difficult areas or sectors: the exemption was ambiguous because each side was able to decide for itself what it meant, and it was constructive because it allowed the agreement to proceed; on the American side, from an industry nervous that its competitive conditions would be eroded, and on the Canadian side, for a government that insisted culture was off the table. The exemption allowed each side to sell the agreement to the various constituents. As Donald MacDonald (1994) wrote: "The Canadian cultural industries exemption gained very high political prominence during the negotiation of the Canada-U.S. Free Trade Agreement" (253). ${ }^{24}$

What has been the legacy of the cultural industries exemption, since entering into force

${ }^{23}$ Some commentators prefer describing the article as "retaliatory", while other prefer "conditional." Another interpretation in ordinary language comes from Ivan Bernier (1998), op cit. note \#3, pp. 123, when he writes that "if a Party is ready to pay the price, it can maintain cultural measures that are incompatible with the FTA." The claim that the article was an improvement over the previous state of affairs comes from Michael Hart (1994), op cit. note \#21, p. 384.

${ }^{24}$ The cultural industries exemption is one of the most frequently criticized aspects of the FTA. See Susan Crean (1988) "Reading Between the Lies: Culture and the Free Trade Agreement" This Magazine 22 (2, May): 2933 for articulate objections. It is worthwhile noting that the criticism partitions along specialist-generalist lines, with trade negotiators, analysts, and policy specialists cognizant of the severe limits placed on such a sensitive sector. Attribution and definition "constructive ambiguity" comes from Don Stephenson, Director-General (Trade Services II), DFAIT, in conversation with author, 22 March 2001. Donald S. MacDonald (1994), op cit. note \#18. 
on January 1, 1989? It remains untested, and hence, unproven and unreliable: one industry spokesperson aptly called it the "anarchy of the exemption" (Stursberg). The Canadian industry placed its faith in an exemption that couldn't deliver what it wanted, including the ability to shield legislation from retaliation. Significantly, the main legacy has been to establish the idea of an exemption, which based on subsequent American reaction, was not anticipated. During the Uruguay Round negotiations on $\mathrm{A} / \mathrm{Vs}$, for example, the precedent constituted an "inconvenient fact" (Sands B9) for American negotiators, something which also "infuriated" American lobbyists (Truehart A34). At the apex of the EU-U.S. impasse, no less a person than French President Francois Mitterand observed: "We have the right to ask the American government to have the same regard for Europeans as they do for our friends the Canadians" (Truehart A34). Irrespective of the exemption's actual effectiveness, the idea of an exemption would persist, and has persisted since it was introduced approximately 15 years ago. ${ }^{25}$

The treatment of the cultural sector, between Canada and the United States, was virtually identical in NAFTA compared to the Canada-U.S. FTA. Article 2106 (Cultural Industries) referred to Annex 2106 for the precise terms and conditions, and the annex stated the culturalsector trading relationship would continue to be governed "exclusively in accordance"with the provisions of the FTA, but only between Canada and the United States and Canada and Mexico. The terms did not apply between Mexico and the United States. The Mexican chief trade negotiator said that the issue had "little relevance for Mexico" and "represented no cause for concern," when asked about their abstention from the cultural industries exemption (GarciaCanclini 143). The definition of cultural industries was broadened to include not only enterprises but also people engaged in the covered activities. The treatment of culture under NAFTA is important because NAFTA superseded the FTA in governing Canada's primary trading

\footnotetext{
${ }^{25}$ Characterization of the exemption's unreliable nature drawn from Keith Acheson \& Christopher Maule (1996) “Canada's Cultural Exemption: Insulator or Lightning Rod?" World Competition (20, September): 67-90. Quote from Richard Stursberg, cited in Christopher Maule (2001) "Globalization, Culture, and the WTO" paper presented at the conference Globalization and the Knowledge Economy, Kuala Lumpur, Malaysia, January 30-31. David R. Sands "Clash of Cultures Creates Latest Block to World Trade Pact" Washington Times, 24 November 1993: B7. Charles Truehart "Culture Clash: Canadian Nationalists Decry American Infiltration" Washington Post, 2 December 1994: A34; Mitterand quote from same article.
} 
relationship, and it is worthwhile to briefly assess the negotiating history and outcome. ${ }^{26}$

NAFTA entered into force on January $1^{\text {st }}, 1994$, having been negotiated during a period of precisely fourteen months, from June 12,1991 to August 12, 1992. The cultural sector was one of the two (the other was compulsory licensing in pharmaceuticals) where negotiators were furthest apart, diametrically opposed in fact; for Canada, culture was again not on the table, while the Americans wanted to prevent the incorporation of the cultural industries exemption. The Canadian position relied on an unshakable industry consensus, the political necessity of exempting culture, the threat of Quebec succession, and the FTA precedent. The Americans were emboldened by industry lobbying. The Motion Picture Association of America (MPAA) and the Recording Industry Association of America (RIAA) were very persistent in insisting on the prevention of inclusion, then the elimination of, the exemption. USTR Chief Carla Hills received a letter from five Congressmen two months before the formal negotiations began, asking her to "use the new negotiations as an opportunity to reverse the damaging precedent ensconced in the Canadian FTA" (5). ${ }^{27}$

The outcome should be considered a victory for Canada. The Americans applied pressure during the endgame of negotiations: Carla Hills pressing Canadian Trade Minister Michael Wilson to abandon the exemption during a private meeting on July $18^{\text {th }}$. He held firm. The original Canadian position helped ensure this, but Canada also knew it could have walked away from the deal, and the Canadians also knew that President George H.W. Bush wanted the agreement delivered before the Republican convention in mid-August. One of the best tactics,

\footnotetext{
${ }^{26}$ The full text of Annex 2106 reads as follows: "Notwithstanding any other provision of this Agreement, as between Canada and the United States, any measure adopted or maintained with respect to cultural industries, except as specifically provided in Article 302 (Market Access - Tariff Elimination), and any measure of equivalent commercial effect taken in response, shall be governed under this Agreement exclusively in accordance with the provisions of the Canada-US FTA [sic]. The rights and obligations between Canada and any other Party with respect to such measures shall be identical to those applying between Canada and the United States." The original source for the quotation for the Mexican chief trade negotiator is Nexos 189 (September 1993): 66-67.

${ }^{27}$ The account in this and the following paragraph is drawn from Maryse Robert (2000) Negotiating NAFTA: Explaining the Outcome in Culture, Textiles, Autos, and Pharmaceuticals, Toronto: U Toronto P, particularly chapter three, "Culture: Preserving the Status Quo" (pp. 47-95). For the claim that culture was one of the two most difficult areas of negotiation, see p. 49. For basis of Canadian position, see p. 94; and for American industry lobbying pressure, see pps. 87, 89. Quotation from "House Letter to Hills on Cultural Exemptions" Inside US Trade, 19 April 1991: 5.
} 
then, was to simply resist until the Americans decided, based on domestic politics, not negotiating strategy, to conclude negotiations. Although the U.S. government conceded the issue by then, American industry did not: the MPAA pressed to have the terms re-opened after the negotiations had concluded. ${ }^{28}$

The NAFTA cultural industries exemption, however, is coloured by a pair of ambiguities. While Canada, in its implementing statement, considers the American right of retaliation limited to measures that are inconsistent with the FTA, the United States has stated they observe no such limitation. For Canada, new areas such as IP couldn't be retaliated against because they weren't covered in the FTA, while the American standard of measures that "unfairly discriminate against U.S. cultural exports" (Congressional Quaterly 175) indicates a commercially operative trigger, rather than the terms defined under the FTA. This difference in understanding is likely attributed to the U.S. desire to chill the possibility of any new policy or practice that would have the effect of an exemption. A more subtle ambiguity exists on the issue of definition. NAFTA encompasses both enterprises and individuals, while the FTA covers only enterprises, but since NAFTA specifies the terms in exclusive accordance with the FTA, some believe it is not clear which definition would prevail if a dispute arose. Ivan Bernier (1998) sorts this out by noting that "there is no such ambiguity because the cross-reference to the FTA is itself subject to the NAFTA definition of cultural industries" (123). The definitions of NAFTA would apply. ${ }^{29}$

As of January 2003, Canada had also entered into bi-lateral trade agreements with Israel (on January 1, 1997), Chile (on July 5, 1997), and Costa Rica (on November 1, 2002). These agreements contain non-retaliatory, or unconditional, cultural exemption clauses. The relevant

\footnotetext{
${ }^{28}$ Regarding overall sector assessments, Robert writes "It is undoubtedly clear that Canada performed well in culture" (93). The July $18^{\text {th }}$ meeting is mentioned on p. 90 ; and the contextual reasons for success, including the President's desire to wrap up the negotiations, are listed on p. 93. The MPAA pressure to re-open the terms is on $p$. 94, as is the RIAA's concern over the precedent the exemption might set in the multilateral process.

${ }^{29}$ The Canadian understanding comes from the Canadian Statement of Implementation of the World Trade Organization, Gazette (Dec 31, 1994), Part I, p. 4926. The contrary American understanding comes from Congressional Quarterly, Vol. XLIX, $103^{\text {rd }}$ Congress, $1^{\text {st }}$ Session, 1993, p. 175. The statutory effect of their interpretation is found in the amendment to section 182 of the U.S. Trade Act (1974). Definitional ambiguity is taken up by Bernier (1998), op cit. note \#3, p. 123, footnote \#42, in response to the original observation of ambiguity by Jon R. Johnson (1994) The North American Free Trade Agreement - A Comprehensive Guide (Aurora, ON. Canada Law Book), p. 472.
} 
text of the Canada-Chile Agreement reads as follows: "Nothing in this agreement shall be construed to apply to measures adopted or maintained by either Party with respect to cultural industries except as specifically provided in Article C-02 (Market Access - Tariff Elimination)." Such wording has relevance because it establishes as a demonstration the incorporation of a genuine exemption into a trade agreement. However, the notion that cultural imports from Israel, Chile, or Costa Rica pose a threat to Canadian producers - or vice versa - is far-fetched, which is the primary reason such an exemption can be inserted in the first place. ${ }^{30}$

The cultural sector is also covered in other regional or preferential trade agreements (PTAs). As mentioned in the Introduction, exhaustive examination of culture within all the PTAs is outside the chapter scope. It is worthwhile to point out that in the MERCOSUR legislation covering Argentina, Brazil, Paraguay, and Uruguay cultural industries barely receive mention. National treatment to investments is provided, though Brazil, Paraguay, and Uruguay excepted the radio, television, and telecommunications sectors, and Paraguay and Uruguay excepted publishing. Audiovisual products have been left mostly unaddressed. Within the EU, Article 128 of the Maastricht Treaty (1992) provides the legislative, indeed constitutional, basis for cultural preservation and, thereby, enshrines the right to set cultural policy: "The community shall contribute to the flowering of cultures of the Member States, while respecting their national and regional diversity and at the same time bringing the common cultural heritage to the fore." Though still the basis of cultural policy, Article 128 has been superseded by Article 151 of the Amsterdam Treaty (1997). ${ }^{31}$

The level of foreign investment coverage differs considerably between the WTO and

${ }^{30}$ See Bernier (1998), op cit. note \#3, p. 126, note \#45 for wording of the legal text. While treatment in the multilateral system, and within the FTA and NAFTA, merit discussion, cultural treatment in these agreements deserve mention, only for reference purposes and thoroughness. It is highly unlikely such treatment could ever be incorporated into the multilateral system or any agreement with the only exporter for cultural products that really matters, the United States. The choice of discussing the FTA, NAFTA, and WTO, while only mentioning these other agreements, reflect the realist outlook noted in the chapter introduction.

${ }^{31}$ Article 128 of Maastricht is the legal text. Article 151 of the Amsterdam Treaty superseded Maastricht 128, and has incorporated minor revisions. And the Nice Treaty (2002) further amends the terms of Maastricht and Amsterdam. The author wishes to thank Rostam Neuwirth for these points. Those wishing more coverage of other PTAs should read Galperin (2000), op cit. note \#2, and Carr (1991), op cit. note \#2, each discussing different free trade areas. 
NAFTA. Within the WTO, the Trade-Related Investment Measures (TRIMs) is limited in scope, acting to clarify national treatment and the quantitative-restriction provisions of the general agreement, so that only investments made in cultural goods could be reviewed and challenged. In contrast, cultural investments under NAFTA continue to be governed exclusively in accordance with the FTA exemption. This grandfathers any investments in place by January 1, 1989 and extends to shield investments from the obligations of Chapter 11. The right of retaliation continues to be applicable for NAFTA cultural-sector investments as well. Canada, the U.S., and Mexico have all listed Annex I and Annex II exemptions. Although it was unnecessary, Canada re-scheduled the FTA exemptions under Annex I; Mexico included Annex I performancerequirement exemptions for the cinema and radio-television industries. The U.S. scheduled Annex II exemptions for radio-television cable services and newspaper publishing, while Mexico listed its broadcasting services. Canada includes an absolute or unconditional exemption for cultural investment in most of its other foreign investment protection acts. ${ }^{32}$

It is likely the conditions imposed by the Investment Canada Act and Regulations are inconsistent with Canada's trade obligations. Canadian performance requirements take the form of a "net benefit" test, where several conditions are taken into account in making such a determination: "the effect of the investment on the level and nature of economic activity in Canada, including...the effect on employment, on resource processing, on the utilization of parts, components, and services in Canada and exports from Canada." The portion stipulating domestic sourcing and utilization of parts explicitly contravenes the TRIMs. Within NAFTA, the retaliatory aspect of the exemption means that cultural investment, if challenged, would expose such investment to the wider range of obligations embodied in Chapter 11, including: national treatment, most-favoured nation, and minimum standard of treatment; in the case of expropriation, the duty to act in accordance with public international law (itself encompassing public purpose, non-discriminatory basis, due process, fair, prompt, and effective compensation); the interdiction of certain performance requirements; and the requirement to permit all transfers of an investment. While the TRIMs offers little substantive coverage and investment obligations,

\footnotetext{
32 See Bernier (1998), op cit. note \#3, pps. 136, 139-140 for general description, and pp. 140-41 for a list of the FIPAs concluded through 1998, including an example provision.
} 
investment under NAFTA is subject to more rigourous obligations, from which Canada exercises its tenuous exemption. ${ }^{33}$

III.

The relationship between trade in goods and trade in services is important for understanding the treatment of culture within the trading system, and the distinction - and blurring of a distinction by the overlap between goods and services — has emerged as a key issue. Motion pictures would have been considered a good by default. While there was discussion about where the source of value resided, the concept of tradable services did not exist in the 1940s. Classification has progressed as new products, and new versions of the same product, have appeared. Making the distinction between goods and services, especially from first principles or inherent properties, has been challenging. As mentioned, the 1961-62 Working Party convened to assess fair-market access for TV programming couldn't reach a consensus over goods or services classification, and similar difficulties arose during the course of the Uruguay Round for A/V products and in the WTO Canada Periodicals case (1997). ${ }^{34}$

For a non-specialist, product classification might seem straightforward. Goods such as toasters, bicycles, cars, and grain are tangible and covered by GATT. The designation of services is more confusing. In the 1970 s and early ' 80 s, there were questions over whether services, "invisibles,"or the non-traded sector, possessed value. Services were to be identified by characteristics in opposition to goods, so if goods were tangible, services were intangible; if goods were visible, services invisible; if goods were durable, services transitory; and if goods were produced and consumed at different times, services were simultaneously produced and consumed. One catch phrase held that you could classify something as a service if you couldn't

\footnotetext{
${ }^{33}$ Net-benefit quote from Bernier (1998), op cit. note \#3, p. 136. Assessment of "net benefit" inconsistency under performance-requirement obligations from Bernier (1998) and William Dymond and Michael Hart (2002) "Abundant Paradox: The Trade and Culture Debate" Canadian Foreign Policy (9, Winter): 15-34, particularly pp. 25-26 and 31 .

${ }^{34}$ The view that motion pictures are a good has been challenged. See Steven S. Wildman and Stephen E. Siwek (1988) International Trade in Films and Television Programs, Cambridge, MA.: Ballinger, p. 136; also, K. Acheson \& C. Maule (1998), op cit. note \#3, p. 9. Brief discussion over the source of value in motion pictures comes from Jackson, op cit. note \#5, p. 293.
} 
drop it on your foot. Classification problems arose because exceptions could be found for all these paired-opposites. Architectural blueprints aren't intangible or invisible, and a university lecture lasts longer than an ice-cream cone, yet the blueprints and the lecture are services. As of January 2003, the WTO recognized fifteen service sectors: accountancy, advertising, audiovisual, distribution, education and training, energy, environmental, express delivery, financial, legal, movement of people, small- and medium-sized service enterprises, regulatory transparency, telecommunications, and tourism. Tangibility and simple opposition to goods continues to be a simple, effective, but not entirely foolproof way to identify something as a service. ${ }^{35}$

The 1961-62 Working Party on TV programming couldn't agree on the classification. While there was a similarity in purpose between motion pictures and TV broadcast, one was physically embodied on celluloid film while the other existed more intangibly, broadcast at a certain frequency over the electromagnetic spectrum. Within the Uruguay Round, American and European negotiators again differed over classification. American domestic courts have ruled, and the U.S. Customs administration has behaved, as though TV programming is a good. U.S. courts have applied the "real purpose of the transaction" test and found that regardless of whether the content was embodied in a videotape or distributed via satellite signals, the "real purpose was to obtain an item of tangible personal property, such as a tape, that an exhibitor can exhibit to the public" (Cahn \& Schimmel 287-88). Likewise, US Customs applies tariffs to the international sale of videotapes, but not to the cross-border provision of services. In contrast, Europe's Directive for A/V policy views TV programming as a service, a view that stems, in part, from the 1974 European Court of Justice Sacchi ruling. In Sacchi, the Court characterized the broadcasting of a television signal as the provision of a service. However, the decision reveals the dual goods-services nature: "While a television signal must...be regarded as provisions of services, trade in material, sound recordings, films, apparatus, and other products used for the diffusion of television signals is subject to the rules relating to freedom of movement of goods" (Cahn \& Schimmel 288, n.50). To further colour the European "service" view, their Customs

${ }^{35}$ See Pierre Sauve (2002) GATS: The Case for Open Services Markets, Paris: OECD for historical claim. The paired-characteristics come from Michael J. Trebilcock \& Robert Howse (1999) The Regulation of International Trade, $2^{\text {nd }}$ ed., London: Routledge, p. 272. 
administration, like their American counterpart, applies tariffs to the international trade in TV programming, which suggests a view of TV programming as goods. ${ }^{36}$

The difficulty in reaching consensus over classification has evolved into the question of demarcation between goods and services. This subject was first addressed for culture by the Canada Periodicals decision in 1997, and again examined in the EU Bananas decision, later in 1997. In March 1996, the USTR announced that it would challenge four measures of Canadian magazine policy, including the alleged inconsistency of Bill C-103 with Canada's trade obligations. The facts need not be presented again, as there are good histories available. The crux of each argument was that, for the U.S., the excise tax (C-103) violated national treatment because it indirectly discriminated against foreign-based split-run magazines. For Canada, the tax was on a service, an advertising service, so GATS, not the GATT, would be the relevant agreement; therefore, a national-treatment challenge simply didn't apply in the Canadian view. The dispute settlement panel ruled that obligations for trade in goods could co-exist with obligations for trade in services: "The ordinary meaning of the texts of GATT 1994 and GATS as well as Article II:2 of the WTO Agreement, taken together, indicates that obligations under GATT 1994 and GATS can co-exist and that one does not override the other" (74). This became the first articulation of what has come to be known as the principle of "co-existing overlap." 37

The panel ruling was appealed by both Canada and the United States, and the Appellate Body affirmed the panel's judgement in respect of overlapping obligations. This ruling raised some unsettling questions. For instance, where do obligations of one agreement end and the other

${ }^{36}$ The Pre-Kennedy Working Party information, contained in L/1741, and also characterized as such by Filipek (1992), op cit. note \#4, pp. 340-342. The distillation of American and European views on TV programming as a service or a good comes primarily from Cahn \& Schimmel (1997), op cit. note \#11. "Real purpose of the transaction" quote from pp. 287-88; short excerpt from Sacchi ruling from p. 288, note \#50. This piece of the ruling makes it clear, and foreshadows, the difficulty in maintaining a goods-services distinction in practice. While one can classify the content as service and the medium as a good in conceptual terms, the distinction becomes difficult if not impossible to maintain for commercial, real-world purposes.

${ }^{37}$ History of the Canadian-American magazine dispute, circumstances surrounding the challenge, and an assessment of the WTO jurisprudence can be found in Ted Magder's excellent occasional paper (1998) "Franchising the Candy Store: Split-Run Magazines and a New International Regime for Trade in Culture" Canadian-American Public Policy (34, April), Orono, ME: U Maine. Quote from Panel ruling, Canada-Certain Measures Concerning Periodicals ("Canada Periodicals") 14 March 1997. Reference code: WT/DS31/R. 
begin, particularly when it comes to trade that embodies some combination of goods and services? And more urgently, when does the affirmation of a right under one agreement equal the negation of a right under another? Within months of Canada Periodicals, the question arose again under EU Bananas. This time, the Appellate elaborated on the problem, providing guidance for future interpretations:

Given the respective scope of the two agreements, they may or may not overlap, depending on the measure at issue. Certain measures could be found to fall exclusively within the scope of GATT 1994, when they affect trade in goods as goods. Certain measures could be found to fall exclusively within the scope of GATS, when they affect trade in services as services. There is yet a third category of measures that could be found to fall within the scope of both the GATT 1994 and GATS. These are measures that involve a service relating to a particular good or service supplied in conjunction with a particular good. In all such cases in this third category, the measure in question could be scrutinized under both the GATT 1994 and the GATS. However, while the same measure could be scrutinized under both agreements, the specific aspects of that measure examined under each agreement could be different. Under the GATT 1994, the focus is on how the measure affects the goods involved. Under the GATS, the focus is on how the measure affects the supply of service or the service suppliers involved. Whether a certain measure affecting the supply of a service related to a particular good is scrutinized under the GATT 1994 the GATS, or both, is a matter that can only be determined on a case-by-case basis. (WT/DS27/AB/5, pp. 87) ${ }^{38}$

This statement serves as guidance for future determinations in drawing the boundary between goods and services. It clearly acknowledges the combination and clearly specifies that distinction must be made individually, on a case-by-case basis, as the cases arise. Furthermore, Interpretative Note $1 \mathrm{~A}$ stipulates that in the event of disagreement between two WTO agreements, the more specific agreement should prevail to the extent of the conflict. While this is useful in establishing a hierarchy between the GATT and the ancillary agreements, GATT and GATS, each being annexes to the Agreement to Establish the WTO, and thus having identical

\footnotetext{
${ }^{38}$ The author acknowledges Bernier's analysis as original and pathbreaking. I have included the same excerpt here because it is the first articulation of the interpretative principle that has come to be known as "coexisting overlap."
} 
standing, don't conform to this hierarchy. Finally, while these interpretations recognize coexisting overlap and the potential problems caused by goods-services distinction, they offer no objective criteria or standards that can be used to demarcate goods from services and vice versa. ${ }^{39}$

The goods-services distinction - and the line of demarcation - is an area within the larger question over whether certain cultural goods constitute trade in goods or services. A lesson can be drawn from the Canada Periodicals case, and EU Bananas argument, to inform negotiating proposals. Obligations under one agreement do not shield a measure from challenge under another agreement. If an exemption or the commitments withheld are precise and agreed upon, then such measures can be confidently understood to be free from challenge. However, in most circumstances, where ambiguity or overlap exist, or the potential exists, dispute settlement will tend to view such a measure under examination as coming within the scope of an agreement that contains positive obligations. Article 31(1) of the Vienna Convention on the Law of Treaties requires interpretation in the context of the treaty and in light of its object and purpose. Since progressive trade liberalization is one of the basic purposes of the WTO, and the agreements will be interpreted consistently with this objective, the dispute-settlement body will be inclined toward opening a measure under scrutiny, and not to take at face value the claim that the measure in question falls outside the scope of a member's obligations.

Beyond the problems posed for dispute-settlement interpretation, the goods-services distinction poses the problem of agreement coherence, which was introduced on page 49 . We might ask, along with Ivan Bernier (1998), "could India's limitations on film distribution in its specific commitments under GATS, although in full conformity with the agreement and accepted by the [members] to it, be challenged successfully under GATT? (113)" Many services, although classified and perhaps having their commitments withheld, may still be subject to trade obligations in respect of goods because they directly and indirectly are combined or supplied in conjunction with goods.

\footnotetext{
${ }^{39}$ The General Interpretative Note to Annex 1A establishes a hierarchy between only the GATT and other ancillary agreements (such as Agriculture, Subsidies and Countervailing Measures, or Sanitary and Phytosanitary). As the case law builds around the principle of co-existing overlap, the jurisprudence can be used as an implicit guide or, better still, criteria and standards will be explicitly identified. Those wishing to check for up-to-date state of affairs should consult the newest GATT Analytical Index.
} 
The telecommunications sector provides a second example of agreement coherence and the line of demarcation. While not identical in nature, because it's not the goods-services overlap under scrutiny, this example demonstrates the problem of agreement coherence, where one set of obligations ends and another set begins, though each set concerns trade in services.

Telecommunications, the transmission infrastructure for video, voice, and data is classified separately from the content carried through its circuits, fibre-optics, and co-axial cables. This distinction between medium and message, carriage and content, has, some have argued, become unsustainable. During the negotiations that produced the Agreement on Basic Telecommunications (1997), the US repeatedly tried to classify Direct-to-Home and Direct Broadcasting Satellite television as telecommunication services, a position that was repeatedly rejected by all WTO members. Hernan Galperin believes that telecommunication liberalization will inevitably lead to the liberalization of TV broadcasting — that technological convergence will pull TV and radio content in through the back door. However, Daniel Roseman, a former Canadian chief negotiator to the WTO on telecommunications, emphasizes that the distinction between telecommunication services and TV and radio broadcasting services, and content, is clearly stated, in paragraph 2(b) of the Annex on Telecommunications: "This annex shall not apply to measures affecting the cable or broadcast distribution of radio or TV programming." Not a distinction, but a wall, in other words. Such clear demarcation, expressed by a trade expert, lends confidence to the view that liberalization in one area will not directly affect the other. Agreement coherence will likely be preserved. ${ }^{40}$

As we have seen, the problem of goods-services distinction is bound up with the difficulties over classification. There are several points worth emphasizing in conclusion. First, classification is not as straightforward as it might appear, for reasons of commercial competitive advantage more than inherent properties. And as the services sector contributes more and more overall GDP, expect more effort to classify business activity as a service. Second, so-called third-

${ }^{40}$ Galperin (1999), op cit. note \#3, p. 70 for sectoral overlap. He cites Dwayne Winseck (1997) "Contradictions in the Democratization of International Communication" Media, Culture, and Society 19(2): 219246 for the idea that broadcasting services will be exposed through the back door opened by media convergence. Daniel Roseman's dissenting opinion comes from a phone conversation with the author, on January 23, 2002. Roseman also stressed that the safeguard embodied in paragraph 2(b) was negotiated with Canada's lead. Presumably, he would know this better than anyone. 
category examinations (from the EU Bananas extract) will multiply. This will reflect the increasing attention transnational business will focus on not having the competitive conditions diminished of any of its related services or service inputs behind foreign borders. Third, the absence of standard criteria for assessment will complicate disputes involving the goods-services distinction. Unlike the criteria that exist for the "like product" first-sentence test of national treatment, or even the less specific criteria that exist for the "directly competitive or substitutable products" second-sentence test, the only guidelines available by January 2003 are to make caseby-case, which is to say narrow, determinations. Fourth, co-existing overlap means members can't use the proliferation of agreements to shield legislation. Rarely is a good or a service a discretely bounded domain, hermetically sealed from other goods or services. More likely, any good or service is subject to several trade obligations directly or indirectly. Furthermore, coexisting overlap is commensurate with the spirit of liberalizing overall trade while respecting certain, specified exceptions, so this principle is consistent with market-opening disputesettlement determinations. It remains possible, as Bernier pointed out, that the affirmation of a right under one agreement may equal the negation of a right under another, but potential concern is diminished to the extent that sectoral and sub-sectoral classification proceeds, covering more aspects, and more specific aspects, of tradable products. ${ }^{41}$

If the goods-services distinction is the first specific issue worth analyzing, then the idea of the cultural sector exemption is the second. The cultural exemption has two distinct aspects: first, the actual effectiveness of the exemptions currently in place, measured by their scope and detail of coverage, degree of acceptance by their members, and reliability and predictably in regulating commercial behaviour and trade retaliation; and second, the simple persistence of the idea of an exemption, in one guise or another.

\footnotetext{
${ }^{41}$ For the point about standard criteria for "like product" and "directly competitive and substitutable products" the basis of assessment was spelled out in the 1970 Working Party on Border Tax Adjustment. A firstsentence national treatment test requires assessing (a) the product's end uses in a given market, (b) consumer tastes and habits, and (c) a product's properties, nature, and quality, all on a case-by-case basis. No equivalent secondsentence test criteria have been established. The "like product" standard is considered one of perfect substitutability, while the "directly competitive" standard is considered one of imperfect substitutability. It is likely that as the Dispute Settlement Body hears more challenges involving overlap, and the case law accumulates, principles of interpretation, and bases of assessment will be explicitly stated.
} 
The actual substance of the FTA, and NAFTA, exemption has been minimal in terms of ensuring Canada's ability to establish cultural policy. A review of the Canadian marketplace, or of cultural policy introduced, will demonstrate that the exemption didn't alter the percentages of foreign to domestic products. The exemption, in place since 1989, didn't prevent the USTR threat over Country Music Television, and the challenge over Canadian magazine policy and Sports Illustrated Canada. It is likely that the exemption, while politically necessary to secure the passage of free trade, has become counter-productive due to the false sense of security and faith misplaced in it by the Canadian cultural sector. And as the reality of a conditional, or retaliatory, exemption dawned on cultural producers, their betrayal has translated into negative publicity for the exemption and their sense of abandonment by the government. Against this weakness, it is important to remember the improvement of limiting retaliation to equivalent commercial effect over the previous state of affairs of unspecified, and so, unlimited retaliation. Given the vast disparity between Canadian and American retaliatory trade potential, the rule of law is an improvement over the rule of power, even when the rule of law is imperfect. One legacy of the exemption is the political expediency afforded by this derogation for the negotiation of a sensitive sector. ${ }^{42}$

More important than the substance of the exemption has been the idea of an exemption. The achievement of ratifying a trade agreement that uses the vocabulary of "exemption" is the real legacy of FTA Article 2005, because once codified, a cultural exemption in one form or another has been a goal in several different contexts. Attesting to the power of precedent setting, the eradication of this exemption was the express goal of the MPAA and RIAA during the NAFTA negotiations, and even after the negotiations were completed. The idea of the exemption, as we saw with Francois Mitterand's quotation, was also pivotal in forcing the stalemate between the US and EU during the Uruguay Round. All this despite the fact the exemption is more shadow than substance! This underlines how enduring an idea can be once codified. However, there is evidence the legacy is fading, and that the idea no longer energizes

\footnotetext{
${ }^{42}$ Speaking scientifically, it isn't possible to be certain that the presence of the cultural-industries exemption didn't alter the market shares throughout the 1990s. However, an examination of the statistical compilations reveals no large or unexplained change, either upwards or downwards, sector by sector.
} 
international policy design the way it once did. At conferences at the University of British Columbia, in October 2000, and Harvard, in March 2001, delegates spoke of the need to consider an approach other than the exemption to cultural trade. While the respective panel chairs noted that cultural policy remained important, they urged presenters to consider solutions based on the concept of cultural diversity, not a cultural exemption or exception per se. The residue of an exemption remains, as does the legacy; however, as we will read in the next two chapters, the idea of a cultural exemption has evolved considerably, so that in 2003, and beyond, an agreement to respect cultural diversity, and the policy that supports such diversity, no longer is designed to be an exemption. ${ }^{43}$

This chapter has illuminated several specific characteristics and general features of culture's treatment within the trading system, which can be distilled into recurrent themes and lessons. The trading system reflects problems that pre-dated the creation of the system. Friction over cultural trade, in other words, is nothing new. Measures to block, limit, or censor American motion pictures have existed since World War I, and Canadian efforts to help domestic magazines, by hindering the domestic competitive conditions of American magazines, date back to 1907 . Related to the problems is the difficulty in reconciling them, as seen in the quotations by Dennis Browne, William Dymond, and William Merkin. And likewise related are gloomy predictions: in 1994, Joyce Zemans wrote "whatever common concerns the U.S. and Canada may share in the cultural domain, the relationship, dominated by the cultural industries, shows every sign of becoming increasingly complicated over the next months and years" (512); and Ivan Bernier said in 2000 "Unless something is done in the coming years to solve the problem, chances are that the existing tension between trade and culture will increase rather than decrease" (3). This triplet of problems that are long-standing, intractable, and surrounded by a pessimistic

${ }^{43}$ The idea of an exemption draws strength from its precedent-setting power, which was covered in detail, and with references, on pages 40-42. UBC hosted the "Rethinking the Line" conference in October 2000; panel cited is "Trade and Cultural Policy in a North American Context," and information comes from Policy Research Initiative's Horizons Conference Report, p. 53. The JFK School of Government, at Harvard, hosted the "Integration Pressures" conference in March 2001; panel cited is "Cultural Policy in France and Italy," and information comes from Policy Research Initiative's North American Linkages Conference Report, p. 19-21. 
climate of opinion is a theme of cultural trade discourse. ${ }^{44}$

The roots of the difficulties include decisive American competitive advantage, the resulting success in foreign markets, and the contribution of the entertainment sector to the U.S. balance of trade and payments. As the world economy has become more open and integrated, so have each of these reasons become more entrenched. In motion pictures, for instance, the U.S. film industry earns more profits from the foreign, rather than the domestic, market. The trade surplus generated by film and TV programming has taken on an even greater importance because of America's declining international trade position, an overall deficit that has grown alarmingly throughout the 1990s. Since both industry and government have a strong interest in preserving the current foreign-market access, it is exceptionally unlikely that any modification to the trade treatment of the audiovisual sector could be negotiated. Slight incremental alterations, rather than wholesale creation, then, constitute another lesson learned. Negotiation goals and industry expectations should, therefore, be modest and restrained. ${ }^{45}$

The treatment of culture within the trading system, multilateral and regional, should be characterized, on the whole, as indirect treatment. The trading system concerns itself with ensuring non-discrimination between domestic and foreign firms, at the border, behind the border, and in various subtle ways. Trade agreements concern measures used, not the objects of those measures. In Canada Periodicals, the examination was of taxation and distribution applied to domestic and foreign magazines; the magazines themselves were secondary. The reasoning for this general focus on measures is sound: trade agreements can't anticipate every product, combination and re-combination of products, that may come into existence as the result of new technology, so the agreements concern themselves will applying the essential principle of free

\footnotetext{
${ }^{44}$ Basis for long-standing claims of film and magazine friction come from J-P. Jeancolas, op cit. note \#7, Ted Magder (1994) Canada's Hollywood, Toronto: UTP, Ted Magder (1998), op cit. note \#37, and Mary Vipond (1977) "Canadian Nationalism and the Plight of Canadian Magazines in the 1920s" Canadian Historical Review 58(1): 43-63. Zemans quote from (1994) “'And the Lion Shall Lie Down with the Lamb': U.S.-Canada Cultural Relations in a Free Trade Environment" American Review of Canadian Studies 24 (4, Winter): 509-536. Bernier quote from speaking notes (2000) "The World Trading System and Culture: Looking at the Problem From a Cultural Perspective" at Culture in a World of Trade Conference, at New York University, March $3^{\text {rd }} 2000$.

${ }^{45}$ Guback (1985), op cit. note $\# 5$, discusses the switch that occurred in the 1980 s, when Hollywood began the trend that hasn't reversed of earning more revenues from abroad than from home. Hernan Gaperin (2000), op cit. note \#3, references the contribution the film and tv sector make to the U.S. balance of payments.
} 
trade, which is non-discrimination, to traded goods and services. ${ }^{46}$

And it is not difficult, given this absence, the American competitive advantage, and the grossly imbalanced trade flows to see why so much friction has resulted from cultural trade. Furthermore, it is not difficult to see why the locus of the debate - and much of the analysis has been in Canada, where national culture is a wellspring of anxiety and is seen to be the pulse of Canada's existence as an sovereign nation. It was entirely predictable that culture had to be off the table in any Canada-U.S. FTA. Despite the difference in position of many countries, there is reason to believe that consensus can be found, owing in part to the desire to maintain a smoothly functioning, stable world economy, which entails respecting the cultural consciousness and identity concerns of member states, a motivation that has taken on a sharpened understanding after the fall of 2001. Capturing this spirit, Geza Feketekuty wrote (2000) "if the United States and Canada, with their similar cultural background and history cannot work out a viable agreement, there is much less hope of overcoming the hurdles in this area on a global basis" (152). This chapter should have provided a better understanding of the trading system, its limits, and potential for negotiation, that now can be used as a foundation to turn from the present to the future, from what is to what might be. ${ }^{47}$

${ }^{46}$ Ivan Bernier (1998), op cit. note \#3, notes, on page 114, that Articles IV and XX(d) of the GATT "specifically refer to cultural goods" but that "cultural goods are subject to the usual GATT disciplines."

${ }^{47}$ Quote from Geza Feketekuty "Trade in Services" in (2000) M. Kreinin (Ed.), op cit. note \#20, (pp. 143152). The view holding cultural distinctiveness as a precondition to national survival, as curious as it may seem to outsiders, has long been an article of faith within Canada. The best evidence for this is the repeated expression in Royal Commissions dedicated to addressing Canadian cultural institutions: from the Aird (1931), to especially the Massey (1951), to the Fowler (1957), to the O'Leary (1961), to the Davey (1970), to the Applebaum-Hebert (1982). 


\title{
Chapter Two:
}

\section{The Two-Level Policy Chessboard}

\begin{abstract}
"The politics of many international negotiations can usefully be conceived as a twolevel game. At the national level, domestic groups pursue their interests by pressuring the government to adopt favourable policies, and politicians seek power by constructing coalitions among those groups. At the international level, national governments seek to maximize their own ability to satisfy domestic pressures, while minimizing the adverse consequences of foreign developments. Neither of the two games can be ignored by central decision-makers, so long as their countries remain interdependent, yet sovereign." Robert D. Putnam (1988)
\end{abstract}

This chapter begins the policy analysis part of this thesis. Chapter One, by detailing the trade treatment of cultural products, provided the framework necessary to realistically assess what can be accomplished through international negotiation. The general objective in this chapter is to determine the degree that recognition for cultural products, or cultural policy, is possible within the trading system, including a specific analysis of how the so-called International Instrument on Cultural Diversity (IICD) might achieve this. For the sake of brevity, the IICD will be refered to as the Instrument. To meet this objective, the chapter will establish the criteria for a two-level policy analysis.

Policy intended to apply within countries as well as between them is especially challenging to analyze. The domestic policy process is a muddle and the outcome messy, an idea captured by the aphorism that policy and sausages are two things one should not watch being made. A policy requiring adherence by a number of countries, or in this case, a large number of countries, adds a second level to the policy chessboard. Each country will have a different interest, one that reflects different compositions of domestic stakeholders; will occupy a different place in the international order of states; might be able to negotiate but unable to ratify an agreement; and may withdraw from, or breach, its commitments. The international level introduces uncertainty into the implementation, adherence, and outcome stage in the real world, and poses a substantial challenge for analysis and prediction, in theory. Chapter Two begins by outlining a framework, and developing several criteria, for understanding domestic policy. The second section repeats this process at the international level. And the final section describes the 
evolution of the Instrument, from its conceptual inception in 1998 to its state of development in 2003 as a work-in-progress. One challenge is that the Instrument, at the time of writing, exists in a liminal state, neither fully formed and in operation, nor only as speculation, a hypothesis, or a blueprint on a shelf. This feature, where it is neither completely in existence, nor completely nonexistence, makes policy analysis a formidable task. Chapters Two and Three are closely linked: while Chapter Two describes the generic criteria for a two-level policy analysis, Chapter Three extends the analysis, by applying the criteria to the Instrument and private proposals.

I.

Policy studies, as Peter DeLeon has noted, have had a long history and a short past. While government actions, policy, and laws have been objects of concern through the ages, the emergence of policy studies as a field, with the application of sophisticated and rigourous methods, dates only to the early 1950s. Pioneered by Harold Lasswell (1951), the "policy sciences" made policy itself the primary object of analysis. Three characteristics defined his approach. First, policy science was multi-disciplinary; it embraced the fields of sociology, economics, law, and political studies. Second, policy science was oriented toward problem solving; by design, it retained relevancy and would not dissolve into the ether of interesting but often sterile debates over abstract issues. Third, policy science was normative; it shouldn't pretend to adopt the pretense of objectivity, or separating goals from means, or of values from techniques. Policy was an inherently value-laden object of analysis. Policy analysis has undergone increasing sophistication and nuance, has produced schools of thought, and has generated a substantial literature in the fifty years since Lasswell's original book chapter. ${ }^{1}$

Policy analysis here means public policy analysis. After all, the unqualified analysis of policy could mean the policy of international corporations, clandestine organizations, local guilds or clubs, even the policy process of non-democratic governments. Public policy, at an elementary

\footnotetext{
${ }^{1}$ Peter DeLeon reference from Michael Howlett and M. Ramesh (1995) Studying Public Policy: Policy Cycles and Policy Subsystems, Toronto, ON.: Oxford UP, p. 18. Original is Peter DeLeon (1994) "Reinventing the Policy Sciences: Three Steps Back to the Future" Policy Sciences 27: 77-95. Claim of Lasswell pioneering the field from Howlett \& Ramesh, p. 3. Outline of three organizing characteristics also from Howlett \& Ramesh, pp. 3-4. Original contribution is Harold Lasswell (1951) "The Policy Orientation" in Daniel Lerner \& Harold D. Lasswell (Eds.), The Policy Sciences: Recent Developments in Scope and Method (pp. 3-15), Stanford, CA: Stanford UP.
} 
level, means "anything a government chooses to do or not to do" (Dye 4). In this view, government is a unified actor and the analytical goal is to explain choice or non-choice. At a sophisticated level, public policy is "a set of interrelated decisions taken by a political actor or group of actors concerning the selection of goals and the means of achieving them within a specified situation where those decisions should, in principle, be within the power or those actors to achieve" (Jenkins 5). Multiple agents each make decisions, which sum to a unified outcome. Parallel to this and with a supplemental dimension, public policy can also be defined as "a purposive course of action followed by an actor or a set of actors in dealing with a problem or matter of concern" (Anderson 6). While this definition is generic, it highlights the multiple decisions made by multiple decision-makers. As such, it encapsulates the dispersed and competitive nature of decision making in democracies. ${ }^{2}$

Public policy analysis must be guided by a way to understand both the process and the content of a given policy. Howlett and Ramesh (1995) identify five stages in the process: (i) agenda setting, (ii) policy formulation, (iii) decision making, (iv) policy implementation, and (v) policy evaluation. While these distinctions are somewhat artificial, the divisions are analytically useful; for instance, formulation and decision making, identified as two steps, are a continuum. They help to locate the process and to fix attention on factors that affect a given stage, ones that likely won't affect others. John Kingdon (1984) offers another stencil of the process: three streams - of problems, of policy, and of politics - that exist independently of one another, yet which must be conjoined for a policy to be legislated into existence. Each stream is a necessary, but not a sufficient, condition for policy implementation. Howlett and Ramesh's delineation of cycles and sub-systems advances understanding of the policy process itself, while Kingdon expands the understanding beyond policy to explain how non-policy forces facilitate or impede

${ }^{2}$ The page references come from Howlett \& Ramesh (1995), op cit. note \#1. The original source for the first quotation is Thomas Dye (1972) Understanding Public Policy, Englewood Cliffs, NJ: Prentice-Hall, p. 2; for the second quotation William Jenkins (1978) Policy Analysis: A Political and Organizational Perspective, London: Martin Robertson; and for the third quotation James Anderson (1984) Public Policy Making: An Introduction, $3^{\text {rd }}$ ed., Boston: Houghton Mifflin. 
policy realization. Their contributions are complementary, rather than competitive. ${ }^{3}$

The stages within the policy cycle require elaboration. According to Howlett and Ramesh, agenda setting is the most critical stage of any policy process. What happens at this stage has a decisive impact on the entire process. Cobb and Elder write (1972): "What happens in the decision-making councils of the formal institutions of government may do little more than recognize, document, and legalize, if not legitimize, the momentary results.... The critical question becomes, how does an issue or a demand become or fail to become the focus of concern and interest within a polity" (12). Kingdon (1984) echoes this: "Out of the set of all conceivable subjects or problems to which officials could be paying attention, they do in fact seriously attend to some rather than others. So the agenda-setting process narrows this set of conceivable subjects to the set that actually becomes the focus of attention" (3-4). The agenda-setting phase is predecisional, yet pre-decisional implies an eventual decision. And this is the essence of the phase. Once an issue is on the agenda, an outcome is assured, it has been structured into the process: maybe not a rational outcome, maybe not a beneficial outcome, or one that sustains harmony among different interests or commands the support of the public at large, and maybe only a symbolic outcome - but an outcome nonetheless. At a deeper level, the power of agendasetting resides in the correspondence of this stage to the recognition of a problem. And recognition of a problem is tantamount to the admission that a certain situation, circumstance, trend, or state of affairs is not a condition to be abided by, but a problem to be changed. Problem recognition comes with a host of factors, like definition, expectation, and focussing events, which will be explained as I account for the development of the Instrument later in the chapter. ${ }^{4}$

The next stage in the cycle, policy formulation, corresponds to proposing a solution. This stage entails defining the problem, considering alternatives, and ultimately accepting an option

${ }^{3}$ Articulation of Howlett \& Ramesh's five stages takes place on page 11, with a chapter (or more) devoted to detailing each stage. John W. Kingdon (1984) Agendas, Alternatives, and Public Policies, Boston: Little, Brown \& Co.

${ }^{4}$ Roger Cobb and Charles Elder (1972) Participation in American Politics: The Dynamics of AgendaBuilding, Boston: Allyn \& Bacon. See Howlett \& Ramesh (1995), op cit. note \#1, chapter five, pp. 104-121; and Kingdon, op cit. note \#3, chapter five, p. 95-121 for detailed discussions of the agenda-setting stage and factors that shape problem recognition. 
while rejecting others. Despite the word "formulation," the process is anything but orderly. The process may proceed without any clear definition of the problem, or without agreement on the problem that needs a solution. More than one set of actors may offer solutions, and their proposals may be similar, complementary, or more often, competing. Since the process is openended until a policy is implemented, formulation and reformulation may occur over a long period of time, in which case problem definition may change, and resource availability may increase or decrease. The open-ended nature of formulation invites appeals or challenges at numerous points along the way, and this tendency is exacerbated because someone always wins and someone always loses in accepting one option but not others. In addition to these proximate considerations, several more nebulous considerations swirl in the background: the nature of the epistemic community; the anticipation of future technical, budgetary, or political constraints; and the distribution of incentives and risks in pursuing some solutions and letting others wither. Rather than visualize the process as linear and orderly, elements lining up in a quene, imagine policy formulation as making a stew that can simmer for a prodigious amount of time and that never tastes the same way twice. John Kingdon refers to this phase as the "policy primeval soup." The path from the policy soup to well-defined alternatives is long and tortuous, with many forks, always subject to change, and never completed, until completed. As we shall see, the Instrument is in the policy formulation stage, where three well-defined alternatives are vying for supremacy as the model to be moved forward. The specific impact and interplay of many of these variables on the Instrument's policy formulation will be described in the upcoming account. ${ }^{5}$

The third stage in the cycle, decision making, is the culmination of the policy formulation: at this point, one option is chosen. Decision making is also the most political part of the cycle because someone will win and someone will lose - it's zero sum. Given this prominence, several ideas exist to shape thinking on the process: rationalism, incrementalism, and the so-called garbage can model. The rational model, which originated in business administration, holds that alternatives are systematically explored, and their costs and benefits

\footnotetext{
${ }^{5}$ For fuller elaboration of factors and considerations, see Howlett \& Ramesh (1995), op cit. note \#1, chapter six, pp. 122-136; and Kingdon (1984), op cit. note \#3, chapter six, pp. 122-151. The title of Kingdon's chapter six is "The Policy Primeval Soup." An excellent condensation of the factors appear on pp. 122-124 of Howlett \& Ramesh.
} 
accounted for, before deciding which choice most logically, most rationally meets the goal. This view presupposes that agents would have knowledge of the complete chain-of-events for each alternative, have perfect information in general, and would decide based on purely logical grounds, not on other grounds, like personal competition, envy, or power. Amid critiques of rationalism, Charles Lindblom (1959) offered an approach called incrementalism, which proposed that decisions are made to address practical problems, not solve lofty goals. Instead of operating in a vacuum, and proposing an ideal, best-case scenario solution, incrementalism described a situation in which there was little room to manoeuvre because radical change would significantly alter the pattern of distribution of costs and benefits, so that decisions often perpetuated continuity, rather that effect change. A debate between the rational and incremental schools had ossified by the mid-1960s, and the attempt to advance understanding of decisionmaking in complex organizations produced the garbage-can model by the 1970 s. This view holds that "decision-making was a highly ambiguous and unpredictable process only distantly related to searching for means to achieve goals" (145). March and Olsen, the creators, argued that the previous approaches incorrectly assumed a level of intentionality, comprehension of problems, and predictability among actors that doesn't occur in the real world. The garbage-can view relaxes many assumption and replaces them with an acknowledgement of the ad hoc and haphazard. The final evolutionary step concerns isolating the elements involved in decisionmaking and identifying different parameters for each. Agents can be one, two, or multiple. The setting can be single and closed to outside input, or multiple and open, and so on with the problem, information, and time schedule. The account of Instrument development, particulary because it conforms to this stage in the policy cycle, will put these models and these elements in action. $^{6}$

\footnotetext{
${ }^{6}$ Howlett \& Ramesh (1995), op cit. note \#1, provides an excellent synopsis of decision making, in chapter seven (pp. 137-152). One important distinction is that rationalism arose, as mentioned, from business administration and organizational development, while incrementalism arose from public administration - and the different contexts do matter. Herbert Simon levelled the powerful critique against the postulates of rationalism, in (1958) Models of Man, Social and Rational, NY: Wiley, which paved the way for Lindblom's idea. The original exposition of the garbage-can model can be found in M. March, J. March, and J. Olsen (1972) "A Garbage Can Model of Organizational Choice" Administrative Science Quarterly 17(1): 1-25. The idea of isolating decision-making elements to establish each of their parameters is from John Forester (1984) "Bounded Rationality and the Politics of Muddling Through" Public Administration Review 44(1): 23-31.
} 
A few other features of the domestic policy chessboard should be introduced.

Understanding structural considerations entails accounting for actors and institutions. Howlett and Ramesh (1995) identify generic actors: elected officials, appointed officials, interest groups (used interchangeably with lobbyists), research organizations, and the media. While the account of the Instrument development will specify different actors, it is important to note that actors often aren't monolithic or unitary. For instance, different research organizations proceed with different agendas, and interest groups exist explicitly to advocate different positions, which will necessarily make them competing. Even within the category of media, it is possible that print media may adopt a different position then television media, which may be different yet again from the advertisers who purchase space or time. Institutions are defined, by Howlett and Ramesh, as "the structures and organization of the state, society, and the international system" (51). One example of institutional difference, in this case, will be the sharp departmental difference of views between Canadian Heritage and Foreign Affairs and International Trade. This illuminates the issue of power sharing and whether inter-departmental collaboration is horizontal or vertical. While DFAIT has the statutory basis for assuming the lead on international issues, the lead role tends to become muddied when an international agreement crosses the border, so to speak, to directly affect a policy that falls squarely within another department's mandate, for instance Canadian Heritage's responsibility over cultural policy. Heritage possesses the expertise on the substantive policy area, but DFAIT maintains the expertise on international diplomacy and bargaining. As will be seen, when jurisdictions are not clearly demarcated, a tangle of priorities and ambitions may ensue.?

Several final elements and considerations should be mentioned, if only for the purpose of accounting for different factors. For instance, is the unit of analysis an individual, a group, or an institution? Be aware of motivation and causation at different stages of the cycle. While it is incorrect to postulate that institutions have themselves motivations, personal motivations or strong leadership will often be confused with an institutional motivation. Institutions are often

\footnotetext{
${ }^{7}$ This overview is drawn from Howlett \& Ramesh (1995), op cit. note \#1, chapter three. Horizontal and vertical collaboration comes from G. Bruce Doern, Leslie Pal, and Brian Tomlin Eds., (1996) "The Internationalization of Canadian Public Policy" (pp. 1-26) in Border Crossings, Toronto: Oxford UP.
} 
taken, incorrectly, to embody a key personality. Be aware of the risks and rewards, costs and benefits, choices and constraints, and advantages and disadvantages at each stage. Keep the notion of tactics, strategies, alliances, and coalitions not far from any macro-level analysis. And what are the determinants of any given causal variable? Finally, metaphors are important as ways to channel our thinking. Does the "policy primeval soup" and "policy chessboard" accurately abstract reality, or distort it? Perhaps the chessboard idea dignifies a process that is, unlike chess, not rational and not even especially strategic, but more like the garbage can: stuff in, stuff out. As such, the metaphors are only starting points for the analysis.

As mentioned above (on pages 60-1), John Kingdon offers a macro-understanding of the policy process, a view that encompasses forces outside of the policy process. Three streams - of policy itself, but also of problems, and of politics - must align in order for a policy to take shape and be legislated into existence. Since Kingdon's account of the policy stream dovetails with the one offered by Howlett and Ramesh, I will highlight salient features of the other two streams, and described how streams are conjoined.

While policy alternatives and proposed solutions tend to exist in a steady state, the impetus for action originates with politics or problems. Problems - a disaster, a crisis, the collapse of a sector of the economy - often galvanize opinion and command a response. Problems of this nature are focussing events, and have the benefit of profile and urgency where problems like the slow erosion of the standard of living for a segment of the population, or the decline in quality of infrastructure, education, or health, does not. Nothing focusses the mind like a hanging. Problems are a necessary, but insufficient, condition for action. The political window may open because of a change in government, a focussing event, a determined leader, or less often, a change in the national mood. There is a built-in bias to politics that has politics reacting to real or perceived problems. (Political decisions are rarely made in the absence of a commanding event solely for the purpose of anticipating a problem.) Both predictable and unpredictable features help to synchronize political window openings and closings. Predictable factors include budgets, reviews, and renewals. Unpredictable factors are synonomous with focussing events. Related to predictability-unpredictability is the discretionary and routine agenda: the program the government pursues as a matter of course, and areas where the 
government decides to intervene. ${ }^{8}$

A capsule statement describes the pre-conditions of confluence: "A problem is recognized, a solution is developed and available in the policy community, a political change makes it the right time for policy change, and potential constraints are not severe" (174). A single stream rarely explains an item with high-agenda status. A problem - airspace congestion may languish as low-profile for years until a mid-air collision instantly establishes it as a highprofile, and high-priority, problem. Now, the political stream becomes engaged. The likelihood of real-world change increases when, with policy options and perhaps a preferred solution in the background, a focussing event catalyzes the political process. The problem and political streams are closely related. In Kingdon's account, the impetus for any substantial change comes from the occurrence of a problem. This straightforward observation has the important implication, in this case, that political capital will be expended to the extent that foreign entertainment products are perceived as a problem. The greater perceived problem, the more political effort might be expended to address it in the form of an international agreement on cultural diversity. If the state of affairs is deemed more a condition than a problem, the likelihood of political expenditure drops. This question is important, in our case, and will be addressed. To foreshadow, the origin of the Canadian policy development and the Canadian-led international capacity building owe much to the Canada Periodicals WTO decision, in 1997, which acted as a lightning rod for the issue of globalization and culture in general. ${ }^{9}$

\footnotetext{
${ }^{8}$ See John Kingdon (1984), op cit. note \#3, chapter eight (pp. 173-204) for a discussion of policy windows and how the streams - or windows - are joined.

${ }^{9}$ Quotation from John Kingdon (1984), op cit. note \#3. Incidentally, the example of airspace congestion and a mid-air collision was also taken from Kingdon, chapter 8, in which a commercial aircraft collided with a private aircraft, in San Diego, in 1981. One may take the assertion that the Canada Periodicals case served to define a condition as a problem one step further, and argue that it was the catalyst to prompt Canadian government action, acting as cause and effect. Terry Cowl, personal correspondence with author, July 9, 2002. There had been several other cultural sector irritants throughout the 1980s and 1990s, the film distribution rights, Country Music Television, satellite broadcasting, Borders Books, and neighbouring rights for sound recording, all of which helped to catalyze the decision to proceed with the international policy process. Each is detailed as a case study, in a separate chapter, in Keith Acheson and Christopher Maule (1999) Much Ado About Culture: North American Trade Dispute, Ann Arbor: U Michigan P.
} 
II.

The foregoing guideline has outlined a framework for understanding the domestic policy process. We must now add a second framework to elaborate this understanding, a way to understand international policy formation and coordination. In 1988, Robert Putnam published "Diplomacy and Domestic Politics: The Logic of Two-Level Games" in International Organization, to "suggest a conceptual framework for understanding how diplomacy and domestic politics interact" (430). The puzzle had been, in simple terms, that international relations (IR) theorists, and their counterparts on the domestic side, political scientists, had tended to prioritize their domain at the expense of the other, each side viewing the other as a black box with fairly predictable outcomes. The result had been absence of satisfactory explanation of both levels. Motivated by his personal experience in the Carter Administration's National Security Agency (NSA), Putnam wanted to outline an integrative approach to account for the reciprocal interaction and influence, and move beyond the metaphor of two-level games to a specific algebra, where relations between actors, institutions, and ideas could be specified. ${ }^{10}$

The analytical aim for many IR theorists was to satisfactorily explain collective-action problems, where states agree to something not necessarily in their national self-interest but in the interest of several nations collectively. The original objects of analysis were the conferences on international economic cooperation, convened at the nadir of the Great Depression and nearing the conclusion of World War II, conferences that addressed exchange-rate stability, trade barriers, external debt and adjustment costs, and macro-economic coordination. The resulting international agreements and implementation posed challenges to the canons of classical realism, where maximizing national interest through rational means was thought to be absolute. ${ }^{11}$

Attempts at integrative international-domestic frameworks preceded Putnam's. James

\footnotetext{
${ }^{10}$ Robert D. Putnam (1988) "Diplomacy and Domestic Politics: The Logic of Two-Level Games" International Organization 42(3): 427-460. Comment on background from Andrew Moravcsik (1993) "Introduction" in Peter B. Evans, Harold K. Jacobson, and Robert D. Putnam Eds., Double-Edged Diplomacy: International Bargaining and Domestic Politics (pp. 3-42), Berkeley, CA: UCP.

${ }^{11}$ The basic dilemma comes from Moravcsik (1993), op cit. note \#10. The two conferences are the 1933 London World Economic Conference, and the 1944 Bretton Woods Conference. The list of specific economic issues comes from page 3 .
} 
Rosenau called attention to "linkage politics," but his approach amounted to an elaborate taxonomy, not a way to generate explanation. Karl Deutsch and Ernst Haas emphasized the role of domestic political parties and spillover on the process of European integration. And Joseph Nye and Robert Keohane are considered, by Putnam, intellectual hiers to this tradition, with their emphases on complex interdependence and transnationalism. The starting point for an integrative framework is to ask on what level is the problem to be analyzed: systemic (or state level), domestic, or individual (statesmen). By custom, systemic analyses assume that states are unified actors and take the internal attributes as given, while domestic-level theorists reverse this: state behaviour constitutes the international system, it doesn't respond to it, so as states differ internally, so does the nature of the international order. Systemic theory explains much about international relations; however, because the state is indeterminate, anomalies cause these theories to degenerate instead of looking inside the state for explanations. This breakdown resulted in the recognition of three limits to the systemic approach. First, the assumption of states as bounded, rational actors must be relaxed. A powerful insight, states can not make purely rational decisions because of the dispersed and competitive nature of decision-making in any democracy. The vast majority of decisions are arrived at via compromise and consensus. Second, the assumption of constant mobilization capacity must be relaxed. Statesman and international negotiators were assumed to be able to mobilize whatever material or symbolic resources were needed to attain an international objective. As will be seen shortly, Putnam paints a different picture, one where international negotiators do as much - or more - negotiating with domestic constituents as they do internationally, and they don't often succeed in securing their original goals. Third, the assumption of stable state preferences must be relaxed. Preferences vary according to coalitions and the distributional consequences of costs and benefits. When domestic support is broad-based, this assumption holds, but the assumption quickly evaporates when there is internal domestic competition, or a change in pattern of costs and benefits. ${ }^{12}$

\footnotetext{
${ }^{12}$ Description of the nature of each approach, and limits to the systemic theory, come from Andrew Moravcsik (1993), op cit. note \#10, particularly pp. 6-15. Work by the forerunners of integrative theory are James Rosenau (1969) "Toward the Study of National-International Linkages" in his Linkage Politics, NY: Free Press; Karl W. Deutsch et al. (1966) Political Community in the North Atlantic Area, $2^{\text {nd }}$ ed., Princeton, NJ.: Princeton UP; and Ernst Haas (1958) The Uniting of Europe: Political, Social, and Economic Forces, 1950-1957, Stanford, CA: Stanford UP; and Robert O. Keohane and Joseph S. Nye (1977) Power and Interdependence, Boston: Little, Brown.
} 
Putnam's solution to the black-box shortcoming was to analytically distinguish between a negotiation and a ratification phase, each phase corresponding to a level of analysis. The lead negotiators, or statesmen, of different countries in discussion comprised the negotiation portion, and the internal, or domestic, process of accepting or rejecting the treaty or bargain comprised the ratification phase. While it is inaccurate in terms of what happens in reality to completely disentangle one phase from the other, it is analytically useful. Putnam then establishes the concept of the "win set," which comprises the items the negotiator must secure from the other negotiator(s) in order to guarantee domestic ratification.

Domestic win-sets are determined by two broad factors: domestic preferences and coalitions; and the institutions themselves required in ratification. Preferences mean what outcome a given industry or sector or lobby will tolerate as an acceptable position for ratification. Coalitions refer to different domestic groups that band together in support of, or in opposition to, the emerging package. In turn, several specific factors shape preferences and coalitions: the cost of not achieving agreement; the relative size of isolationists versus internationalists; and whether preferences are homogenous - spread across different groups - or heterogenous - whether, say, the automobile sector stands to gain but pharmaceuticals stand to lose. The second broad factor, institutional ratification, refers to whether ratification is a straightforward vote to accept or reject the tentative agreement, or whether it's a not-straightforward process of voting and amending. Straightforward acceptance or rejection requires negotiators to deliver a stronger agreement, one that is tolerated by most, or all, of the domestic constituents, and one not subject to eleventh-hour defections or side deals. ${ }^{13}$

The direct bargaining between statesmen or -women comprises the negotiation phase. Contrary to conventional wisdom, as much or more negotiation actually takes place internally, between the statesman and their domestic constituents. Robert Strauss, former Special Trade Representative during the Tokyo Round trade negotiations, has written (1987): "I spent as much time negotiating with domestic constituents (both industry and labor) and members of U.S. Congress as I did negotiating with our foreign trading partners" (vii). Indeed, the domestic level

\footnotetext{
${ }^{13}$ See Putnam (1988), op cit. note \#10, pp. 435-452 for a detailed discussion of the determinants, and interaction, among the win-set elements.
} 
— the win-set necessary for ratification — set the parameters for the international-level negotiation. Negotiators will often exploit incomplete information on the part of their counterparts to drive a harder bargain, however the negotiator also has an interest in maximizing his or her counterparts' win-set: the larger the other win-set, the more room for concessions on his or her part, so the better deal a negotiator should be able to deliver for his or her constituents - and this includes the appearance that the negotiator was "tough," able to bargain his or her counterpart(s) down. The chief negotiator uses a host of other tactics and strategies to help ensure domestic acceptance, including the insistence that constituents accept a position because it was the best that could be negotiated, or that it was imposed by the nature of multi-lateral acceptance. Finally, in principle ratification and negotiation are distinct phases, but in reality they are "intertwined and simultaneous" (Moravscik 23). While negotiation is determined by what states will accept, ratification is determined by what domestic constituents will accept. ${ }^{14}$

In place of theories that impoverished one level of analysis while examining another, Putnam's "two-level games" or "double-edged diplomacy" advances understanding for two reasons. One, he insists that both levels must be analyzed because both play indispensable roles in shaping the outcome. Two, beyond shining the spotlight in two places, he outlined a framework for analysis. One suspects his contribution remains substantial because of the emphasis he places on understanding the nature of coalitions and cleavages among domestic constituencies, and the constraints imposed by altering the distributive pattern of costs and benefits as a result of negotiation - a point that echoes the insight of Charles Lindblom. In the following chapter, policy analysis will be guided by many of the postulates presented here. To introduce some doubt to the international-level of the policy chessboard, we should consider the applicability of this thinking to questions other than international economic cooperation and coordination. For instance, Does Putnam's logic apply to security and defense issues? Does it apply within the multilateral trading system, the WTO, which has higher institutional coherence than other parts of the international economy? Does it apply between democratic and non-

\footnotetext{
${ }^{14}$ Putnam (1988), op cit. note \#10. Robert Strauss quote from (1987) "Forward" (p. vii) in Joan E. Twiggs The Tokyo Round of Multilateral Trade Negotiations: A Case Study in Building Support for Diplomacy, Washington, DC.: Georgetown University Institute for the Study of Diplomacy. Quote from Moravcsik (1993), op cit. note \#10.
} 
democratic governments? Does it apply between the developed and developing world? Each of these last two questions apply because non-democratic (or quasi-democratic) and developing countries are WTO members and, particularly, members of the coalition striving to have culture recognized within the international trading system. The advantages and limitations of two-level bargaining must be kept in mind as we consider the attempts toward the international recognition of culture. ${ }^{15}$

III.

This third section of this chapter details the policy and political development of the International Network on Cultural Policy (INCP). Founded at a conference held in Ottawa, in June 1998, the INCP functions as an venue for informal discussion on subjects relating to culture and globalization, and it had 19 founding member countries, including Canada and France. The group next met in Oaxaca, Mexico, in 1999, where they resolved to create a Working Group on Cultural Diversity and Globalization, charged with "discussing the possibility of working on a global scale to determine cultural policies that are appropriate for all countries and create the necessary tools for countries to implement policies that favor, preserve, and promote cultural diversity" (1). The International Network for Cultural Diversity (INCD), a non-governmental organization with similar objectives, met in parallel with the INCP. ${ }^{16}$

The INCP gained momentum and capacity at its third annual meeting, in Santorini, Greece, in September 2000. The INCP welcomed the INCD in an official capacity, and attending ministers agreed that an international instrument on cultural diversity should be the global focal point for ensuring cultural expression. The Working Group agreed on an illustrative list of cultural diversity principles that should guide elaboration of the Instrument's descriptive content. By that time, NCP membership had grown from 19 to 45 countries. Although the Network

\footnotetext{
${ }^{15}$ Questions over the scope of applicability of Putnam's logic were introduced by the authors, in the Preface (p. ix). See P. Evans, H. Jacobson, and R. Putnam, op cit. note \#10.

${ }^{16}$ Unless otherwise specified, all information about the INCP comes from the INCP website: www.incpripc/org. The quotation about the Oaxaca purpose is from the page entitled, "Annual Meetings: Paper for Ministerial Consideration: Scope and Framework of an International Instrument on Cultural Diversity."
} 
serves as a forum for national cultural ministers, cultural ministers from Quebec and Newfoundland, or their representatives, also participated in the meetings. ${ }^{17}$

At the fourth meeting, in Lucerne, Switzerland, in September 2001, the INCP adopted a two-year mandate for articulating the instrument. This included "a common vision, objectives and norm-setting elements," recognition of "the legitimate role of governments to preserve and promote cultural diversity through the development and implementation of cultural policies at all levels [and] the needs of developing countries" in "requir[ing] increased attention in order to augment their capacity in the field of cultural development" (1). The rationale of instrument development was broader than merely attempting to create a broad cultural-industries exemption. Animated by UNESCO's Report entitled “Our Cultural Diversity” (1995) and Stockholm's Action Plan (1998), cultural policy was identified as a key component of endogenous and sustainable development. This conception of cultural policy entailed not only cultural industries (the now-familiar film, video, broadcasting, publishing, and sound recording sectors), but tangible and intangible heritage, historic treasures and architecture, and was intended to promote literacy and help alleviate poverty. As such, the widened rationale fell within the ambit of several international and national organizations: the World Bank, the Organization of American States (OAS), the Francophonie, the Inter-American Development Bank (IDB), and the Council of Europe. And many of these organizations incorporated discussion of cultural diversity. ${ }^{18}$

As in founding the network, Canada also played a key role in inspiring dialogue. The Government of Canada, responding to the recommendations of the February 1999 SAGIT, announced in October 1999: "Canada should pursue a new international instrument on cultural diversity. As described by the SAGIT, the purpose of the agreement would be to set out clear ground rules to enable Canada and other countries to maintain policies that promote their culture while respecting the rules of the international trading system and ensuring markets for cultural exports. The agreement would recognize the special role of cultural goods and services and the

${ }^{17}$ Report: “Santorini Meeting, September 2000."

${ }^{18}$ Quotations from INCP website, page entitled “Annual Meetings: An International Instrument on Cultural Diversity." Connection between the instrument and its broad rationale comes from INCP website, page entitled "Working Groups: International Instrument on Cultural Diversity: Reader." 
right of governments to preserve and promote cultural diversity" (1). Importantly, this statement asserts the need for special recognition of cultural products at the same time as implying such recognition should be within the established trading system. This decision represents a pivot in the Canadian Government's position: from seeking an exemption to working for recognition within the trading system (and thus implying no exemption). ${ }^{19}$

The OAS Quebec-City Summit, in April 2001 recognized cultural diversity, and the Action Plan launched a series of initiatives to ensure further consideration. The G8 Summit, in July 2000, also recognized cultural diversity as a source of economic and social dynamism. The momentum built with a similar declarations at the Francophonie meeting, in June 2001, and as the Council of Europe adopted a similar declaration in December 2001. Finally, the General Conference of UNESCO adopted a Universal Declaration on Cultural Diversity, in November 2001 , that recognized "the specificity of cultural goods and services which, as vectors of identity, values, and meaning, must not be treated as mere commodities or consumer goods" (2). The accompanying Action Plan also specified that international discussion should be deepened, which would serve as a platform from which to help negotiate and ratify a cultural-diversity instrument. $^{20}$

There were several related developments in late 2001 and 2002, that promised to complicate the continued policy and political development of the instrument. At the Doha WTO Ministerial, in November 2001, the French delegation refused to consider any discussion of cultural diversity at the trade talks, despite the desire of Canadian officials to submit a proposal on the issue. This reflected French concern over Canadian language on (from previous paragraph) "while respecting the rules of the international trading system." The French desired a solution either outside the WTO, or if inside a clear cultural exemption, while the Canadians were pressing for a rules-based approach, not a straightforward or comprehensive exemption sought in years past. At the World Summit on Sustainable Development, in Johannesburg, in September 2002, French President Jacques Chirac called for the development of "an international

${ }^{19}$ SAGIT (2002) "An International Agreement on Cultural Diversity: A Model for Discussion," available at www.dfait-maeci.gc.ca, particularly pp. 1-3.

${ }^{20}$ Quoted page from SAGIT (2002), op cit. note \#19. 
convention on cultural diversity", under the auspices of UNESCO. A month later, at the Fifth INCP meeting, in Cape Town, a draft of the Instrument was presented. One important ministerial resolution was that "UNESCO is the appropriate international institution to house and implement an International Instrument on Cultural Diversity." They also resolved that a meeting should be convened between INCP representatives and UNESCO's Director General to address this issue. Significantly, not one, but three versions of the Instrument were submitted: one from Canada's Foreign Affairs and International Trade Department, entitled "An International Agreement on Cultural Diversity" (IACD); one from the INCP; and one from the INCD. ${ }^{21}$

The policy development, and political capacity building, have each conformed to cycles identified by Howlett and Ramesh. The Canada Periodicals decision (1997) provided a crisis, an event that focused a discussion underway over the effects of globalization and trade liberalization on cultural policy and national culture. Murmurings over cultural sovereignty have long been a background feature of Canadian political discourse. The Canada-U.S. free trade negotiations elevated this murmur into a dialogue. The US challenge, and victory, over four measures in support of Canadian magazines further galvanized support and catalyzed action. The background discourse was a necessary condition, onto which the Canada Periodicals decision became the sufficient provocation. It is also instructive to note the pace and sequence with which events and policy transpired. The WTO handed down the Canada Periodicals appeal on June 30, 1997; within one year, Canada had hosted the founding conference of the INCP; and by February 1999, SAGIT released its report, "Canadian Culture in a Global World: New Strategies for Culture and Trade," which called for solutions to address the culture-trade interface. While the pace of policy statements and actions constitutes only circumstantial evidence, the pace does stand out as exceptional. Cultural policy and trade agreements had been recognized as a problem by some, and as a condition by others, throughout the 1990s. Canada Periodicals removed any hesitancy in defining the situation as a problem, and with this change the issue moved rapidly onto the

\footnotetext{
${ }^{21}$ Information about Jacques Chirac's pronouncement comes from Pierre Pettigrew, "The Next Step Forward for Trade and Culture," remarks to the International Institute of Communications, November 28, 2002. The text of his remarks, as well as the "IACD: A Model for Discussion" are available on the DFAIT website.
} 
policy agenda. ${ }^{22}$

The Instrument, as it stands in April 2003, corresponds to the second phase of the policy cycle: policy formulation. A substantial portion of the INCP's work, from Oaxaca (1999) until the present has been devoted to policy formulation. And as seen, the process is a "policy primeval soup." Instrument development commenced with only vaguely defined goals, and several sets of actors - governmental, non-governmental, and differing intra-governmental have advanced their formulations. The open-ended character of this phase has allowed the French to apparently challenge the Canadian-led position. Moreover, changes domestically and internationally, due to geo-political concerns, may yet impede or facilitate consensus and an ultimate decision. Within Canada, the transition of Liberal Party leadership in 2003 may bear indirectly on Instrument development, and budgetary and macro-economic issues loom large on the horizon, and eventually may serve to scuttle resources that would have been used to build domestic consensus to ratify the Instrument. The struggle between different government departments, principally DFAIT and Heritage, may play out in unforeseen and dramatic ways. At a simple level, the two fundamental decisions, corresponding to the two-level chessboard, that must be made are (1) what is the final position of the Canadian government, which implies eventual inter-departmental and stakeholder consensus and unanimity, and (2) what is the final form of the Instrument agreed to by Members of the INCP.

As of summer 2003, the Instrument is in the decision-making phase, and the decision to officially place the Instrument on the international agenda will take place shortly. INCP members agreed at Lucerne, in 2001, to develop a detailed Instrument within two years. The drafts, some more advanced and some less, were floated during the Cape Town meetings in October 2002, which was the half-way point along the way to finalizing a decision. INCP members, including Canada, are therefore obliged by mandate to accept one version while rejecting the others in 2003. Despite the procedural time constraints, it is possible that the decision may not come until 2004. If the goal of international adoption by 2005 is to be met, then decisions at both the

\footnotetext{
${ }^{22}$ Establishment of causation, and not simply correlation, between Canada Periodicals and the push for the IICD comes from Terry Cowl (2000) "Changing Canada's Trade Policy on Culture" Course paper written for Norman Paterson School for International Affairs \#46.500; also from conference presentation "Unfinished Business" at Canadian Communication Association, Halifax, NS., June 2, 2003. See also note \#9, p. 66.
} 
domestic and international level must come soon. Finally, in October 2003, the General Conference of the United Nations Educational Scientific Cultural Organization will formally vote on whether to proceed with the Instrument. This is self-evidently a crucial step, representing the important jump onto the agenda. Should the vote be to proceed, then it is likely an Instrument will ultimately take shape, be adopted, and the only question will be one of effectiveness and enforceability. $^{23}$

${ }^{23}$ Information in this paragraph comes from the INCP Paris Communique News Release "Ministerial Meeting of the Working Group on Cultural Diversity and Globalization of the International Network on Cultural Policy (INCP)," available at INCP website; and the "Preliminary Study on the Technical and Legal Aspects Relating to the Desirability of a Standard-setting Instrument on Cultural Diversity" UNESCO, Doc. \# 166EX/28, Paris 12 March 2003. 


\section{Chapter Three:}

\section{Policy Analysis and Implications}

"We have the right to ask the American government to have the same regard for Europeans as they do for our friends the Canadians." Francois Mitterand (1994)

"If the United States and Canada, with their similar cultural background and history cannot work out a viable [cultural] agreement, there is much less hope of overcoming the hurdles in this area on a global basis." Geza Feketekuty (2000)

Chapter Three continues, then concludes, the policy analysis, including the implications for the IICD, and is divided into four parts. The chapter first sets out considerations that need to be made prior to any realistic attempt to recognize culture within the trading system, about location, nature and substance, and whether the initiative should be pursued on a Canada-U.S. bilateral or multi-lateral basis. While Chapter Two presented generic criteria to evaluate policy, chapter three applies the criteria. The second section describes the sophisticated proposals made by experts - surprisingly, there have been only two despite the attention devoted to the subject. The third section of the chapter analyzes the versions of the Instrument currently under consideration, proceeding in a detailed, point-by-point, article-by-article explication to determine the likelihood of eventual success. The second and third sections, combined, constitute an indepth text analysis. The chapter concludes with section four, which analyzes and explains decisions already taken that concern the Instrument's development. There is an implicit chronological organization to the chapter overall. While the initial analysis is prospective, the final analysis is retrospective, because it explains after the fact why a certain pathway was chosen; furthermore, the private proposals under review in the second section were unveiled (in 1999 and 2001) before the two versions of the official proposal were unveiled (in the fall of 2002).

I.

Several key factors and decisions need to be presented or revisited before specific proposals are assessed, which together constitute a foundation for analysis. First, the aim of 
securing recognition for culture within the international trading system is constrained by the general nature of how the WTO provisions apply. While this does not apply to Canada's regional trade agreements, culture is treated only indirectly in the multi-lateral system, whenever various provisions relate to domestic cultural measures. This general application has lead to irritants and disputes, because cultural policies and the competitive conditions they create are subject to nondiscrimination, and other, commitments. Second, there is variation in the nature and substance of the recognition sought: some favour broad, comprehensive treatment, like an exemption, while others prefer narrow, defined specification, like a sectoral agreement or even, more narrowly, a measures-based agreement. Third, there is the question of whether the Instrument should be located at the WTO, or independently of it. One might suppose because of the Organization's object and purpose, and the aim of the Instrument, that the logical location would be within the WTO. However, others argue that expediency and strategy militate against the trade authority and instead argue for UNESCO, an international body with an explicitly cultural mandate. The first factor - the general of treatment in the trading system - is a condition of existence for the policy portion of my thesis. The second and third factors are two key questions, the answers to which determine, in a path-dependent way, the subsequent policy implications.'

The pre-eminent question for recognition of culture within the trading system is whether to pursue an agreement, understanding, or Instrument inside of, or independent to, the WTO. The large majority of analysts argue for a solution within the WTO. Most importantly, and this reason cannot be over-emphasized, the WTO automatically provides recognition, which is the sine qua non that ensures domestic adherence to international treaties. So elemental is recognition in international affairs that pursuing an agreement outside a recognized and legitimate international council immediately calls into question any hypothetical agreement's validity. After conferring

${ }^{1}$ The general nature of treatment for culture in the multi-lateral system was noted on pp. 56-57. In the debate over a cultural exemption, see pp. 53-54 for description of change in opinion: at an October 2000 conference at the University of British Columbia, and a March 2001 conference at Harvard's JFK School of Government those formerly in favour of a broad exemption suggested a new approach, presumably the instrument but undefined at the time. An embedded issue of the general applicability nature is that often inconsistency or violation won't be known until a cultural measure is challenged, which is to say, tested. (This was the case with a Canadian tariff code, actually an import prohibition, on split-run magazines. In existence for three decades, it wasn't tested until the Canada Periodicals case.) 
recognition, the next questions involve the suitability of the WTO, its structure, membership, object and purpose, and negotiating procedures to the task of recognizing culture. Again, analysts are united that pursuit of the multi-lateral route within the WTO would benefit from the structure, negotiating procedures, and working-group format. The Organization has a permanent existence, a defined timetable of negotiations, known as the built-in agenda, and a Secretariate to oversee working groups on many issues, be they on-going sectoral bargaining (like agriculture or services), or issues that require clarification (like food labelling and sanitation). The necessity of recognition, bringing adherence and standing with it, is the compelling reason for most analysts. ${ }^{2}$

Analysts who favour the WTO route do disagree, however, among themselves over the type of agreement that should be sought. William Dymond and Michael Hart believe an ad hoc, or minimalist, approach to be best. They suggest confirming that the WTO's provisions apply in general terms to the cultural sector, and then interpret, only as necessary, how certain provisions apply to the cultural industries. As a result of negotiations, countries could seek derogations from certain provisions. Christopher Maule notes two paths, each within the WTO framework. The first is a sectoral agreement, or annex. This could be large, like agriculture or services in general, or more likely, small, like the telecommunications, financial services, or maritime transportation services annexes attached to the GATS. The second path would include the cultural industries under the current agreements, general, sectoral, and special. This is a much more difficult task, as it would entail determining what provision from which agreement affected what cultural measure. The difference between these variations is between concentrating or diffusing the coverage and obligations. These approaches will be detailed in the second and third sections of

\footnotetext{
${ }^{2}$ The following are included under the description of "most analysts." Christopher Maule (2002) "Overview of Trade and Culture" Canadian Foreign Policy, 9(2), 1-14; William Dymond and Michael Hart (2002) "Abundant Paradox: The Trade and Culture Debate" Canadian Foreign Policy, 9(2), 15-34; Daniel Schwanen (2001) "A Room of Our Own: Cultural Policies and Trade Agremments" Choices, 7(4), Montreal: IRPP; Chi Carmody (1999) “"When Cultural Identity Was Not At Issue': Thinking About Canada - Certain Measures Concerning Periodicals" Law and Policy in International Business, 30(2), 231-320; Rostam Neuwirth (2002) "The Cultural Industries and the Role of Article IV GATT: Reflections on Policy Options for Canada and the EU in the New WTO Round" Paper presented at the Cultural Traffic conference, Carleton University, November 21-22. Dennis Browne (1999) "Canada's Cultural Trade Quandary: How Do We Resolve the Impasse?" International Journal, 54, 363-374. A pair of analysts that aren't prescriptive, and their account, is Stephen Azzi \& Tamara Feick (2003) "Coping with the Cultural Colossus: Canada and the International Instrument on Cultural Diversity" in David Carment, Fen Osler Hampson, and Norman Hillmer (Eds.), Canada Among Nations, 2003 (pp. 100-120), Toronto: Oxford UP.
} 
this chapter. ${ }^{3}$

One wrinkle to the strategy for those who favour the WTO route is whether to pursue recognition multi-laterally, or bi-laterally between Canada and the U.S. Two American analysts endorse, or have endorsed, this approach. William Merkin, a former U.S. trade negotiator, has written "No other country in the world, including Mexico, faces a challenge anywhere as difficult as Canada does in attempting to retain its unique cultural identity while living next door to the U.S." (18). This condition is the basis for a bi-lateral approach. Christopher Sands elaborates on the basis, noting what incentives each country has. For the U.S., a deal would introduce predictability into a sector historically closed and subject to arbitrary and discriminatory Canadian government actions. A deal would also encourage investment in Canadian firms, which would likely increase the amount of Canadian content available. And a deal would lower the overall temperature of Canada-U.S. trade relations. For Canada, a deal would restore confidence in policy formulation and allow the Government of Canada to proceed to nurture preferred sectors. Successful policy development, opposed to policy inaction or chill, would help rebuild the Canadian cultural sector's faith in the government. One problem — but the most intractable one with the bi-lateral approach — would be an agreement's precedent-setting nature. While a hypothetical Canada-U.S. Cultural Trade Agreement may be warranted, what is to prevent other like-minded countries, say France, Italy, or Portugal from demanding similar treatment? An already-used quotation may be used again, because it states the problem of precedent in dramatically unequivocal terms: when French President Francois Mitterand said, in 1994, "We have the right to ask the American government to have the same regard for Europeans as they do for our friends the Canadians" (Truehart A2). ${ }^{4}$

\footnotetext{
${ }^{3}$ See William Dymond and Michael Hart (2002), op cit. note \#2, pp. 27-29 for their suggestions and reasoning. The clearest articulation of Christopher Maule's approach comes from an as-yet unpublished paper, (2001) "Globalization, Culture, and the WTO" presented at a Kuala Lumpur conference on January 30-31. It should be noted that the Agreement on Basic Telecommunications, or ABT, is held up as the example for a similar cultural agreement. It should be observed that Maule's suggestions were made approximately 18 months previously to Dymond and Hart's.

${ }^{4}$ William Merkin (1999) "U.S. Trade Policy and Canadian Culture: What Can Be Accomplished Through Trade Negotiation?" Working Paper presented at U.S. Trade Strategy and Canadian Culture Workshop, Center for Strategic and International Studies, Washington, D.C., April 23; Christopher Sands (1999) "An Argument for the Negotiation of a Bilateral Agreement on Cultural Trade with Canada - Why Now?" Working Paper presented at
} 
Against the large majority who favour the WTO route, there is only a murmur of partial dissent. In a book chapter in Capacity for Choice (2002), and a journal article in an edition of Canadian Foreign Policy (Winter, 2002) devoted to the cultural trade quandary, Gilbert Gagne acknowledges the role the established trading system must have in any solution, but includes UNESCO, governmental, and non-governmental civil-society groups in his recommendation. He believes UNESCO to be a congenial forum within which to build consensus, and writes that cultural-recognition discussions held there can be used to "take to trade negotiations" (174). Likewise, the governmental INCP and civil-society NCD will help build consensus that cultural recognition needs to occur within the WTO. So Gagne's "dissent" is really only a qualified or indirect strategy that still prefers the WTO as the institution in which to seek international recognition for the special treatment of culture. ${ }^{5}$

Awareness of these key factors and decisions will improve the analysis of the academic and official proposals that have been, and are in the process of being, formulated. It is striking that despite the abundance of strategy, lessons, and commentary offered about aspects of the cultural trade quandary, there has been a surprising absence of detailed, specific proposals. There have only been two. This is one reason why Hart and Dymond (2002) describe the debate as mired in "the sterile center" (2). The absence of proposals also reflects the difficulty between advancing the issues, furthering the debate, and merely pointing out problems, mentioning inconsistencies, and reacting to the current state of affairs - a difference that sets experts apart from pundits, which is why we now turn to expert opinion, first two private proposals and then

U.S. Trade Strategy and Canadian Culture Workshop, Center for Strategic and International Studies. Washington, D.C., April 23. See also the follow-up article by Christopher Sands (2001) "A Chance to End Culture Trade Conflict between Canada and the United States" American Review of Canadian Studies, 31(3), 483-500. It is interesting to contemplate the reason why Sands isn't as enthusiastic for a bi-lateral deal in the latter publication. Quotation originally used on p. 87. Charles Truehart (1994) "Culture Clash: Canadian Nationalists Decry American Infiltration" Washington Post December 2: A2.

${ }^{5}$ Gilbert Gagne (2002) "North American Integration and Canadian Culture." In George Hoberg (Ed.), Capacity for Choice: Canada in a New North America (pp. 159-186), Toronto: U Toronto P. Quote from his chapter. Also Gilbert Gagne (2002) "The Canada-U.S. Border and Culture" Canadian Foreign Policy, 9(2), 159 170 . Here, see particularly pp. 164-67 for his strategy and reasoning. 
the official versions presented for consideration. ${ }^{6}$

II.

The first serious proposal is a "cultural waiver," contained in Chi Carmody's journal article (1999). A Canadian S.J.D. Candidate (the law equivalent of a Ph.D.) at Georgetown University Law Center, Carmody has provided a comprehensive and, likely, realistic, recommendation. It also bears mentioning that the paper was reviewed by John Jackson, Professor at Georgetown and dean of international trade lawyers, an observation that should increase the seriousness with which we consider Carmody's proposal. He proposes a "waiver," not an "exception." Under GATT jurisprudence, he notes, exceptions occur only after there has been a breach of some provision. Furthermore, exceptions have been interpreted narrowly, in accordance with principles of treaty interpretation for exceptions. The post hoc nature and narrow scope strongly suggest that an exception is ill-suited for the purpose of safeguarding culture, because of culture's expansive, changing, and nebulous nature. Waivers, on the contrary, are the intentional or voluntary relinquishment of a known right and are unilateral. The use of waivers dates from the first decade of the GATT system, when they "were given frequently and with little foresight" (310). As a result of abuse, waivers under the WTO are not only more difficult to obtain, they must also detail explicit terms and conditions of operation and specify a termination date, making waivers a temporary, not permanent, solution. So not only are waivers inherently better suited to the purpose of cultural safeguarding than exceptions, they also possess a different status within the WTO, one that is likely more congruent with the contemporary emphasis on implementation, effectiveness, and coherence. ${ }^{7}$

\footnotetext{
${ }^{6}$ Quotation from "The Trade and Culture Debate: Abundant Paradox" paper presented at Trade and Culture Conference, Ottawa, November 28, 2001. The phrase "sterile center" was not incorporated into the final version of this paper, published in Canadian Foreign Policy (Winter, 2002).

${ }^{7}$ See note \#2 for the complete Carmody citation. Distinction between waiver and exception, as drawn by Carmody, is found on pp. 309-310. Assessment of emphasis on implementation, effectiveness, and coherence from two leading Canadian experts: Debra Steger (2000) "The World Trade Organization: A New Constitution for the Trading System" in Marco Bronckers \& Reinhard Quick (Eds.), New Directions in International Economic Law (pp. 135-154), The Hague: Kluwer; and Donald McRae (2000) "GATT Article XX and the WTO Appellate Body" in Marco Bronckers \& Reinhard Quick (Eds.), New Directions in International Economic Law (pp. 219-238), The Hague: Kluwer.
} 
After establishing his choice of legal instrument, Carmody appends a sample of such a "cultural waiver" to discuss terms, scope, and operation. The hypothetical waiver has a brief preamble, nine articles, and an annex that defines the covered sector. The annex uses the familiar vocabulary of "cultural industries" to define the sectors and sub-sectors covered by the waiver. These include book, magazine, and newspaper publication and distribution; the production, distribution, sale, or exhibition of films and videos, as well as audio and video music recordings; and publication, distribution, and sale of music recordings; and radio, television, cable, and satellite programming and broadcasting services not covered by the Agreement on Basic Telecommunications (ABT). The covered industries, in other words, are virtually identical to the standard definition of cultural industries used by the Canadian government since the late 1980s. A second important point, the waiver is part of the single-undertaking, linking any derogations or special treatment directly to the set of agreements that constitute the WTO. The institutional status is established by article II of the waiver, "Basic Rights and Obligations," and it draws attention to the relationship between GATT 1947 articles III and XI, the multi-lateral agreements listed under Annex 1A, and between GATT 1994 articles XVI-XXI. The waiver, though not a match for either the sectoral bargain, or the option where the terms were comprehensively written into the agreements, offered above, approximates the sectoral approach. ${ }^{8}$

The second article, titled "Basic Rights and Obligations," and third article, titled "Assessment of Risk and Determination of the Appropriate Level of Protection for Cultural Industries" establish norms for countries in setting cultural policy. Article II, paragraph two states, for instance: "Members shall ensure that any measure taken under this Waiver is applied for the purpose of protecting cultural industries and applied to the extent necessary for an appropriate level of cultural protection" (316 emphasis added). Paragraph three goes on to state: “...A measure for the protection of cultural industries shall not be invoked abusively or in a manner which would constitute a disguised restriction on international trade" (316). A clear line dividing the intent behind a measure is established. This constitutes part of the norm-setting function and clearly states what intent is not allowed. Article three operationalizes the principle

\footnotetext{
${ }^{8}$ The sample text is appended on pages $315-320$ of Carmody, op cit. note $\# 2$.
} 
of article two, and adds more legitimacy to genuine cultural objectives. Paragraph one states that any adopted measure must be "based upon an objective and impartial assessment" (316) of the risks to domestic cultural life and specifies that the risk determination is to be "conducted by an independent body" (316). The determination of risk, therefore, is separated from the ability to implement policy: a government helps to ensure legitimacy of intent by separating powers. The government, in other words, does not play police man and judge. The criteria or standards for the test to determine risk are specified in paragraph three, and include: (i) lost domestic production or sales, (ii) the establishment or spread of foreign cultural goods or services, (iii) the cost of controlling foreign cultural goods and services while allowing domestic culture to flourish. Paragraph six entrenches the norm of legitimate intent: “...Members shall make every reasonable effort to ensure that such a measure is not more trade restrictive than required to achieve the appropriate level of cultural protection" (317). The second and third articles, together, establish a clear norm that is compatible with the international trading system. ${ }^{9}$

The most significant contribution of the waiver is contained in Article six, entitled "Consultation and Dispute Settlement." Paragraph one stipulates that should any member deem another member's actions or policies inconsistent with the waiver, the country "may bring the matter before the Ministerial Conference," (318) which after prompt examination will recommend a solution, including the possibility of pursuing the matter under the Dispute Settlement Understanding. This is a significant, indeed crucial, difference from the way disputes currently work. Carmody proposes to interpose the Ministerial Conference, or General Council working in its steed, between the dispute-settlement process and individual members. Article Six seeks to pre-empt the automatic nature of one country deeming a measure inconsistent and the resulting dispute-settlement decision, which tends to favour the complaining country. As it currently works, dispute settlement favours complainant's over defendants by $80 \%$ to $20 \%$. Furthermore, once dispute-settlement is engaged, the system favours opening up, or liberalizing,

\footnotetext{
${ }^{9}$ A couple of points are worth highlighting. First, the test to determine risk, in article III, paragraph 3 , is weak because it leaves undefined or unspecified thresholds that must be met to invoke action. For instance, it is unclear how the simple spread of foreign cultural products pose a risk. Second, the language in article III, paragraph 6 (" every reasonable effort") is reminiscent of the "where practicable" language of Article 128 of Maastricht, which has been counter-productive because it is only a norm and not a rule and, as such, falls victim to accusations that attempts have not been strong enough to follow such a norm.
} 
the measure under scrutiny. The complainant simply has to demonstrate violation of, or inconsistency with, the relevant provision, which tends to be easier to do than for the defendant to demonstrate the legitimate public policy purpose of a cultural measure. The object and purpose of the WTO is to progressively liberalize trade, which means those arguing that a measure constitutes an impediment to this purpose will always have an inherent advantage. ${ }^{10}$

It is difficult to overstate the importance of what might seem like a minor procedural change. By interposing the Ministerial Conference, or General Council, working in an advisory and conciliatory role before the adjudicatory role, this revision hopes to reduce the disputes by subjecting different views on the consistency of cultural policy to a peer-review process. Carmody writes that "panels appear to demand an almost mathematical certainty when they deal with non-economic phenomena" (307), an approach that is challenging to apply to many issues of the so-called "trade and..." agenda, like trade and environment, trade and labour, trade and human rights, and in our case, trade and culture. The requirement to seek conciliation prevents the mechanical application of WTO jurisprudence without due regard for the legitimate public policy purpose enshrined in the Agreements. Should the conciliation fail to yield a consensus, and the matter proceed to dispute-settlement, another revision enters into effect. Paragraph two states "In a dispute referred to a panel advice should be sought from experts chosen by the panel in consultation with the parties to the dispute. To this end, the panel may, when it deems appropriate, establish an advisory group on culture, or consult UNESCO, at the request of any principal party..." (318). Advice and input will be sought from experts inclined to understand the goals of cultural policy, and their role should leaven the tendency to mechanically apply WTO provisions narrowly and without attempting to understand the non-economic rationales of the policy under dispute. By their nature, composition, and mission, UNESCO is predisposed to argue in favour of the legitimacy of cultural policy. ${ }^{11}$

\footnotetext{
${ }^{10}$ The calculation of an $80 \%$ probability that a complainant will win comes from Andrew Shoyer, at WTO Dispute Settlement Symposium, Ottawa, March 27, 2000.

${ }^{11}$ Carmody's Article 6, entitled "Consultation and Dispute Settlement" is short, contained entirely on page 318 and encompasses only three paragraphs. It is likely that it is the most significant single contribution to the proposals to solve the cultural trade quandary.
} 
Article Seven, "Administration," elaborates on the dual conciliatory and adjudicatory nature of Article Six. Paragraph one stipulates "A Committee on Culture is hereby established to provide a regular forum for consultations" (318), and paragraph two goes on "The Committee shall maintain close contact with the relevant international organizations in the field of culture and cultural protection, particularly UNESCO...." (318). The purpose is to establish institutionally an expertise on cultural policy and cultural matters that will help to reach consensus over legitimate cultural measures ensured by the adoption of the waiver, and in the event of irreconcilably different views on a particular measure, help adjudicate the dispute in a balanced fashion, taking both economic and non-economic criteria into consideration. This article, then, enhances the norm-setting and institutional influence functions of Carmody's waiver. The inclusion of such a hypothetical consultation and dispute-settlement clause would be a dramatic victory for the cultural-policy community. The alternative procedure, the standing given to cultural opinion, would go some distance toward erasing the bias that cultural policy may face inside a dispute-settlement process that was conceived to handle standard economic and commercial issues, not unorthodox discrepancies. ${ }^{12}$

Overall, Chi Carmody's proposal is excellent. It is worth considering because of the expertise he brings to the area, and the setting in which his proposal is made: that it is taken seriously at Georgetown University Law Center is validation in itself. Particular strengths are viewing the waiver as part of the WTO system, and part of the single-undertaking; and furthermore, that the status of a waiver suits the purpose to which it is suited and would not require a burdensome amount of work to re-open, or substantially revise, the existing agreements. Another strength is the procedural revision, whereby the General Council, or Ministerial Conference, is placed before the automatic recourse to dispute-settlement. Not only is this a benefit because it allows the possibility to pre-empt what some believe would be a fait accompli of the dispute-settlement process, it also fosters norm-setting and institutional influence, which may be subtle but also significant for longer-term change. John Jackson praises the proposal, in a foreward to the issue: "Mr.Carmody's work on the role of culture within the WTO system is an

${ }^{12}$ Article seven, "Administration," is also a brief article, contained in entirety on pages 318-19. 
example of the type of research that must be done for each issue that arguably falls outside the 'GATT paradigm' on international economic regulation" (190). What is concerning, however, is when Jackson mentions "cultural rights being at stake" as a reason to support Carmody's proposal. "Cultural rights" are considerably different from reconciling cultural policy measures in the multilateral trading system, cultural rights belonging to the domain of international human rights. That John Jackson would couch his rationale in the vocabulary of a different field strongly suggests how particular this problem is to Canadian policy makers, and just how much work and how difficult it may be - to build a widespread consensus over what, exactly, is to be addressed. The final point, and this is a weakness of the proposal is the test, and criteria for a test, stipulated in article three. As it stands, the criteria for assessing risk are unclear, at least in empirical terms, and this would undoubtably lead to confusion in a real-world application of the test. $^{13}$

The second serious proposal comes from Daniel Schwanen (2001), in an article entitled "A Room of Our Own: Cultural Policies and Trade Agreements." Schwanen is a senior economist with the Institute for Research on Public Policy (IRPP), a right-of-center research organization based in Montreal. He proposes an "interpretative code," which would spell out positive and specific cultural-policy rights and obligations, that would be integrated multilaterally within the WTO. The proposed measures apply to both production and distribution of content, two distinct points on the supply chain. And like Carmody, Schwanen provides both a sample text and the descriptive rationale to support and qualify the text itself. Such an interpretative code isn't either a sectoral agreement or the equivalent of writing cultural terms into the collection of WTO agreements, but also like Carmody's waiver, this code functions as a

13 John H. Jackson (1999) "Forward" (pp. 189-192) in Law and Policy in International Business. The idea of "cultural rights" is from the United Nations' Charter and ancillary agreements and protocols. The right, for example, to have access to one's culture, to preserve cultural artifacts, heritage, and property, are expressions of such rights. Cultural rights sit alongside the idea of minority collective rights, in political philosophy, and in this context are discussed by Will Kymlicka, Wayne Norman, and Charles Taylor, among other Canadian contributors to the discourse. This is a distinct domain from international economic relations, and international trade regulation, as these fields have emerged in public international law. 
binding memorandum of understanding. ${ }^{14}$

Schwanen states that his "interpretative code" would be a "mutually agreed code of interpretation" that would "effectively direct how dispute settlement panels should interpret trade agreements" (17). He goes on to state that such a code could be adopted on a bi- or multi-lateral basis, and he provides the precedent of anti-dumping and subsidy rules as an area where a code of conduct was developed, negotiated, and implemented. Before the institutional and political climates are assessed to determine the likelihood for successful adoption, the text of the proposed code will be detailed. He begins from the position that the state should have a right to set cultural policy, a point also made by Ivan Bernier (1997) and Michael Wernick (2001). Bernier wrote "The real issue in the debate on the place of cultural products in international trade agreements is the state's ability to make cultural development policy" (87). And Wernick, then-Assistant Deputy Minister at Canadian Heritage, said in conference remarks that there remained a need to ensure a cultural policy space and that he didn't feel this idea needed defending. Schwanen states that "an affirmation of the space must be accorded cultural policy, rather than negatively by avoiding the problem of the interaction of cultural policies and trade" (15). In ordinary-language terms, Schwanen wants to address the quandary by defining trade-acceptable cultural policy, rather than having cultural policy defined for governments by what is challenged and deemed acceptable or unacceptable. ${ }^{15}$

After establishing the basis for this "positive" approach, Schwanen fills in the text of his 10-paragraph interpretative code. Paragraph one defines the terms used in the proposed code. "Creative and performing activities" include activities covered under Article 2 of the Berne Convention, which aims to ensure the international application of copyright protection. A "creator or performer" is defined as someone "who creates or performs such content and who is a

\footnotetext{
${ }^{14}$ Daniel Schwanen (2001) op cit. note \#2. Note Schwanen's interpretative code was published in April 2001, while Carmody's waiver was published in June 1999.

15 See Schwanen (2001), op cit. note \#2. Ivan Bernier (1997) "Opening Markets and Protecting Culture: A Challenging Equation" FORCES, 117, 84-87. Michael Wernick (2001) Remarks made at Trade and Culture Conference, November 28, 2001, Ottawa, ON. Wernick's comment that a cultural policy space doesn't need defending implies an inherent right or entitlement on the part of government to set policy for legitimate public policy purposes, a right that is recognized under the WTO and an embedded idea of sovereignty.
} 
permanent resident of the Party" (20). The third piece of his definition stipulates that "domestic cultural products" are "goods or services that are aimed particularly at informing residents of that Party" (20). This piece of the definition is problematic, because strictly speaking it is impossible to know if certain products are intended for a certain audience. Rather, intention is simply inferred from nationality of content, so French content must be aimed at French audiences by dint of the French commonality. The error is assuming that content predicts audience, much as a related error of assuming that nationality of ownership predicts nationality of content. Despite the faulty logic, it is reasonable to assume a certain transitive property between content and audience and on this basis it is possible that such a definition could be codified in trade agreements. ${ }^{16}$

Paragraph two affirms the basic right to financially support content creation and production. Elaborating on this right, paragraphs three and four establish the right to support products aimed primarily at a domestic audience. While this assertion might seem redundant or superfluous, the real purpose is to clearly limit domestic content as the only category of content eligible for national public funds. This right remains the norm in 2003, however the national eligibility criteria for subsidies was questioned in the EU-U.S. Television Without Frontiers negotiation. Furthermore, the U.S. has stipulated in the GATS schedules that only American citizens and residents are eligible for National Endowment of the Arts grants, which has led analysts to conclude that national eligibility will be challenged in the near future. Paragraph four goes on to stipulate three types of acceptability that a public subsidy may take: (a) a direct subsidy, under GATT III:8; (b) a tax inducement to sponsors or clients; and (c) direct subsidies for distribution or exhibition. Direct subsidies have come under dispute-settlement scrutiny, concerning the meaning of "exclusively" and "directly," so the first form is a re-affirmation of the right to straightforwardly subsidize a content creator directly. Tax-incentives are considered promotional forms of subsidization, and are thereby considered acceptable. The third type mentioned, at distribution or exhibition, are potentially controversial, because the further down the supply chain aid is provided, the greater the chance the subsidy will prevent a non-subsidized

${ }^{16}$ Text of paragraph one on p. 20 of Schwanen (2001), op cit. note \#2. Paragraph one is explained on p. 18. Too much shouldn't be made of the phrase "aimed at..." as this language is customary to distinguish between content or product intended for domestic or foreign audiences. 
product from competing, which then raises the possibility of discrimination. While the general right may be affirmed, much would depend on the specific nature of distribution or exhibition assistance to determine if it would remain trade consistent. ${ }^{17}$

Paragraph five sets out a bold idea. "Where distribution channels for cultural products are limited by physical constraints (eg. theatres, bookstores, broadcast channels, magazine displays), governments may mandate easily accessible, reserved 'shelf space' for products covered by paragraph three, and/or require that all distribution channels carry a certain percentage of domestic cultural products covered by paragraph three" (20). Paragraph five seeks to continue use of a quota system, where quotas have been used, and by introducing a market-share measurement, winnow out certain quotas. As such, paragraph five would be controversial. Quotas, generally, are not allowed within the trading system, because they are discriminatory against foreign products. This hypothetical provision would use "objective measurement criteria" (21) to determine what the market share held by a particular domestic sector was, and then quotas would be established to ensure that domestic product could occupy that percentage of shelf space. An operational problem might ensue: the quota would be set after determining the domestic market share, but there's no reason to expect this domestic market share would remain constant over time. In a good year, for instance, Canadian books might account for $38 \%$ of all fiction titles sold in Canada, while in a weaker year the number may be $21 \%$. What makes it difficult operationally is that market share depends on capricious and unpredictable factors, like whether Rohinton Mistry, Margaret Atwood, Carol Shields, and Wayne Johnston all wrote books in a particular year, or if none of them did. A third observation is that quotas only ensure availability, not consumption. Canadian television programming is instructive here: while Canadian content regulations stipulate an allotment of Canadian programming be carried by domestic broadcasters, there are no guarantees it will be watched. Finally, paragraph five covers distribution and not production or creation. This is an important distinction because generally

${ }^{17}$ The proposed text of paragraphs two, three, and four come from p. 20, Schwanen (2001), op cit. note $\# 2$, explanation comes from p. 18. See pp. 34-36 of chapter four for discussion of subsidy linkages during the Television Without Frontiers negotiations, and see Hernan Galperin (2000) Cultural Industries Policy in Regional Trade Agreements: the Cases of NAFTA, the European Union, and Mercosur Media, Culture, and Society, 21(5), 627-648 for conclusion about the shape of things to come in respect of national eligibility criteria. 
measures that assist production or creation are promotional and, hence, acceptable, which is not necessarily the case as one moves down the production-consumption chain. ${ }^{18}$

Paragraph six ensures the acceptability of co-production agreements. "For the purpose of this code, a cultural production or performance involving among its key creative personnel more than 50 percent of non-residents of a Party may, with respect to measures defined in paragraphs 3,4 , and 5, obtain for those non-residents a status equivalent to that of resident creators or performers ("national treatment") provided that a reciprocal agreement to that effect has been arranged between the Party and the government of the non-residents involved" (21). Film and video co-production agreements are currently scheduled as an exemption under GATS, an exemption which is terminated after 10 years and one that does not apply to U.S. foreign-location film shooting. Paragraph six also reserves the right to prevent a flood of U.S. foreign-location films from qualifying under these terms. This provision represents a real gain for Canadian cultural policy, because co-productions are politically successful and popular with the industry. Inclusion of such a provision is also probably realistic because co-productions don't occupy enough market share to materially injure U.S. producers, and so would not be opposed on commercial grounds. ${ }^{19}$

Paragraphs seven through ten, instead of specifying what policy may be implemented, further establish general principles. Paragraph seven stipulates that, except for the reservation of shelf-space in paragraph five, no measures will be taken that will limit the circulation of a foreign cultural product, which re-affirms unconditional national treatment. The usual caveat, involving the general and national-security exemptions in the GATT and GATS, is invoked. Paragraph eight extends national treatment for investments: "With respect to undertakings involved in the production or distribution of cultural products, whether domestic or foreign, Parties will accord national treatment to investors of another Party and to their investments" (21). It is noteworthy that foreign investments in respect of production or distribution are designated as acceptable. Paragraph eight also stipulates that the right of investment review shall continue, so long as it is

\footnotetext{
${ }^{18}$ Paragraph five can be found on p. 20, Schwanen (2001), op cit. note \#2, with the explanation coming from p. 18. The trade permissibility and non-permissibility were discussed in chapter four.

${ }^{19}$ Paragraph six can be found on p. 21, Schwanen (2001), op cit. note \#2, with explanation on pp. 18-19.
} 
conducted along objective lines, which is to signal that arbitrary decisions against foreign investors should not be permitted. The extension of national treatment to foreign investment would likely be a substantial incentive for the U.S. to agree to the interpretative code, as increased access for foreign investment is a basic negotiating goal for the Americans. Paragraphs seven and eight, together, establish broad non-discrimination in the cultural sector, with exceptions only for the specific measures and circumstances (quotas, funding, co-productions) laid out. As such, the interpretative code represents a substantial change in norm-setting from the absence of an agreement and the $a d$ hoc measures, many of which are discriminatory, that currently exist. ${ }^{20}$

Paragraph nine affirms "the unrestricted right of competent authorities on its territory to set its own educational curriculum, standards, and qualification requirements" (21). This provision is a firewall against the ability of foreign investors to set domestic educational standards. While it may seem unnecessary, the wide scope of services coverage under GATS has led to concerns that education, basic utilities, and other government-provided services will fall under foreign control. Paragraph nine seeks to unconditionally prevent this. Paragraph ten affirms the right for domestic authorities to continue to apply competition policy and labelling and identification procedures. Both paragraphs should not be controversial, because they re-affirm policies, measures, and the exercise of authority that remains firmly based with national governments and uncontested. The last two paragraphs mirror and balance the second last pair of paragraphs: paragraphs seven and eight affirm national treatment and market access for foreign cultural products, while nine and ten re-affirm domestic policy making and capacity. ${ }^{21}$

The institutional and political aspects of the proposed code are more difficult to analyze. The presentation has amply demonstrated what the code offers for Canada, and countries likeminded about preserving the right to set certain cultural policy. But what does the code offer as

${ }^{20}$ Paragraphs seven and eight are found on p. 21, Schwanen (2001), op cit. note \#2, with description on p. 19. Improved foreign investment access was the top priority during the post-WTO decision of the Canada-U.S. magazine negotiations, which was reflected in the negotiated settlement of Bill C-55 and the Agreement on Periodicals. The foreign-investment restrictions were eliminated for the magazine sector, though a prohibition against takeovers of existing operations remained.

${ }^{21}$ Paragraphs nine and ten are found on p. 21, Schwanen (2001), op cit. note \#2, with description on p. 19. 
an incentive for the U.S.? Why would they agree to its adoption? The code would clarify the sector by establishing what measures are acceptable and which are not. This would, in turn, reduce disputes, because countries would not implement measures on a reactive basis that would discriminate or materially injure a U.S. company after it had already begun operation. A country could still react, and implement measures, but the type and nature of the measures would be circumscribed before hand, which lends predictability and clarity to the cultural sector. The code may also encourage further A/V sector liberalization. As the WTO service provisions stand, countries are not obliged to continue extending market-opening access commitments, and many countries will not. However, clarifying what is and is not possible may lend confidence to those same countries, who will begin to further liberalize. Since multi-lateral $A / V$ sector liberalization is in the U.S. interest, the code offers a quid pro quo that may serve market expansion: in effect permanently safeguarding certain measures in exchange for scheduling more $A / V$ openness, a mutually beneficial form of linkage. Finally, extending national treatment to foreign investment is a major incentive for the U.S. A broad, strategic goal is to increase market-access and ensure non-discriminatory and non-arbitrary treatment for foreign investment, so this offer constitutes a significant incentive, one for which it is reasonable to assume the U.S. would be prepared to sacrifice. Daniel Schwanen has wisely designed an interpretative code that offers strong incentives for each side, to ensure that each side trades off acceptable costs for positive benefits. He states the Canadian situation in simple terms as well: "Canada should offer and secure a fundamental tradeoff between abandoning policies at home that are redundant from the standpoint of legitimate cultural objectives and gaining an international recognition for the right to foster a specifically Canadian choice" $(17){ }^{22}$

What would the interpretative code's legal existence be? Would it be an annex, a waiver, an additional sectoral agreement, like the Agreement on Agriculture? The WTO Agreements already contain an interpretative code, Interpretative Code $1 \mathrm{~A}$, which specifies a priority in the relationship between all the agreements in the event of a conflict. 1A stipulates that the more specific agreement will prevail over the general agreements to the extent there is an overlap

\footnotetext{
${ }^{22}$ See Schwanen (2001), op cit. note \#2, pp. 19-22 for his description of, in his words, "What's in it for the United States?".
} 
between two agreements: the TRIPs would prevail over the national treatment provisions in GATT 1994 in respect of a dispute over intellectual property. As mentioned above, he sees his proposal as a "mutually agreed code of interpretation" (17) which would be negotiated and adopted multi-laterally, which is to say that it would have institutional standing within the WTO. He goes on to say that as the code evolves, it would "effectively direct how DS panels should interpret agreements in specific circumstances" (17). He does not, however, specify the mechanism by which this would occur. Within the organizational structure, would the code fit within the Dispute Settlement Body, available once the dispute-settlement process was initiated? Would the code reside somewhere else, attached to, for example, the Council for Trade in Services, the General Council, or the Trade Policy Review Body?

Schwanen goes on to state that precedents exist for codes of interpretation, citing the gradual inclusion of anti-dumping and countervailing subsidies provisions within the WTO agreements. Rules on anti-dumping and countervailing subsidies began to be formulated during the Kennedy Round on multi-lateral trade negotiations (1964-67). Importantly, it was "agreed at the outset that this round should tackle more than tariffs" (Hart 91), and dumping and subsidies were a source of friction between several countries. What is equally important for our purposes is the gradual, or progressive, fashion in which the code of conduct was developed, thickened, clarified, and adopted, so that the conclusion of the Uruguay Round (1986-1994), approximately 25 years later, saw the emergence of a trade agreement devoted to the subject — on Subsidies and Countervailing Measures (the SCM Agreement). A consensus for discussion as well as a consensus for action was necessary both at the outset and throughout that process. Only because the issue was a concern for the major countries was it addressed. The same condition would have to prevail to ensure an interpretative code for the cultural sector could be developed and implemented. Dennis Browne (1999) made a similar point, using the OECD's Committee on Agriculture as the necessary precursor to the Agreement on Agriculture. The Committee worked from 1982 to 1986, while the Agreement was negotiated between 1986 and 1994. Using NGOs, like the INCD, and international governmental organizations, like the INCP, as a gauge, it is difficult to conclude that the cultural sector commands a depth of concern comparable to the subsidies and anti-dumping duties, or that it commands a broad-enough concern that 
encompasses all the major members of the WTO. For the moment, not enough general consensus seems to exist to provide the required inertia to propel the process. ${ }^{23}$

I think the unstated mechanism of Schwanen's proposal is norm-setting and institutional influence. The interpretative code is an attempt to determine what measures are and are not acceptable for countries to implement. This determination would serve as a guide in the event of future cultural-sector dispute-settlement. And these agreed-upon measures - the new norms would then serve to help guide - influence - the Panels and Appellate Body. The formal linkage mechanism may be less important than it otherwise might appear, because the interpretative code would function tantamount to previous case law by establishing guidelines and principles for dispute interpretation. The code would function as a quasi-precedent. The absence of a formal link, or precisely defined institutional mechanism, would also obviate the need to build consensus, and negotiate an outcome through the Working-Party system. It would save time and not be subject to displacement by the already over-burdened built-in agenda. The purposes of norm-setting and institutional influence, I believe, are central to the design and strategy of the official proposals we will consider later in the chapter.

Chi Carmody's "cultural waiver" and Daniel Schwanen's "interpretative code" are the two best non-governmental proposals. How do they compare? Substantive differences are found in two areas: the revised procedures and nature of new rules. Carmody is specific when he proposes to interpose a conciliatory function at the Ministerial Conference or General Council before a conflict proceeds to the dispute-settlement body. Carmody's proposal, in effect, keeps the legislative process close to, and with oversight of, the agreed consensus. This prevents achieving through litigation what was not achieved through legislation: the triumph of litigation over legislation. Schwanen is less specific about his revised procedure. The interpretative code would be negotiated through the legislative process, but he does not specify how the resulting code would interact with the different functions of the WTO, or where it would be located organizationally within the WTO. Although Carmody's proposal is stronger on this point than

${ }^{23}$ Schwanen (2001), op cit. note \#2, argues for precedent on p. 17. Michael Hart quote from (1998) Fifty Years of Canadian Tradecraft: Canada and the GATT, 1947-1997. See pp. 91-92 and 133-134 for the story of antidumping duties and countervailing subsidy inclusion. Dennis Browne (1999), op cit. note \#2 for the supplemental example. 
Schwanen's, it may be that Schwanen's proposal needs to be elaborated on the institutional point. On the nature of the new rules, Schwanen's proposal betters Carmody's. Schwanen's interpretative code is detailed, specific, and relevant to current cultural policy and anticipates points of irritation and friction in the near future. The paragraph by paragraph exposition of his sample text demonstrates this. His proposal is motivated by the premise shared by other experts and the Department of Canadian Heritage: that it is better to provide positive and specific rules, rather than infer what is acceptable from what is not challenged. Carmody's proposal, on the other hand, provides meta-principles or meta-measures rather than the measures themselves. He sets a limit on the type of measures that can be set, and he sets out a prohibition against arbitrary and unjustifiable measures, instead of detailing, like Schwanen, precise measures that can or can not be taken. Likewise, he sets out the conditions under which derogations can be taken from other provisions, rather than attempting to pinpoint the derogations themselves. Because of the "meta-" nature of Carmody"s proposal, his recommendations are similar to a memorandum of understanding, not a binding agreement with specific points. An observation about style, Carmody uses a more formal nomenclature, designating articles with proper titles, compared to Schwanen's use of untitled paragraphs. Given the foregoing analysis, of each proposal individually and in comparison, it will be instructive to look for "footprints" in the government proposals, to which we now turn. ${ }^{24}$

III.

The third section contains the analysis of the two official versions of the Instrument, the draft attempts to have culture recognized by the international trading system. (A third draft, published by the INCD, will not be reviewed because it was unfinished while this thesis was researched.) The first version to be considered will be the IICD, which was circulated at the $5^{\text {th }}$ annual INCP meeting, in Cape Town, South Africa in October 2002. The second version will be the IACD, which was prepared under the auspices of the Cultural Industries SAGIT for DFAIT,

${ }^{24}$ As mentioned, Carmody and Schwanen's proposals were realistically sophisticated, but other, earlier, inchoate proposals also existed. See M. Braun and L. Parker (1993) "Trade in Culture" Denver Journal of International Law and Policy, 22(1), 155-xxx; and Phillip Nichols (1996) "Trade Without Values" Northwestern University Law Review, 90, $\mathrm{xxx}-\mathrm{xxx}$. 
and was made available by September 2002. The parallel proposals illustrate the competing claims that both the Departments' of Heritage and Foreign Affairs have on this initiative. As mentioned on page 64, Foreign Affairs has statutory authority to conduct Canada's external relations, has the diplomatic, legal, and policy expertise, and of course trade and trade-related agreements fall within its purview. However, Heritage has authority because the initiative reaches behind the border and impacts directly on a range of cultural measures and on cultural policy development, all of which are firmly within its purview. ${ }^{25}$

The version of the Instrument presented under the auspices of the INCP, and championed by Canadian Heritage, contains six chapters and a preamble. The version under analysis here was tabled at Cape Town and is intended for consideration as a stand-alone text, which doesn't imply any pre-determined location or organization. In the Instrument's front matter, it was stated that issues of enforceability, an administrative body, a dispute-settlement mechanism, and provisions for entering into, and exiting from, force are needed, all issues related at the international relations level. ${ }^{26}$

The Instrument's preamble situates the object and purpose within Article 27 of the Universal Declaration of Human Rights, and within Article 15 of the United Nations International Covenant on Economic, Social, and Cultural Rights, which establishes the right of people everywhere to participate in the cultural life of their community. The preamble incorporates several declarations on the development of cultural diversity. The preamble further recognizes different aspects of culture, identity, globalization, communication technologies, creativity, and the pressures or inter-connection between these conditions and forces, and concludes by "affirming the importance of promoting coherence between provisions of

\footnotetext{
${ }^{25}$ An overview of horizontal and vertical collaboration comes from G. Bruce Doern, Leslie Pal, and Brian Tomlin (Eds.), "The Internationalization of Public Policy" (pp. 1-26) in Border Crossings, Toronto: Oxford UP. Strictly speaking, "the Instrument" refers to only the version presented by the INCP (and Canadian Heritage). SAGIT's (and DFAITs) is an agreement.

${ }^{26}$ The International Instrument on Cultural Diversity can be found at www.incp-ripc.org (accessed December 9, 2002). A revised version may subsequently be available in the Summer 2003.
} 
multilateral trade policies and cultural policies" $(5){ }^{27}$

Chapter One contains the "Definitions, Objectives, and Scope." Several key terms are defined, including "culture," "cultural diversity," "cultural policies," "cultural expression," "cultural content," "cultural industries," "independent cultural industries," "public service institutions." Article Two (within Chapter One) outlines objectives. There are several noteworthy statements. In point two, the objective is listed as "to preserve the right of States to maintain or adopt the measures they consider appropriate..." (6). One purpose, then, is to assert the legitimacy of something states already do. In point three, another objective is to "serve as a frame of reference for all those States..." (6). Here, akin to the private proposals, the purpose is to set norms and influence institutions. In point five, another objective is "to provide the basis for the promotion of the principles of this Convention in other international fora, including international trade fora" (6). This aim reinforces the above, by establishing the goal of norm-setting and helping to set norms in other related organizations. Together, points three and five comprise an attempt to set a code of conduct for the interaction between cultural policies and trade agreements. Chapter Two is titled "General Principles Relating to the Promotion and Preservation of Cultural Diversity," and it articulates ideas about the nature of cultural products, the balance inherent to cultural diversity, the importance of public policy, intellectual property, and freedom of expression and information. In establishing these principles, Chapter Two of the draft helps to shape new norms. ${ }^{28}$

Chapter Three is titled "Ensuring the Development of Cultural Expression and Cultural Diversity at the National Level" (7). Articles Twelve through Seventeen affirm the right of states to continue setting cultural policy, so long as the policy is consistent with earlier principles. Article Thirteen, in particular, is important: "Acting in conformity with the principles of balance [Article Five] and transparency [Article Seven] enunciated in Chapter Two, Members determine in light of their own particular conditions and circumstances what measures are appropriate to

\footnotetext{
${ }^{27}$ Preamble found on pages 4-5 of the sample text. It is noteworthy that the aim of coherence between the trade system and domestic cultural policies is the last point, suggesting this may be the over-arching goal of the Instrument.

${ }^{28}$ Chapters one and two can be found on pages 5-7 of the sample text.
} 
ensure the promotion and preservation of cultural expression" (8). This says, in effect, that countries can self-determine their own policies. The second paragraph of Article Thirteen elaborates on specific measures that can be chosen: "For greater clarity, Articles 14 to 17 deal with certain types of policies that appear particularly important for the development and preservation of cultural expression. The mention of these policies does not exclude in any way recourse to other measures" (8). Article Fourteen recognizes "language or content requirements" as appropriate to reserve shelf space for domestic products; Article Fifteen recognizes public finance, packaged in a way determined by individual states; and Articles Sixteen and Seventeen specify, respectively, the legitimacy of public institutions and independent cultural industries. We will return to the self-determining aspect after the Instrument presentation is complete. ${ }^{29}$

Chapter Four is entitled "Preserving and Enhancing Cultural Diversity at the International Level." Articles Eighteen through Twenty-two reinforce cultural co-operation, provide for development assistance, and promote cultural diversity in other international fora. At a concrete, policy level, Article Twenty encourages "the conclusion of cultural co-production and codistribution agreements" (9). Film and video co-productions fall under this provision. Film and video co-productions are already covered under Article II Exemptions in the GATS, as mentioned, and the International Agreement on Cultural Diversity (IACD), also stipulates the right of states to continue to pursue these politically popular initiatives. Competition laws are recognized, also under Article Twenty, as a legitimate basis to ensure access to diverse cultural expression. $^{30}$

Chapters Five and Six, at the time of the Cape Town meeting, were the least developed portions of the Instrument. While there is enough substance to present and analyze, because this portion deals with institutional arrangements and dispute settlement, it involves answering complex and inter-related questions of international relations. Article Twenty-three establishes the Council. The Council will have several responsibilities to discharge: to "develop a framework of governance for the Convention, including setting up of a Secretariat;" (10) two, to "discuss

\footnotetext{
${ }^{29}$ Articles Twelve through Seventeen, of chapter three, can be found on pages 7-8.

${ }^{30}$ Articles Eighteen through Twenty-two can be found on pages 8-9.
} 
and resolve questions relating to implementation of this Convention;" (10) and among three others, to "decide upon the application of States to accede to this Convention" (10). The Council, in sum, has constitutional authority and responsibilities for the agreement. Article Twenty-three also provides for the creation of a "Committee on Cultural Policies" to "monitor and promote cooperation on the implementation and administration;" (10) "provide a forum for the Members to consult on related issues at least annually;" (10) and "report annually to the Council" (10). The Committee is functionally subordinate to the Council. A remarkable feature for the Council, given it is enshrined with constitutional authority, is how spare Article Twenty-three is in filling out the details. This might be more understandable if the Agreement, overall, were to be formally connected to an already existing agreement within an institutional framework, such as the WTO. But given that the Instrument, during this reading, is a stand-alone agreement, and unattached to any institution, the absence of specific provisions may provoke unnecessary delays. ${ }^{31}$

Article Twenty-four provides for dispute settlement. Two alternatives are presented. Alternative one requires members to resolve their disputes through a Committee of Experts, which consists of four individuals familiar with cultural policy. Consultations must begin 20 days after written notice of a contested measure is given, and once the dispute-settlement process has begun, the Committee has 45 days to receive written submissions and a further 60 days to consider the arguments and render a decision. This timetable and procedure are contained in points one through five of Article 24 and Annex 1. The Committee must reach its determination through consensus. The decision is submitted to the Council for approval; and if approved, the decision must be implemented in good faith. Alternative two is more confusing, because it itself contains three further options. Alternative two, to begin, is modeled after the Convention on Biological Diversity. In the event of a dispute, members may request mediation by a third party. If members agree to mediate, the dispute will be resolved by arbitration of by the International Court of Justice (ICJ). If the members can not agree on the resolution approach, then the dispute moves to conciliation. Annex 2 details both the arbitration and conciliatory timetables and procedures. The Arbitration Part itself contains 17 articles and is modeled after the customary

${ }^{31}$ Article Twenty-three, that details the Council, can be found on page 10 of the Instrument. 
commercial arbitration procedure adopted by the UN. Three arbiters conduct the process, according to procedures, rules, and limits self-decided but within the bounds of customary public international law. The important difference between arbitration and the dispute-settlement of option one is that arbitration does not have to achieve consensus: the arbiters only have to have a simple majority, with the dissenting arbiter rendering an opinion. This feature ensures a decision will be reached. However, as mentioned, if the members can not agree on arbitration or the ICJ process, then a Conciliation Commission is established. The quintessential problem with the conciliatory route is its non-binding character. Although the decision requires only a majority vote, Article 5 of the Conciliation stipulates "It shall render a proposal for resolution of the dispute, which the parties shall consider in good faith" (16). Not "shall adopt," or "shall implement," but "shall consider." For most circumstances in international relations, "shall consider" likely ensures that nothing will be changed or implemented. ${ }^{32}$

The first well-defined option, the IACD, was designed by the SAGIT committee. Available in September 2002, the International Agreement on Cultural Diversity (IACD) was presented as a "proposed draft for discussion purposes" (10). The IACD views itself as rulesbased and not a declaratory instrument; independent of the WTO but with informal and eventually formal links; having institutional expressions (such as an Executive Council, the right to delegate functions externally, and a Cultural Dispute Resolution Body), and likely to be housed at UNESCO. The objectives and principles animating the IACD are that (a) "governments have a legitimate role to play in supporting, preserving, and promoting cultural diversity," that (b) "cultural goods and services play a broader role in our societies than that of simple commodities" and that (c) "governments...may ensure choice, space, and visibility for both domestic and foreign cultural content" (10-11). ${ }^{33}$

The IACD sets out definitions, scope, and a test for determining if a policy contributes to

${ }^{32}$ Article Twenty-four, on Dispute Settlement, can be found on pages 10-12 of the Instrument, while Annexes 1 and 2 can be found on pages 13-16. The annexes contain the specific details of panel or arbitration composition, the timelines, procedures, rules of evidence and reporting.

33 SAGIT (2002) "An International Agreement on Cultural Diversity: A Model for Discussion," available at www.dfait-maeci.gc.ca, particularly pp. 1-3. The three animating principles, included here, are drawn from Article I, "Declaration of Principles" and Article II, "Objectives." 
cultural diversity in Articles V, VI, and VII. Article V defines "cultural content" to encompass creative expression in performing arts, visual arts and crafts, architecture and design, as well as sounds, images, and texts from the cultural industries, including new- and multi-media productions, and museum, gallery, and library collections. Cultural content is limited to exclude the physical embodiment, or platforms, of expressions - the cd cases and videocassettes. Article VI prescribes each members' right to take measures they deem consistent with general principles and objectives of the Agreement, and their right to self-determine what constitutes cultural content of national origin. An annex is attached to the Agreement that serves as a guideline to what measures are already considered to be consistent with the principles of cultural diversity: measures such as film quotas, production subsidies, fiscal measures and incentives, content quotas, and public service broadcasting. ${ }^{34}$

An attentive reading of the proposed IACD leads to the conclusion that the Agreement is intended to influence the WTO by changing norms. "The proposed new international instrument on cultural diversity is intended to serve as a code of conduct for all those States that consider the preservation and promotion of distinct cultural expression and of cultural diversity itself as an essential component of globalization" (9). Article III states as a goal of international cooperation: "the promotion of the principles of this Agreement in other international fora" (11). The normsetting function will result because of cultural policies implemented by Members but also as a result of dispute-resolution decisions within the CDRB. These decisions, instead of being determined according to international trade law, and adjudicated by trade lawyers, will be heard by "governmental and/or non-governmental individuals who are familiar with cultural matters and cultural industries" (15). These panelists, in this setting, will presumably reach different conclusions from the ones conceivably reached at the WTO. Not only will measures that support cultural diversity be endorsed by adoption of the IACD, but also case law, or quasi-case law, will accumulate that may help to influence disputes brought before the WTO. ${ }^{35}$

${ }^{34}$ Articles V, VI, and VII of the IACD are set out on pages 12-13.

${ }^{35}$ IACD, op cit. note \#33. For elaboration of panel composition, and other dispute-resolution procedural issues, see Part IV, which encompasses Articles IX through XIV, especially Article XIII, "The Establishment of Panels." 
Several references are made to the connection between the IACD, its Executive Council, and the WTO, which is the basis for inferring the goal of institutional influence. Reference is made to international labour conventions and environmental agreements and how they might interact with the WTO agreements, although the descriptive front matter notes "there is not yet a consensus among WTO members on the relationship between such agreements and WTO agreements" (8). In a strong hint of ultimate intentions, the descriptive portion of the IACD writes of "facilitat[ing] an eventual formal relationship with the WTO and/or other relevant trade agreements" (9). In Article IX, "the Executive Council," the Agreement establishes the right to create sub-committees (in paragraph 3), create a Secretariate (in paragraph 6), and importantly for my argument, to delegate some functions to "one or more existing organizations" (in paragraph seven). This would likely be the WTO. One over-arching goal of the Instrument appears to endorse in a hortatory, or declaratory, fashion promotional cultural policies. This is phase one for norm setting. As international consensus coalesces around accepting this norm, several members may have their policies challenged by other members, in the Cultural Dispute Resolution Body (CDRB). The decisions then serve as precedent, as case law, which becomes an expeditious way to influence any cultural trade disputes that are brought before the WTO. The CDRB case law serves to soften any future pertinent WTO case law because its arguments, principles, reasoning, and decisions would be more sympathetic to legitimate cultural policy designed in a spirit of openness to foreign content. This is phase two, the institutional influence. This description and abbreviated analysis portrays the Instrument as it exists in April 2003. Consideration of the benefits and drawbacks, in the context of international policy coordination and the existing trade system, will continue. ${ }^{36}$

The dispute-settlement provisions of the IICD, and the IACD, require analyzing, because reconciling open trade with domestic cultural policies relies on the effectiveness of an international cultural-trade mechanism. And effectiveness means, in the short term, the ability to

\footnotetext{
${ }^{36} \mathrm{IACD}$, op cit. note \#33. The writing is on the wall, in my view, that the goal is to influence the WTO, much in the same way that other so-called non-trade agreements (for labour, environment, human rights) attempt to do so. Reading page eight of the pre-text description should be convincing. Article III(1) on the "promotion of principles of this Agreement in other international fora" should be as well; however, one may argue that other international fora beside the WTO, like UNESCO, the OAS, the IDB, the Council of Europe, the Francophonie, are the implied organizations.
} 
resolve disputes with enforceable decisions. Within the IICD, the several options presented range from purely conciliatory, which will not be binding or enforceable at all, to ostensibly binding decisions. The first option is described as "ostensibly binding" because although the article and annex stipulate the binding nature, the option is located within an legal instrument that at the time of presentation remains a stand-alone agreement. It is not part of the WTO, with a disputesettlement procedure that is binding and that has its legitimacy ensured by the membership of all major countries. This option, however, becomes more binding to the extent that formalized links are developed between the Instrument and the WTO. Within the IACD, the nature of dispute settlement is similar. Articles X through XIV establish the Cultural Dispute Resolution Body (CDRB), the procedure and time-lines. The decisions are not binding, but advisory: Article $\mathrm{XIV}: 1$ stipulates "The decision of the panel shall be advisory only, unless the parties to the dispute agree in advance to give it binding force" (15). It is difficult to imagine that the losing country would voluntarily agree to impose costs on domestic constituents. ${ }^{37}$

Why have a dispute-settlement process at all, if the government proposals are, ultimately, non-binding? The answer has several elements: precedent, norm-setting, longer-term strategy, and institutional influence that either induces a chill on possible litigation, or might alter a future dispute-settlement ruling. One essential point is that this initiative is designed to work in the longer-term. Current trade agreements will not be modified, nor will any memorandum of understanding be drawn up between countries to specify not launching a trade challenge. The initiative is intended to give formal status, and legal weight, to a consensus that governments have a right to continue to set legitimate cultural policy. This is the second essential point: the establishment of a norm, in terms of international opinion, and precedent as the legal expression of such a norm.

We have already seen different strategies on how best to ensure the norm and precedent. Chi Carmody would have the General Council intervene before a dispute-settlement ruling. Daniel Schwanen would have an Interpretative Code that articulates specific, acceptable measures. And both the IICD and IACD devoted a considerable portion of their sample texts to

\footnotetext{
${ }^{37}$ See International Agreement on Cultural Diversity (IACD), p. 15 for quote on nature of decision.
} 
asserting norms, and supporting them with specific policy that was acceptable. The attempt at norm-setting is reflected in the idea of "codes of conduct" used by both Schwanen and the IACD, and that one of the aims was to "promote principles" in other fora. A third essential point is that the norms and precedence developed by initiative are intended to influence the interface between trade agreements and domestic cultural policy. This may be through institutional influence, by creating the "eventual formal relationship with the WTO and/or other relevant trade agreements" (9), or by establishing precedent in the CDRB, nudging a future WTO dispute-settlement decision away from a mathematical analysis of a cultural issue. This institutional influence, in other words, may be formally and directly connected to the WTO, or it may be informally and indirectly connected to the WTO, an outcome that will depend on whether UNESCO administers the Instrument and how it develops. A third mechanism of influence would also be informal and indirect. The accumulation of precedent favourable to specified cultural measures may also have the salutary benefit of chilling a country's desire to launch a challenge. In the first several years of the WTO, challenges were implicitly encouraged because the outcomes have favoured litigation. This could change if precedent meant a much more difficult argument, and a less certain outcome. $^{38}$

The longer-term factor explains much for supporting a dispute-settlement process that isn't currently binding, and the evolution of the dispute-settlement procedure from the GATT to WTO system offers a helpful parallel. The original GATT dispute resolution apparatus, in place since 1947, rendered decisions that were non-binding and unenforceable. (This shortcoming, incidentally, was an important motivator for negotiating the DSU change in the Uruguay Round that provided for an enforceable mechanism.) The newly created WTO, as of 1995, had a dispute-settlement understanding that provided for binding rulings and a mechanism to ensure enforcement, and to ensure adoption of the rulings. The cases heard under the DSB, however, drew from older GATT case law, so even though almost half a century's worth of cases may have been non-binding and, strictly speaking, ineffective, they were effective in establishing precedent that has been drawn on numerous times since. By analogy, GATT rulings helped shaped norms

\footnotetext{
${ }^{38}$ Quotation from IACD, op cit. note \#33.
} 
and establish precedent before it was truly effective, so the Instrument might do likewise until its rulings are given international weight in the WTO dispute-settlement forum. One developmental pathway was from GATT to WTO - or pre-WTO to WTO, while the Instrument's developmental pathway may be from outside the WTO to inside the WTO. Predicting outcomes is risky; however, as a general rule, regimes grow, so to a significant extent success should be identified with the multi-lateral consensus and capacity building that is on-going. ${ }^{39}$

Analysis of dispute settlement is central to any cogent argument about location and effectiveness of the instrument, and we will return to a further aspect in the conclusion of the chapter. Chapter Six of the IICD, entitled "Final Provision," stipulates several other important points for the potential operation of the Instrument. Article Twenty-five requires that members notify other members, via the Committee on Cultural Policies, which would be established by the Council, of changes to existing laws, regulations, or administrative guidelines. Article Twentysix specifies the time-line and procedure to propose and adopt an amendment. Article Twentyseven stipulates that the agreement shall enter into force thirty days after ratification. Articles Twenty- eight and -nine specify, respectively, the terms for accession and withdrawal. And Articles Thirty- and Thirty-one designate, respectively, the Chairman of the Council as a depositary and the authentic languages of the text as English, French, and Spanish. All of these final provisions are standard apparatus for international treaties. ${ }^{40}$

IV.

The final section will apply the analysis begun in the first section, where factors for analyzing the proposal were initially outlined. Importantly, a commitment to the Instrument has been made, so the policy development is no longer disembodied, but is attached to an institution and a process. And this entails a necessary analytical switch, from prospective to retrospective,

\footnotetext{
${ }^{39}$ See John Jackson, William Davey, and Alan Sykes, Jr. (1995) Legal Problems of International Economic Relations, $3^{\text {rd }}$ ed. St. Paul, MN: West Group, for an expert account of the evolution from GATT to WTO dispute settlements. See Stephen Krasner (1982) "Structural Causes and Regime Consequences: Regimes as Intervening Variables" International Organization, 36(2), 185-206.

${ }^{40}$ The Final Provisions are covered on pages 12 and 13 of the IICD.
} 
and to explaining why certain choices were made. At the Cape Town Meeting of the INCP, in October 2002, the Ministers agreed that "UNESCO is the appropriate international institution to house and implement an International Instrument on Cultural Diversity" (2). The explicit reason for this choice was stated in a February 2003 Communique: "[The] Ministers believe that UNESCO's mandate in culture and its adoption of the Universal Declaration on Cultural Diversity in 2001 lay the ground work for a legally binding Convention that would ensure the world a diversity of cultural expression" (1). The Communique resulted from an INCP meeting with the Director-General of UNESCO, in which he "indicated his willingness to launch the process of elaborating a Convention on cultural diversity in UNESCO" (1). One of the most consequential choices - the location of the instrument - had been made. ${ }^{41}$

The final section will explain why UNESCO was chosen. Though the explicit reason of the fidelity between UNESCO's mandate, and its adoption of the Declaration, is plausible, on its own it is neither necessary nor sufficient to explain why the INCP abandoned the WTO route. As discussed at the start of the chapter, the WTO automatically confers recognition and legitimacy, provides as institutional structure, complete with working-group and negotiating machinery, and ultimately ensures international compliance because of its enforceable dispute-settlement mechanism. For these reasons, analysts with diplomatic and trade negotiation experience were unanimous in advocating the WTO over UNESCO, or other institutions, as the location for the Instrument. The choice against the WTO, therefore, warrants a detailed explanation. There are three reasons for choice against the WTO as the host institution: a structural reason; the French position; and the nature of the policy community responsible for formulating the Instrument. ${ }^{42}$

The first reason for choosing UNESCO is structural and itself has two parts. The EU contains, as of April 2003, fifteen members states, which differ considerably on whether they are

\footnotetext{
${ }^{41}$ Cape Town Statement available on the INCP website: www.incp-ripc.org. The specific decision cited is found under "Cultural Diversity and Globalization: Review of an International Instrument on Cultural Diversity." The Communique is also available on the INCP website, under "News Release (February 5 \& 6, 2003)."

${ }^{42}$ The argument for the WTO route is laid out on pages 76-79. A list of analysts and commentators who advocated the WTO position includes William Dymond and Michael Hart, Christopher Maule, Daniel Schwanen, Dennis Browne, Rostam Neuwirth, and Chi Carmody (with the works in which they make their cases listed in footnote \#2).
} 
net exporters or importers of cultural products, and whether in general terms, they view outside cultural influence benignly or as a threat. Portugal, Spain, Italy, and France have traditionally employed protectionist cultural policy, measures underwritten by the assumption of concern for their national cultures and traditions. This concern has translated, according to the Danish Ambassador to Canada, Svend Roed Nielsen, into a "sound skepticism" in Danes over the likely flourishing of their national culture. They could be expected to favour an Instrument that might involve an exemption. On the other hand, Germany and the Netherlands are home to transnational firms (Bertelsman and Philips NVD). Though they may also have concerns about preserving their traditions, the German and Dutch governments should not be expected to favour an exemption-, or quasi-exemption- type Instrument that would undermine the interest of their domestic companies. William Dymond and Michael Hart (2002) underline this: "It is delusional to base any position on the prospect [of Instrument development] that the U.S. or other major trading countries, such as Germany or the UK, will accept any dilution of the international trade rules to the disadvantage of their industries" (29). The first part of the problem is that neighbouring EU countries, due to their different industry profiles, have different negotiating interests. The second part of the problem is that as members of the EU, they must agree on a single, unified position. The European Union, through the European Commission, votes with one voice at the WTO. It becomes structurally impossible to adequately reconcile these two positions into a single EU WTO position: a position acceptable to many of the Mediterranean countries would be unacceptable to Germany, and vice versa. ${ }^{43}$

The second reason for choosing UNESCO is the French position on cultural trade. While Canada has sought an exemption from trade provisions for some cultural products and policies, France contends that the solution should be entirely outside or, and independent of, the multilateral trading system. Canada was unsuccessful at incorporating language that recognized "cultural diversity" into memos at both the WTO Seattle (in November 1999) and Doha

${ }^{43}$ See William Dymond and Michael Hart (2002), op cit. note \#2. The advantages and constraints of the EU position were pointed out by Daniele Smadja, Ambassador, Head of the Delegation of the European Commission in Canada, during the "Ties that Bind" Conference, sponsored by CTPL, in Ottawa, ON., on April 18, 2002. The phrase "voting with one voice" comes from her remarks. Svend Roed Nielsen spoke at the "Cultural Traffic: Policy, Culture, and the New Technologies in the EU and Canada" conference, held in Ottawa, ON., November 22-23, 2002. 
Ministerials (in November 2001), because the French opposed these attempts on the grounds that even the negotiation of culture at the WTO was an abdication of the principle that culture and trade should not meet. The French steadfast refusal to consider pursuing a solution inside of the multilateral trading system constitutes a second barrier to the WTO route, one just as formidable as the structural irreconcilability. Curiously, this absolute French position differs from the one it held a decade earlier, during the Uruguay Round negotiations (which is detailed on pages 33 to 37). In Uruguay, the French abided the European Commission's negotiating position, that first sought an "exception" in GATS Article XIV and second sought "specificity" through GATS Article XIX. The exception would have permanently safeguarded certain audiovisual products, while the specificity would have modified the negotiating schedule for setting commitments. Although neither solution ultimately prevailed, each solution was within the WTO system. This change in French position, from a flexible negotiation to what might be called absolute exceptionalism is one of the most dramatic changes in the cultural trade debate over the last decade. $^{44}$

The third reason for choosing UNESCO is the nature of the policy community primarily responsible for Instrument development. Paradoxically, this reason may contribute more than each of the first two to the decision to pursue a solution outside the WTO, yet it may be more difficult to argue and demonstrate this point persuasively. The first point to note is that the policy community is broad and diffused. There are two primary groups dedicated to detailing an Instrument version: the INCP, which speaks for Canadian Heritage within the Canadian Government; and the SAGIT, which speaks for DFAIT. Beyond this inner sanctum there are a range of groups, some more and some less engaged. The SAGIT consists of members of academia, industry associations, lawyers, and consultants. Inferred from their proposal, SAGIT members employ a norm that seeks recognition in the multilateral trading system yet at the same time wishes to preserve states' rights to set cultural policy. They also believe that cultural policy

\footnotetext{
${ }^{44}$ France's change warrants further examination. Prima facie, France's absolute position may reflect the lessons drawn over the Canada-U.S. FTA, then NAFTA, "cultural industries exemption." On seeing that this provision isn't an exemption under the ordinary meaning of the terms, the French may have decided to forego the constructive ambiguity of trade agreements. It must be noted, however, that the original position during the Uruguay Round, the "exception," was intended to be a non-retaliatory, or unconditional, exemption. So even though that solution was posed inside the multi-lateral system, it would have been in theory a bona fide exemption.
} 
is inherently legitimate public policy. They don't propose a solution inside of the WTO, only one with "eventual formal" links to the trade body. As the second policy community, the INCP membership is composed of representatives of national government's cultural, heritage, and arts ministeries. This group, by virtue of its professional background, comes from a narrower range than the SAGIT. INCP members are cultural policy professionals who would be expected to see cultural policy as inherently legitimate and worthwhile, a position reflected in their proposed Instrument. The composition of the INCP predisposes them - and this is their norm - away from a solution that might curtail the future creation and exercise of cultural policy. It is still premature to know with certainty whether the SAGIT or the INCP version will prevail. ${ }^{45}$

Several parameters of decision making contribute to the policy community's decision to seek a solution independent of the WTO. Severe constraints push a decision away from the rational model. There is no fixed timetable, prescribed by legislation or judicial decision, that compels a decision and pushes for action. In 2001, the INCP Ministers' declared that they wanted to have an Instrument draft within two years, but this timetable is self-imposed, not imposed by an outside authority. The information, knowledge base, and arguments are all contested, as they have been for years, which has prevented any consensus; though it may be more accurate to say this feature has paralyzed the ability to achieve a confident consensus. The absence of consensus is underwritten by the complexity of the problem and the potential complexity and pitfalls of a solution. Finally, decision making is shared, by the Ministers of Canadian Heritage and International Trade, and at the pre-cursory and intermediate stages the process is partially open, which implies a susceptibility to input by groups with particular, interested, unrealistic, and possibly extreme positions. These severe constraints create a complex policy sub-system, which

\footnotetext{
${ }^{45}$ See Howlett \& Ramesh (1995) Studying Public Policy: Policy Cycles and Policy Subsystems, Toronto: Oxford UP, pp. 129-131 for implications of different configurations of the policy communities. For instance, the nature of the interaction, including decision making, is determined by whether the community has an agreed-upon leader or is leaderless and whether there is a consensus between the state and society. The secondary policy community is too numerous to list, but includes as examples, the INCD, the Canada Council, the American National Endowment for the Arts, the Center for Arts and Culture. Given the international interest, there are scores of other non-Canadian and non-American groups. A listing of SAGIT members who signed the IACD proposal is listed on page ii of that document.
} 
makes the final decision difficult to reach. ${ }^{46}$

While the first two reasons were clear and limited, the third reason is complex but powerful. Norms, goals, expectations, and biases are powerful, if challenging, to operationalize and demonstrate as part of a causal chain. They are intangible but real. Turning away from the trading system may reflect practical experience, in Canada's case with the FTA, and it may also reflect implacable ideological opposition, for France. The sense of unrealized expectations, even betrayal, is well capture in Dennis Browne's Forward to The Culture/Trade Quandary (1998): "In recent years, the differences of perception between the Canadian cultural community and Canadian trade officials have driven a large wedge between the two communities. Lack of trust based on mutual misunderstandings had resulted in an unwillingness, possibly even an inability, to work together" $(v)$. It is likely that the failed expectation of a substantial cultural industries exemption in the FTA, and the increase in cultural sector irritants and disputes in the 1990s, helped shape the notion that there would not be consensus any time soon to commit the cultural trade issue, even circumscribed as an A/V services issue, to a WTO Working Group. ${ }^{47}$

A final observation may be adduced in support of a norm against a WTO solution. In December 2000, the U.S. tabled a negotiation proposal for Audiovisual and Related Services designed for the upcoming WTO round. It contained language striking for the recognition of cultural sensitivity of the A/V sector. The Introduction, for instance, stated the goal was to "...contribute to the continued growth of this sector by ensuring the open and predictable environment that recognizes public concern for the preservation and promotion of cultural values and identity" (1). Substantively, the proposal suggests: "In conjunction with negotiated

\footnotetext{
${ }^{46}$ See Howlett \& Ramesh (1995), op cit. note \#45, pp. 145-149, for the parameters of decision-making and the resultant styles. Howlett \& Ramesh draw from John Forester (1984) "Bounded Rationality and the Politics of Muddling Through" Public Administration Review 44(1), xx-xx; and Martin Smith (1994) "Policy Networks and State Autonomy" in S. Brooks and A.-G. Gagnon (Eds.), The Political Influence of Ideas: Policy Communities and the Social Sciences (pp. Xx-xx), NY: Praeger.

${ }^{47}$ Dennis Browne, ed. (1998) The Culture/Trade Quandary: Canada's Policy Options, Ottawa, ON.: CTPL. Although Mr. Browne's comments refer to the division between the two camps within the Canadian Government, the division springs from different expectations about what was achieved, and what should have been achieved, in the FTA negotiations. Once distrustful of a solution within the formal trading system, it is natural that one policy community should seek to pursue a solution independent of the process and outcome that previously failed it.
} 
commitments for audiovisual services, members may also want to consider developing an understanding on subsidies that will respect each nation's need to foster its cultural identity by creating an environment to nurture local culture" (3). ${ }^{48}$

The Proposal effectively suggests a quid pro quo: schedule more A/V service-sector commitments in exchange for the permanent safeguarding of the right to subsidize content creators. The design of this pre-Round proposal reflects the Uruguay Round difficulty and ultimately failure to achieve broader $\mathrm{A} / \mathrm{V}$ service-sector liberalization. Not wanting a repeat stalemate, the U.S. wanted to placate concerns about content subsidies being eligible to foreignbased media conglomerates: the fear that Disney could apply for, and receive, French subsidies to produce "national content" is a noxious thought for French negotiators. Remarkably, there was little sustained or serious discussion of an otherwise interesting proposal. The absence of such consideration reveals a preference for pursuing a cultural trade solution outside of the trading system. Stephen Azzi and Tamara Feick (2003) agree that the U.S. might be more willing to compromise than they are often given credit for, however, an overwhelming international consensus will be required to translate the compromise into special recognition. ${ }^{49}$

The development of the Instrument, from February 1999 to April 2003, demonstrates a desire to work outside the multilateral trading system, independent of the WTO. This contradicts the advice of trade-policy specialists and several academics, and it goes against the two specific proposals, by Carmody and Schwanen, earlier presented and analyzed. The current drafts under consideration envision, at best, only "an eventual formal link." After having attempted to explain the UNESCO route chosen, I conclude that this likely reflects structural reasons, a country position, and the norms and composition of the primary policy community concerned with developing the Instrument. The frustrations in the recent past of reconciling cultural trade goals within negotiations, combined with anticipated impediments to constructive work within the WTO, has translated itself into a high risk strategy to set norms (or standards) and institutional

\footnotetext{
${ }^{48}$ The Audio-Visual and Related Services Proposal (GNS/W/120) can be found on the USTR website: www.ustr.gov/sectors/docsves.shtml. One of the few analyses of the proposal, and negotiating implications, can be found in the unpublished paper by Christopher Maule (2001), op cit. note \#3.

${ }^{49}$ Stephen Azzi \& Tamara Feick (2003), op cit. note \#2. See pp. 113-14 for discussion of this challenge.
} 
influence, though there are never any sure bets on bridging from outside to inside the multilateral trading system. ${ }^{50}$

It will be interesting for the reader to keep this analysis in mind, as progress and events unfold over the next two to four years. The INCP has announced that the Instrument should be adopted by 2005 , but international policy, requiring both international agreement and national ratification, often bogs down. There are several questions the reader should bear in mind. One, What exactly is agreed to? (Will the Instrument change any on-going cultural trade; will it safeguard the right for states to set cultural policy, or certain policy; or will it merely be symbolic tokenism?) Two, Are any cultural policies being challenged in the WTO, or under other trade agreements; and if so, what are the evidence, arguments, and outcome of such challenges? (Has the Instrument, or attempt to develop the Instrument, modified norms and exerted any influence on how a dispute is handled? If arguments, for instance, are different than those employed in Canada Periodicals, perhaps more receptive to cultural policy objectives, then norms have been altered.) Three, What is the outcome of the A/V service-sector negotiations in the Doha Round? Four, What is the U.S. position in respect of the Instrument, and how has it changed, if at all? The answers to these questions will help us gauge the effectiveness of the Instrument in particular as well as changes in the cultural trade quandary. ${ }^{51}$

It might be regrettable that the Instrument is pursued outside the WTO. The official and the private proposals had a lot to offer: Carmody's idea of interposing a legislative and conciliatory function before a judicial one was excellent; likewise, the specificity and positive nature of including cultural measures for safeguarding made Schwanen's recommendations practical. What distinguished these suggestions from the quixotic was their focused, pragmatic nature. Underneath the suggestions was a vision that recognized the absence of the recognition of cultural products in the trade system. The understanding that one is dealing with absence, rather

${ }^{50}$ The official start date of Instrument development is established on February 1999, when SAGIT published its first report, Canadian Culture in a Global World, which publically announced the possibility that an International Instrument may best address the cultural trade quandary.

${ }^{51}$ Credit for the idea that the Instrument may be symbolic should be given to Monica Gattinger (2002) "Globalization, Two-Level Negotiations and Symbolic Policy: The Case of Canada's Cultural Industries in Trade" paper presented at the Canadian Political Science Association meeting, in Toronto, ON., May 29-31, 2002. 
than presence, of a framework is the precondition for any feasible proposals.

Beyond an analysis of drafts, there are larger issues that directly affect how resolution of the quandary will play out. Consensus over the recognition of a problem, the foundation for action, may sadly be lacking. In her Afterword on the subject of the "Trade and..." conundrum, Debra Steger (2002) listed seven areas of difficult political or conceptual inferface, such as trade and the environment, or trade and public health - "trade and culture" was not among them. For the former Director of the Appellate Body Secretariate at the WTO to not acknowledge the issue does not augur well. The omission, and the climate of ideas among trade professionals that fosters such an absence, indicates a long, difficult road for the intellectual capacity building required to insert an issue onto the formal agenda. Perhaps this is yet another reason why the UNESCO route, the road less travelled, was chosen.

Nonetheless, real and perceived cultural consequences sit alongside a broad range of concerns over economic liberalization, in the form of globalization or North American integration, to do with policy capacity, financial openness, economic embeddedness, identity, and sovereignty. As these concerns have fomented outrage among some segments of the population in recent years, they have precipitated "a sound skepticism" and disquiet among the more reflective. True to early predictions, the issue has grown more complicated and more vexing. Attempts to reconcile an expanding trade system with domestic cultural policy have proven exceedingly difficult, and it may be that the cultural trade quandary remains a quandary, which permanently resists solution. Efforts must persevere, because though the quandary may have originated in Canada, this is no longer the case: as globalization has pressed in on national and other identities, so is the quandary now experienced in different places, a realization that should encourage collective, collaborative, and multi-lateral action. ${ }^{52}$

This concludes the portion of the thesis devoted to understanding the treatment of culture, cultural products, and cultural policy within the trading system, and that attempts to analyze to what extent international recognition of the cultural sector is possible, and to gauge success of

\footnotetext{
${ }^{52}$ Debra Steger (2002) “Afterword: The 'Trade and...' Conundrum - A Commentary” American Journal of International Law, 96(1), 135-145. Ms. Steger's list runs trade and environment, public health, labor rights, human rights, competition, investment, and intellectual property. The phrase "sound skepticism" comes from Svend Roed Nielsen's remarks, op cit. note \#43.
} 
the International Instrument on Cultural Diversity. The thesis shifts to theoretical considerations, by trying to unravel the reality and perception underneath the policy, the ideas of cross-cultural influence and loss that supposedly results from the importing of foreign entertainment. As will be seen, the conceptual challenges will be as daunting as impediments were to the policy process. 


\section{Chapter Four:}

\section{The Influence of Media Content on Culture}

"The debate about media effects...remains unresolved. This is partly because the debate is more about the epistemological limitations of social science research than it is about the media in particular." Sonia Livingstone (1996)

Chapter Four marks a transition in the thesis, from policy analysis to theoretical and conceptual considerations. Chapters Four and Five examine the root question that animates the entire study, What influence does foreign entertainment have on domestic culture and national identity? Such an abstract and general question requires a specific and systematic approach for any contribution to be made to advancing knowledge. This chapter examines the question by reviewing the literature in two fields, on "effects" in general (still a large area), and on crosscultural influence in particular, a defined area that has been addressed by two parallel approaches. The purpose is to distill the research record in order to draw lessons specific enough to answer, or to help refine an answer, for the over-arching question. Chapter Five extends the theoretical inquiry by discussing the key concepts of "national identity" and "culture" or "national culture" that underlie much of the policy efforts.

The understanding and explanation of mass communication "effects" has been central to the development of the field. As the International Encyclopedia of Communication says "the history of the field may be read as a persistent search for effects that better describe the social roles of media" (492). In their book addressing cross-cultural media influence, Tamar Liebes and Elihu Katz (1990) write "[t]he study of television is the study of effect" (8). Other recent reviews conclude likewise that inquiries into influence constitute the largest body of research in the field. And Denis McQuail (1994) states "[t]he entire study of mass communication is based on the premise that media have significant effects, yet there is little agreement on the nature and extent of these assumed effects" (327). It is the little-agreement qualification that motivates this research overview. To be able to discuss cross-cultural influence of media on domestic culture, we must first review what is and isn't known about influence in general.'

${ }^{1}$ International Encyclopedia of Communication (1989); T. Liebes \& E. Katz (1990) Export of Meaning; and McQuail (1994) Mass Communication Theory, $3^{\text {rd }}$ ed. The recent reviews are Corner (2000) “'Influence': The 
However, the history of the communications field has become more complicated in the last thirty years. We can no longer confidently assert the effects tradition as the unchallenged understanding of the field's development. In the 1970s, the received history centered on what Veikko Pietila called "Mass Communication Research" or the "effects" tradition, but after gathering momentum in the $1970 \mathrm{~s}$, two rival versions accounted for the field in different ways. Stuart Hall (1982) and James Carey (1989) wrote persuasive heterodox accounts, which were followed up by complementary historiographies. ${ }^{2}$

Accordingly, three contending histories make up the field today: the effects, critical, and cultural perspectives. As a way to encapsulate each version, John Durham Peters (1993) provides a quick-reference geneology of the field by pairing a seminal thinker with a recent historical review. The effects tradition is associated with Paul Lazarsfeld and a review by Katz (1987), while the critical tradition is associated with the Frankfurt School and an important update by Hall (1982), and the cultural tradition with John Dewey and Carey's compilation (1989). The tradition described by Katz was social-scientific enquiry into effects, the one described by Hall was social critique focussing on power and ideology, and Carey's version was social philosophy focussing on culture and democracy. The revisionism of the last thirty years has led to a dispute over the founding "fathers" of mass communication. For the effects tradition, Paul Lazarsfeld, Harold Lasswell, Curt Lewin, and Carl Hovland are the founders. For other traditions, Horkeimer \& Adorno, John Dewey, even Walter Lippmann comprise the wise men. The debate over

Contested Core of Media Research" in J. Curran et al (Eds.), Mass Media and Society, $3^{\text {rd }}$ ed., (pp. 376-397), London: Arnold; Sonia Livingstone (1996) "On the Continuing Problem of Media Effects" in J. Curran et al (Eds.), Mass Media and Society, 2" ed., (pp. 305-324), London: Arnold; and Veikko Pietila (1994) "Perspectives on Our Past: Charting the Histories of Mass Communication Studies" Critical Studies in Mass Communication (11): 346361.

${ }^{2}$ Historical overviews of the field, and accounts of the revisionism, are from John Durham Peters (1993) "Geneological Notes on the Field" Journal of Communication 43(4): 132-139; and Veikko Pietila (1994) "Perspectives on Our Past" Critical Studies in Mass Communication 11: 346-361. Stuart Hall (1982) "The Rediscovery of 'ideology': Return of the Repressed in Media Studies" In M. Gurevitch, T. Bennett, J. Curran \& J. Wollacott (Eds.) Culture, Society, and the Media (pp. 56-90) London: Methuen. James Carey (1989)

Communication as Culture: Essays on Media and Society. Boston: Unwin Hyman. Other important historiographies include Dan Schiller (1996) Theorizing Communication: A History, NY: Oxford UP; Hanno Hardt (1992) Critical Communication Studies: Communication, History, and Theory in America, NY: Routledge; and Gertrude Robinson (1988) "'Here Be Dragons:' Problems in Charting the U.S. History of Communication Research" Communication, 10(2): $97-119$. 
paternity might well lead one to conclude that the study of mass communication is the bastard child of other, more established disciplines. ${ }^{3}$

My thesis holds that the effects tradition remains the dominant perspective, and the principal way to organize thinking about the field's development, but recognizes that it's a contested dominance. This view is defensible because the volume of literature collected under the effects rubric vastly out-weighs that under alternative configurations, and John Peters' (1993) view is that despite apparent distinctions, meaning (pursued by cultural tradition) and power and ideology (pursued by the critical tradition) each blends into effects - or the absence of effect and the prevention of change. For these two reasons, I will be reviewing the research record organized around the dominant history of the field. It is important to note, however, that I will present findings from Cultural Studies and the audience (reception) approach when these became prevalent (after 1980). Though they are best seen within the cultural tradition, they concern themselves with effects, their primary object of study is audience influence, and their findings contribute to the stock of communication knowledge. Any review of the development of a field should be organized chronologically. ${ }^{4}$

\footnotetext{
${ }^{3}$ Katz (1987) "Communication Research Since Lazarsfeld" Public Opinion Quarterly (51): 25-45 complements Hall (1982) and Carey (1989) for contending histories. See Pietila (1994), Peters (1993), Schramm (1983), Schiller (1996), and Hardt (1992) for assessments of each history, their relative merits, seminal figures, and key works. The four-founders list from the mass communication tradition comes from Schramm (1983) and ultimately Berelson (1959). John D. Peters, whose own historiography has the greatest affinity for the culturalist tradition, identifies Dewey, Lippmann, and Lazarsfeld as founders. See Peters (1986) "Institutional Sources of Intellectual Poverty in Communication Research" Communication Research, 13(4): 527-559. The pairing used by Peters (1993) isn't intended to elevate the thinkers listed to the exclusion of others, simply as a concrete way to organize the competing lineages.

${ }^{4}$ Pietila (1994) argues that the popularity of influential mass-communication texts is a valid way to support the rise and continued place of the dominant version. See notes $2 \& 3$ for full list. Selections include Paul Lazarsfeld (1941) "Remarks on Administrative and Critical Communications Research" Studies in Philosophy and Social Science, vol. 9.; B. Berelson (1950) Public Opinion and Communication; J. Klapper (1960) Effects of Mass Communication; and De Fleur (1966) Theories of Mass Communication (now through five editions). Another valid indicator of the continued relevancy of the effects tradition is that the most influential journal in the field, Journal of Communication, favours publishing articles that fit within the dominant perspective. John Peters (1993) view of blending can be inferred from his statement "[Y]ou find that Katz is as interested in meaning as Carey, Carey as interested in power as Hall, and Hall as interested in effects as Katz" (135), op cit. note \#2.
} 
I.

The first period of mass communication research lasted from approximately 1900 to the late 1930s. In its nascent phase, communication was a topic or object of study by philosophers, sociologists, political scientists, and when it emerged as a field in the 1920 s, social psychologists. There was no field of communication per se and communication did not reside in a disciplinary home within the university. Chicago sociologists such as George Herbert Mead, Robert Park, and Charles Cooley saw in communication potential to strengthen democracy by providing information which would help the citizen exercise greater rationality. In contrast, Walter Lippman, influenced by pessimistic European mass society theory, recognized the subversive potential of mass communication: propaganda and the manufacture of consent could be put to ruinous purposes. In a philosophic sense, William James, I.A. Richards, and C.K. Ogden viewed communication as a way of overcoming solipsism and opening the way to genuine and authentic inter-personal communication. Regardless of research aim and temper of researcher, the assumption that legitimated this period as a coherent whole was the view of the inherent power in communication. The assumption of powerful effects, which were supposedly direct and immediate, drew support from events such as the success of World War I propaganda, the apparent connection between advertising and increased consumerism, and the mass panic of the War of the Worlds broadcast, in $1938 .^{5}$

The second period in the development of thinking about effects lasted from the late 1930s until 1959. This phase is demarcated by research that slowly refined and reined in the notion of powerful effects: from effects that were powerful, direct, and immediate to a more limited view. The central research questions of the previous period concerned campaigns: persuasion for political or consumer purposes. The research agenda in this period refined earlier findings.

\footnotetext{
${ }^{5}$ See John Peters (1999) Speaking Into the Air, Chicago: U Chicago Press (chapter 1) for presentation of early $20^{\text {th }}$-century theorizing on communication. It is important to note, with Pietila (1994), that characterizations of the period before the Second World War are disputed. Peters claims that, to the extent a consensus on the development of the field exists, the consensus begins with Lazarsfeld at Columbia University in the very-late 1930s. As part of the recent revisionism, it is important to note that there's some dispute over whether the magic-bullet or hypodermic-needle conceptions were ever part of the thinking. For the argument that powerful-effects was a strawman to be knocked down by subsequent administrative communication researchers, see J. M. Sproule (1994) "Progressive Propaganda Critics and the Magic Bullet Myth" Critical Studies in Mass Communication 6(3): 225246.
} 
Studies such as The People's Choice (1944), Personal Influence (1955), Hastorf \& Cantril (1954), Warner \& Henry (1948), Levine \& Murphy (1943), Herzog (1944), Kendall \& Wolff (1949), Hyman \& Sheatsley (1950) explored, among other things, how citizens made voting decisions, how college football fans perceived referee fairness, the reasons housewives listened to daytime soaps on radio, how people used knowledge about classical music to advance their social standing, and how comic book readers understood bigotry. The accumulated results had a seismic effect on the accepted notions of media influence. Interpersonal networks and personal attitudes were now seen as far more important than media content itself in shaping opinions and guiding behaviour. While the media only offered opinions or news, it was through personal conversation and relationships where and how one's final opinion was shaped. Likewise, the social psychological research demonstrated that people were selective in the messages they exposed themselves to, the meaning they derived, and their ability to retain their impressions. To borrow the title of Hyman \& Sheatsley's article, there are "Some Reasons Why Information Campaigns Fail." During this phase, the study of mass communication became institutionalized. Lazarsfeld's work on communication was located in the Bureau of Applied Social Research, at Columbia. In the decade after World War II, the first schools, institutes, departments, and programs appeared. The University of Illinois established the Institute of Communication Research in 1948, and Stanford established the Institute for Communication Research in 1956. The emergence of formal research and teaching facilities is the reason there is a greater degree of consensus over the history after, rather than before, the Second World War. ${ }^{6}$

\footnotetext{
${ }^{6}$ Full citations for the studies cited (in order presented) are: Paul Lazarsfeld, Bernard Berelson, and Hazel Gaudet (1944) The People's Choice, Elihu Katz and Paul Lazarsfeld (1955) Personal Influence, A. Hastorf \& H. Cantril (1954) "They Saw a Game: A Case Study" Journal of Abnormal and Social Psychology (49): 129-134; W. L. Warner \& W. E. Henry (1948) "The Radio Daytime Serial: A Symbolic Analysis" Genetic Psychoanalysis (37): 3-71; J. Levine \& G. Murphy (1943) "The Learning and Forgetting of Controversial Material" Journal of Abnormal and Social Psychology (38): 507-517; H. Herzog (1944) "What Do We Really Know About Daytime Serial Listeners?" in Lazarsfeld \& Stanton (Eds.), Radio Research: 1942-1943; P. Kendall \& K. Wolff (1949) "The Analysis of Deviant Case Studies in Communications Research" in P. Lazarsfeld \& Stanton (Eds.), Communications Research 1948-1949; and H. Hyman \& P. Sheatsley (1950) "Some Reasons Why Information Campaigns Fail" Public Opinion Quarterly (11): 412-423. These studies are referred to as the "lost sociology" in the convergence-new revisionism debate. The summary statement about interpersonal factors and selectivity comes from Elihu Katz (1980) "On Conceptualizing Effects" In T. McCormack (Ed.) Studies in Communication (pp. 119141). Katz's reformulation comes from (1959) "Mass Communication Research and the Study of Popular Culture: An Editorial Note on a Possible Future for this Journal" Studies in Public Communication (2): 1-6.
} 
The third period begins in 1959 and ends in 1980. As a result of the ascendancy of communications research programs, this phase produced an enormous contribution to the understanding of effects. The distinguishing feature of this era was the discovery of two key processes that intervened to curtail media power: inter-personal relationships and selectivity. Interpersonal relationships meant how opinion and effect took shape in conversation and within different and overlapping groups. Selectivity meant the psychological processes a person employed in watching, interpreting, and retaining a message. Advances in understanding effects were drawn from studies that focussed on the refinement of either process. Research in this phase extended, and challenged, limited effects. Uses and gratifications, social learning theory, cultivation analysis, agenda setting, knowledge gap, and the spiral of silence all emerged as schools of thought during this time. ${ }^{7}$

In response to the public's concern over high levels of violence on television, researchers undertook an extensive research agenda to analyze the speculative effects on children. Research placed intervening variables such as predispositions or social situations between content and the child's behaviour, and they introduced concepts such as fantasy, escape, arousal, and catharsis to account for different cognitive or affective factors. Studies did find conclusive evidence for some particular relationships. For example, children with low selfesteem preferred fantasy content, while children that had difficulty with their parents used content as a way to escape. Researchers also found that post-viewing acts of violence depended on the identity of the victim, identity of the assailant, and whether the assailant was punished for his or her (usually his) crime. The studies weren't able to formulate general laws from the particular findings, and researchers concluded that personal agents of socialization - parents,

\footnotetext{
${ }^{7}$ Two events establish 1959 as the benchmark year beginning a new era. One, Katz placed people at the center of investigation. Two, Public Opinion Quarterly, the leading communications journal of the time, published a series of stock-taking articles on the state of research. Bernard Berelson wrote, according to Wilbur Schramm, a eulogy for the field, while Raymond Bauer, David Reisman, and Schramm replied with more optimistic assessments. Pertinent for us, Bauer suggested that Berelson mistook growing out of the borders with withering away (from Schramm [1983] Journal of Communication, p.6). For the seminal article associated with each school, see M. E. McCombs \& D. L. Shaw (1972) "The Agenda-Setting Function of Mass Media" Public Opinion Quarterly (34): 159-170; P.J. Tichenor, G.A. Donohue, \& C.N. Olien (1970) "Mass Media Flow and the Differential Growth in Knowledge" Public Opinion Quarterly 34(2): 159-170; Katz, Blumer, \& Gurevitch (1974) "Utilization of Mass Communication by the Individual" in J. Blumer \& E. Katz (Eds.), The Uses of Mass Communication (pp. 19-32), Beverly Hills, CA.: Sage.
} 
peers, and teachers - were better predictors of violent acts. Inter-personal processes played a significant intervening role between media and effect. ${ }^{8}$

Uses and gratifications, another predominant school of thought, refined and broadened the notion of selectivity. While earlier notions of selectivity were based on the assumption that people sought to avoid cognitive dissonance, contemporary notions held that individuals sought media content that gratified some psychological or sociological need. People were selective in their pleasure-seeking behaviour. Katz, Blumer, and Gurevitch (1974) postulated that social or psychological needs (such as personal contact, identity, or diversion), which originated independently of the media, created expectations that lead to patterns of media usage, which could be understood as the gratification of the original needs. Their hypothesis placed egogratifications psychology within the understanding of media effects. ${ }^{9}$

Research of this period also challenged the assumption of limited effects. Agenda-setting abandoned the search for effects per se, instead emphasizing the process of what individuals think about, not what they think. And there has been disagreement over whether this period represented a distinct research era or was merely the extension of earlier limited-effect studies. The third phase illuminated the complexity and contingency of the idea of effects: the conditions under which they happen, the inter-personal and intra-personal (selective) processes that intervene, and the cognitive and affective predispositions one brings to the encounter. Effects could never again be considered simple, linear, direct, or crudely causal. ${ }^{10}$

${ }^{8}$ It is not an exaggeration to claim that the effects of media violence on children has been the research question for communication research. At the direction of the United States Congress, the Surgeon General convened the Committee on Television and Social Behaviour in 1971. The eventual report, by George Comstock, cites 2,300 research reviews and studies on the question. The issue remains contentious today, with an advertising campaign by high-profile Americans urging Hollywood to restrain the graphic portrayals of violence aimed at youth and teens. For a snapshot of the research, see George Comstock (1975) "The Evidence So Far" Journal of Communication 25(4): 25-34.

${ }^{9}$ Elihu Katz, Jay Blumer, and Michael Gurevitch (1974), op cit. note \#7. Katz (1980), cited in note \#6, for claim that selectivity was broadened to include positive goals.

${ }^{10}$ J.D. Slack \& M. Allor (1983) "The Political and Epistemological Constituents of Critical Communication Research" Journal of Communication 33(3): 208-218 challenge the claim that this period is distinct from the previous limited-effects period. See pp. 212-215 for the argument that schools such as gate-keeping, uses and gratifications, and the two-step flow are simply elaborations that add intervening variables in a relationship that remains simple and direct. 
We need a brief diversion from the historical development of the field to changing philosophical foundations, because changes in meta-theory swept communication theory and method (and the social sciences in general) by the 1970s. There was recognition of the limits to both social theory and epistemology in explaining social phenomena. Anthony Giddens (1979) pointed out the mutual constitution of social institutions and individual actions and intentions, which implied that the structure-agency problem was an irreducible circle. This conclusion rested on, among others, Berger and Luckmann's (1967) argument for the constructed nature of all social institutions, indeed all social reality. Robert Craig (1993) pointed out the insuperable epistemological problem of when a theory shapes the phenomena that it is trying to explain.

Several commentators noted the shift away from a method, concerned with scientifically deriving laws from instances, to a method based on interpreting particular cases. And Robert Craig (1993) and Clifford Geertz (1980) noted that social sciences and humanities had suddenly become more theoretical without becoming more scientific. ${ }^{11}$

A detailed explanation of the reasons for the revolution in philosophy is outside the scope of this review. Origins of the change lay in recognition of the constructed nature of language, knowledge, law, and social institutions and conventions. Private theories of meaning had also been demolished. The state of affairs and conditions of existence that in 1900 had been taken to be natural, were by 1980 held to have been social and, hence, constructed. The change in worldview was seismic. In epistemology, the shift was from foundationalism to coherentism, and in ontology, the shift was from realism to idealism (or mentalism). This resulted in the idea that rules or universals were conceptual or nominal. Incorporating emerging positions within the philosophy of science, theorists such as Derrida, Foucault, Kuhn, Levi-Strauss, and Lyotard exerted influence over contemporary theory and method debates. Theory was no longer certain

${ }^{11}$ Robert Craig (1993) "Why Are There So Many Communication Theories?" Journal of Communication 43(3): 26-33; and Anthony Giddens (1989) "The Orthodox Consensus and the Emerging Synthesis" In B. Dervin, L. Grossberg, B. O'Keefe \& E. Wartella (Eds.), Rethinking Communication, vol. 1 (pp. 53-65) for the claim of 1970s as beginning of the philosophical upheaval. Other works cited: Anthony Giddens (1979) Central Problems in Social Theory; and Peter Berger and Thomas Luckmann (1967) The Social Construction of Reality; Clifford Geertz (1980) "Blurred Genres: The Refiguration of Social Thought" American Scholar, 49, 165-179. 
knowledge, but discourse, no longer value-free but value-laden. ${ }^{12}$

Communications, like other fields, experienced disorientation, and soon it was proclaimed that the field was in "ferment." These deep changes, like shifting tectonic plates, would be felt as rumbles on the surface, leading to a disruption in continuity between earlier and contemporary approaches. For the purposes of my thesis, the legacy of interpretation and the attention to hermeneutics is important. Beginning around 1980, communication research had to incorporate ethnographic, survey questionnaire, or in-depth interview techniques to probe the interpretation process. The object was to understand how an individual made meaning. ${ }^{13}$

The fourth period in the development of thinking about effects started in 1980 and runs to the present. In this phase, contributions to effects research come primarily from the refinement of two ideas: on the variability of meaning, and about the active audience. Nineteen eighty is somewhat of an annus mirabulus for audience research, because in the same year, Stuart Hall's "Encoding/Decoding" article and David Morley's Nationwide study introduced fundamental breaks from earlier assumptions and methods. The fourth period is challenging to present in a unified narrative, even moreso than the previous era, because the philosophical tremors continued to divide, sub-divide, shake-up and cross-pollinate disciplines and fields. ${ }^{14}$

\footnotetext{
12 The statement of theory as discourse comes from Craig (1993). The simplified epistemological and ontological evolutionary path of the $20^{\text {th }}$ Century comes from Simon Blackburn (1999) Think: A Compelling Introduction to Philosophy. London: Oxford U Press. Blackburn, a Distinguished Professor of Philosophy at University of North Carolina, details the developments in chapter 1, "Knowledge," (pp. 15-48) and chapter 7, "The World," (pp. 233-269).

13 "Ferment in the Field" was the title of a special edition of the Journal of Communication 33(3), in 1983. Attesting to the on-going ferment, the Journal of Communication 43(3/4), in 1993, titled itself "Defining Media Studies." The European Journal of Communication (1990) also dedicated itself to issues of self-definition. An excellent discussion of problems besetting communication theory and method remains Brenda Dervin, Larwence Grossberg, B.J. O'Keefe, and E. Wartella (Eds.), (1989) Rethinking Communication (2 vols). Newbury Park, CA: Sage. Rosengren, Karl. (1989). Paradigms Lost and Regained. In Brenda Dervin, Lawrence Grossberg, Barbara O'Keefe \& Ellen Wartella (Eds.), Rethinking Communication, vol. 1 (pp. 21-39), Newbury Park, CA.: Sage.

${ }^{14}$ The two seminal articles are Stuart Hall (1980) EnCoding/Decoding. In Culture, Media, and Language (pp. 197-208), London: Hutchinson; and David Morley (1980) The "Nationwide" Audience: Structure and Decoding, London: BFI. See William Evans (1990) "The Interpretative Turn in Media Research: Innovation, Iteration, or Illusion?" Critical Studies in Mass Communication (7): 147-168; and David Morley (1996) "Populism, Revisionism, and the 'New' Audience Research" in J. Curran, D. Morley \& V. Walkerdine (Eds.), Cultural Studies and Communication (pp. 279-294), London: Arnold for claims that meaning variance and audience activity are the two distinguishing features of post-1980 audience research. Semiotics, critical theory, discourse analysis, post-
} 
The signifier-signified relationship had been challenged. Structural linguistics held that words were endowed with meaning because of the relationship to other words, not because of an external reality. Meaning floated within a field but wasn't fixed or determined. Within semiotics, the meaning of signs and symbols became multiple, or polysemic. Incorporating advances in linguistics, literary theory argued these points to their logical conclusion: since meaning floated and the signifier-signified relationship was indeterminate, the message couldn't be an immanent property of a text itself, waiting to be discovered; rather meaning was made. Stuart Hall (1980) incorporated this indeterminancy into his critical approach that examined how hegemonic worldviews were naturalized by viewers, and argued that because readers employed their own structures of meaning, they could produce variable interpretations. This included interpretations different - oppositional or alternative - from those intended by producers. ${ }^{15}$

The active-audience idea attracted research attention, partly as a result of the recognition of meaning making, and mainly as a result of the ascendancy of ethnography. David Morley's study (1980) was the exemplar, relying on extensive interviews, self-reporting, and unobtrusive set-top box recording. This was entirely congruent with Geertz's (1973) famous description that his theory of culture was based on an interpretative search for meaning, rather than an experiment that deduced a law.

In contrast to the indeterminancy of meaning, which was a change in assumption, the rise in ethnography was the improvement in method. Throughout the 1980s and 1990s, communication researchers combined the presumption of polysemic messages with ethnography to generate numerous audience studies: Janice Radway's Reading the Romance (1984) advanced the concept of interpretative communities. Meaning-making, or the horizon of interpretation, occurred at the boundaries of community membership. Meaning was neither presented nor received, but was arrived at through the conversations of an interpretative community, which could be any group that coalesced around a common interest. Consistent with the contemporary

structuralism, feminism, and ethnography have contributed to the proliferation of schools: reception studies, populism, Cultural Studies, New Revisionism, and public issues, or what Jenny Kitzinger calls "new effects research." Hutchinson.

${ }^{15}$ Stuart Hall. (1980). Encoding/Decoding. In Culture, Media, and Language (pp. 128-138). London: 
philosophical dispensation, meaning was socially constructed within an in-group that shared an idiom, competence, and an understanding of that particular symbolic universe. Imparting a sense of deja $v u$, interpretative community is reminiscent of the idea of inter-personal networks in opinion formation. ${ }^{16}$

The claims of, and results that followed from, open meaning and audience activity became controversial. Although Morley insisted on a limited spectrum of interpretation ("structured polysemy"), and Hall introduced the possibility of oppositional readings, the pendulum swung to the extreme. Interpretations could be limitless, the sovereign consumer or reader residing in a semiotic democracy. Not only was the idea of audience activity evoking deja $v u$, it now provoked disdain from mass communication researchers and Cultural Studies scholars who insisted on analytical rigour for their semiotic readings. ${ }^{17}$

The aura of the discovery of audience activity, or re-discovery of inter-personal networks, touched off a debate. James Curran (1990) labelled this so-called new area the "new revisionism," his principal accusation that it re-discovered the wheel of pioneering 1940s and '50s uses and gratifications. David Morley (1992) replied that Curran's view was premised on a straw-man version of hypodermic-needle research that never actually existed. He pointed out that the pioneering work was lost in a spiral of silence as mass communication became increasingly administrative and quantitative through-out the subsequent period. Although Schroder and Liebes side with Curran, I maintain that the argument is a stalemate. Curran prevails to the extent that early gratifications work is an accurate precursor to contemporary audience research, in findings though not in method or approach. Morley prevails when he insists that the lost sociology

\footnotetext{
${ }^{16}$ Janice Radway (1984). Reading the Romance. Chapel Hill, NC.: U North Carolina Press. See Thomas Lindlof (1988) "Media Audiences as Interpretative Communities" Communication Yearbook (11): 81-107 for an excellent discussion of the influences of social phenomenology and ethnomethodology on the idea that meaning is conjured within groups defined by their object of interest, ie. an audience. See also, Tamar Liebes (1989) "On the Convergence of Theories of Mass Communication and Literature Regarding the Role of the Reader" in B. Dervin \& M. Voight (Eds.), Progress in Communication Sciences (pp. 123-143) Norwood, NJ: Ablex.

${ }^{17}$ John Fiske bears the burden for the extreme pendulum swing. See Celeste Condit (1989) "The Rhetorical Limits of Polysemy" Critical Studies of Mass Communication 6(2): 103-122 for an excellent critique over the laxity of limitless interpretation. It is noteworthy that she prefers "polyvalent" to "polysemic." She writes "Polyvalence occurs when audience members share understandings of the denotations of a text but disagree about the valuation of those denotations to such a degree that they produce notably different interpretations" (106).
} 
wouldn't have been re-discovered were it not for current interest in audience interpretations. The wheel, for Morley, was reinvented only because researchers discovered new techniques for spoke and hub construction. ${ }^{18}$

The real differences between early and contemporary audience research were those of research technique. Occuring elsewhere but best illuminated at the Glasgow University Media Research Group (GUMRG), audience-measurement techniques were refined throughout the late 80 s and 90s. Public issue research asserts the primacy of viewer interpretation in the hermeneutic process. Current methodology stresses a qualitative approach that is sometimes subject to quantitative analysis. Techniques such as script-writing and recall exercises, individual and group interviews demonstrate how knowledge is used, and selected, in interpretation, and how different content genres will also be used selectivity.

What has this review of the effects tradition demonstrated?

The development of the field can be understood as the oscillation between the assumptions of strong and weak effects. It can also be understood to have evolved in tandem with the understanding of the role interpersonal and selectivity factors play. Little agreement seems to exist, to recall McQuail's remarks (on page 116), about the nature, extent, (and we should add) duration of effects. Findings haven't yielded a unified theory of effect or change, but the record has demonstrated several things: that individuals selectively gratify needs as much as avoid dissonance; that content is but one way to socialize attitudes along with parents, peers, and teachers; that meaning is made, not found; and furthermore, that the interpretative process is shaped by individual and group (including cultural) forces. This general understanding has emerged from the research record. Instead of characterizing the search in terms of a disappearing

\footnotetext{
${ }^{18}$ The original article was James Curran (1990) "The New Revisionism in Mass Communication Research: A Reappraisal" European Journal of Communication (5): 130-164. The reply, David Morley (1992) "Populism, Revisionism, and the 'New' Audience Research" Poetics 21(4): 329-344. Rejoinders are Curran (1996) "Media Dialogue: A Reply" in J. Curran et al. (Eds.), Cultural Studies and Communication (pp. 294-299); and Morley (1996) "Media Dialogue: Reading the Readings of the Readings..." J. Curran et al. (Eds.) Cultural Studies and Communication (pp. 300-305). Although writing before the Curran-Morley debate, Schroder and Liebes concur with Curran to the extent that the debate is also over historical versions of the field. Kim Schroder (1987) "Convergence of Antagonistic Traditions? The Case of Audience Research" European Journal of Communication 2: 7-31; and Tamar Liebes (1989) "On the Convergence of Theories of Mass Communication and Literature Regarding the Role of the 'Reader'." in Brenda Dervin \& Melvin Voight (Eds.), Progress in Communication Sciences (pp. 123-143). Norwood, NJ.: Ablex Press.
} 
audience or vanishing effects, we should view accumulating research as successive approximations toward an answer we'll never ultimately reach. As calculus is only an approximation of an ever-changing number, communication research can only circumscribe, never pinpoint, effects. ${ }^{19}$

II.

Section two examines the literature on cross-cultural influence. While the effects literature was vast, the cross-cultural influence literature itself remains broad, encompassing the domains of cultural imperialism, international flow of information, and cross-border television impact. This area is central to my thesis question, because inquiries specifically presume that outside or foreign content influences domestic culture. ${ }^{20}$

The notion of cross-cultural influence is closely related to the idea of cultural globalization. Within globalization studies, cultural globalization occupies an interesting, even paradoxical, place. It is perhaps the most difficult aspect to study, yet it is the most directly perceived and experienced form of globalization. The ubiquity of Western, usually American, symbols and media lends intuitive support to claims that diverse cultures are being squeezed out around the globe and replaced by a mongrel American variety. As David Held and co-authors argue, the meaning and significance of these phenomena are unknown, yet their presence are readily taken as valid evidence to support the homogenization thesis. This review of crosscultural influence will thus contribute to discerning the meaning and significance of cultural

${ }^{19}$ The "oscillations" characterization comes from David Morley (1989) "Changing Paradigms in Audience Studies" in E. Seiter et al (Eds.), Remote Control: Television, Audiences, and Cultural Power, NY: Routledge; and the "interpersonal and selectivity" characterization comes from Katz (1980), cited in note \#6. Understanding research results in terms of "the disappearing audience" comes from Fred Fejes (1984) "Critical Mass Communication Research and Media Effects: The Problem of the Disappearing Audience" Media, Culture, and Society (6): 219-232.

${ }^{20}$ See Michel Elasmar \& John Hunter (1997) "The Impact of Foreign TV on a Domestic Audience: A Meta-Analysis" Communication Yearbook (20): 47-69 for relationship between domains; also Duane Varan (1998) "The Cultural Erosion Metaphor and the Transcultural Impact of Media Systems" Journal of Communication 48(2): 58-85 for comments. 
globalization. ${ }^{21}$

Thinking and research on cross-cultural influence began in the 1960s. Here, research can be categorized as either radical political economy or as empirical, and within empirical, first psychological-behavioural and then ethnographic. It is striking that these two strands developed contemporaneously, yet in considerable isolation from one another, an absence that reflects irreconcilable methods and goals. ${ }^{22}$

The radical political economy approach produced the cultural imperialism thesis, and this approach grew from the dependency school of thought within international political economy. Early scholars such as Pasquali (1963), Beltran (1978), Matta (1977), and Kaplun (1973) came from Latin America. Throughout the 1950s and 1960s, Latin American broadcasting systems relied heavily on American broadcasting infrastructure and content, and these scholars, and others, were alarmed over the supposed cultural consequence of such preponderant American presence. Herbert Schiller's Mass Communication and American Empire (1969) crystallized the cultural imperialism thesis: that American entertainment content and media infrastructure extend Western capitalist organization into the developing world. Armand and Michelle Mattelart, Dallas Smythe, and Ariel Dorfman published on cultural imperialism in the $1970 \mathrm{~s}^{23}$

By the late 1970 s, doubts about the cultural imperialism theory began to appear, and by the mid-1980s, the idea of dominance was critiqued. Incorporating the growing discontent, John Tomlinson wrote a hard-hitting critique in 1991. Cultural imperialism, he contended, wasn't a coherent, unified thesis at all; rather it was a congeries of four different discourses: on media imperialism, nationality, global capitalism, and modernity. Media imperialism assumes that

21 See David Held, Anthony McGrew, David Goldblatt \& Jonathon Perraton (1999) "Globalization, Culture, and the Fate of Nations" Global Transformations (pp. 327 - 375). Stanford, CA: Stanford UP.

${ }^{22}$ See Elasmar \& Hunter (1997), op cit. note \#20, for support of distinct development.

${ }^{23}$ See Colleen Roach (1997) "Cultural Imperialism and Resistance in Media Theory and Literary Theory" Media, Culture, and Society (19): 47-66 for the list of the pioneering scholars from the dependency school. See also, Michael Salwen (1991) "Cultural Imperialism: A Media Effects Approach" Critical Studies in Mass Communication (8): 29-38; and Michael Tracey (1985) "The Poisoned Chalice? International Television and the Idea of Dominance" Daedalus (Fall): 17-56 for cultural imperialism's intellectual roots in the dependency school within international political economy. 
consumption of foreign content is tantamount to cultural influence. The nationality discourse overlooks tough ontological and epistemological questions about national identity and culture, the conditions of formation, maintenance, and erosion. And the global capitalism and modernity discourses are separated by a thin line, with global capitalism - globalization - a concern over the extension of private means of accumulation and commodification of experience, and with modernity a teleological concern that world historical development is predetermined to follow a route of Western science and technology. Each of these four discourses explained one cultural aspect of globalization, but none convincingly explained exactly how the domestic culture was changed. $^{24}$

In response to a growing negative chorus, Schiller produced a revised edition (1991). He stated in his new introduction that American entertainment products continued to flood the world, their exports growing in absolute (year by year) and relative (in comparison to other nations' exports) terms. He then states that the idea must be re-cast: that cultural products serve as an advertising component for other American products. He de-emphasized a direct ideological or cultural effect by replacing it with the notion that they promoted consumerism. John Thompson (1995) pointed out the fallacy of internalism: "Schiller tries to infer, from an analysis of the social organization of media industries, what the consequences of media messages are likely to be for the individuals who receive them" (171). The presence of entertainment content and American-style broadcasting infrastructure doesn't imply effect. The cultural imperialism thesis reduced (cognitive, affective, behavioural, and cultural) effects to economic factors, which is some distance from demonstrating individual or societal effects and influences, which is some distance again from demonstrating effects within a sophisticated anthropological and semiotic understanding of culture as a signifying system. ${ }^{25}$

\footnotetext{
${ }^{24}$ Colleen Roach (1997), op cit. note \#23, and Michael Tracey (1985), op cit. note \#23, list the rise of doubts over the thesis. John Tomlinson (1991) Cultural Imperialism: A Critical Introduction, Baltimore, MD: Johns Hopkins U.

${ }^{25}$ The crux of Schiller's revised position is found on page 12 of his 1991 edition. Two points are worth making. First, Schiller's claim of "relative increase" misses the change to trade patterns, whereby other centers of production like Brazil, Egypt, and India started to increase exports relative to U.S. or developed countries. UNESCO's World Culture Report (2000). Second, his claim that entertainment content fostered consumerism is supported by numerous other studies, and we'll return to this. See chapter 5, "The Globalization of
} 
In parallel to cultural imperialism, there were a considerable number of empirical investigations into the question of cross-cultural impact of foreign television. Michel Elasmar and John Hunter (1997) reviewed this literature and counted 177 studies conducted between 1960 and 1995, including unpublished Master's theses and Doctoral dissertations (7 examples), conference papers, and published primary investigations or secondary analyses and commentaries. What is startling (as mentioned above) is that a bibliography from one article often contains no references to articles from the other strand: never shall the political economy or psychological-behavioural strands meet. For their meta-analysis, Elasmar and Hunter sorted through the corpus to determine that only 27 studies could be directly compared, because they adopted an explicit theoretical approach and worked within an experimental methodology that used similar independent and dependent variables. The independent variable was the amount of exposure to foreign television, and the dependent variable was change in knowledge (for 2 studies), beliefs (for 11 studies), attitudes (for 6 studies), behaviour (for 2 studies), or values (for 7 studies). The following paragraphs will detail several of the more rigourous studies and will conclude with lessons that can be drawn from them collectively. ${ }^{26}$

The empirical studies on the 1960s and 1970s should be considered quasi-natural experiments. They took advantage of the introduction of broadcasting systems, and American content, and they were designed to detect change in a dependent variable such as values, attitudes, opinion, and behaviour based on the presence, absence, or level of exposure to American programming, the independent variable. The cases that follow approximate a lab setting, with a control group (that didn't have TV) and a treatment group (that did have TV). ${ }^{27}$

Commmunication" (pp. 149 - 178) in John Thompson (1995) Media and Modernity, Stanford, CA: Stanford UP for an outstanding dissection of Schiller's idea.

${ }^{26}$ See Michel Elasmar \& John Hunter (1997), op cit. note \#20, for criteria and details of the sorting process. Of particular interest, they note an increase in the distribution varying according to time: two studies in the 1960s, five in the 1970s, eighteen in the 1980s; they also note, on p. 54, the distribution of theoretical frameworks: cultivation theory as the most prevalent, cultural imperialism second, acculturation third, socialization fourth, dependency fifth, modernization sixth, and social learning seventh. Fully one-quarter of empirical studies did not identify the primary theory from which they derived their hypotheses (p. 54).

${ }^{27}$ See Michel Elasmar \& John Hunter (1997), op cit. note \#20, for description of these studies as natural experiments. 
Payne and Peake's (1977) study in Iceland is an excellent example of a type of quasinatural experiment. They examined attitude change among urban adolescents (aged 11-14) in three cities, chosen because of the availability or absence of U.S. TV programming. The object of analysis was three attitudes: Icelandic attitudes toward U.S.; Icelandic level of knowledge about U.S. current affairs; and whether U.S. attitudes, as portrayed on television, would replace Icelandic beliefs. Attitudes and perceptions of change were obtained by participant self-report and experimenter interview, and four measures were used: city of residence (which established TV or no TV availability), length of TV ownership, self-report on viewing duration and program choices, and self-report on message impact. Exposure to U.S. programming didn't make Icelanders want to emigrate to the U.S., nor did U.S. programming impart any statistically significant increase in Icelander knowledge about American politics. Immediately after the study, in 1968, Icelandic programming commenced, and this domestic content proved to be more popular than U.S. programming. Payne and Peake concluded "that these data provide no real evidence for the cultural imperialism hypothesis and specifically that part which says that TV acts to transfer foreign political information" $(529) .{ }^{28}$

There are alternative, opposite hypotheses about cross-cultural influence. The first hypothesis holds that a starting point of greater cultural difference equals greater insulation and, so, permits less change. The second holds that greater cultural difference associates with greater potential for change. Cross-cultural experiments were conducted in first-category instances, such as Iceland, Philippines, and Korea, and in second-category instances, such as Canada. Perhaps not surprisingly, the effect of U.S. TV on Canada is the most frequent pair chosen, with 9 studies in total ( 4 on Canadian indigenous populations, 5 on Canadian non-indigenous). The second-

\footnotetext{
${ }^{28}$ David Payne \& Christy Peake (1977). "Cultural Diffusion: The Role of U.S. TV in Iceland" Journalism Quarierly (54): 523-531. See pp. 524-526 for design and 530-531 for conclusions. The three cities from which subjects were drawn: Akureyi (control - no TV), Reykjavik (treatment - TV), and Vestmannaeyjar (control). Researchers concluded that there was no imparting of knowledge of U.S. events because there was no difference between control and treatment groups over recognition of, for example, President Richard Nixon and Premier Ho Chi Ming, each prominent in the news of 1968. Subjects recognized them as much as the British Prime Minister, Danish Prime Minister, and West German Chancellor.
} 
most studied culture is Korea, with 4, and Japan is the third-most, with $3 .^{29}$

Sparkes (1977) used a mail survey of Canadian (in Kingston, Ontario) and American (in Potsdam, New York) residents to assess different attitudes and TV preferences of viewers who watched programming of both countries. Canadians did tune in to American programming disproportionately higher to watch entertainment, but they preferred their own news programs. Heavy-watching Canadians had greater knowledge about U.S. current affairs; likewise, these viewers were more concerned about U.S. cultural influence. American viewers in this study didn't watch enough Canadian TV for the researcher to draw valid conclusions. Sparkes concluded that a third variable, education, likely signaled the proper association. For example, although heavy-viewing Canadians had more knowledge about U.S. current affairs, education level correlated positively with high viewing (and reliance on different media in general), so it is reasonable that U.S. current-affairs knowledge is a function of education, with American TV programming as a means to this end. Likewise, education may be the operative variable to explain increased concerns over American influence. Sparkes concluded that there is "very little or no effect on attitude difference associated with exposure to foreign TV" (46). Sparkes hypothesized that the greater the cultural difference, the greater the potential for negative impact; however, the greater the difference, the less chance viewers will watch due to selective exposure. The gulf of cultural difference translates into less identification and interest, which will disincline viewership. While the potential for change exists, viewers disinclination to watch will mitigate against change. ${ }^{30}$

Canada-U.S. cross-national comparisons, as mentioned, are the most common pairing. David Payne (1978) examined the road less travelled, the influence of Canadian TV on American residents. In a well-designed experiment subject to sophisticated statistical analysis, Payne assessed a range of cognitive and attitudinal variables in three towns in Northern Minnesota: one having both U.S. and Canadian television; one having only U.S. television; and one having only

${ }^{29}$ See Michel Elasmar \& John Hunter (1997), p. 55., op cit. note \#20, for breakdown of country and culture studied and contending hypotheses. 27(4): $40-47$.

${ }^{30}$ Vernon Sparkes (1977). "TV Across the Canadian Border: Does it Matter?" Journal of Communication 
Canadian television. U.S. viewers of Canadian television knew more about Canada than their U.S.-TV only counterparts, yet these same viewers didn't score lower on domestic knowledge, current affairs, or cultural questions. These same U.S. viewers of Canadian television did display markedly less favourable attitudes toward Canada than their U.S.-TV only counterparts. Placing his study within similar efforts, Payne concluded from the former finding that foreign content can and does have an additive knowledge or information effect but not a subtractive effect. The latter portion is significant because it detracts from claims that watching foreign content will reduce national identity. He argued that knowledge addition is easy given circumstances of low previous knowledge. He argued that the lack of subtractive effect is explained because other agents of socialization serve as alternative knowledge sources. For his experiment, Americans who didn't have U.S. TV access simply received their American news and other information from alternative sources, which were readily available. The findings are consistent with other research that suggests cognitive effects are stronger than attitudinal effects: it is easier to change information than to change attitudes. ${ }^{31}$

Speculation over the role of cultural difference as either an insulator or a liability was tested in other Canada-U.S. studies. Two different studies, one by Coldevin (1985) and one by Granzberg (1985), examined the effect the introduction of satellite TV had on Canadian Cree, Algonquin, and Inuit peoples. Unlike studies that sample from one point in time, Granzberg stands out because the investigation was conducted over eight years, using anthropologists who resided in their communities for between six to twenty weeks. The group that received satellite TV had changes to report: children became more aggressive and modeled their behaviour after Euro-Americans and -Canadians; and routine chores and outdoor activities were disrupted. But, over time, behaviours and routines returned to near pre-satellite TV levels, presumably reflecting the wearing off of the novelty and temporary disruption caused by satellite TV. This cultural

\footnotetext{
${ }^{31}$ David Payne (1978) "Cross-National Diffusion: The Effects of Canadian TV on Rural Minnesota Viewers" American Sociological Review 43 (October): 740-756. Details of design and method on pp. 740-746. It is noteworthy that he used 24 different variables to control for outcomes, including Canadian relatives, vacation history into Canada, consumption of Canadian radio, magazines, and novels to name five. His study would likely be one of the more rigourous of the experimental variety. Also of note, he cautions against grouping results from the three different kinds of TV diffusion studies together: intra-national, cross-national on developing countries, and cross-national on developmentally similar countries are not generalizable.
} 
abrasion lends qualified support to the claim that greater change is possible due to greater cultural difference. ${ }^{32}$

Moving from earlier studies in the 1960s and 1970s to contemporary analyses, Duane Varan studied the introduction of broadcasting and American programming into the Cook Islands in the early 1990s. The Cook Islands lie in the vast expanse of the South Pacific Ocean: a flight from Auckland to Los Angeles would fly directly overhead. Using ethnographic techniques, field surveys, focussed interviews, he researched how people in two different villages responded to the phasing in of U.S. TV, in 1991, when neither group had television; in 1993, when one had television; and in 1995, when both had television. Following the introduction of television, attendance at church and community groups dropped 50\%; however the pre-television habits, routines, and balance between indoor and outdoor pursuits returned. There was no detectable change in attitudes, beliefs, or values associated with Cook Islanders; for example, respect for the elderly remained constant. Cook Islanders became more reliant on consumer goods to fill needs and requirements in their daily life, and they sought the particular items and brands that appeared in television advertisements. Although Coca-Cola didn't distribute the so-called buddy bottle (with the classic hour-glass shape) prior to American TV, soon after they saw the ads, Cook Islanders insisted on them. Cook Islanders also insisted on a farm food not previously used, but one used in New Zealand. The overall results are consistent with Herbert Schiller's claim that the effect will be an adoption of an increased consumer outlook and behaviour, one that reflects the idea that products are an essential part of daily living. ${ }^{33}$

What are the accumulated findings of this experimental cross-cultural research? First, that

${ }^{32}$ This paragraph overview comes from several studies. G.O. Coldevin (1979) "Satellite Television and Cultural Replacement Among Canadian Eskimos: Adults and Adolescents Compared" Communication Research (6): 115-134; G.O. Coldevin et al. (1985) "Effects of a Decade of Satellite Television in the Canadian Arctic: EuroCanadian and Inuit Adolescents Compared" Journal of Cross-Cultural Psychology (16): 329-354; G. Granzberg et al. (1977) "New Magic for Old: TV in Cree Culture" Journal of Communication 27(4): 154-158; G. Granzberg (1982) "Television as Storyteller: The Algonquin Indians of Central Canada" Journal of Communication 32(1): 43 52; G. Granzberg (1985) "Television and Self-Concept Formation in Developing Areas: The Central Canadian Algonquin Experience" Journal of Cross-Cultural Psychology (16): 313-328. Characterization of this process as "cultural abrasion" comes from Duane Varan (1998), op cit. note \#20.

${ }^{33}$ Duane Varan (1998), op cit. note $\# 20$, for design, method, findings, and conclusion of his research. This article summarizes his Ph.D. dissertation, "The Costs and Benefits of Television: Applying the Emerging Paradigms of Development Communication to the Cook Islands Experience," U Texas (Austin), 1992. 
exposure to foreign TV increases the desire for foreign products, as measured by purchases before and after the introduction of television and specific advertisements. This finding was documented in the largest number of studies, including those using different theoretical frameworks and methodology. Second, that exposure to foreign TV has a very small effect on domestic values, attitudes, or behaviours. Different studies investigated different domains after all, behavioural change is different from attitudinal change, and attitudinal change in one area is different from change in another area, and attitudinal change is different from cognitive change. Findings suggest that peripheral attitudes, those concerned with fashion or music preferences, are most susceptible. What might be called core values are less so. To the extent that peripheral attitudes are related to a rise in consumerism, the second finding may be thought of as an extension of the first. Third, greater cultural distance translates into greater potential for observable change. Best seen in Granzberg, Coldevin, and Varan, the introduction of American TV impacts traditional cultures. The nature of the impact is not to uniformly hasten the extinction of the traditional culture; rather, it precipitates change in consumer behaviour and fosters the idea that material goods will fill a need or solve a problem. ${ }^{34}$

With the philosophical upheavals on the 1970s came a new approach to the study of cross-cultural effects. Ethnography emerged and soon eclipsed the quantitative, behavioural tradition rooted in psychology and sociology that measured attitude change. Ethnography emphasized the qualitative dimension, the interpretative description of experience, and drew its method from anthropology and concepts from literary analysis. As mentioned in section one, 1980, with the publication of Morley's Nationwide study and Hall's "Encoding/Decoding" article, serves as a convenient benchmark, the point in time when newer, ethnographic research

${ }^{34}$ Additional support for point one comes from Omar Oliveira (1993) "Brazilian Soaps Outshine Hollywood: Is Cultural Imperialism Fading Out?" in K. Nordenstreng and H. Schiller, (Eds.), Beyond National Sovereignty (pp. 116-131), Norwood, NJ: Ablex; Schiller (1991) Mass Communications and American Empire, Boulder, CO: Westview; and M. Elasmar \& J. Hunter (1997), op cite. note \#20. Elasmar \& Hunter (1997) also conclude in favour of point two, as does V. Sparkes (1977), op cit. note \#30; and D. Payne \& C. Peake (1977), op cit. note \#28; and D. Payne (1978) "Cross-National Diffusion: The Effects of Canadian TV on Rural Minnesota Viewers" American Sociological Review (43): 740-756. Support for point three comes from Varan (1992), op cit. note \#20; and Granzberg (1985) and Coldevin (1985), both op cit. note \#32. 
overtook the behavioural, quantitative studies. ${ }^{35}$

The American prime-time drama Dallas appeared in 1978, roughly coinciding with the new approach to the study of cross-cultural influence, and its phenomenal export success engendered a dozen studies. Domestic cultural reception of Dallas was studied in Algeria, Brazil, Canada, Denmark, Germany, Israel, Japan, Morroco, the United Kingdom, and the United States. After completing reception studies of Dallas in six communities, Tamar Liebes and Elihu Katz published Export of Meaning (1990). ${ }^{36}$

The design and methodology of ethnography incorporated qualitative understanding along with quantitative measurement. Units of analysis for quantitative approach were typically incidents of violence or the number of ethnic people portrayed as heroes or villains, while the units of analysis for the qualitative approach were descriptions of character motivations or plot summaries. Because character, plot, or thematic assessments don't conform to numerical indices, these aren't truly units of analysis, which is why they're qualitative measures. Liebes and Katz employed a multi-method approach: first, a background questionnaire; second, a focus-group interview to ascertain how the group arrived at a consensus meaning; and third, explanation of interpretation according to concepts and knowledge from literary theory, linguistics, and social psychology. ${ }^{37}$

The viewing sample consisted of six groups: Russians emigres in Israel; Arabs emigres in Israel; Morrocan Jews living in Israel; $2^{\text {nd }}$-generation Jews living in Israel; Anglo-Americans living in Los Angeles; and Japanese living in Tokyo. The sample varied along ethnic lines, instead of age, education, gender, or other socio-economic variables, because the objective was to establish cultural difference. The background questionnaire, part one of the method, helped

\footnotetext{
${ }^{35}$ See Geertz (1980), op cit. note \#11, for support of the rise of ethnography and the fall of quantitative approaches. See Giddens (1979), op cit. note \#11, for support of transition in philosophy that precipitated interpretativism.

${ }^{36}$ M. Tracey (1985), op cit. note \#23, for Dallas's 1978 introduction. Cross-cultural reception studies of Dallas listed in bibliography of T. Liebes \& E. Katz (1990) Export of Meaning, New York: Oxford UP. A revised edition was published in 1993. Ien Ang also produced a book-length interpretation of the cross-cultural consequences (1985) Watching Dallas, London: Methuen.

${ }^{37}$ See chapter 3, "The Research Design" (pp. 20-33) for details and rationale for each aspect of the study.
} 
control for homogeneity within each sample group. Each group watched an episode as a group and afterward was subjected to a focus-group interview, organized around specific questions, afterward.

Liebes and Katz drew on numerous literary, linguistic, and social psychological concepts to understand the process of interpretation and meaning construction. They categorized the style of narrative re-telling as linear, segmented, or thematic, depending respectively on whether the group emphasized story line and plot (linear), character assessments and motivations (segmented), or governing ideas and themes (thematic). They categorized the groups' position toward the episode and characters as referential or critical: coming from Roman Jakobson, referential assumed the show to deal with reality, while critical assumed the show was fictional, governed by aesthetic rules. They further categorized group responses social psychologically, as typifying identification, para-social interaction, and the expression of latent opinion. The socalled "pattern of involvement" emerged from the cumulative result of each mode of interpretation. This sophisticated and nuanced explanatory concept begins to lay down concrete hermeneutic reference points, landmarks laid down on terra incognita, on the void left by simply declaring a reading open and an audience active. ${ }^{38}$

They found marked differences between the six groups' patterns of involvement. The traditional groups tended to read referentially and morally, while Americans and Russian emigres tended to read critically. The Americans emphasized plot, character, theme, and were aware that the show was a fictional construct, but did not question producer motivations or any indoctrinating consequences. The Russians were suspicious of producer motivations and wary of Dallas as propaganda. They employed their often formidable literary analytic skills to unmask ideology. Two traditional groups (Arabs and Morrocan Jews) told the story in linear form and emphasized kin relations as the motive force, while Americans emphasized individual

\footnotetext{
${ }^{38}$ Narrative re-telling schema is adopted from Roland Barthes (1975) S/Z, NY: Hill \& Wang. Katz \& Liebes defend applicability on pages 33 and 39 . Referential and critical orientations are adapted from Jakobson (1972) Linguistics and Poetics. In Richard DeGeorge \& Fernande DeGeorge (Eds.), The Structuralists: From Marx to Levi-Strauss, NY: Anchor for linguistic and meta-linguistic frames. The social-psychological contributions are defended on pages 33-34. The patterns of involvement concept received its first formal articulation in T. Liebes \& E. Katz (1986) "Patterns of Involvement in Television Fiction: A Comparative Analysis" European Journal of Communication 1(2): 151-172.
} 
motivations and non-family inter-personal dynamics as central to any larger explanation. Liebes and Katz made an interesting observation in terms of the group's narrative re-telling. "While there is little variation among the ethnic communities in the subjects of the referential statements, there is substantial difference in their formulations" (103). Each group described similar plot and character developments, but they differed over motivations, understanding of meanings and significance of events and actions. This closely parallels Celeste Condit's description (1989) of polyvalence, which "occurs when audience members share understandings of the denotations of a text but disagree about the valuation of those denotations to such a degree that they produce notably different interpretations" (106). In each case, there is agreement over basic elements but disagreement, differing interpretations, over judgements about the content. From these findings, they concluded that readings were highly subject to cultural conditioning. In their case, ethnic difference was tantamount to cultural difference. ${ }^{39}$

It is important to highlight that the above findings indicate cross-cultural differences in interpretation, not cross-cultural impact. Referring collectively to all the studies, Biltereyst (1991) states that "Dallas has not been received slavishly, but rather in strongly divergent and culturally determined ways" (471). The relationship between decoded meanings, different interpretations, and cultural impact is uncertain. Biltereyst contends that it is reasonable to view patterns of involvement linked to potential impact, because the greater and more intricate the involvement the greater the dependence. We're obliged to be cautious about impact because the mechanism of impact is likely to be as complex, indeterminate, and unpredictable as the process of interpretation. In a case study involving Flemish Belgian residents interpretations of American and local programming, Biltereyst's findings were consistent with the idea of patterns of involvement. The Belgian audience preferred U.S. content for entertainment purposes, and identified higher production values and unified stories as the reasons, while they recognized that domestic programming provided a forum for them to consider their identity and other existential

${ }^{39}$ Findings come from chapters 5, 7, and 8. Second quote from Celeste Condit (1989) “The Rhetorical Limits of Polysemy" Critical Studies in Mass Communication 6(2): 103-122. 
themes. ${ }^{40}$

What can be summarized about the cross-cultural effect of foreign content?

While the cumulative literature that addresses cultural influence is large, oddly enough, however, the radical political economy approach often sidesteps the direct question of influence. Elasmar and Hunter write: "Although large bodies of literature have been written about various aspects of international communication, few authors have directly addressed this issue of crossborder TV impact" (47). A second striking observation is how deaf each school of thought is to the other: perusing an article bibliography from cultural imperialism will likely contain no references to any empirical studies, either psychological or ethnographic. And after all of the energy expended in pursuit of cross-cultural effects, by political economists, psychologists, and media ethnographers, there has been precious little definitive evidence of direct cultural impact to show. Michael Tracey wrote (1985) "[i]n the heart of darkness, which is the image offered by the many views of the adverse consequences of imported television, there is a vacuum: an absence of evidence and good theory" (38). ${ }^{41}$

Contrary to the paucity of striking revelations, my review has demonstrated several things. First, recent media ethnographies tend to reinforce early experimental psychological approaches. In particular, knowledge acquisition is found in, for example, Payne \& Peake's study in Iceland as much as Liebes \& Katz's reception study of Dallas, and cognitive and affective selectivity in the former is similar to polyvalence in the latter. Also, the greater the cultural distance for Varan's Cook Islanders or Granzberg's Canadian Aboriginals study is similar to Liebes \& Katz's for Russian Jews or Arabs: in each case, the greater the cultural distance between foreign and receiving cultures, the more noticeable was the impact. Often the psychological and ethnographic studies report corresponding results using a different set of concepts, measurements, and in a different vocabulary. Second, all three approaches tend to find

${ }^{40}$ Daniel Biltereyst (1991) "Resisting American Hegemony: A Comparative Analysis of the Reception of Domestic and US Fiction" European Journal of Communication (6): 469-497.

${ }^{41}$ M. Elasmar \& J. Hunter (1997), op cit. note \#20; M. Tracey (1985), op cit. note \#23. For a convenient list of the empirical studies of cross-cultural influence, 37 in all, see Elasmar \& Hunter bibliography, pp. 66-69. They have indicated by asterisk those sources they subjected to meta-analytic assessment. The list of 37 provide an excellent overview of the subject matter, countries studied, and year of study. 
that increased viewing of foreign content leads to increased consumerism. Radical political economy, and empirical psychological and media ethnographies all found that the introduction of American TV programming prompted locals to desire goods they hadn't wanted before, encouraged them to insist on specific products that were alien to their culture, and in general fostered the idea that needs should be satisfied materially. Within this consensus, the empirical work found that after the initial disruption, local routines, including purchasing preferences and consumer philosophies, tended to return to pre-introduction levels. The political economy studies don't report this re-adjustment and instead emphasize only the long-term disruption. Third, despite the persuasive refutation of cultural imperialism, the residue of the idea pervades the general discussion of cultural influence and cultural globalization. This is a curious artifact, probably attributable to how (as mentioned on page 125), directly perceived and experienced certain content or symbols are, despite evidence of how consequential this thin layer of global culture might be, an instance of stark difference between perception and reality.

At a more specific level, the idea of effects needs to be carefully delimited. Cognitive effects are different from behavioural effects, which are different from attitudinal effects, which are different from changes in beliefs. A common finding in results presented here was that there were cognitive effects (viewers gained knowledge, of politics, or geography, and so forth) or behavioural effects (viewers altered habits of indoor-outdoor activities, or decreased church or community-group attendance) but no attitudinal effects (viewers didn't view the U.S. or their own country more or less favourably). Based on this type of evidence, it is reasonable to believe that foreign content may alter preferences for clothes, music, and other goods and preferences what Varan calls "peripheral attitudes" - but likely won't alter core beliefs or attitudes. When a commentator asserts change or influence, it behooves her to specify the precise nature and limit of the effect. ${ }^{42}$

There are several essential distinctions that need to be made when trying to establish a position, even a provisional one, on cross-cultural effects. Finding zero effect is different from

\footnotetext{
${ }^{42}$ David Payne (1978), op cit. note \#31, pp. 741-744, for contention to separate different types of effect. Duane Varan (1978), op cit. note \#20, also for conclusion that effects need to be separated on basis of his research findings.
} 
finding negligible effect, which is different again from finding minimal effect. And after a critical mass of studies, there is another important difference between concluding no effect and concluding that not enough is yet known to assert either way. Although reviews, like Michael Salwen (1991), Joseph Straubhaar (1991), Sinclair, Jacka, and Cunningham (1996), Budd, Entman, and Steinman (1990), as well as older ones like Browne (1967) and Beltran (1978) confidently conclude for zero effect, I believe caution and reasonable doubt militate against these claims. I believe a more defensible position is that effects are minimal to negligible, subject to a reciprocal or circular influence to be discussed in the following paragraph. A second essential distinction, also seldom made, is between the process of interpretation and the process of influence or effect. To say someone has a differing interpretation, has received the content differently, isn't to say necessarily anything about influence or effect. The tacit direction of thinking in conjunction with interpretative analysis has been to conclude in favour of no influence or effect solely on the basis of variable (oppositional or alternative) interpretation. In the previous generation, research has made progress on interpretative processes, moving from a conception of preferred or monolithic meaning to received and constructed meaning. With hope, the next step taken will be to further penetrate the process of influence and effect. ${ }^{43}$

Any scholarly analysis of cross-cultural influence of entertainment content will inevitably end up trying to pinpoint influence precisely within a dynamic reciprocal or circular process. Many studies stress that content affects culture at the same time as culture affects content - in terms of how cultural norms condition an interpretation. McAnany (1986), Salomon (1985), Selwin (1991), Williams (1974), Kellner (1995), Land (1995), Roach (1997), Stabile (1995), Biltereyst (1991), and Liebes \& Katz (1990) all conclude for the reciprocal relationship between

\footnotetext{
${ }^{43}$ Full citation for Salwen (1991), op cit. note \#23. Joseph Straubhaar (1991) "Beyond Media Imperialism: Asymmetrical Interdependence and Cultural Proximity" Critical Studies in Mass Communication (8): 39-59; J. Sinclair, E. Jacka, and S. Cunningham (1996) "Peripheral Vision" in same authors (Eds.), New Patterns in Global Television (pp. 1-32), New York: Oxford UP; M. Budd, R. Entman, and C. Steinman (1990) "The Affirmative Character of U.S. Cultural Studies" Critical Studies in Mass Communication (7): 169-184; L.R. Beltran (1978) "TV Etchings in the Minds of Latin Americans: Conservatism, Materialism, and Conformism" Gazette 24(1): 61-85; D. R. Browne (1967) "Problems in International Television" Journal of Communication 17(3): 198-210. A further observation on the second distinction is interesting to ponder. Often, the appearance or availability and not the influence or effect provokes backlash against American content. The availability of MTV or Hollywood movies provokes claims of irreversible cultural loss in so-called traditional societies more than any demonstrated effects these products actually have.
} 
outside influence and inside interpretation or resistance. Gavriel Salomon (1985), in his article entitled "The Study of Television in a Cross-Cultural Context," spells out this circularity as firstand second-order interactions. The first order is how a person is influenced by TV, its images, messages, plots, lessons, and portrayals. The second is how the person's pre-conceived and culturally conceived attitudes, notions, experiences, and opinions lead her or him to filter the message. Trying to assign one side the upper hand, to locate the true locus of influence, is bound to result in a maddening roundabout, a chicken and egg exercise. Consistent with the results presented in section one, I believe that the different paths of socialization, the constructed nature of meaning, and different reasons to seek content all support concluding in favour of minimal effects or influence. One's framework of interpretation is ultimately culturally conceived. John Thompson (1995) stresses "the process of appropriation remains inherently contextual and hermeneutic," and "[t]he appropriation of media products is always a localized phenomenon, in the sense that it always involves specific individuals who are situated in particular socialhistorical contexts" (174). Place and culture matter for interpreting foreign entertainment content, and like morning fog, limited effects tend to burn off with time. ${ }^{44}$

\footnotetext{
${ }^{44}$ Several of the full citations can be found in the previous footnote. The others are E. McAnany (1986) "Cultural Industries in International Perspectives: Convergence or Conflict" In Brenda Dervin \& Melvin Voigt (Eds.), Progress in Communication Sciences, vol. 7 (pp. 1-30), Norwood, NJ: Ablex; Gavriel Salomon (1985) "The Study of Television in a Cross-Cultural Context" Journal of Cross-Cultural Psychology 16(3): 381-397; Raymond Williams (1974) Television: Technology and Cultural Form, NY: Schocken; Douglas Kellner (1995) "Media Communications vs. Cultural Studies: Overcoming the Divide" Communication Theory 5(2): 162-177; F.M. Land (1995) "Reggae, Resistance, and the State: Television and Popular Music in the Cote d'Ivoire" Critical Studies in Mass Communication 12: 438-454; C. Roach (1997), op cit. note \#23; Carol A. Stabile (1995) "Resistance, Recuperation, and Reflexivity: The Limits of a Paradigm" Critical Studies in Mass Communication 12: 403-422; Biltereyst (1991), op cit. note \#40. John Thompson (1995), op cit. note \#25.
} 


\section{Chapter Five:}

\section{Formidable Limits: Perspectives on National Identity and Culture}

"[A 'nation':] We know what it is when you do not ask us, but we cannot very quickly explain or define it." Walter Bagehot (1887)

Chapter five examines the concepts of national identity and culture. Chapter four reviewed the extensive research record on effects and influence, including specifically crosscultural effect, and this chapter extends that discussion by vividly portraying the extraordinary challenge "national identity" and "culture" present when one tries to argue for benefits to these categories as a result of policy. "Influence" is preponderantly difficult to locate because socialization proceeds through numerous pathways that often cross-influence each other. Influence on national identity and culture is even more difficult to show because of philosophical, definitional, and evidentiary problems inherent in these concepts. This chapter presents competing perspectives on national identity, then presents advances in the understanding of culture in order to determine what can, ultimately, be defensibly said about each. It is more important to incisively understand the weakness about these categories of thought, since one objective of this chapter is to demonstrate the inherent instability and tenuousness of rationale for policy design and outcomes intended to benefit culture and national identity. As will be seen, there is no final word, or definitive encapsulation, for either.

\section{I.}

National identity is a wider phenomenon out of which nationalism emerges as an ideological movement. As fields of literature, national identity and nationalism are largely coextensive. Although there were examples of attempts to theorize national identity in the $19^{\text {th }}$ and early $20^{\text {th }}$ Century, the field began growing rapidly in the 1950s and 1960s, with the period of African and Asian de-colonialism, and the field has grown explosively in the 1980s and 1990s, coinciding with the fall of the Berlin Wall, dissolution of the Soviet Union, and the proliferation of virulent ethnic nationalisms. Anthony D. Smith, the pre-eminent theorist of nationalism, claims that it is now "impossible to keep abreast of the tide of publications in the field" (xi). 
Regrettably, conceptual development has not kept pace with the rapid increase in publications. ${ }^{1}$

Theories and descriptive accounts alike turn on basic questions, which need to be kept in mind as the chapter proceeds to review competing perspectives. One question is whether nations are ancient (or medieval) or modern? This pits "modernists" versus "perennialists". The modern view holds nations as products of one or more processes that include the Reformation, French Revolution, capitalism, industrialization, and technological advances, specifically the printing press. The perennial view, in contrast, holds nations as ancient, extending back to time immemorial and rooted in an ethnicity, if not ancestry or pedigree. The second over-arching question concerns the nature of ethnicity and pits "instrumentalists" versus "primordialists". The instrumental view holds that humans have always lived and worked in a range of groups, and as a result people have a variety of collective identities, including ethnic identity. The primordialist view sees ethnic identity as inalienable, much as we have speech, sight, or smell. For this school of thought, ethnic communities are natural or organic: nations and ethnic communities are indistinguishable. The first section of this chapter presents different perspectives on national identity and the two questions of cardinal importance. The section first reviews an older perspective entitled classical modernism, then accounts for the shift to newer perspectives, before detailing several answers to the question, What is national identity? ${ }^{2}$

Each of the contemporary variants that will be reviewed seeks to answer theoretical deficiencies of the classical modern paradigm, or incorporate philosophical insight that was not

\footnotetext{
${ }^{1}$ See Anthony Smith (2002) National Identity, Reno, NV.: U Nevada P for relationship between national identity and nationalism, p. vii. Quotation from Anthony Smith (1998) Nationalism and Modernism: A Critical Survey of Recent Theories of Nations and Nationalism, London: Routledge. See Smith's (1971) Theories of Nationalism for a book-length review of perspectives prevalent in the 1950s and 1960s. These two books can be read as companion volumes for a comprehensive account of the development of theories of nationalism throughout the $20^{\text {th }}$ Century. Alternatively, Smith (1998), chapter 1, distills the earlier book and earlier period. Eric Hobsbawm (1990) Nations and Nationalism Since 1780: Programme, Myth, Reality, Cambridge, Cambridge UP, regards Anthony Smith as "the main guide in the field for readers of the English language" (2). Hobsbawm states the while the field grew in publication volume during the 1950s-60s, it wasn't until the 1970s that significant theoretical advances were made (3-4).

${ }^{2}$ Distinction on the question over nations and ethnicity comes from (again) Anthony Smith (1995) Nations and Nationalism in a Global Era, London: Polity. Specifically, explanation of modern and perennial approaches comes from pp. 4-6, 29-30, 35-48, 52-54 while explanation of instrumental and primordial approaches come from 30-35, 39-40. Note that Smith himself, in different publications, replaces "instrumentalist" with "situationalist." The technical difference in terms is less important than its general meaning as a contrastive concept to "primordialist".
} 
available during that previous era. Smith (1998) summarizes the classical modern perspective as "the idea that nations are real entities, grounded in history and social life, that they are homogenous and united, that they represent the major social and political actors in the modern world" (2). Furthermore, "this conception of nations and nationalism [and national identity] is intrinsic to the nature of the modern world and to the revolution of modernity" (4). Early examples include Lord Acton's (1862) essay entitled "Nationality," Ernest Renan's (1882) lecture, Qu'est-ce qu'une Nation?, and Walter Bagehot's (1887) Physics and Politics. These scholars and statesmen reacted to the history that was unfolding around them, the nation-building of the long $19^{\text {th }}$ century. Germany, Italy, and Hungary were consolidating federal governments, and more generally, democracy was replacing aristocracy unevenly throughout Western and Central Europe, a trend that quickened as a result of World War I. The classical modern perspective achieved canonization when many leading European historians, writing between the World Wars, sought to explain, describe, or predict the course of nationalist projects. The perspective retained its pre-eminence because although canonized by European thinkers, it was embraced by a generation of mainly American political scientists in the 1950 s who were concerned with elements required for democratic nation-building and for identifying and isolating the key features of Western political culture. By the late 1960s, fissures in the paradigm had appeared, as a result of changes in meta-theory, the philosophical acceptance of the constructed nature of the social domain, which created irreconcilable difficulty for maintaining the "homogenous, united,...and intrinsic" propositions about national existence. ${ }^{3}$

Unlike the pre-1970 period, when there was relative agreement over the classical modern understanding of nationalism, several new perspectives distinguished themselves after 1970 . Ernest Gellner (1983) expounded a sociocultural perspective that linked nationalism to industrial society. The migration from rural to urban societies, from traditional to modern living, posed the most disruptive aspect of industrialization, with people experiencing the anomie and

\footnotetext{
${ }^{3}$ Characterization of the classical modern perspective comes from Smith (1998), op cit. note \#1, pp. 2-4 and 8-24 (chapter 1). As mentioned, Smith (1971), op cit. note \#1, details this perspective, including the prevailing formulation during the 1950s and 1960s. The European historians who participated in the canonization include Carleton Hayes, Hans Khon, Frederick Hertz, Alfred Cobban, E.H. Carr, Louis Snyder, and Boyd Shafer (list from Smith [1998], p. 16). The post-World War II American political scientists include Gabriel Almond, Richard Bendix, Karl Deutsch, Shmuel Eisenstadt, Daniel Lerner, Lucian Pye, and Sidney Verba (from Smith [1998], p. 20).
} 
disorientation described by classical sociological theory. To offset this insecurity, a common language and culture replaced the traditional family and small-society relations as focal points for commonality. The state played an instrumental role, fostering this cohesion first through literacy of a national language and, second, through a national education curriculum. The resultant nationalism homogenized and co-ordinated difference, which was essential for industrial-scale production. For Gellner, then, nationalism in the industrial and modern era replaces the identity function of family relationships of the pre-industrial era; but serves more than intrinsic identity purposes, serving also the instrumental purpose of nation-building through industrial development. His central proposition remains that nationalism was logically contingent but sociologically necessary for the successful functioning of modern society. Nationalism existed prior to nations, and was the sine qua non that bound them together. He also held that nationalism was a political principle whereby legitimacy was achieved when political and national units were congruent and existed within co-extensive territory. National identity, then, is derived from the satisfaction or frustration of this condition being fulfilled or unfulfilled. ${ }^{4}$

The second perspective on national identity is socio-economic, because it accounts for the rise and spread of nations and nationalism from the social consequences of capitalism, or more generally, from economic motivations and economic change. Tom Nairn (1977) propounds a Marxist explanation, while Michael Hechter $(1975,1987)$ adopts a rational choice model. Nairn considers nationalism the most ideal and subjective of all ideological phenomena, then argues that it's the uneven development resulting from capitalism that catalyzes national sentiment. Nationalist motivation derives from the inequitable distributional consequences between center and periphery, supplemented by class consequences of uneven distribution, where the upper

\footnotetext{
${ }^{4}$ The philosophical shift was indicated on pp. 120-21, under the epistemological change from foundationalism to coherentism and ontological change from realism to mentalism. Gellner straddles the 1970 transition. "Early" Gellner is represented by (1964) Thought and Change, London: Weidenfeld \& Nicolson, while "latter" Gellner is found in (1983) Nations and Nationalism, Oxford: Blackwell. Anthony Smith (1998) Nationalism and Modernism, London: Routledge, maintains that his theories retain their irreducible core reliance on the transition from traditional to modern societies as the engine for nationalism, and industrialization as principle around which nationalism is organized. See Smith, chapter 2. Robert Skidelsky (2003) "The Mystery of Growth" New York Review of Books, March 13, pp. 28-31 incisively criticizes the logic that nationalism organized industrial and economic growth: "Why should nationalism make people more systematically frugal, or for that matter, enterprising, as opposed to more systematically warlike?" (29).
} 
class, with the assistance of the intelligentsia, seek to inculcate a romantic and popular nationalism as a balm against awareness of material deprivation and unfairness. This is a thinly veiled false consciousness argument. Replacing economic determinism with rational-choice individualism, Michael Hechter seeks to explain British sub-nationalisms (Scottish and Welsh) primarily with economic reasons. His description battens on the validity of shared production and consumption interests, together with the requisite communication infrastructure as the motive force for nationalism: the occurrence of these factors within a political territory that has been conquered predicts national sentiment. These socio-economic theories suffer from a number of flaws. One, economic deprivation alone isn't a valid predictor of national movements, as subnational and ethnic nationalism flourish in healthy economies just as much as depressed ones. Two, economic perspectives, especially rational choice, excludes by design beliefs and ideas as irrational as a basis for action, which is a fatal error in any theory construction of nationalism precisely because, as we have seen, nationalism is entirely subjective. Three, ethnic communities are removed from explanation, which is another fatal error in explaining the resurgent movements of the late $20^{\text {th }}$ Century. Anthony Smith (1998) critiques this omission in the overall socio-economic perspective: "only in circumstances where regional economic disparities are conjoined and coterminous with particular ethnic communities [is] there is a likelihood of a nationalist movement emerging in that region" $(54) .^{5}$

The third new perspective is political, and it is the predominant perspective on national identity, nationalism, and the nation. This modernist political perspective contains three variants, each associated with a major work. Anthony Giddens published The Nation-State and Violence (1985), while Michael Mann produced a two-volume work, The Sources of Social Power (1986 and 1993), and John Breuilly published Nationalism and the State (1983 [rev ed. 1993]). While there are major differences between each, they all have in common the view that a close connection existed between the rise of nations and the rise of modern states. They each locate the

\footnotetext{
${ }^{5}$ Tom Nairn (1977) The Break-up of Britain: Crisis and Neo-Nationalism, London: New Left Books; Michael Hechter (1975) Internal Colonialism: The Celtic Fringe in British National Development, 1536-1966, London: Routledge and Kegan Paul; and Hechter (1988) "Rational Choice Theory and the Study of Ethnic and Race Relations" in John Rex \& David Mason (Eds.), Theories of Ethnic and Race Relations (pp. 264-279), Cambridge: Cambridge UP. Smith quotation from Smith (1998), op cit. note \#1.
} 
rudimentary emergence of nations in $17^{\text {th }}$ and $18^{\text {th }}$ century European absolutism, as it developed within the Westphalian system of states. State consolidation helped to forge national identity because the centralizing process reduced differences within each state as it expanded the differences between them. Furthermore, all three have several other factors in common: that relations of domination were insured and exercised by an administrative state over a unified territory; that emergent civil society was the catalyst for nationalism; and that the process is inherently modern because the communications and bureaucratic and administrative revolutions of Modernity played a key role in nation formation. While the roots of explanation in each case see the nation and state implicated in the other's formation, the branches of each account begin to diverge. ${ }^{6}$

Giddens sees nationalism and national identity as secondary to state consolidation as it exercises administrative, territorial, and violent (both externally, for national defence, and internally, for policing) functions. In earlier forms, the state raised armies to fight wars paid for through land rents or taxes; over the course of the $18^{\text {th }}$ through $20^{\text {th }}$ century, the functions and responsibilities the state has assumed has increased dramatically. This variation views nationalism as a psychological phenomenon, but importantly what distinguishes national identity from other group loyalties is the connection to an administrative state. For Giddens, the nation legitimizes the state's activities. ${ }^{\text {? }}$

Mann emphasizes the evolution of military functions in creation of a nation and deemphasizes the administrative purview. Mann is more definitive than Giddens on the idea of nations and state sequence, believing that nations could not have preceded state formation. Mann

\footnotetext{
${ }^{6}$ Anthony Giddens (1985) Contemporary Critique of Historical Materialism: The Nation-State and Violence, Cambridge: Polity Press; Michael Mann (1986) The Sources of Social Power, vol. 1, Cambridge: Cambridge UP; and Mann (1993) vol. 2; and John Breuilly (1993) [1982] Nationalism and the State, Manchester: Manchester UP. It is no coincidence that each of these books are massive, something partly due to scope, partly due to the amount of theory and history involved. The commonalities come from Smith (1998), op cit. note \#1, pp. 7096. For the European-absolutist origins, see Charles Tilly, ed. (1975) The Formation of National States in Western Europe, Princeton, NJ: Princeton UP, p. 19.

${ }^{7}$ Giddens (1985), op cit. note \#6, for presentation of the so-called reflexive state. It is worthwhile to pause to consider the gulf of difference in state-legitimate functions that exist between Adam Smith's classic nightwatchman state of the late $18^{\text {th }}$ Century and that between any of a number of Western welfare states of the mid-20th Century.
} 
contends that cross-class allegiance is important to state formation, but in the final analysis, it is the warring aspect of states that serves to sharply demarcate territory and establish sovereignty and legitimate residency. Wars of independence or secession or self-determination become less important than wars against external enemies in galvanizing a national consciousness. ${ }^{8}$

Breuilly's formulation, according to Smith, offers "the most elaborate and comprehensive political theory of nationalism" (84). Breuilly holds that nationalism is a doctrine with three tenets. First, there exists a nation with a particular character. Second, the interests of this nation take priority over all other interests. Third, the nation must be as independent as possible, striving for complete political sovereignty. In contrast to the untestable grand-style theories of Giddens and Mann, Breuilly's tenets are closer to postulates that can be scrutinized for validity by comparison to specific historical examples. The litmus test is (a) the peculiar and particular nature of each nationalism and (b) the requirement of seeking political sovereignty. This leads, controversially, to disqualifying the American Revolution on the grounds that its guiding principles were universal, not particular; a rather weak point of disqualification. Another problem, not with an analytical outcome, but with criteria, is that his formulation doesn't admit cultural identity on the grounds of irrationality. He acknowledges a place for it only when demands for self-determination are related to special interests. ${ }^{9}$

All three political variants suffer, to greater or lesser degrees, from several flaws. First, a Western, Euro-centric bias taints them all, because although some (Breuilly's case studies) consider non-Western examples, they assume the Western, nation-to-state trajectory to be natural, the stencil used for comparison. Second, there is a reduction in definition. Nation only has conceptual status when linked to the state, which doesn't allow adequate conceptions for the

\footnotetext{
${ }^{8}$ Mann (1986) and (1993), op cit. note \#6, for elements. Smith (1998), op cit. note \#1, again provides the comparison and contrast with Giddens. Readers wishing elaboration should compare Mann (1986) to Mann (1993), as there are differences. For example, Mann (1986) said there was a precursor national identity in the late Medieval period, a view which he disavows in 1993; he also emphasizes the link between nations and class in 1993, something which is absent in 1986.

${ }^{9}$ Breuilly (1993), op cit. note \#6. Smith (1998), op cit. note \#1, summarizes his views, and inherent weakness, pp. 84-92. His dismissal of the American Revolution as illegitimate does seem weak, considering the number of particular, concrete grievances - the Intolerable Acts and non-representation - understood to have triggered it. More compelling is Breuilly's idea that nationalism is recognized post facto by the success in achieving political independence, an ends-defines-the-means approach.
} 
idea of nation as community or diaspora. Third, if nation is accorded a status independent of the state, the analyses quickly run adrift on the problem of reification. Several critics have pointed out the error and trouble with considering "nation" as a real, enduring, stable category. Foreshadowed in the chapter introduction, this philosophical problem is not easily overcome. Despite the bruises and shortcomings of the political theories, this group is beneficial to furthering our conception of national identity. They highlight the central place concepts such as citizen, equality, and legitimacy have in formation of Western, civil national identity; how the conception also requires a bounded, unified territory overseen by an administrative state; and they only gesture toward the role of the state in promoting nationality and as guardian of national culture and values. ${ }^{10}$

Together, Eric Hobsbawm's The Invention of Tradition (1983) and Benedict Anderson's Imagined Communities (1991 rev. ed) constitute a fourth perspective, a modernist one that emphasizes the constructed nature of nations and national identity. For both, nations are constructs and artifacts, from which the analyst should uncover their form and contents to reveal how elite interests benefit from the received narratives. Each approach explicitly acknowledges its Marxist origins. ${ }^{11}$

Eric Hobsbawm put forward the proposition that the key to understanding the nation, any nation, is understanding its invented traditions, especially its invented national traditions. The "invented tradition is taken to mean a set of practices, governed by...accepted rules and of a ritual or symbolic nature, which seek to inculcate certain values and norms of behaviour by repetition, which automatically implies continuity with the past" (1). This set of ritualized and symbolic practices, because of the implied continuity, lend legitimacy, stability, and permanency to the

${ }^{10}$ See Smith (1998), op cit. note \#1, pp. 89-96 for three general criticisms. Smith himself redresses the Western, Euro-centric bias in theories of nationalism and national identity in his book National Identity (2002), op cit. note \#1.

${ }^{11}$ Eric Hobsbawn and Terrence Ranger, eds. (1983) The Invention of Tradition, Cambridge: Cambridge UP. See E. Hobsbawm (1990) Nations and Nationalism Since 1780, Cambridge: Cambridge UP [rev. ed (1993)] for elaboration of his earlier ideas. Benedict Anderson (1983) Imagined Communities: Reflections on the Origin and Spread of Nationalism, London: Verso [rev. ed (1991)]. These two accounts are designated as "modern" because they view the nation as belonging to the modern phase of history and the sentiment of national identity as created or constructed. 
nation and its institutions. There are three types of invented traditions: first, those to establish and symbolize social cohesion and group membership; second, those to establish and legitimize institutions, status, or relations of authority; and third, those to socialize by nurturing beliefs and reinforcing value systems as well as conventions of behaviour. The essential point in his perspective holds that invented traditions confer solidity to nations that are in reality, not ancient, eternal, natural, or given, and that these traditions have an instrumental or programmatic function of perpetuating a system that benefits, according to Hobsbawm, the elite. ${ }^{12}$

Well-known and highly influential, Benedict Anderson's Imagined Communities (1983) was a response to the problems unresolved by Marx's national question: why had nationalism flourished throughout the $20^{\text {th }}$ century, instead of being replaced by cross-national class consciousness? Anderson assumes nations and national identity to be products of modern history, and he also assumes them to be closer to religion or kinship relations in their irrationality than to explicit political ideologies like liberalism or fascism. The nation is imagined as inherently limited and sovereign, and he views the Tomb of the Unknown Solider as the most revealing national symbol. The transformation from three traditional preconditions fostered the nation as an imagined community: (1) the rise of standardized languages to replace multiple vernaculars and especially sacred script communities; (2) democratic states to replace aristocratic and dynastic realms; and (3) modern, linear time to replace the eternal presentness of cosmological time. Subsequent scholarship has focused on print capitalism as fostering national sentiment, because fixing words and grammar allowed for the creation of a standard, which could then be adopted as the official version. It has been pointed out that print capitalism is a necessary but not sufficient condition for national identity formation, and Anderson himself allowed for other intervening variables, such as collaboration between the church and state officials to foster nationalism. Despite the influence his formulation has had, Anderson's main achievement has been to successfully graft postmodern approaches of deconstruction onto a thoroughly modern approach

\footnotetext{
${ }^{12}$ Quotation from Hobsbawm \& Ranger (1983). Description from Hobsbawm \& Ranger (1983), op cit. note \#11, and Smith (1998), op cit. note \#1, pp. 117-131. See The Invention of Tradition (1983) for examples, inter alia, including the creation of British coronation ceremony, Highland Scots tradition, several Catholic Church rituals. See Susan G. Davis (1986) Parades and Power: Street Theater in Nineteenth-Century Philadelphia, a study on the creation of American symbols in the early national period.
} 
and assumptions, and reinforce the power that the printing press, literacy, and the rise of a reading public had on national identity. ${ }^{13}$

Now that we have outlined several of the contemporary approaches to national identity formation, we should return to the over-arching questions on the nature of nations and ethnicity. In the debate over nations, the two contending positions are modernism and perennialism. They concern themselves with the relationship between nations, as definable political communities, and nationalism, the loyalty toward the political community. Did nations exists before nationalism, or did nationalism create nations? For example, did France or the U.S. emerge as a state, only to have the population develop sentiments of loyalty? Or did sentiments exist prior to, and actually forge, the nation-state? The modern-perennial debate over nations is somewhat of a chicken-and-egg exercise, a maddening roundabout of an attempt to locate the necessary and sufficient force leading to modern nationalism.

The modern view holds that nations date from the French Revolution, the result of agglomerating and centralizing forces. Capitalism, industrialization, secularization, technologies of transportation and communication, and centralized government combined to foster the emergence of nations. Of these, government activities like taxation, conscription, war-making, and administration over a unified territory were the most influential in fostering nations. This pattern emerged slowly and unevenly throughout Europe, and it isn't until the late $19^{\text {th }}$ and early $20^{\text {th }}$ century that governments extend themselves into educational curricula and language standardization as supplemental means of nation building. This perspective is understood to be modern because it is the cluster of forces that ushered in Modernity - capitalism, industrialization, and secularization - that created nations as well. Centralized government authority and discharge of responsibilities encouraged deep identification with the nation, for it was the national state that patterned life over a given territory. The centralizing processes reduced the cultural, economic, and social differences within nascent states but in doing so, emphasized

\footnotetext{
${ }^{13}$ See Smith (1998), op cit. note \#1, pp. 131-142, for a snapshot of Anderson's perspective. Smith makes that point that only the print-capitalism historical precondition has received adequate scholarly attention. See Natalie Zemon Davis (1991) "Printing and the People" in C. Mukerji \& M. Schudson (Eds.), Rethinking Popular Culture (pp. 65-96), Los Angeles, CA: U California P, for closer consideration of the limits to print-capitalism and a reading public as the sole source of modern nationalism.
} 
differences between different states. ${ }^{14}$

The perennial view, in contrast, believes that modern nations are only recent examples of an age-old phenomenon, the immemorial nation, which can be traced back to medieval and ancient times. Modern nations are only nations within states, while medieval and ancient nations didn't occupy clearly demarcated states. For perennialists, the breadth and involvement of contemporary nations, and nationalism, is but a difference in degree, not kind, over pre-modern nationalism. Russia, England, and Switzerland are commonly cited as medieval examples, and Israel, Egypt, and Greece are cited as ancient examples of nations still in existence. While these possess common myths, a collective proper name, and to varying degrees common memories, Anthony Smith argues that none of them can accurately be called a nation. In classical Greece, while citizens of the different city-states identified with pan-Hellenic culture, their loyalty was local. Israelites identified intensely with their religious identity, but given the secular nature of contemporary nations, the ancient Israelite community is better understood as religious and ethnic, and not a nation. The criteria of common territory for economic purposes also precluded ancient Egypt or medieval Switzerland, as residents had to pay tributes or duties when conducting commerce in neighbouring territories within an otherwise unified kingdom. ${ }^{15}$

Despite intriguing connections made by perennialists, the balance of evidence, both as theoretical support and empirical grounds, tilts in favour of modern views. First, ancient and medieval collectivities, while displaying some characteristics of nations, are more accurately thought of as ethnic communities, or ethnies (in French), or religious communities. Second, the assumption of an immemorial nation was held by early generation of scholars, before a better grasp of the invented and constructed nature of nation-building was realized. For them, nations

\footnotetext{
${ }^{14}$ Assignment of several general processes in the creation of nations comes from Anthony Smith (1995), op. cite note $\# 2$, p. 35 , while assignment of the specific state activities that encouraged nations comes from Smith (2002), op cit. note \# 1, pp. 59-61. See Tilly (1975), op cit. note \#6, for valuable insight about states reducing difference within and expanding differences between. See also David Held, Anthony McGrew, David Goldblatt \& Jonathan Perraton Eds., (1999) Global Transformations: Politics, Economics, and Culture, Stanford, CA.: Stanford UP, p. 36. Tilly and Held associate the centralizing processes with the rise of European absolutism.

${ }^{15}$ See Smith (2002), op cit. note \#1, pp. 43-51 for succinct explanation of perennialist views. Also see Smith (1998), op cit. note \#1, ch. 1 for an elaboration. The best specific examination of whether nations and national identity extends back into medieval or ancient times is Anthony Smith (1994) "The Problem of National Identity: Ancient, Medieval, and Modern?" Ethnic and Racial Studies 17(3): 375-399.
} 
were fixed essences, dormant and only in need of re-awakening from their slumber. However, the modern view of nations, and its corollary that nations helped create the state, needs to be qualified. Although a cluster of forces have been identified as shaping nations, historians remain divided over whether the Reformation, the French Revolution, or the late $19^{\text {th }}$, early $20^{\text {th }}$ century is the accurate starting time to see the flowering of nations. Dissent results because the cluster of contributing forces themselves are general and appear unevenly as they emerge over a long period. Nations created the state, but out of something pre-existing. Nationhood comes about when ethnie elements already exist. Gellner (1964) stresses "it invents nations where they do not exist, but it does need some pre-existing differentiating marks to work on, even if these are purely negative" (168).

Before we weigh the contending positions on ethnicity, we should recognize the importance ethnicity has for collective identity. Ethnicity, not gender, class, familial, territorial, or religious, holds pride of place as the dimension, the circle in a concentric rings of circles, that will most fully overlap with nationality. It isn't uncommon for claims of national selfdetermination to coincide with ethnic boundaries. The two contending positions over the nature of ethnic communities, or ethnies, are the primordialist and situationalist. The primordial view holds that ethnicity is given, that one has ethnicity as one has sight, smell, or touch, that it's an irreducible, and inalienable, attribute of identity. This position is associated with the early $19^{\text {th }}$ century German Romantics, although contemporary socio-biology has lent some credence to this claim. In contrast, for the situationalists, ethnicity is "a matter of attitudes, perceptions, and sentiments that, by their nature, are fleeting and mutable" (Smith [2002] 20). As a person finds him- or herself in a different situation, so will his or her group identification change. The key difference between each view is that ethnicity is a collective property for primordialists and an individual property for situationalists. ${ }^{16}$

This study adopts a middle-ground position, advocated by Smith. It understands ethnicity to be more social than biological, but also believes the social bonds to be felt prior to any given situation and exceeding powerful. Shaping this position is the reality of contemporary

\footnotetext{
${ }^{16}$ Outlines for each position, primordial and situational, come from Smith (1995), op cit. note \#14, pp. 3135 and Smith (2002), op cit. note \#1, pp. 20-21.
} 
nationalism, which is predominantly ethnic nationalism. Ethnicity is social because it may be partly given biologically, but draws from history as the resource to empower it. A key application of the social nature of ethicity is the instrumental purposes to which it can be put. Groups seeking to secede from a larger territory employ an ethnic homogeneity as the reason, and groups seeking to amalgamate into other states employ ethnic re-unification as their reason. The process of coalescence or division can be legitimated by appeals to the ethnie. ${ }^{17}$

What can be summarized about national identity?

Nations, which are the object or focal point of study for national identity, have reflected a shift in thinking. Now they are conceived as a product of recent, which is to say Modern, history and are constructed in nature; they are not immutable, external, and given. This movement corresponds to the change from a perennial to modernist view, and traces the contemporary explanations overtaking the classical modern approach of mid-twentieth century. Smith (2002) himself writes: we are in fact dealing with a complex set of processes over time rather than with fixed 'essences' (43)". As we have seen, the set of processes, or cluster of forces, include the arrival of capitalism, industrialization, secularization, urbanization, technologies of transportation and communication, and especially state formation and consolidation, which above all set in motion the twin processes of homogenizing within states and differentiating between, and providing more for citizens while simultaneously expecting more in return. ${ }^{18}$

An important step is to realize that national identification is a latent force, a near universal condition where it manifests only in particular circumstances. In other words, national identity is historically embedded. It requires the general idea of nation to be available, but also demands particularized history, memory, myths, and symbols to congeal around. Smith (1995) writes "[National identity] depends for its power not just on the general idea of the nation, but on the presence and character of this or that specific nation which it turns into an absolute. Its

\footnotetext{
${ }^{17}$ Smith's middle-ground position is explicitly stated on p. 20, of Smith (2002), op cit. note \#1, and his thoughts concerning the instrumental application of ethnicity can be found on Smith (2002), pp. 24-28, as well as Smith (1995), op cit. note \#14, pp. 30-31 and 39-40.

${ }^{18}$ Quotation from Smith (2002), op cit. note \#1. The summary of forces is drawn from the overview of accounts, particularly the political and modern approaches. The shift from the classical modern approach to the newer accounts is detailed on pp. 142-43.
} 
success, therefore, depends on specific cultural and historical contexts, and this means that the nations it helps to create are in turn derived from pre-existing and highly particularized cultural heritages and ethnic formations" (viii). National identity exists equally, as a condition, across all countries, yet the appearance and relative strength will vary with the particular ethnic and historical configurations, which are obviously not equal across countries. ${ }^{19}$

National identity - we know it when we feel it, but ultimately it eludes or defies rigourous definition. There are caveats on, and limits to, national identity in my study. First, no satisfactory criteria - objective, subjective nor individual, collective - can be discovered for adequately deciding when a nation is a nation. After sifting through all the possibilities, and examining the cases, only consciousness or choice remain as residue of a criteria for determining nationality. For instance, one has a Canadian identity because one has consciousness of belonging. It is impossible to know beforehand when a nation is a nation. This realization means that national identity is only knowable a posteriori. Second, recognizing that national identification does exist, despite its purely subjective quality, there is no accounting for the strength of feeling among different members of the nation, nor for the evenness or intensity of feeling. It will soon be seen that while some members, or groups, have a sharply demarcated, and profoundly deep, sense of national identity, other individuals or groups will not - they may value other collective identifications far above their national identity; and indeed, some may be actively hostile to their national identity. Third, not only does national identification vary with people or groups, it also varies across space and time. People in different regions of the same country will likely identify differently with the idea of a nation. Likewise, it is common that national identity will ebb and flow due to events. The Olympics, World Cup soccer championship, a scientific achievement, an election, an international dispute, a war, and a civil war all have the potential, and have served as catalysts in specific circumstances as concrete

\footnotetext{
${ }^{19}$ The point about historical embeddedness is important if we want to answer the question of why some countries appear to have more national identity than others, suggesting that we understand the lack of historical memory in the national consciousness. Quotation from Nations and Nationalism in a Global Era, op. cite note \#2.
} 
referents for national identity. ${ }^{20}$

This review has demonstrated that national identity doesn't exist independently of emotional or mental states. Subjective self-identification, tautology, and variation across time and space raise insurmountable methodological problems: how do you claim with validity that foreign entertainment will diminish national identity, or that domestic content will enhance it? In chapter four, we encountered the difficulties in demonstrating influence, yet were able to show influence has a certain reach and form. The review in this chapter should have been persuasive in showing that national identity, while a potent force, is inherently unstable and too tenuous to employ as a specific cultural policy aim. From a disinterested point of view, it would be intellectually dishonest to claim otherwise.

II.

Getting a perspective on culture will be as difficult as it was for national identity. Defining "culture" presents a formidable challenge. "Culture," Raymond Williams famously wrote, "is one of the two or three most complicated words in the English language" (87). It is exceedingly difficult to define because of its long and intricate etymological development, its varied usage within different disciplines and traditions of thought, and because its high level of generality permits numerous interpretations. Scholars often resort to metaphors or imagery to convey its perpetual elusiveness - "akin to trying to encage the wind" (Borofsky, in Throsby [3]), and "like trying to nail jelly to the wall" (Elkins in Formisano [394]). ${ }^{21}$

The confusion is compounded when we move between specialized discourses, or from specialized discourse to general usage. Within political science, the study of "culture" has a fifty year history. Commenced in 1956, by Gabriel Almond's article "Comparative Political Systems,"

\footnotetext{
${ }^{20}$ These caveats come from Eric Hobsbawm (1990), op. cite note \#1, pp. 5-6. See his discussion about the insufficiency of either subjective/objective or individual/collective properties or characteristics in determining before the fact where national identity will emerge and where it will not.

${ }^{21}$ Raymond Williams (1983) "Culture" in Keywords: A Vocabulary of Culture and Society, rev. ed. (pp. 87-93), Oxford: Oxford UP. David Throsby (2001). Economics and Culture, Cambridge: Cambridge UP; and Ronald Formisano (2001) "The Concept of Political Culture" Journal of Interdisciplinary History 31 (3, Winter): 393-426.
} 
the study of political or civic culture, often as a set of variables that lend predictability to the developmental path of democracies, has motivated, intrigued, perplexed, and confused political scientists. Within diplomatic history, the "theme of 'culture' has increasingly informed understandings of the origins, development, execution, and evolution of the United States foreign affairs" (Stuart 427). Recently, there has been a renaissance for political culture, which should be partly attributed to Robert Putnam's influential Making Democracy Work (1993), which attempted to identify and isolate the variables responsible for democracy's relative success in Northern Italy and its relative failure in Southern Italy. In 1996, Michael Mazaar wrote "[c]ulture is the newest fad sweeping the literature on international relations, security studies, and international economics. A throng of recent essays and books point to culture as the basic force impelling nation-states, other institutions, and individuals to act and organize themselves as they do" (177). It will become clear that the domain of political studies understands culture differently than does anthropology, literary studies, or communications. ${ }^{22}$

Moving from specialized to general usage, "culture" is used in a further bewildering variety of contexts. One hears of "corporate culture" of this or that firm or government department. In 2002, a "culture of greed" supposedly infected corporate America: Enron, WorldCom, Tyco. One can speak about the culture of a time and place, Victorian culture or the culture of 1960 s America. One can speak of the culture, usually sub-culture, of people dedicated to particular lifestyles: the sub-culture of punks, of Hell's Angels, of surfers, of ski bums, or of Grateful Dead fans. There is little or no overlap between many of these usages, and between them, taken together, and specialized use above. Paradoxically, using more examples only confounds a single definition. Although Tim O'Sullivan (1994) is making the point for a

\footnotetext{
${ }^{22}$ The study of political or civic culture - the terms overlap significantly — has generated a large literature. See Ruth Lane (1992) "Political Culture: Residual Category or General Theory?" Comparative Political Studies 25(3): 362-387 for an excellent overview. The pioneer article is Gabriel Almond (1956) "Comparative Political Systems" Journal of Politics (18): 391-409. Important contributors include Gabriel Almond, Sidney Verba, Lucien Pye, and more recently Ronald Inglehart, Aaron Wildavsky, and Robert Putnam. An intellectual history can be found in Gabriel Almond (1980) "The Intellectual History of the Civic Culture Concept." In Gabriel Almond \& Sidney Verba (Eds.), The Civic Culture Revisited (pp. 1-36), Boston: Little, Brown. First quote from Reginald Stuart (2001) "Death of the Nation State?" Roundtable Discussion, Society for Historians of American Foreign Relations (SHAFR), in Toronto, June 2000, American Review of Canadian Studies 31(3): 427-440. Stuart specifically had in mind the journal Diplomatic History for his quotation. The second quote from Michael J. Mazarr (1996) "Culture and International Relations: A Review Essay" The Washington Quarterly 19(2): 177-197.
} 
different cluster of examples, his response applies equally well here, when he writes "The trouble arises when you notice that even in these examples the term culture seems to mean half-a-dozen different things. What on earth do all these things share that can be encompassed by the single term? The answer, oddly enough, is nothing" $(68){ }^{23}$

That said, the aim of this section is to present a definition of culture, supported by description, that will allow for appraisal of the erosion of national culture by foreign entertainment content. The section begins with an etymology, and then sets these definitions into motion by describing the conceptual development. Conceptually, culture developed through several stages, each more sophisticated than the last. This section will aim for a balance between conceptual explication and empirical examples, and the philosophical pitfalls that hinder a rigourous definition will be addressed.

The earliest cognate of "culture" is colere (Latin), which had several meanings: "inhabit," "protect," "honour with worship," and "cultivate." "Inhabit" evolved through colonus (L) to "colony," while "honour with worship" developed through cultus (L) to "cult." "Cultivate," via cultura (L), began the branch that led to the contemporary usage. In Middle English, "cultivate" meant "tending of crops or animals," a noun of process. Beginning in the early $16^{\text {th }}$ Century, "culture" assumed not just physical processes, but the processes of spiritual, moral, and aesthetic development, and this secondary differentiation of the branch contains the range of definitions we associate with culture today. Grammatically, "culture" underwent a shift in its part of speech: becoming an abstract noun, capable of carrying meaning independent of specific activity. ${ }^{24}$

Further differentiation in the $18^{\text {th }}$ and first-half of the $19^{\text {th }}$ Centuries resulted in the three major senses understood today. Culture (sense one) means the "general process of intellectual, spiritual, and aesthetic development" (90) familiar to $18^{\text {th }}$ Century universalist, Enlightenment histories. Culture (sense two) indicates "a particular way of life, whether of a people, a period, a

${ }^{23}$ From entry on "culture" in Tim O'Sullivan, John Hartley, Danny Saunders, Martin Montgomery, and John Fiske Eds., (1994) Key Concepts in Communication and Cultural Studies, ${ }^{\text {nd }}$ ed. (pp. 68-71), London: Routledge.

${ }^{24}$ The etymology presented in this and the following two paragraphs come from Williams' (1980) Keywords, op cit. note $\# 21$. 
group" (90). Herder cleaved this meaning away from the previous sense, the difference one of particular against universal. This usage was carried forward by E.B. Tylor, in 1870, and conforms closely with anthropological usage in the $20^{\text {th }}$ Century. Culture (sense three) describes "the works and practices of intellectual and especially artistic activity," (90) and is the usage most often associated with culture today. Matthew Arnold, in 1867, tied aesthetic and taste criteria to this usage, which throughout the first two-thirds of the $20^{\text {th }}$ Century lead to the distinction between high (or elite) and mass (or popular) culture, and incorporated class distinctions in its connotations.

The word "culture" has had an epochal existence and has evolved through several stages: from Latin to Middle to Modern English; as a noun of physical process, to encompass human development; grammatically, from a specific, concrete noun, to an abstract noun that would evolve independent meanings; and decisively, to describe a particular way of life, which would differentiate to encompass the material and spiritual/aesthetic realm, acquiring connotations of superior knowledge, class, moral refinement, and aesthetic and taste distinctions between high and popular culture. The final two usages - particular ways of life and artistic and intellectual activity - often blend together to frustrate a coherent definition. Raymond Williams offers a synthetic definition: "[t]he complex of senses indicates a complex argument about the relations between general human development and a particular way life, and between both [of these] and the works and practices of art and intelligence" (91). This definition should be emphasized because, despite the generality, it offers the fullest explanation, one that encompasses culture in the anthropological and aesthetic sense.

Describing culture as a concept undergoing increasingly sophisticated elaboration will put these definitions in motion. Anthropology, with its preferred usage of "way of life," had achieved dominion over the concept in the $20^{\text {th }}$ Century. One standard textbook collected eleven definitions that, despite the distribution of meaning over a couple of domains, clustered around the idea of learned or patterned behaviour as a semantic center of gravity. Culture was described as residing in the brute pattern of behaviour within some identifiable community, with attention sometimes focused on the norms that precipitated the behaviour and regulated or normalized the patterns. The emphasis was on actions themselves, whether the actions of national groups or 
traditional societies. ${ }^{25}$

The most important development for the definition of "culture" came after World War II, when culture was defined "not as all learned behaviour but as that category or aspect of learned behaviour concerned with meaning" (41). This insight was crucial: the jump from analysis of behaviour to analysis of meaning that is embodied and conveyed by behaviour. Culture was meaning, more metaphysical than physical. Until this change, the focus was on surface, the gesture without meaning, the free-floating signifier. In the culture-as-meaning concept, the study of culture proliferated. One approach postulated that culture was an institutional sphere devoted to the production, circulation, and use of meanings. A second approach, in contrast to Marxian materialism, viewed culture as creativity and agency, and concerned itself with establishing the independence between material and ideal, structure and culture. The third approach understood culture as a system of symbols and meanings, and due to Clifford Geertz, this approach would become the prevalent one. A final approach, which emerged as a reaction to Geertz, viewed culture as a practice, shaped by power relations. Regardless of the different approaches, the study of culture was now the search for meaning. ${ }^{26}$

Clifford Geertz's "Thick Description" (1973) has had a "phenomenal influence" (Sewell 36) in entrenching a semiotic understanding of, and interpretative approach to, culture. Geertz started from Weber's belief that humans are suspended in webs of significance that they themselves have spun, with "culture" the word used for "webs of significance." Geertz felt that

${ }^{25}$ Clyde Kluckhorn (1949) Mirror for Man presents the following eleven definitions in his chapter on concepts. I have grouped similar definitions to illustrate three tendencies. The definitions of "the total way of life of a people" (1), and "a way of thinking, feeling, and believing" (3) are broad, starting points. The definitions of "learned behaviour" (8), "a mechanism for the normative regulation of behaviour" (9), "a set of standardized orientations to recurrent problems" (7), "an abstraction from behaviour" (4), and "a set of techniques for adjusting both to the external environment and to other men" $(10)$ are based on physical actions and mental codes, and reflect leading mid-20th Century anthropology. The definitions of "the social legacy the individual acquires from his group" (2), "a storehouse of pooled learning" (6), and "a precipitate of history" emphasize the continuity of culture through history.

${ }^{26}$ Quotation from William H. Sewell Jr. (1999) "The Concept(s) of Culture" in Victoria E. Bonnell \& Lynn Hunt (Eds.), Beyond the Cultural Turn: New Directions in the Study of Society and Culture, (pp. 35-61), Berkeley, CA.: U California Press. Sewell Jr.'s article is an excellent intellectual history and presents an up-to-date understanding of culture. Sewell Jr. elaborates on each of the four schools, and places them in intellectual context (pp. 41-46). 
inquiry into the ontological status of culture was misconceived; rather, that the goal is to understand "what is getting said" (10) through agency or occurrence. Analysis, then, is an interpretative search for meaning, not an experimental search for a law, and culture is a system of construable signs, socially established structures of meaning, a context for behaviour, that can be intelligibly described. The aim of analysis is akin to decoding, where one sorts out structures of signification by working her or his way through piled-up layers of meaning and implication. Even though culture as a system resides in the realm of meaning, that meaning is ascertained indirectly by interpreting symbolic action, or the flow of behaviour. Anyone who has read his essay will remember the distinction between winks and blinks used to vividly underscore how an identical action can confer two different meanings. Out of the field of meaning, the flow of behaviour crystallizes, or precipitates. ${ }^{27}$

Attesting to the influence of his conception, subsequent scholars elaborated upon the semiotic approach. The main tendency of revision was to reclaim action itself, habits of actions, from the metaphysical domain of meaning. Pierre Bourdieu (1977) outlined his theory of practice, and James Clifford and George Marcus's Writing Culture (1986) began to re-balance culture-as-practice with culture-as-system. From the late 1970 s to the 1990 s, the conception of culture was re-balanced, following Erving Goffman, in drama, performative, and game terms. Although the idea of roles and the drama metaphor had been in sociological use since the 1930s, the frequent reliance on it distinguished its newer use. In his review, William H. Sewell Jr. emphasized a conception of culture based on mutual constitution, as both system and practice. "System and practice are complementary concepts: each presupposes the other. To engage in cultural practice means to utilize existing cultural symbols to accomplish some end....[h]ence practice implies system. But it is equally true that the system has no existence apart from the succession of practices that instantiate, reproduce, or - most interestingly - transform it. Hence system implies practice" (47). The analogy to linguistics was direct: system was to practice as

${ }^{27}$ Clifford Geertz (1973) "Thick Description: Toward an Interpretative Theory of Culture," The Interpretation of Cultures (pp. 3-30), NY: Basic Books. The presentation of his ideas in this paragraph closely follow the presentation in his book. His article was primarily an argument for a particular understanding and method to explain culture. 
langue was to parole, each inseparable from the other, each mutually constitutive. ${ }^{28}$

The prevailing conception of culture is that culture is a system of construable signs, the meanings of which can be intelligently described. Culture is both the interior realm of meaning abstracted from life, and behaviour and social action in the exterior realm. To borrow from Wittgenstein, to find our feet within a culture is to find the elusive correspondence between the flow of behaviour and the field of meaning. William Sewell Jr., incorporating advancements to Geertz's conception, insists that cultures are contradictory (not consistent), loosely integrated (not uniform), contested (not consensual), changing (not unchanging), and permeable (not bounded or hermetic). For Sewell Jr. a culture is a distinct world of meaning. ${ }^{29}$

Most important is the characteristic of culture as permeable, or weakly bounded. It is extremely unusual for societies or their cultures to be isolated or sharply bounded. With the rarest of exceptions, societies have come in contact, merged, been exterminated, cross-pollinated, and evolved since time immemorial. Classic sociology - more than anthropology — viewed societies as closed systems that could be studied as though they were molecules in a gas chamber. Sewell Jr. asserts "[s]ystems of meaning do not correspond in any neat way with national or societal boundaries - which themselves are not nearly as neat as we sometimes imagine. Anything we might designate as a 'society' or a 'nation' will contain, or fail to contain, a multitude of overlapping and interpenetrating cultural systems, most of them subsocietal, transsocietal, or both" (55). This realization naturally leads to the important recognition that cultures are thinly coherent. The coherence may revolve around, for instance, the idea of a national identity. A thin coherence for Canadian culture exists independently of Canada's plural, regional, multi-cultural reality and means that a Canadian culture to be understood as such

\footnotetext{
${ }^{28}$ Claims for culture-as-system versus culture-as-practice re-balancing come from Sewell Jr. Clifford Geertz (1980) "Blurred Genres: The Refigurations of Social Thought" American Scholar (49): 165-179 argues for the rise of dramaturgical thinking to understand culture.

${ }^{29}$ I recognize that this so-called prevailing conception is only one, with others in use in other fields or disciplines. The characteristics come from Sewell Jr. (1999), op cit. note \#26, pp. 52-54, which is where the summary of culture as a distinct world of meaning also comes from. In fact, Geertz borrowed from Wittgenstein (p. 13), so I'm borrowing from Geertz's already-borrowed usage.
} 
doesn't have to be uniform. An example should elaborate on this. ${ }^{30}$

However, to speak in terms of a national culture is to imply a single integrated culture of a particular nation: the Swiss nation, the Brazilian nation, the Canadian nation. This is a false presumption. As Sewell Jr. writes "[c]lassic ethnographies recognized that societies were composed of different spheres of activity...and that each of these component parts had its own specific cultural forms" (53). The meaning attributed to certain behaviour in rural Switzerland will likely differ from the attribution in Geneva or Zurich. The meaning attributed to violence in Canadian hockey is different than to violence in Canadian schools: to say violence is part of the culture of hockey sanctions it, something which doesn't occur in an educational setting. To describe national culture as unevenly experienced or displayed is another way of describing loose integration. Within Canada, it is reasonable to conclude that Southern Ontario possesses more of a national ethos than does Southern Alberta. Additionally, it is incorrect to hold national culture to a standard of impermeability. "It is extremely unusual for societies or their cultural systems to be anything like isolated or sharply bounded" (Sewell 54). This misconception underwrites many nationalist projects that seek to reconcile the borders of nations with the borders of states, in search of isomorphic nation-states - one people, one state. Immigration, diaspora, return migration, assimilation, multiculturalism, the spread of the great religions, differentiation within them, and diffusion and adoption of secular systems of thought undermine the possibility of a truly bounded culture, originating and evolving endogenously, and virtually immune from external religious, political, economic, legal, demographic, or technological influences. An estimate in 1972 claimed that, at most, only $10 \%$ of the then-existing nation-states could legitimately declare themselves as pure. In the intervening thirty years, we might reasonably wonder whether there are any non-plural states left — any $17^{\text {th }}$ Century Icelands — only to conclude that, to different degrees, all nation-states are plural. ${ }^{31}$

In addition to these characteristics, three errors are commonly made in thinking about

${ }^{30}$ William H. Sewell Jr. (1999), op cit. note \#26.

${ }^{31}$ Discussion of non-uniformity and permability of cultures found on pp. 53-58 of Sewell Jr., op cit. note \#26. The 1972 claim is from Walker Conner (1972) "Nation-Building or Nation-Destroying?" World Politics (24): 319-355, as reported in Anthony Smith (2002) National Identity, Reno, NV: U Nevada Press, p. 15. 
culture: reification, reduction, and formalism. To reify is to conjure something into existence by naming it, by treating it as a thing, to assume an abstract noun has a corresponding real-world entity. For Geertz, the error was to "imagine that culture is a self-contained 'super-organic' reality with forces and purposes of its own" (11). To believe that a French or a German national culture is given, or exists in nature independently of people, is to make the mistake of reification. To reduce is to believe that "mental descriptions are made true purely by facts about behaviour" (Blackburn 322). For Geertz, the error was to claim that culture "consists in the brute patterns of behavioural events we observe" (11). To understand one cultural difference between North Americans and the French as the greeting-and-departure cheek kissing is to slip from underlying difference to a behaviour-level explanation. The error of formalism operates under the rubric of ethnoscience, componetial analysis, or cognitive anthropology as a misconception that an ethnographic algorithm can be discovered and explained in terms of laws that can be written out as systematic rules for a given culture. It's not possible to generalize across cultures, only to generalize within, because of a degree of coherence. ${ }^{32}$

The previous example illustrated how these characteristics apply to Canadian culture, especially the notions of permeability and coherence. This next example is a brief cultural analysis of a stark Canadian-American difference, that a national gun culture, showing how norms and social action merge to shape and perpetuate a field of meaning and flow of behaviour.

Michael Bellesiles's book Arming America (2000) examines (as announced in the subtitle) "The Origins of a National Gun Culture." He concludes that "America's gun culture is an invented tradition. It was not present at creation" (114). Conventional wisdom holds that the high level of firearms' ownership and violence should be attributed to the militia movement of the Revolutionary War, the guarantee provided by the Bill of Rights' Second Amendment, and the rugged individualism necessary to survive lawless Western settlement. Bellesiles demonstrates that few American's possessed firearms during the late $18^{\text {th }}$ Century; rather it was "values that came to be associated with owning and using weapons" (116) - the field of

\footnotetext{
32 The pitfalls of this conception are discussed in Geertz, op cit. note \#27, pp. 11-13 and 24-28. Definitions and descriptions of the philosophical errors come from Simon Blackburn, ed. (1996) Oxford Dictionary of Philosophy, London: Oxford UP.
} 
meaning - that produced the contemporary national gun culture. One trajectory of cultural development had gun ownership associated with full enfranchisement. Since only propertied white men served in militias, and since only militiamen carried guns, gun ownership was a hallmark of citizenship. As the circle of inclusion widened throughout the $19^{\text {th }}$ Century, to include non-propertied white men, then African Americans (in the North) into the militia, gun ownership signaled enfranchisement. The norm of citizenship, not a propensity toward violence, prompted gun ownership. A second trajectory ties guns to individual rights and property rights. Beginning with the Bill of Rights, and further entrenched by self-defense statutes, American law granted exceptionally wide latitude in gun use to an owner who feared property violations or personal threat. While English law compels a person menaced with force to flee if possible, and to use deadly force only if it is impossible to avoid it, American statutes allow a person to use deadly force if he perceives himself or his property under threat, even if he is able to escape. (This law acquitted a Louisiana man in 1993 after having shot an unarmed Japanese exchange student who mistakenly came to his door looking for a Halloween party. $)^{33}$

The norm of individual rights and property protection - the field of meaning - permits private violence in a wide variety of circumstance - the flow of behaviour. America's national gun culture is the result more of legal norms and citizenship aspirations than of simple availability or an ethos of violence that supposedly drifts through the air: "[t]he number of guns in circulation is certainly an element in the modern gun culture, but the cultural ethic that sanctions private violence is the critical element. Switzerland and Israel, where army reservists maintain their own weapons, have comparable levels of distribution. Yet those weapons are rarely used for private revenge or crime... What makes the difference is not just the availability of weapons but the ethic, rooted in our cultural history, that teaches the people how, when, and on whom violence may be used" (118). This example illustrates national cultural difference in respect of firearms and violence. The value lies in demonstrating how the flow of behaviour, which can be directly observed, is a precipitate from the field of meaning, which can't be directly

\footnotetext{
${ }^{33}$ Information, and pages numbers, from Richard Slotkin's excellent review, "The Fall into Guns" Atlantic Monthly (November 2000): 114-118, of Michael A. Bellesiles (2000) Arming America: The Origins of a National Gun Culture, New York: Knopf.
} 
observed. $^{34}$

To underscore how challenging both defining culture can be, as well as its analysis, a second example illustrates national cultural differences with a dialectic approach. A contrastive example will put into play the notion that Canadians are more collectivist and statist compared with supposed American individualism and anti-statism to show the ebb and flow of meaning and behaviour. Conventional wisdom holds Canadians are oriented toward collective action and inclined to tolerate greater government involvement in their lives because they have been, since the American Revolution, loyal to authority embodied in British constitutional monarchy. By contrast, Americans rejected aristocratic authority, becoming suspicious of centralized power and government. The experience of Protestant sects in the $17^{\text {th }}$ and $18^{\text {th }}$ Centuries, and the selfreliance necessary to settle the frontier in the $19^{\text {th }}$ Century imbued the American character with individualism. This sociological perspective attributes meaning after the fact based on historical intangibles, like loyalty or direct religious experience. It is more likely that divergent material factors, economic conditions of existence, shaped institutions and the resulting culture differently. Economic historians argue that Canada's presence of, and the United States' relative absence of, government should be attributed to a small Canadian market unable to sustain economies of scale compared to the emergence of an American continental-wide common market that emerged much earlier. By the late $19^{\text {th }}$ Century, these divergent material conditions shaped American laissez-faire and Canadian dirigiste, or "defensive expansion" attitudes. Today's tolerance of more or less government, then, is determined more by economic reality than by traditions of thought. This pair of examples emphasizes how material and economic origins shape the ideal realm, or thought, to account for a particular cultural difference; not by analyzing the field of meaning merging with flow of behaviour. ${ }^{35}$

\footnotetext{
${ }^{34}$ Additional information on the cultural roots of violence and weapons' use from Richard Slotkin (1973) Regeneration Through Violence: The Mythology of the American Frontier, 1600-1860, New York: HarperCollins.

${ }^{35}$ Sociological characterizations from Seymour Martin Lipset (1986) "Historical Traditions and National Characteristics: A Comparative Analysis of Canada and the United States" Canadian Journal of Sociology 11(2): 113-155; and (1990) Continental Divide: The Values and Institutions of the United States and Canada, NY: Routledge. The historical explanation, and quotation, from Hugh G.J. Aitken (1959) "Defensive Expansionism: The State and Economic Growth in Canada" in Aitken (Ed.), The State and Economic Growth (pp. 79-114), NY: Social Science Research Council. J. Bradford DeLong (2002) "What's New about the 'New Economy'?" ISUMA 3(1): 11-
} 
The concept of culture is complex, challenging, variegated, and vexing. The problem is that, due to its slipperiness, culture never leaves a bona fide version in operation for general and specific use. This frustration is evident within anthropology, where despite it being culture's favourite preserve, contemporary practitioners have abandoned the term yet have found the concept indispensable. It can been seen that culture can have knowable specific meaning, as norms that constitute a field of meaning and as social action that appears as behaviour. But as Geertz himself claimed one can't write a general theory of cultural interpretation, because one can never generalize across cultures, only within. He strikes close to home for this study when he writes that "[t]he notion that one can find the essence of national societies...is palpable nonsense" (22). Retreating from the idea of "essence," the semiotic conception of culture has a particular implication for "national culture" as an analytical concept. The idea of a nation, of Canada in this case, is at the center, so the system of symbols, the flag, the anthem, and others, orbit the idea. A direct implication is that Canadian culture must continue to exist as long as Canada as a political community continues to exist, because Canada, as a category of existence, will continue as an organizing idea. The objects in orbit may change, but the idea of Canada will exert gravity. This means the search for Canadian culture may move toward, but never reach, the vanishing point, a destination on the horizon that we can never arrive at. It is only a slight over-simplification to say that as Canada goes, so goes its culture. ${ }^{36}$

What then can be concluded about the impact foreign entertainment might have on national cultures? The most generous position to adopt in good conscience is agnosticism. Importing the conclusions from Chapter Four to our examination of the concept of culture, it is difficult to believe that something as nebulous, tenuous, and amorphous as culture could be influenced by foreign entertainment content, when it was shown that the scope of influence was

16 supports the claims of circumstance that shaped America's economic-governmental development path. Although outside the scope of this section, interesting alternative explanations, historical and material, can be provided for United Empire Loyalist, and post-Loyalist migrations (1783 and 1791-1812) and for the balance between dominionprovincial relations in 1867. See John H. Thompson \& Stephen J. Randall's (1997) Ambivalent Allies, $2^{\text {nd }}$ ed., Athens, GA: U Georgia P, p. 241 for corroboration that the sociological argument is incomplete.

${ }^{36}$ Clifford Geertz (1973), op cit. note \#27. It is Sewell Jr. (1999), op cit. note \#26, that noted that anthropologists have jettisoned the term, not the concept. 
restricted and limited to specific behaviours - "peripheral attitudes:" buying a particular brand of clothes, adopting a certain hairstyle, using a phrase. A general conclusion of this chapter, incorporating both sections, is that national identity and culture each place formidable limits on the claims of influence, effect, or impact. Each key term presents some unique problems, and some pitfalls in common, but an abiding lesson here should be one of caution toward claims that content impacts, either positively or negatively, on these categories, for the existence of the categories themselves expose to many accompanying problems and require too large a leap of faith. 


\section{Epilogue: Prospects for The Quandary}

"Culture and identity, two of the important bulwarks of the modern state, are becoming de-territorialized." Janice Stein \& David Cameron (2002)

"[T]he cultural arguments cannot be dismissed, not least because of the intensity and pervasiveness with which they are held. They may or may not be 'wrong,' but the problems posed by irrational arguments in support of unfair barriers to trade is no more likely to be solved by dismissing such beliefs as self-serving irrationalism than are problems of global population growth likely to be solved by relegating intensely held desires for children to a conceptual and ethical rubbish bin." Richard Collins (1993)

This epilogue will bring together some of the key themes of this study. The primary objective is, after having marched through a detailed review and point-by-point arguments, to think more openly, more associatively, about the arguments presented herein, to leave the reader with not only conclusions, but also with distinct impressions. A secondary objective of this epilogue is to summarize and conclude, in the conventional sense. A doctoral dissertation, as a scholarly exercise, can imply a disinterested attitude on the part of the researcher toward the object of study. This attitude has implicitly informed the organization, presentation, argument, and voice of the document. I depart from this in the epilogue, by abandoning the detached observer point of view to become an active participant, an interlocutor, in the debate over the cultural trade quandary and the various discussions and conversations that sit alongside specific issues. The epilogue unfolds as follows. After presenting the different problems and conundrums that constitute the quandary, I argue for and against the idea of cross-cultural influence. Next, I refute the notion of cultural globalization and engage with the related speculation that North American economic integration threatens Canadian culture and identity. In doing this, I want to highlight what I believe to be an under-conceptualized trend: the emergence of cultural and identity consciousness, and how this will likely impact on the Canada-U.S. relationship in coming years. I close by pointing out trends in several areas (scholarship, policy development, and concepts) that will serve future students as challenging and fruitful objects of study.

On page three of the Introduction, the quandary was expressed as "what policy will 
reconcile open trade with the promotion of national culture?" It was the duality, the search to find balance between open and closed economies, where trade agreements and liberalization (an opening force) inherently clashed with cultural policy measures (a closed condition). While this is what the denotation of the quandary means, it also has - or can have - several connotations. One, since many of the policies are discriminatory, and many sectors possess such measures, it is a quandary to determine how to reconcile so much. Two, despite the benefits of cultural policy (economically, commercially, for talent development, prestige and national image promotion), there remains a yawning silence over what, exactly, the cultural and identity benefits are, which adds profoundly to the quandary. Three, the distribution of responsibilities across different departments means that inter-departmental rivalry results from one department advocating the fullest possible cultural policies while another department struggles to keep Canada's policies consistent with its trade obligations, which presents an organizational quandary. Four, instead of fading away, the issue of cultural identity and identity consciousness continues to rise in many places, and the suspicion is that cultural policy, and the resulting content and domestic expression, will not mollify these deep-seated, collective, existential forces. Therefore, the cultural trade quandary is a definite policy problem that spins out many related concerns in its wake.

Also on page three of the Introduction, I highlighted several questions pertinent to the idea of cross-cultural entertainment influence. "Do motion picture, printed material, and television programming contribute to national identity, or strengthen national bonds, in any tangible way?" "Do these media shape the self-image of a people, or foster a national spirit?" "Is there a definite cultural connection between ownership and content?"

Arguments for the cross-cultural influence of entertainment on domestic culture and identity seem to be intuitive and have common sense on their side. The idea of influence is indispensible in thinking about the role of media in society. Advertising and marketing is predicated upon the expectation that one can be influenced to buy this or that product. Pollsters and party strategists likewise believe that a citizen's choice to vote for one candidate or the other can be influenced by good and bad information. And any parent who has ever prevented his or her child from watching a movie has likely done so because it is thought that the content will 
exert a bad influence on the child. So, influence is integral to consumer choice, political choice, and media and parenting. The perplexing problem has always been that influence can be demonstrated under certain circumstances, in different types of media encounters, or consistent with some personality profiles, yet a general theory of influence will likely never be created. On the quintessential influence question - TV's impact on children - Wilbur Schramm (1961) answered in a way that serves as a guideline, a starting point for any honest inquiry into influence: "[f]or some children, under some conditions, some television is harmful. For some children under the same conditions, or for the same children under other conditions, it may be beneficial. For most children, under most conditions, most television is probably neither particulary harmful nor particularly beneficial" (11). The answer of influence boils down to: it depends. If the strongest conclusion over cross-cultural influence is "it depends," let's look at the counter-argument.'

Arguments against cross-cultural influence have gathered momentum in recent years. A spate of studies tackled the question from the 1960s through to the early 90s with different, sometimes starkly opposed, ideological and methodological approaches and turned up few precious stones of evidence; we have been left with only the residue that cross-cultural influence exists, hardly a gold- or silver standard. What's been observed time and again is how localized and particularlized socializing factors overwhelmingly influence the interpretation of content for any given show, or clusters of shows; the notions of selective interpretation and retention argue against straightforward influence; the idea that identity is shaped by numerous pathways parents, education, religion, peers, and media - and that media is likely the least influential. A piece of powerful counter-argument is the presumption by the last generation of audience research and reception theory that meaning - and after all, we are talking about meaning-making when we talk about cross-cultural influence - is made, not discovered. And the process of meaning-making is always local and particular. And this line of argument against influence rests on only examining the idea of influence and interpretation.

A second line of argument against cross-cultural influence rests on the object of change

\footnotetext{
${ }^{1}$ Wilbur Schramm, J. Lyle, and E.B. Parker (1961). Television in the Lives of Our Children. Stanford, CA.: Stanford UP.
} 
itself: national culture and national identity. The idea of national identity is fraught with challenging problems: imprisoned within pure subjectivity; or conversely with, a posteriori conditions and therefore subject to the error of tautology; it varies and is unevenly felt - a collective property experienced differently by different individuals. The idea of culture as a category of examination was just as formidable. "National" culture presumes a knowable and legitimate unit of culture, and arguments for preserving national culture also falsely presume a purity or authenticity to their culture that never existed at any point in the past, a presumption that dissolves into golden-age nostalgia. David Held and colleagues (1999) write "If national economies are hard enough to define meaningfully, then national cultures are doubly so. What is Swedish or German culture, how can we chart its changes? Are we simply looking for changing cultural practices? Are we tracking beliefs and solidarities? Can we meaningfully gauge how Swedish the Swedes feel or how French the French? [And importantly,] [e]ven if we were able to do any of these things, could we track changes in intensity of identification and relate it to shifts in cultural enmeshment?" $(369)^{2}$

The balance of evidence favours arguments against cross-cultural influence. The problems posed by the objects of analysis, and the difficulties in marshalling evidence of influence, cannot be overcome. A shadow of a doubt prevents me from concluding that no influence results from cross-border entertainment consumption: the influence is more honestly stated as negligible to minimal. Another difficulty has been the absence of valid evidence, unclear standards or criteria necessary to claim influence, and the disagreement over burden of proof or persuasion, which has all lead to a sterility in the debate, rather than genuine advances. A disappointingly striking feature of the debate over cultural change has been the tendency to simply re-state positions, and repeat proposals, instead of presenting new directions for discussion. ${ }^{3}$

${ }^{2}$ Quotations from David Held, Anthony McGrew, David Goldblatt, and Jonathon Perraton Eds., (1999) "Globalization, Culture, and the Fate of Nations" in Global Transformations (pp. 327-375). Stanford, CA.: Stanford UP.

${ }^{3}$ The phrase "the sterile centre" comes from William Dymond and Michael Hart (2002) "Abundant Paradox: The Trade and Culture Debate" Canadian Foreign Policy, 9(2), 15-34. 
This pulls us nicely up alongside our so-called adjacent conversation of cultural globalization, which represents only a slightly different point in the cycle of the debate: that economic liberalization taking place on the global level dilutes and will ultimately homogenize national cultures. (Thus it's a different point because it doesn't rely solely on media products as the agent of change, as did the cross-cultural line of argument.)

Richard Barnet's and John Cavanagh's (1996) article "Homogenization of Global Culture" earnestly argues a dubious case, which can be parsed into four claims. First, that "[s]atellites, cables, walkmans, videocassette recorders, CDs, and other marvels of entertainment technology have created the arteries through which modern entertainment conglomerates are homogenizing global culture" (71). This is a rigid kind of technological determinism, and easily dismissed: just because technology widens the circle of participation, doesn't mean that any one outcome necessarily follows, or that all users of technology will be effected the same way. Second, "governments, families, and tribal structures are thrown into crisis by the sweeping changes of late twentieth-century society" (72). This is a gross exaggeration masquerading as a lament against Modernity: how has the Canadian government been thrown into crisis? (What's their definition of a "crisis"?) Third, they assert that "hundreds of millions of children and teenagers around the world are listening to the same music and watching the same films and videos" (73) which results in "a widely shared passion for more global goods and vicarious experience" (73). This is a quasi-passive audience argument, where no one adapts technology to their own ends, or interprets the meaning consistent with their backgrounds and against the dominant, presented message. Fourth, "[m]usicians, social critics, and politicians in poor countries...worry that the massive penetration of transnational sound will...doom the traditional music of their local culture" (74). This is the argument against impure or inauthentic forms of cultural expression, which rests on the specious notion that pure or authentic cultures exist, or have existed. While cultures, including national cultures, might vary in the richness and variety of customs, traditions, and identifiable features, it is leading the argument to assert that there have been hermitically sealed cultures. David Held and colleagues (1999) cogently rebut this claim: "Cultural diffusion and emulation has been a chronic feature of human history since the 
beginning of settled civilization" (340). ${ }^{4}$

A close reading of Barnet's and Cavanagh's article yields a powerful insight: the importance of resolving cultural globalization arguments into their components. What may appear coherent, and appeal to emotion or nostalgia when presented whole can be demonstrated false, or seriously called in question, when presented in part. And the illusion of coherence is fostered by the successfulness of emotional appeals. Their argument battens on four planks: (a) technological determinism, (b) anti-Modernity, (c) assumption of a passive audience, and (d) complaints against an impure or inauthentic cultural standard. (It should be recalled that John Tomlinson dissolved Herbert Schiller's cultural imperialism thesis into four constituent parts, with two of the pieces identical to those above: media imperialism, nationality, global capitalism, and Modernity). So the notion that cultural globalization accurately describes the contemporary cultural condition of economic liberalization on a global scale is alarmist, exaggerated, and reliant on invalid premises and weak reasoning. However, it would seem that there's a sliver of truth to the concept of de-territorialization.

The notion of "de-territorialization" has been used by several theorists. Garcia-Canclini (1995) uses it in a broad way to mean "the loss of 'natural' relation of culture to geographical and social territories" (229). It is the pedestrian complaint that with the presence of foreign business, products, and symbols the once-strong affinity between geographical place and social space will be altered: the meaning of a particular territory will no longer be as distinct as it once was. The hypertrophied complaint is that, say, Madrid will feel less Spanish with McDonald's and Virgin Mega Stores; in Canada, it's the familiar anxiety that, with the rise of Wal-Mart and demise of Eaton's, Canada is becoming Americanized. A culture is considerably more than the profile of foreign and domestic businesses. By exaggerating the degree of change, the de-coupling of territory with social (and economic) space above, these claims suffer from distortion. However, there is a patina of accuracy to the notion that foreign presence - products, business, and symbols - alters slightly the local culture. While it would be accurate to say that de-

\footnotetext{
${ }^{4}$ Richard Barnet and John Cavanagh (1996) "Homogenization of Global Culture" in Jerry Mander \& Edward Goldsmith (Eds.), The Case Against the Global Economy (pp. 71-77). San Francisco, CA: Sierra Club. See op. cit. note \#2 for David Held and colleagues (1999).
} 
territorialization occurs and affects national cultures, it would be a stretch to the point of falsity to say it changes a culture substantially. ${ }^{5}$

Related to the allegation of cultural dilution and homogenization are the worries over Canadian identity as a result of North American economic integration, which revives the existential conditions, the interior monologue of the entire study, the historical Canada-U.S. relationship. Assertions of difference and independence have always formed part of that monologue. For the last two generations, these assertions have been embodied electorally in the politics, and nationalism, of the New Democratic Party (NDP), with its goal of preserving an independent Canada by creating a viable North American social democracy. With the convergence of some Canadian and American attitudes (reflected in the adoption of several free trade agreements and in approval for sustained federal budget surpluses), this distinction has lost meaning and ceased to be an accurate barometer of difference. (The result being pronouncements, wrongly in my opinion, about the death of Canadian nationalism.) There is a new nationalism taking shape - what Richard Gywn calls "Canadianism," distinguished by its exhuberance, embracing itself in full measure, and announcing itself loudly. Still nascent in specific content and without defined counters, this emerging identity is a new stream of consciousness in the Canadian mind, a pulse of feeling, void at present of linear syntax and fully formed ideas. As this idiom drifts over the land, however, enough is recognizable to hazard two guesses on how the relationship will be translated into political choices. ${ }^{6}$

First, economic integration and economic openness is consistent with the emerging

${ }^{5}$ Nestor Garcia-Canclini (1995) Hybrid Cultures: Strategies for Entering and Leaving Modernity. Minneapolis, MN.: U Minnesota P. Brief review of other theorists who use "de-territorialization" comes from John Tomlinson (1999) Globalization and Culture, p. 106, and includes Appadurai, Mlinar, Lull, Featherstone, Latouche, Mattelart, and Morley and Robbins. Another critique against arguments of cultural loss can be found in Paul Krugman (1999) "Enemies of the WTO: Bogus arguments against the World Trade Organization" Slate Magazine, www.slate.com, in Krugman's typically sharp-tongued prose.

${ }^{6}$ The term "Canadianism" comes from the journalist Richard Gwyn in remarks made to the Conference Board of Canada, July 8, 2003. He noted that in the most recent population survey administered by Statistics Canada, 30\% of respondents self-identified as "Canadian," much higher than in previous surveys. For the locus classicus of the nationalism of independence, see George Grant's (1965) Lament for a Nation. For further discussion of this flowering Canadian nationalism, and the use of examples in advertising and consumer culture, see the sources in chapter one, p. 15 (note \#19). 
Canadianism. Matthew Mendelsohn (2003) supports this unequivocally: "Canadians have embraced the trade agenda and are prepared to enter into new trade agreements" (A13). When economic integration proceeds without threatening to diminish or erase potent symbols of sovereignty - the Canadian dollar, for instance - Canadians are supportive. Second, the emerging Canadian identity is at odds in international affairs with American uni-lateralism and reliance on force, a characteristic sharply expressed in 2002 and early 2003 over the U.S.-led war in Iraq. Aside from the divergence, the change in Canadian world view is a dramatically underreported phenomenon, captured well by Michael Ignatieff (2003): "[t]here is something very curious about the way the military spine that was part of a central national identity of our culture has just slipped away, so that when you make a claim in defence of national defence and military expenditure, you are ultimately regarded as some kind of foaming-at-the-mouth war monger. It is a very odd thing and literally incomprehensible to my parents' and grandparents' generation." (17 emphasis added). Notice these implications push in opposite directions: the identity change in favour of economic integration implies a closer Canada-U.S. relationship; the identity divergence in international affairs implies a distancing or incompatible Canada-U.S. relationship. ${ }^{\text {? }}$

This change in national identity - should it continue to mature - extruding from the Canada-U.S. relationship, and re-shaping the monologue as the stream of consciousness assumes improved coherence, will make the quandary more difficult to address in the years ahead. This is despite some shifting sand underneath the quandary, the appearance of several trends, that actually lead toward a solution.

An emboldened Canadian identity is entirely consistent with a trend observed worldwide: the flowering of cultural and identity consciousness, and the demands for more inclusion, more responsiveness, and a better share of the distribution of wealth (a trend that partly explains the rise of ethnic nationalism and the decline of deference to traditional political authority). Increasing demands for cultural expression and identity have no natural supply limit, because of

\footnotetext{
${ }^{7}$ Matthew Mendelsohn (2003, July 2) "Listen up, Canada" Globe \& Mail, A13. Michael Ignatieff (2003) "Canada in the Age of Terror - Multilateralism Meets a Moment of Truth" Policy Options, 24(2), 14-18. For an elaboration of Mendelsohn's ideas, see the paper by Robert Wolfe \& Matthew Mendelsohn (2002) "Values, Interests, and Globalization: The Continuing Compromise of Embedded Liberalism" paper presented at the Canadian Political Science Association annual meeting, in Toronto, ON., May 29-31.
} 
their immaterial existence: since these demands are the expression of a collective need, and needs are bottomless, or infinite, in theory no amount of cultural product and policy could satisfy this need. The clash of the rational with irrational is captured by the spirit of Richard Collins' (1993) epigraph to this chapter. Upon reflection, this should not be a surprise. It has been exceedingly difficult for economists to demonstrate cultural products (or the cultural sector) deserves special treatment, in the form of an exemption or recognition, despite adopting different public- and private goods approaches. Yet despite the difficulty in advancing the cultural arguments, and even more pointedly despite any evidence that cultural products and policies deliver benefits of national spirit, identity, and cohesion, the demand for these policies have increased over time. ${ }^{8}$

This leaves the quandary, and public policy makers who wish to reconcile the trading system with cultural policies, exposed to the vicissitudes of politics, rather than fortified by the certainties of evidence. So it shouldn't be a surprise that the attention devoted to cultural trade, measured by conferences convened or by graduate-student theses and dissertations, have increased sharply in the last several years. ${ }^{9}$

Cultural policy, at least in Canada, has risen on the agenda throughout the 1990s, due to economic, institutional, industry-organizational, and personality factors. As Monica Gattinger (2003) writes "[a]rguably of greatest significance was a macro-economic influence: the federal surplus" (201-2), though she points out the availability of a year-end surplus is a necessary, but

${ }^{8}$ Richard Collins (1993) "The Screening of Jacques Tati: Broadcasting and Cultural Identity in the European Community" Cardozo Arts and Entertainment Law Journal, 11, 361-385. For an overview of economic approaches to the cultural arguments, see Jeff Dayton-Johnson (2000) "What's Different About Cultural Products? An Economic Framework" Report by Strategic Research and Analysis (SRA), Department of Canadian Heritage.

${ }^{9}$ Conferences, symposia, and workshops (in chronological order) are: (1) The Culture/Trade Quandary, hosted by the Centre for Trade Policy and Law (CTPL), on October 9, 1997; (2) Workshop on U.S. Trade Strategy and Canadian Culture, hosted by the Center for Strategic and International Studies (CSIS), on April 23, 1999; (3) The Culture in a World of Trade Conference, at New York University, on March 3, 2000; (4) the Globalization, Trade, and Culture Conference, at University of California (Berkeley), on February 28 \& March 1, 2001; and (5) CTPL held a reprise conference titled Trade and Culture, on November 28, 2001. The theses devoted to the subject (also in chronological order) are Marilyn Smith (1999) Cultural Carve-Out Versus Cultural Cohesion: The Canadian Exemption for Culture in the M.A.I. (Carleton U, M.A.); Glenn Gottselig (1999) Canada and Culture: Can Current Cultural Policies Be Sustained in the Global Trade Regime? (U of Toronto, LL.M.); Wendy Cohen (2000) Negotiating Culture in an Era of Globalization: The Potential for Multilateral Cooperation (Carleton U; M.A.). 
not a sufficient, condition, for support of arts and cultural policy. At least as important, in my opinion, was the relocation by the Chretien Government of the Department of Canadian Heritage as the seat of cultural policy and programs, which automatically guaranteed that cultural policy would be championed as a way of solidifying departmental identity and enhancing prestige. (This departmental mandate would run into conflict with others, notably Foreign Affairs and International Trade, and Industry Canada.) At the level of industry, film producers, television broadcasters, book and magazine publishers may be as tenacious and sophisticated in their lobbying as any other sector. What distinguishes the cultural sector from any other, though, is that they own the means to shape public opinion and, as such, have the ability to present the government, or individuals, in a positive or negative light. This feature of control over visibility and agenda-setting is inherent to the cultural sector, unlike any other. Finally, any political analysis of the cultural sector must situate the personalities of Prime Minister Jean Chretien, and long-time Heritage Minister Sheila Copps in the explanation ${ }^{10}$.

Sheila Copps began as Heritage Minister in January 1996. She has proven herself a tireless champion of Canadian cultural expression. She was so closely associated with lobbying for Canadian television production funds, that the resulting Canadian Television Fund (CTF) becarne known as "Sheila's Money." Although she shared joint responsibility for implementing a solution to the WTO Canada Periodicals ruling, in 1997, with Trade Minister Sergio Marchi, many felt that it was she who had the Prime Minister's ear during sensitive phases. And she is well-known to be influential beyond her official status as Heritage Minister in the Cabinet. Given these characteristics and examples, it should be no surprise that she initiated the International Network on Cultural Policy, in June 1998, and is among its foremost exponents. To foreshadow the future of this initiative, one must wonder what may become of the initiative if it doesn't receive domestic consensus by the time either a new government takes power, or she leaves the

\footnotetext{
${ }^{10}$ Monica Gattinger (2003) “The Liberals' 'Reinvestment' in Arts and Culture: From Patron to Patronage?" in G. Bruce Doern (Ed.), How Ottawa Spends, 2002-03: The Security Aftermath and National Priorities.
} 
Ministerial position $?^{11}$

Prime Minister Jean Chretien also deserves some of the credit for the rise of Canadian cultural policy. He began as Prime Minister in November 1993, intending to distinguish himself as a patron of the arts and protector of Canadian culture, at least in comparison to his predecessors, Kim Campbell and Brian Mulroney. However, real generousity for culture doesn't become apparent until Chretien's third term and is better explained by his pre-occupying search for a legacy. In Chretien's first mandate, arts spending dropped 7\%; during his first two mandates (from 1993 to 1998), overall arts and cultural funding dropped 17\%. It was not until the third Liberal red book that any significant space was devoted to the sector. On May 2, 2001 Jean Chretien and Sheila Copps announced the initiative, Tomorrow Starts Today, $\$ 568$ million for supporting primarily artists, promoting access, and increasing Internet content. This infusion was the single-biggest experienced in the cultural sector in fifty years, since the Massey Commission recommendations were adopted in 1951 . The ambitiousness of the IICD, requiring the departmental capacity, would not have been possible without the climate of generousity in Prime Minister Chretien's third term. But again one must wonder, what will happen to the climate and receptivity of pro-cultural ideas once the government, and the Prime Minister, changes? ${ }^{12}$

On balance, this cluster of factors (personality, industry-organizational, departmental, and macro-economic) tilt in favour of a solution to the quandary. The departmental profile, capacity of policy staff, expertise and engagement of senior bureaucrats, existence of an industry advisory group inside a definite process all lend confidence to this prediction - it's a positive trend.

A second trend has policy development moving toward a more realistic cultural-trade solution. Cultural policy until well after the Second World War embodied the distinction between elite and mass, or high and popular, culture originally articulated by Matthew Arnold

${ }^{11}$ A snapshot of the minister's personality is provided in Gattinger (2003), op cit. note \#10, p. 202. The information of her Prime Ministerial influence during the magazine dispute, and subsequent implementation, comes from my commissioned research to write The Canada-U.S. Magazine Dispute (1993-1999), where time and time again officials from DFAIT were frustrated by the inordinate sway she seemed to have at the expense of Sergio Marchi, their minister.

${ }^{12}$ Monica Gattinger (2003), op. cit. note \#10, p. 198 for budgetary allocations through the first two terms. For a fuller picture of the accounting, see pp. 196-199. 
and later T.S. Eliot. Adorno and Horkheimer introduced the phrase "the culture industry" into the conceptual field as instruments of deception intending to instill false consciousness. The Government of Canada had adopted the plural form of the term by the late 1970s, though without the Marxist baggage, and only intending to convey the large-scale, or industrial, nature required for producing and distributing motion pictures, TV, and sound recording. (There is some disagreement over who brought the term "cultural industry" into government: Michael McCabe, then Executive Director of the Canadian Film Development Corporation or Francis Fox, then Minister of Communications.) Paul Audley's (1983) Canada's Cultural Industries was very important from a normative point of view, because it framed the sector within a nationalist model: based on prohibition, regulation, import substitution, and funding support all within the inward orientation of a closed economy. By the early 1990s, a change in terms — "cultural development," "the cultural sector," and later "cultural diversity" - signaled a shift where cultural policy embodied the commercial goal of market success, looked to foreign markets for potential sales, and shifted emphasis (often under pressure or as a direct result of an international trade ruling) to non-discriminatory promotion. ${ }^{13}$

Michael Dorland (2003) describes this as "realism...understood as the setting and attainment of reasonably modest goals as regards the gathering of data concerning the cultural sector, much more detailed information about cultural audiences, their consumption of cultural goods and services...[i]t includes such things as the Canadian-led creation of the International Network on Cultural Policy" (107). It is this long-run evolution, from inward- to outwardlooking, from the national to realist model, that lends more optimism to finding a solution, or partial solution, to the quandary. It is also a change toward realistic attitudes and expectations. ${ }^{14}$

${ }^{13}$ Theodore Adorno and Max Horkheimer (1972) "The Cultural Industry: Enlightenment as Mass Deception" in Dialectic of Enlightenment, NY: Herder \& Herder; the claim that Michael McCabe first used "culture industries" in the GOC comes from Michael Dorland (1996) "Cultural Industries and the Canadian Experience: Reflections on the Emergence of a Field" in Michael Dorland (Ed.), The Cultural Industries in Canada (pp. $347-$ 365) and the claim that Francis Fox first used it comes from Kevin Dowler (1996) "The Cultural Industries Policy Apparatus" in Michael Dorland (Ed.), The Cultural Industries in Canada (pp. 328-346). Paul Audley (1983) Canada's Cultural Industries: Broadcasting, Publishing, Records, and Films, Toronto: James Lorimer \& Co.

${ }^{14}$ Michael Dorland (2003) "'Money for Nothing; Things for Free': The Dire Straits of Contemporary Cultural Policy Analysis" Topia, 9, 101-108. This re-orientation from inward to outward-looking policies is described in Keith Acheson and Christopher Maule (1999) Battlefields and Birds: New Directions for Cultural 
Realism here has a general usage, one that reflects the institutional learning of the Department of Canadian Heritage for the cultural sector within trade agreements. Institutional learning, in turn, really means the education of individuals within the organization. The turn toward realism entails the balancing of priorities, stakeholder interest with the public interest, which includes setting and implementing policy to advance domestic cultural goals while not materially injuring the operation of foreign commercial firms. Narrowly, realism incorporates promotional, rather than discriminatory, elements of policy design. It also reflects a broader vision of international political economy, where a rules-based trading system that serves Canadian interests is valued more than unilateral instances of discriminatory policy setting. Realism, then, means accepting that the goals of cultural policy and trade liberalization are inherently opposed, and it also has meant the learning and the acceptance of changing priorities for the sector and for policy makers.

This trend in policy development is consistent with applied policy, in Canada and elsewhere. Mentioned in the Introduction, the Government of Canada committed in October 1999 to pursue the IICD as the recognition, not an exemption, of cultural policy in the rulesbased trading system. While this was a statement in principal, applied gains have been made in Europe. In the European Union, the right to subsidize public broadcasters, even when this disadvantages competitive commercial considerations, has been enshrined in the Treaty of Amsterdam (1997). Writes Marc Raboy (2002) “[t]he European Union's justification for this measure was that the importance of public broadcasting as an instrument of democracy outweighed the economic rights of the private broadcasting corporations" (115). The trends outlined in the last two paragraphs - away from inward-looking discriminatory policy and

Policies. In Fen Osler Hampson, Michael Hart, and Martin Rudner (Eds.), Canada Among Nations (pp. 155-173), Toronto: Oxford UP. "Realism" needs further definition, as the term has specific usage in philosophy and international relations. In philosophy, "realism" means affirmation of some kind of thing, fact, or state of affairs (Oxford Dictionary of Philosophy, p. 319). For international relations, realism assumes that the international environment is anarchic, a jungle, where actors behave aggressively and human nature is - or is possibly wicked and evil. International order is retained not by law, but by power. (Characterization drawn from Graham Allison and Philip Zelikow [1999] Essence of Decision: Explaining the Cuban Missile Crisis, $2^{\text {nd }}$ ed.) 
toward recognition - lead toward a solution, trends that are each embodied in the IICD. ${ }^{15}$

I believe the prospects are good but bittersweet for resolving the cultural trade quandary. The increased political attention, policy expertise, what amounts to a profound change in expectation augur well for at least a partial solution, and as observers we should remember that problems in international relations rarely have complete, permanent solutions. The quandary is well described: "quandary" is defined as "a state of perplexity" and "a practical dilemma." The problem of reconciling trade liberalization with cultural policy, and the associated expressions of identity and sovereignty, embody perplexity and dilemmas, including the several dilemmas mentioned at the outset of the epilogue. ${ }^{16}$

Despite cause for optimism, I have to caution against the intrusion of self-defeating perceptions. The quandary is akin to putting Canada on the couch and trying to sort through its collective psychological issues. A flowering identity, the new Canadianism, will tend to bend our expectations out of reach, so any trade-policy solution will fall outside or below our existential threshold of satisfaction. Will we recognize a victory as a victory? Catharsis might be permanently beyond our grasp: for Canada can never be too independent of the United States, or possess a culture too distinct. There is an inherent danger when we have nonequivalent quantities on opposite sides of a scale, on one side the existential or immaterial, on the other side policy or commercial units, and this should alert us to the possibly, even the likelihood, of a bittersweet outcome. Even as we make progress on the trade side of the quandary, the cultural side may always elude any ultimate answers. But perhaps recognizing this is a first step toward greater satisfaction.

${ }^{15}$ Marc Raboy (2002) "Communication and Globalization: A Challenge for Public Policy" in David R. Cameron \& Janice Stein (Eds.), Street Protests and Fantasy Parks: Globalization, Culture, and the State (pp. 109140), Vancouver, BC: University of British Columbia Press.

16 "Quandary" defined by the Oxford Modern English Dictionary (1992). 


\section{Bibliography}

Acheson, Keith \& Christopher Maule. (1996). Canada's Cultural Exemption: Insulator or Lightening Rod? World Competition, 20(September), 67-90.

-----, ----. (1998). International Agreements and the Cultural Industries. North American Outlook, 6(4), 7-24.

-----, -----. (1999a) Battlefields and Birds: New Directions for Cultural Policies. In Fen Osler Hampson, Michael Hart, and Martin Rudner (Eds.), Canada Among Nations (pp. 155173). Toronto: Oxford UP.

----, ----. (1999b). Much Ado about Culture: North American Trade Disputes. Ann Arbor, MI.:

U Michigan P.

Adorno, Theodor and Max Horkheimer. (1972). The Culture Industry: Enlightenment as Mass Deception. In The Dialectic of Enlightenment. New York: Herder \& Herder.

Aitken, Hugh. (1959). Defensive Expansionism: The State and Economic Growth in Canada. In Hugh Aitken (Ed.), The State and Economic Growth (pp. 79-114). New York: Social Science Research Council.

-----. (1961). American Capital and Canadian Resources. Cambridge, MA.: Harvard UP. Allison, Graham \& Philip Zelikow. (1999). Essence of Decision: Explaining the Cuban Missile Crisis, $2^{\text {nd }}$ ed. NY: Longman.

Almond, Gabriel. (1956). Comparative Political Systems. Journal of Politics, 18, 391-409.

-----. (1980). The Intellectual History of the Civic Culture Concept. In Gabriel Almond \& Sidney Verba (Eds.), The Civic Culture Revisited (pp. 1-36). Boston: Little, Brown. Alston, Jon, Theresa Morris, and Arnold Vedlitz. (1990). Comparing Canadian and American Values: New Evidence from National Surveys. American Review of Canadian Studies, 26(3), 301-314.

Anderson, Benedict. (1991). Imagined Communities: Reflections on the Origin and Spread of Nationalism, rev. ed. London: Verso.

Anderson, James. (1984). Public Policy Making: An Introduction, $3^{\text {rd }}$ ed. Boston: Houghton Mifflin.

Ang, Ien. (1985). Watching Dallas. London: Methuen. 
Angus, Ian. (1997). A Border Within: National Identity, Cultural Plurality, and Wilderness. Montreal: McGill-Queen's.

Appadurai, Arjun. (1990). Disjuncture and Difference in the Global Cultural Economy. Public Culture, 2(2), 1-24.

Audley, Paul. (1983). Canada's Cultural Industries: Broadcasting, Publishing, Records, and Films. Toronto, ON.: James Lorimer \& Co.

Azzi, Stephen and Tamara Feick. (2003). Coping with the Cultural Colossus: Canada and the International Instrument on Cultural Diversity. In David Carment, Fen Osler Hampson, and Norman Hillmer (Eds.), Coping with the American Colossus: Canada Among Nations, 2003 (pp. 100-120). Toronto, ON.: Oxford UP.

Baer, Doug, Edward Grabb, \& William Johnston. (1990). The Values of Canadians and Americans: A Critical Analysis and Reassessment. Social Forces, 68, 693-713. ----, ----, ----. (1990). A Rejoinder. Social Forces, 69, 273-277.

Bagehot, Walter. (1887). Physics and Politics. London: K. Paul, Trench, Trubner \& Co.

Banting, Keith, George Hoberg, and Richard Simeon. (Eds.) (1997). Degrees of Freedom:

Canada and the United States in a Changing World. Montreal, PQ: McGill-Queen's UP. Barkley, Murray. (1975). The Loyalist Tradition in New Brunswick: The Growth and Evolution of an Historical Myth, 1825-1914. Acadiensis, 4(2), 3-45.

Barnet, Richard and John Cavanagh. (1996). Homogenization of Global Culture. In Jerry Mander \& Edward Goldsmith (Eds.), The Case Against the Global Economy: And for a Turn Toward the Local (pp. 71-77). San Francisco, CA.: Sierra Club.

Barnett, George and Thomas McPhail. (1980). An Examination of the Relationship of United States Television and Canadian Identity. International Journal of Intercultural Relations, 4, 219-232.

Barnouw, Erik, editor-in-chief. (1989). International Encyclopedia of Communication, $2^{\text {nd }}$ ed. New York: Oxford University Press.

Barthes, Roland. (1975). S/Z. NY: Hill \& Wang.

Bellesiles, Michael. (2000). Arming America: The Origins of a National Gun Culture. New York: Knopf. 
Beltran, L. (1978). TV Etchings in the Minds of Latin Americans: Conservatism, Materialism, and Conformism. Gazette, 24(1), 61-85.

Berelson, Bernard. (1950). Reader in Public Opinion and Communication. Glencoe, IL.: Free Press.

Berger, Peter and Thomas Luckmann. (1966). The Social Construction of Reality: A Treatise in the Sociology of Knowledge. Garden City, NY: Double Day.

Bernier, Ivan. (1997). Opening Markets and Protecting Culture: A Challenging Equation. Forces, $117,84-87$.

----. (1998). Cultural Goods and Services in International Trade Law. In Dennis Browne (Ed.), The Culture/Trade Quandary (pp. 108-154). Ottawa: Center for Trade Policy and Law.

----. (2000, March 3). The World Trading System and Culture: Looking at the Problem From a Cultural Perspective. Remarks at the Culture in a World of Trade Conference, New York University.

Biltereyst, Daniel. (1991). Resisting American Hegemony: A Comparative Analysis of the Reception of Domestic and US Fiction. European Journal of Communication, 6, 469497.

Blackburn, Simon. (Ed.) (1996). Oxford Dictionary of Philosophy. London: Oxford UP. ----. (1999). Think: A Compelling Introduction to Philosophy. London: Oxford UP.

Bothwell, Robert \& John English. (1977). Canadian Trade Policy in the Age of American Dominance and British Decline, 1943-1947. Canadian Review of American Studies, $18(1), 52-65$.

Bourdieu, Pierre. (1977). Outline of a Theory of Practice, Trans. by Richard Nice. Cambridge: Cambridge University Press.

Bowles, Richard. (1973). Canada and the US: Continental Partners or Wary Neighbours? Scarborough, ON.: Prentice-Hall.

Braun, M. and L. Parker. (1993). Trade in Culture. Denver Journal of International Law and Policy, 22(1), 155-xxx.

Breuilly, John. (1993). Nationalism and the State, rev. ed. Manchester: Manchester UP. Brigham, John \& Linda Giesbrecht. (1976). "All in the Family": Racial Attitudes. Journal of 
Communication, 26(4), 69-74.

Brooks, Stephen. (2002). Comments on "Here's Where We Get Canadian: English-Canadian Nationalism and Popular Culture." American Review of Canadian Studies, 32(1), 35-40.

Browne, Dennis. (1998). The Culture/Trade Quandary: Canada's Policy Options, Ottawa, ON.: CTPL.

----. (1999). Canada's Cultural Trade Quandary: How Do We Resolve the Impasse?

International Journal, 54(Summer), 363-374.

Browne, D. (1967). Problems in International Television. Journal of Communication, 17(3), 198210.

Budd, Mike, Robert Entman, and Clay Steinman. (1990). The Affirmative Character of U.S. Cultural Studies. Critical Studies in Mass Communication, 7, 169-184.

Cahn, Sandrine and Daniel Schimmel. (1997). The Cultural Exception: Does it Exist in GATT and GATS Frameworks? How Does it Affect or is it Affected by the Agreement on TRIPS? Cardozo Arts and Entertainment Journal, 15(2), 281-314.

Cameron, David and Janice Stein. (Eds.) (2002). Street Protests and Fantasy Parks: Globalization, Culture, and the State. Vancouver, BC: UBCP.

Canada. Royal Commission on Radio Broadcasting. (1931). Report. Ottawa: King's Printer.

----. Royal Commission on National Development in the Arts, Letters, and Sciences. (1951). Report. Ottawa: King's Printer.

-----. Royal Commission on Broadcasting. (1957). Report. Ottawa: Queen's Printer.

-----. Royal Commission on Publications. (1961). Report. Ottawa: Queen's Printer.

-----. Special Committee of the Senate on Mass Media. (1970). Report. Ottawa: Information Canada.

-----. Federal Cultural Policy Review Committee. (1982). Report. Ottawa: Minister of Supply \& Services.

-----. (2002). An International Agreement on Cultural Diversity: A Model for Discussion. Available at www.dfait-maeci.gc.ca.

Carey, James. (1989). Communication as Culture: Essays on Media and Society. Boston: Unwin Hyman. 
Carmody, Chi. (1999). When "Cultural Identity Was Not At Issue": Thinking about CanadaCertain Measures Concerning Periodicals. Law and Policy in International Business, 30(2), 231-320.

Carr, Graham. (1991). Trade Liberalization and the Political Economy of Culture: An International Perspective on the FTA. Canadian-American Public Policy Occasional Paper \#6. Orono, ME.: U Maine P.

Chao, T. (1996). GATT's Cultural Exemption of Audiovisual Trade: The United States May Have Lost the Battle But Not the War. University of Pennsylvania Journal of International Economic Law, 17(4), 1127-xxxx.

Clarkson, Stephen. (1998). Fearful Asymmetries: The Challenge of Analyzing Continental Systems in a Globalizing World. Canadian-American Public Policy Occasional Paper \#35. Orono, ME.: U Maine P.

Clifford, James and George Marcus. (Eds.) (1986). Writing Culture: The Poetics and Politics of Ethnography. Berkeley, CA.: University of California Press.

Cobb, Roger and Charles Elder. (1972). Participation in American Politics: The Dynamics of Agenda-Building. Boston: Allyn \& Bacon.

Cohen, Wendy L. (2000). Negotiating Culture in an'Era of Globalization: The Potential for Multilateral Cooperation. Unpublished M.A. thesis, Carleton University.

Coldevin, G.O. (1979). Satellite Television and Cultural Replacement Among Canadian Eskimos: Adults and Adolescents Compared. Communication Research, 6, 115-134.

Coldevin, G.O et al. (1985). Effects of a Decade of Satellite Television in the Canadian Arctic: Euro-Canadian and Inuit Adolescents Compared. Journal of Cross-Cultural Psychology, $16,329-354$.

Collins, Richard. (1990). Communication, Culture, and National Identity: The Case of Canadian Television. Toronto: University of Toronto Press.

----. (1993). The Screening of Jacques Tati: Broadcasting and Cultural Identity in the European Community. Cardozo Arts \& Entertainment Law Journal, 11, 361-385.

Comstock, George. (1975). The Evidence So Far. Journal of Communication, 25(4), 25-34. Condit, Celeste. (1989). The Rhetorical Limits of Polysemy. Critical Studies in Mass 
Communication, 6(2), 103-122.

Connor, Walker. (1972). Nation-Building or Nation-Destroying? World Politics, 24, 319-355.

Cook, Ramsey. (1977). Cultural Nationalism in Canada: An Historical Perspective. In Janice

Murray (Ed.), Canadian Cultural Nationalism (pp. 15-44). New York: NYUP.

Corner, John. (2000). "Influence": The Contested Core of Media Research. In James Curran \& Michael Gurevitch (Eds.), Mass Media and Society, $3^{\text {rd }}$ ed. (pp. 376-397). London: Arnold.

Cowen, Tyler. (2002). Creative Destruction: How Globalization is Changing the World's Cultures. Princeton, NJ.: Princeton UP.

Cowen, Tyler and Eric Crampton. (2001). Uncommon Culture. Foreign Policy (July/August), $\mathrm{xx}-\mathrm{xx}$.

Craig, Robert. (1993). Why Are There So Many Communication Theories? Journal of Communication, 43(3), 26-33.

Crean, Susan. (1988). Reading Between the Lies: Culture and the Free Trade Agreement. This Magazine, 22(May), 29-33.

Curran, James. (1990). The New Revisionism in Mass Communication Research: A Reappraisal. European Journal of Communication, 5, 130-164.

----. (1996). Media Dialogue: A Reply. In James Curran, David Morley \& Valerie Walkerdine (Eds.), Cultural Studies and Communication (pp. 294-299). London: Arnold.

Dalgren, Peter. (1998). What's the Meaning of This? Viewers' Plural Sense-Making of TV News. Media, Culture, and Society, 10(3), 285-301.

Davis, Natalie (1991). Printing and the People. In Chandra Mukerji \& Michael Schudson (Eds.), Rethinking Popular Culture: Contemporary Perspectives in Cultural Studies (pp. 65-96). Berkeley, CA. U California P.

Davis, Susan. (1986). Parades and Power: Street Theater in Nineteenth-Century Philadelphia. Berkeley, CA.: U California P.

Dayton-Johnson, Jeff. (2000). What's Different About Cultural Products? An Economic

Framework. Strategic Research and Analysis reference paper \#501. Ottawa, ON. Department of Canadian Heritage. 
De Fleur, Melvin. (1966). Theories of Mass Communication. New York: D. McKay.

DeLeon, Peter. (1994). Reinventing Policy Sciences: Three Steps Back to the Future. Policy Sciences, 27, 77-95.

DeLong, J. Bradford. (2002). What's New About the "New Economy"? Canadian Journal of Policy Research, 3(1), 11-16.

De Rivery, Eric. (1995). Unresolved Issues in the Audiovisual Sector and the US/EU Conflict. In Jacques Bourgeois, Frederique Berrod, and Eric Fournier (Eds.), The Uruguay Round Results (pp. 435-443). Brussels: Inter-University Press.

Dervin, Brenda, Lawrence Grossberg, Barbara O'Keefe, and Ellen Wartella. (Eds.) (1989).

Rethinking Communication, 2 vols. Newbury Park, CA: Sage.

Deutsch, Karl. (1969). Political Community and the North Atlantic Area: International Organization in Light of Historical Experience, $2^{\text {nd }}$ ed. Princeton, NJ.: Princeton UP.

Doern, G., Leslie Pal, and Brian Tomlin. (Eds.) (1996). The Internationalization of Canadian Public Policy. In Border Crossings: The Internationalization of Canadian Public Policy (pp. 1-26). Toronto: Oxford UP.

Dominant U.S. Culture Worries Canadians, poll shows. (2002, July 1). Globe and Mail, p. A6.

Dorland, Michael. (Ed.) (1996a). The Cultural Industries in Canada: Problems, Policies, and Prospects. Toronto: James Lorimer \& Co.

----- (1996b). Cultural Industries and the Canadian Experience: Reflections on the Emergence of a Field. In Michael Dorland (Ed.), The Cultural Industries in Canada: Problems, Policies, and Prospects (pp. 347-365). Toronto: James Lorimer \& Co.

-----. (2002). Money for Nothing; Things for Free: The Dire Straits of Contemporary Cultural Policy Analysis? Topia, 9, 101-108.

Dorland, Michael and Maurice Charland. (2002). Law, Rhetoric, and Irony in the Formation of Canadian Civic Culture. Toronto, ON.: U Toronto P.

Dowler, Kevin. (1996). The Cultural Industries Policy Apparatus. In Michael Dorland (Ed.), The Cultural Industries in Canada: Problems, Policies, and Prospects (pp. 328-346).

Toronto: James Lorimer \& Co.

Dye, Thomas. (1972). Understanding Public Policy. Englewood Cliffs, NJ.: Prentice-Hall. 
Dymond, William. (2000). Cultural Issues. In Mordechai Kreinin (Ed.), Building a Partnership: The Canada-United States Free Trade Agreement (pp. 113-115). East Lansing, MI.: Michigan State UP.

Dymond, William and Michael Hart. (2001, November 28). The Trade and Culture Debate: Abundant Paradox. Paper presented at Trade and Culture conference, Ottawa, ON. ----, ----.. (2002). Abundant Paradox: The Trade and Culture Debate. Canadian Foreign Policy, 9(2), 15-34.

Eggleton, Art. (1997, January 27). Can Canada Maintain its Cultural Identity in the Face of Globalization. Remarks made at Osgoode Hall Law School.

Elasmar, Michel and John Hunter. (1997). The Impact of Foreign TV on a Domestic Audience: A Meta-Analysis. Communication Yearbook, 20, 47-69.

Engel, Charles and John Rogers. (1996). How Wide is the Border? American Economic Review, (December), 1112-1125.

Errington, Jane and George Rawlyk. (1984). The Loyalist-Federalist Alliance of Upper Canada. American Review of Canadian Studies, 14(2), 157-176.

Evans, William. (1990). The Interpretative Turn in Media Research: Innovation, Iteration, or Illusion? Critical Studies in Mass Communication, 7, 147-168.

Falkenberg, Karl. (1995). The Audiovisual Sector. In Jacques Bourgeois, Frederique Berrod, and Eric Fournier (Eds.), The Uruguay Round Results (pp. 429-434). Brussels: European Inter-University $\mathrm{P}$.

Fejes, Fred. (1984). Critical Mass Communication Research and Media Effects: The Problem of the Disappearing Audience. Media, Culture, and Society, 6, 219-232.

Feketekuty, Geza. (2000). Trade in Services. In Mordechai Kreinin (Ed.), Building a Partnership (pp. 143-152). East Lansing, MI.: Michigan State UP.

Filipek, Jon. (1992). "Culture Quotas": The Trade Controversy Over the European Community's Broadcasting Directive. Stanford Journal of International Law, 28, 324-370.

Footer, Mary and Christoph Graber. (2000). Trade Liberalization and Cultural Policy. Journal of International Economic Law, 3(3), 115-144.

Footer, Mary. (1995). The Future for a Cultural Exception in the World Trade Organization. 
Paper presented at the International Law Association (ILA) Meeting, Geneva, June 22-23. Provided courtesy of the author.

Forester, John. (1984). Bounded Rationality and the Politics of Muddling Through. Public Administration Review, 44(1), 23-31.

Formisano, Ronald. (2001). The Concept of Political Culture. Journal of Interdisciplinary History, 31(3), 393-426.

Foss, Krista. (2002, February 26). “'Incredible team' of Olympians greeted with smiles and tributes" Globe and Mail, A1, A2.

Friedman, Thomas. (1999). The Lexus and the Olive Tree. New York: Farrar, Straus, and Giroux.

Fry, Earl. (2003a). Canada-US Economic Relations: A Window for Opportunity. Policy Options, (February), 33-38.

----. (2003b). Prospects for Further North American Integration: A U.S. Perspective. Paper presented at the Canadian Political Science Association Conference, Halifax, NS. June 1.

Fukuyama, Francis. (2001). Economic Globalization and Culture. On-line discussion, hosted by Merrill Lynch Forum on Globalization. www.ml.com/woml/forum/global. Accessed February 22, 2001.

Gaddis, John. (1986). The Corporatist Synthesis: A Skeptical View. Diplomatic History, 10(4), 357-362.

Gagne, Gilbert. (2002a). The Canada-US Border and Culture. Canadian Foreign Policy, 9(2), $159-170$.

----. (2002b). North American Integration and Canadian Culture. In George Hoberg (Ed.), Capacity for Choice: Canada in a New North America (pp. 159-186). Toronto: University of Toronto Press.

Galperin, Hernan. (1999). Cultural Industries in the Age of Free Trade Agreements. Canadian Journal of Communication, 24(1), 49-77.

----. (2000). Cultural Industries Policy in Regional Trade Agreements: the Cases of NAFTA, the European Union, and Mercosur. Media, Culture, and Society, 21(5), 627-648.

Garcia-Canclini, Nestor. (1995). Hybrid Cultures: Strategies for Entering and Leaving Modernity. Minneapolis, MN.: U Minnesota P. 
Garten, Jeffrey. (1998, November 30). “Cultural Imperialism” Is No Joke. Business Week, p. 26. Gattinger, Monica. (2002a). Globalization, Two-Level Negotiations and Symbolic Policy: The Case of Canada's Cultural Industries in Trade. Paper presented at the Canadian Political Science Association meeting, in Toronto, May 29-31.

----. (2002b). The Liberals" "Reinvestment" in Arts and Culture: From Patron to Patronage? In G. Bruce Doern (Ed.), How Ottawa Spends, 2002-03: The Security Aftermath and National Priorities (pp. 196-215). Toronto: Oxford UP.

Geertz, Clifford. (1973). Thick Description: Toward an Interpretative Theory of Culture. In Interpretation of Cultures (pp. 3-30). New York: Basic Books.

----. (1980). Blurred Genres: The Refigurations of Social Thought. American Scholar, 49, $165-$ 179.

Gellner, Ernest. (1964). Thought and Change. London: Weidenfeld \& Nicolson.

---- (1983). Nations and Nationalism. Oxford: Blackwell.

General Agreement of Tariffs and Trade. (1961, November 16). Application of GATT to International Trade in Television Programs. GATT Doc. L/1615.

---.-. (1961, November 24). Application of GATT to International Trade in Television Programs: Statement by the United States Representative on 21 November 1961. GATT Doc. L/1646.

----. (1961, December 18). Application of GATT to International Trade in Television Programs: Working Party on Application... GATT Doc. L/1686.

----. (1962, March 13). Application of GATT to International Trade in Television Programs:

Report of the Working Party. GATT Doc. L/1741.

----. (1962, November 10). Application of GATT to International Trade in Television Programs: Revised United States Draft Recommendations. GATT Doc. L/1908. Giddens, Anthony. (1979). Central Problems in Social Theory: Action, Structure, and Contradiction in Social Analysis. London: MacMillan.

----. (1985). Contemporary Critique of Historical Materialism: The Nation-State and Violence. Cambridge: Polity Press.

-----. (1989). The Orthodox Consensus and the Emerging Synthesis. In Brenda Dervin, 
Lawrence Grossberg, Barbara O’Keefe \& Ellen Wartella (Eds.), Rethinking

Communication, vol. 1 (pp. 53-65). Newbury Park, CA.: Sage

Goff, Patricia. (2000). Invisible Borders: Economic Liberalization and National Identity. International Studies Quarterly, 44(4), 533-562.

Goodenough, Oliver. (1998). Defending the Imaginary to Death? Free Trade, National Identity, and Canada's Cultural Preoccupation. Arizona Journal of International \& Comparative Law, 15, 203-253.

Gottselig, Glenn. (1999). Canada and Culture: Can Current Cultural Policies Be Sustained in the Global Trade Regime? Unpublished LL.M. thesis, U Toronto.

-----. (2000). Canada and Culture: Can Current Cultural Policies Be Sustained in the Global Trade Regime? International Journal of Communications Law and Policy, 5, 1-44.

Granatstein, Jack. (1975). Canada's War: The Politics of the MacKenzie King Government, 1939-1945. Toronto: Oxford UP.

-----. (1985). The Issue That Will Not Go Away. In Denis Stairs and Gilbert Winham (Eds.),

The Politics of Canada's Economic Relationship with the United States (pp. 11-54).

Toronto: U Toronto P.

----. (1989). How Britain's Weakness Forced Canada into the Arms of the United States.

Toronto: U Toronto P.

Grant, George. (1965). Lament for a Nation: Defeat of Canadian Nationalism. Toronto:

McClelland \& Stewart.

Granzberg, G. (1982). Television as Storyteller: The Algonquin Indians of Central Canada. Journal of Communication, 32(1), 43-52.

----. (1985). Television and Self-Concept Formation in Developing Areas: The Central

Canadian Algonquin Experience. Journal of Cross-Cultural Psychology, 16, 313-328.

Granzberg, G. et al. (1977). New Magic for Old: TV in Cree Culture. Journal of Communication, 27(4), 154-158.

Guback, Thomas. (1985). Hollywood's International Market. In Tino Balio (Ed.), The American Film Industry (pp. 463-486). Madison, WI.: U Wisconsin P.

----. (1985). Non-Market Factors in the International Distribution of American Films. In Bruce 
Austin (Ed.), Current Research in Film (pp. 111-126). Norwood, NJ.: Ablex.

Gwyn, Richard. (1985). The $49^{\text {th }}$ Paradox: Canada in North America. Toronto: McClelland \& Stewart.

-.--. (2003). Remarks made at the Conference Board of Canada, July $8^{\text {th }}$. Ottawa, ON.

Haas, Ernst. (1958). The Uniting of Europe: Political, Social, and Economic Forces, 1950-57.

Stanford, CA.: Stanford UP.

Hall, Stuart. (1980). Encoding/Decoding. In Culture, Media, and Language (pp. 128-138).

London: Hutchinson.

----. (1982). The Rediscovery of "Ideology": The Return of the Repressed in Media Studies. In Michael Gurevitch, [T] Bennett, James Curran, and [J] Wollacott (Eds.), Culture, Society, and the Media (pp. 56-90). London: Methuen.

Handler, Richard. (1994). Is "Identity" a Useful Cross-Cultural Concept? In John Gillis (Ed.), Commemorations: The Politics of National Identity (pp. 27-41). Princeton, NJ.: Princeton University Press.

Hardt, Hanno. (1992). Critical Communication Studies: Communication, History, and Theory in America. New York: Routledge.

Harrington, Julian. (1949). Development and Character of Canadian Nationalism. Letter of July 5 to Secretary of State, Washington, D.C. National Archives at College Park, Maryland: Decimal File 842.00/7-549, Record Group 59.

Hart, Michael. (1998). Fifty Years of Canadian Tradecraft: Canada and the GATT, 1947-1947. Ottawa, ON.: CTPL.

----. (2002). A Trading Nation: Canadian Trade Policy from Colonialism to Globalization. Vancouver, BC: UBCP.

Hart, Michael and William Dymond. (2002). NAFTA Chapter 11: Precedents, Principles, and Prospects. In Laura Ritchie Dawson (Ed.), Whose Rights? The NAFTA Chapter 11 Debate (pp. 129-170). Ottawa: Centre for Trade Policy and Law.

Hart, Michael (,with Bill Dymond and Colin Robertson). (1994). Decision at Midnight: Inside the Canada-US Free Trade Negotiations. Vancouver, BC: UBCP.

Hastorf, A. and Hadley Cantril. (1954). They Saw a Game: A Case Study. Journal of Abnormal 
and Social Psychology, 49, 129-134.

Hechter, Michael. (1975). Internal Colonialism: The Celtic Fringe in British National Development, 1536-1966. London: Routledge \& Kegan Paul.

----. (1988). Rational Choice Theory and the Study of Ethnic and Race Relations. In John Rex and David Mason (Eds.), Theories of Ethnic and Race Relations (pp. 264-279).

Cambridge: Cambridge UP.

Held, David, Anthony McGrew, David Goldblatt and Jonathon Perraton. (1999). Globalization, Culture, and the Fate of Nations. In Global Transformations (pp. 327-375). Stanford, CA.: Stanford UP.

Helliwell, John. (1996). Do National Borders Matter? Canadian Journal of Economics, 29, 507522.

Helliwell, John and John McCallum. (1995). National Borders Still Matter for Trade. Policy Options, (July-August), 44-48.

Helliwell, John, Frank Lee, and Hans Messinger. (2002). Effects of the FTA on Interprovincial Trade. In George Hoberg (Ed.), Capacity for Choice (pp. 17-60). Toronto: U Toronto P. Herzog, Herta. (1944). What Do We Really Know About Daytime Serial Listeners. In Paul Lazarsfeld \& F. Stanton (Eds.), Radio Research, 1942-1943 (pp. xx-xx). PUBLISHER.

Hoberg, George. (2002). Capacity for Choice: Canada in a New North America. Toronto: U Toronto $\mathrm{P}$.

Hobsbawm, Eric and Terrence Ranger. (Eds.) (1983). The Invention of Tradition. Cambridge: Cambridge UP.

Hobsbawm, Eric. (1993). Nations and Nationalism Since 1780, rev. ed. Cambridge: Cambridge UP.

Hogan, Michael. (1986). Corporatism: A Positive Appraisal. Diplomatic History, 10(4), 363-372. Howlett, Michael and M. Ramesh. (1995). Studying Public Policy: Policy Cycles and Policy Subsystems. Toronto: Oxford UP.

Hyman, Herbert and Paul Sheatsley. (1950). Some Reasons Why Information Campaigns Fail. Public Opinion Quarterly, 11, 412-423.

Ignatieff, Michael. (2003). "Canada in the Age of Terror - Multilateralism Meets a Moment of 
Truth" Policy Options, 24(2), 14-18.

Innis, Harold. (1956). Essays in Canadian Economic History. Toronto: U Toronto P.

Inside U.S. Trade. (1991, April 19). House Letter to Hills on Cultural Exemptions. Washington, DC., p.5.

International Trade Reporter. (1993, September 29). Debate Over EC's Attempt to Exclude Audiovisual Sector from GATS Continues, 10(38), p. 1628.

Jackson, John. (1969). World Trade and the Law of GATT. Charlottesville, VA.: Michie Press.

-----. (1999). Forward. In Law and Policy in International Business, 30(2), 189-192.

Jackson, John, William Davey, \& Alan Sykes, Jr. (1995). Legal Problems of International Economic Relations, $3^{\text {rd }}$ ed. St. Paul, MN.: West Group.

Jakobson, Roman. (1972). Linguistics and Poetics. In Richard DeGeorge \& Fernande DeGeorge (Eds.), The Structuralists: From Marx to Levi-Strauss. NY: Anchor.

Jarvie, Ian. (1992). Hollywood's Overseas Campaign: The North Atlantic Movie Trade, 19201950. Cambridge: Cambridge UP.

Jeancolas, Jean-Pierre. (1998). From the Blum-Byrnes Agreement to the GATT Affair. In Geoffrey Nowell-Smith \& Steven Ricci (Eds.), Hollywood and Europe: Economics, Culture, and National Identity, 1945-1995 (pp. 47-62). London: British Film Institute.

Jenkins, William. (1978). Policy Analysis: A Political and Organizational Perspective. London: Martin Robertson.

Jensen, Klaus and Karl Rosengren. (1990). Five Traditions in Search of the Audience. European Journal of Communication, 5, 207-238.

Johnson, Jon. (1994). The North American Free Trade Agreement - A Comprehensive Guide. Aurora, ON.: Canada Law Book.

Kaplan, Robert. (1998, August). Travels Into America's Future. Atlantic Monthly, 282, 37-61. Katz, Elihu. (1959). Mass Communication Research and the Study of Popular Culture: An Editorial Note on a Possible Future for this Journal. Studies in Public Communication, 2, 1-6.

----. (1980). On Conceptualizing Media Effects. In Thelma McCormack (Ed.), Studies in Communication, vol. 1 (pp. 119-141). Greenwich, CT: JAI Press. 
----. (1987). Communication Research Since Lazarsfeld. Public Opinion Quarterly, 51, 25-45.

Katz, Elihu, Jay Blumer \& Michael Gurevitch. (1974). Utilization of Mass Communication by the Individual. In Jay Blumer \& Elihu Katz (Eds.), The Uses of Mass Communication (pp. 19-32). Beverly Hills, CA.: Sage.

Katz, Elihu and Paul Lazarsfeld. (1955). Personal Influence. Glencoe, IL.: The Free Press.

Kellner, Douglas. (1995). Media Communications vs. Cultural Studies: Overcoming the Divide. Communication Theory, 5(2), 162-177.

Kendall, Patricia and K. Wolff. (1949). The Analysis of Deviant Case Studies in Communications Research. In Paul Lazarsfeld \& NAME Stanton (Eds.), Communications Research, 1948-1949 (pp. xx-Xx). PUBLISHER.

Keohane, Robert and Joseph Nye. (1977). Power and Interdependence. Boston: Little, Brown, and $\mathrm{Co}$.

Kingdon, John. (1984). Agendas, Alternatives, and Public Policies. Boston: Little, Brown, and Co.

Klapper, Joseph. (1960). Effects of Mass Communication. Glencoe, IL: The Free Press.

Kluckhorn, Clyde. (1949). Mirror for Man: The Relationship of Anthropology to Modern Life. New York: Wittlesey.

Krasner, Stephen. (1982). Structural Causes and Regime Consequences: Regimes as Intervening Variables. International Organization, 36(2), 185-206.

Krugman, Paul. (1991). Geography and Trade. Cambridge, MA: MIT P.

----. (1999a). Enemies of the WTO. Slate, November 23. On-line at www.slate.msn.

-----. (1999b). O Canada. Slate, October 18. On-line at www.slate.msn.com/dismal/99-10-18.

Land, F. (1995). Reggae, Resistance, and the State: Television and Popular Music in the Cote D'Ivoire. Critical Studies in Mass Communication, 12, 438-454.

Lane, Ruth. (1992). Political Culture: Residual Category or General Theory. Comparative Political Studies, 25(3), 362-387.

Lasswell, Harold. (1951). The Policy Orientation. In Daniel Lerner \& Harold Lasswell (Eds.), The Policy Sciences: Recent Developments in Scope and Method (pp. 3-15). Stanford, CA.: Stanford UP. 
Lazarsfeld, Paul. (1941). Remarks on Administrative and Critical Communications Research. Studies in Philosophy and Social Science, vol. 9 PUBLISHER.

Lazarsfeld, Paul, Bernard Berelson, and Hazel Gaudet. (1944). The People's Choice. NY: Duell, Sloan \& Pearce.

Levine, J. and G. Murphy. (1943). The Learning and Forgetting of Controversial Material. Journal of Abnormal and Social Psychology, 38, 507-517.

Liebes, Tamar. (1989). On the Convergence of Theories of Mass Communication and Literature Regarding the Role of the "Reader". In Brenda Dervin \& Melvin Voight (Eds.), Progress in Communication Sciences (pp. 123-143). Norwood, NJ.: Ablex.

Liebes, Tamar and Elihu Katz. (1986). Patterns of Involvement in Television Fiction: A

Comparative Analysis. European Journal of Communication, 1(2), 151-172.

----, ----. (1993). Export of Meaning: Cross-Cultural Readings of Dallas, rev. ed. New York: Oxford University $\mathrm{P}$.

Lindblom, Charles. (1959). The Science of Muddling Through. Public Administration Review, 19(2), 79-88.

Lindlof, Thomas. (1988). Media Audiences as Interpretative Communities. Communication Yearbook, 11, 81-107.

Lipset, Seymour. (1979). The First New Nation: The United States in Historical and Comparative Perspective, $2^{\text {nd }}$ ed. New York: Norton.

-..-. (1986). Historical Traditions and National Characteristics: A Comparative Analysis of Canada and the United States. Canadian Journal of Sociology, 11(2), 113-155.

----. (1990). Continental Divide: The Values and Institutions of the United States and Canada. New York: Routledge.

---. (1990). A Reply. Social Forces, 69, 267-272.

Livingstone, Sonia. (1996). On the Continuing Problem of Media Effects. In James Curran \& Michael Gurevitch (Eds.), Mass Media and Society $2^{\text {nd }}$ ed. (pp. 305-324). London: Arnold.

Lovewell, Mark. (2002). In Search of Canada's Character. Literary Review of Canada, 10(10), 10-13. 
MacDonald, Donald. (1994). The Canadian Cultural Industries Exemption Under Canada-US Trade Law. Canada-United States Law Journal, 20, 253-262.

MacKinnon, Neil. (1973). The Changing Attitudes of the Nova Scotia Loyalists Towards the United States, 1783-1791. Acadiensis, 2(2), 43-54.

Magder, Ted. (1994). Canada's Hollywood: The Canadian State and Feature Films. Toronto: U Toronto P.

----- (1998). Franchising the Candy Store: Split-Run Magazines and a New International Regime for Trade in Culture. Canadian-American Public Policy Occasional Paper \#34. Orono, ME.: U Maine P.

Mann, Michael. (1986). The Sources of Social Power, vol. 1. Cambridge: Cambridge UP. -.--. (1993). The Sources of Social Power, vol. 2. Cambridge: Cambridge UP.

March, M., J. March and J. Olsen. (1972). A Garbage Can Model of Organizational Choice. Administrative Science Quarterly, 17(1), 1-25.

Massey, Vincent. (1947). On Being Canadian. Toronto: Dent \& Sons.

Maule, Christopher. (2001). Globalization, Culture, and the WTO. Paper presented at a Kuala Lumpur Conference on new technologies, January 30-31.

----. (2002a). Overview of Trade and Culture. Canadian Foreign Policy, 9(2), 1-14.

-.--. (2002b). Trade and Culture: Rhetoric and Reality. Policy Options, March, 39- 44.

-----. (2003). State of the Canada-U.S. Relationship: Culture. American Review of Canadian Studies, 33(1), 121-142.

Mazarr, Michael. (1996). Culture and International Relations: A Review Essay. The Washington Quarterly, 19(2), 177-197.

McAnany, Emile. (1986). Cultural Industries in International Perspectives: Convergence or Conflict. In Brenda Dervin \& Melvin Voight (Eds.), Progress in Communication Sciences, vol. 7 (pp. 1-30). Norwood, NJ.: Ablex.

McAnany, Emile \& Kenton Wilkinson. (Eds.) (1996). Mass Media and Free Trade: NAFTA and the Cultural Industries. Austin, TX.: U Texas P.

McCallum, John. (1995). National Borders Matter: Canada-US Regional Trade Patterns. American Economic Review, 85(June), 615-623. 
McCombs, M. and D. Shaw. (1972). The Agenda-Setting Function of Mass Media. Public Opinion Quarterly, 34(2), 159-170.

McQuail, Dennis. (1994). Mass Communication Theory, $3^{\text {rd }}$ ed. London: Sage.

McRae, Donald. (2000). GATT Article XX and the WTO Appellate Body. In Marco Bronckers \& Reinhard Quick (Eds.), New Directions in International Economic Law (pp. 219-238). The Hague, Netherlands: Kluwer.

Mendelsohn, Matthew. (2003, July 2). "Listen up, Canada" Globe and Mail, A13. Merkin, William. (1999, April 23). U.S. Trade Policy and Canadian Culture: What Can Be Accomplished Through Trade Negotiation? Working Paper presented at U.S. Trade Strategy and Canadian Culture Workshop, Center for Strategic and International Studies. Washington, D.C.

Millard, Gregory, Sarah Riegel, and John Wright. (2002). Here's Where We Get Canadian: English-Canadian Nationalism and Popular Culture. American Review of Canadian Studies, 32(1), 11-34.

----, ----, -----. (2002). Reply to Stephen Brooks. American Review of Canadian Studies, 32(1), 41-44.

Molot, Maureen and Fen Hampson. (2000). Does the $49^{\text {th }}$ Parallel Matter Anymore? In Vanishing Borders: Canada Among Nations (pp. 1-26). Toronto: U Toronto P.

Moravcsik, Andrew. (1993). Introduction. In Peter Evans, Harold Jacobson \& Robert Putnam (Eds.), Double-Edged Diplomacy: International Bargaining and Domestic Politics (pp. 3-42). Berkeley, CA: U California P.

Morley, David. (1980). The "Nationwide" Audience: Structure and Decoding. London: British Film Institute.

-.--. (1989). Changing Paradigms in Audience Studies. In E. Seiter, H. Borchers, G. Kreutzner \& E. Warth (Eds.), Remote Control: Television, Audiences, and Cultural Power (pp. 1643). New York: Routledge.

----. (1996). Media Dialogue: Reading the Readings of the Readings..." In James Curran, David Morley \& Valerie Walkerdine (Eds.), Cultural Studies and Communication (pp. 300305). London: Arnold. 
----. (1996). Populism, Revisionsism, and the 'New' Audience Research. In James Curran, David Morley \& Valerie Walkerdine (Eds.), Cultural Studies and Communication (pp. 256-278). London: Arnold.

Morton, William. (1961). The Canadian Identity. Madison, WI.: U Wisconsin P.

Muirhead, Bruce. (1989). Trials and Tribulations: The Decline of Anglo-Canadian Trade, 19451950. Journal of Canadian Studies, 24(1), 50-65.

Mundell, Robert. (1963). Capital Mobility and Stabilization Policy Under Fixed and Floating Exchange Rates. Canadian Journal of Economics and Political Science, 29(4), 475-485.

----- (1964). A Reply: Capital Mobility and Size. Canadian Journal of Economics and Political Science, 30(3), 421-431.

The Myths About Globalization (6). (2001, April 18). Globe and Mail, p. A15.

Nairn, Tom. (1977). The Break-up of Britain: Crisis and Neo-Nationalism. London: New Left Books.

Nichols, Phillip. (1996). Trade Without Values. Northwestern University Law Review, 90, xxxxxx.

Nielsen, Svend Roed. (2002, November 22-23). Remarks made at conference on Cultural Traffic: Policy, Culture, and the New Technologies in the EU and Canada. Ottawa, ON.

Neuwirth, Rostam. (2002, November 22-23). The Cultural Industries and the Role of Article IV GATT: Reflections on Policy Options for Canada and the EU in the new WTO Round. Paper presented at "Cultural Traffic: Policy, Culture, and the New Technologies in the EU and Canada" conference, held at Ottawa, ON.

Nossal, Kim. (1985). Economic Nationalism and Continental Integration: Assumptions, Arguments, and Advocacies. In Denis Stairs \& Gilbert Winham (Eds.), The Politics of Canada's Economic Relationship with the United States (pp. 55-94). Toronto: UTP.

Oliveira, Omar. (1993). Brazilian Soaps Outshine Hollywood: Is Cultural Imperialism Fading Out? In Kaarle Nordenstreng \& Herbert Schiller (Eds.), Beyond National Sovereignty (pp. 116-131). Norwood, NJ: Ablex.

On Being Canadian, Forever. (1997, July 1). Globe and Mail, p.

O'Sullivan, Tim. (Ed.) (1994). Culture. In Key Concepts in Communication and Cultural 
Studies, $2^{\text {nd }}$ ed. (pp. 68-71). London: Routledge.

Payne, David. (1978). Cross-National Diffusion: The Effects of Canadian TV on Rural Minnesota Viewers. American Sociological Review, 43(October), 740-756.

Payne, David and Christy Peake. (1977). Cultural Diffusion: The Role of U.S. TV in Iceland. Journalism Quarterly, 54, 523-531.

Peters, John. (1986). Institutional Sources of Intellectual Poverty in Communication Research. Communication Research, 13(4), 527-559.

----. (1993). Geneological Notes on the Field. Journal of Communication, 43(4), 132-139.

---.- (1999). Speaking Into the Air: A History of the Idea of Communication. Chicago: U Chicago P.

Pettigrew, Pierre. (2002, November 28). The Next Step Forward for Trade and Culture. Remarks made to the International Institute for Communications.

Pietila, Veikko. (1994). Perspectives on Our Past: Charting the Histories of Mass Communication Studies. Critical Studies in Mass Communication, 11, 346-361.

Potter, David. (1967). Canadian Views of the United States as a Reflex of Canadian Values: A Commentary. In Robert Brown \& Sidney Wise (Eds.), Canada Views the United States: $19^{\text {th }}$ Century Political Attitudes (pp. 121-130). Seattle: U Washington Press.

Putnam, Robert. (1988). Diplomacy and Domestic Politics: The Logic of Two-Level Games. International Organization, 42(3), 427-460.

--.--, (with Robert Leonardi and Raffaella Nanetti). (1993). Making Democracy Work: Civic Traditions in Modern Italy. Princeton, NJ.: Princeton University Press.

Raboy, Marc. (2002). Communication and Globalization: A Challenge for Public Policy. In David Cameron \& Janice Stein (Eds.), Street Protest and Fantasy Parks: Globalization, Culture, and the State (pp. 109-140). Vancouver, BC.: University of British Columbia Press.

Raboy, Marc, Ivan Bernier, Florian Sauvageau \& Dave Atkinson. (1994). Cultural Development and the Open Economy: A Democratic Issue and a Challenge to Public Policy. Canadian Journal of Communication, 19(3/4), 37-62.

Radway, Janice. (1984). Reading the Romance: Women, Patriarchy, and Popular Literature. 
Chapel Hill, NC: U North Carolina P.

Randall, Stephen. (2000). Integrating Canada and the U.S.: The Historical Framework. Canadian Journal of Policy Research, 1(1), 32-38.

Rawlyk, George. (1976). The Federalist-Loyalist Alliance in New Brunswick, 1784-1815.

Humanities Association Review, 27(2), 142-161.

Resnick, Phillip. (2002, October). "Can Canada Survive Free Trade?" Literary Review of Canada, 10(8), 12-13.

Ritchie-Dawson, Laura (2002). Whose Rights? The NAFTA Chapter 11 Debate. Ottawa, ON.:

Centre for Trade Policy and Law.

Roach, Colleen. (1997). Cultural Imperialism and Resistance in Media Theory and Literary

Theory. Media, Culture, and Society, 19, 47-66.

Robert, Maryse. (2000). Negotiating NAFTA: Explaining the Outcome in Culture, Textiles, Autos, and Pharmaceuticals. Toronto: U Toronto P.

Robinson, Gertrude. (1988). Here Be Dragons: Problems in Charting the US History of

Communication Research. Communication, 10(2), 97-119.

Roseau, James. (1969). Linkage Politics. New York: Free Press.

Rosengren, Karl. (1989). Paradigms Lost and Regained. In Brenda Dervin, Lawrence Grossberg, Barbara O'Keefe \& Ellen Wartella (Eds.), Rethinking Communication, vol. 1 (pp. 21-39). Newbury Park, CA: Sage.

Ruggerio, Renato. (1998). Address by Director-General Renato Ruggerio. Geneva WTO Ministerial Statement. www.wto.org/english/news. Accessed February 2, 2001.

-.--. (1999). Beyond the Multilateral Trading System. WTO News. www.wto.org/english/news. Accessed February 2, 2001.

Salomon, Gavriel. (1985). The Study of Television in a Cross-Cultural Context. Journal of Cross-Cultural Psychology, 16(3), 381-397.

Salwen, Michael. (1991). Cultural Imperialism: A Media Effects Approach. Critical Studies in Mass Communication, 8, 29-38.

Sands, Christopher. (2001, April 23). An Argument for the Negotiation of a Bilateral Agreement on Cultural Trade with Canada - Why Now? Working paper presented at U.S. Trade 
Strategy and Canadian Culture Workshop, Center for Strategic and International Studies, Washington, DC.

----. (2001). A Chance to End Culture Trade Conflict between Canada and the United States. American Review of Canadian Studies, 31(3), 483-500.

Sands, David R. (1993, November 24). Clash of Cultures Creates Latest Block to World Trade Pact. Washington Times, p. B7.

Sauve, Pierre. (2002). GATS: The Case for Open Services Markets. Paris: OECD.

Sewell Jr., William. (1999). The Concept(s) of Culture. In Victoria Bonnell \& Lynn Hunt (Eds.), Beyond the Cultural Turn: New Directions in the Study of Society and Culture (pp. 3561). Berkeley, CA.: U California P.

Schiller, Dan. (1996). Theorizing Communication: A History. New York: Oxford UP.

Schiller, Herbert. (1991). Mass Communications and American Empire, rev. ed. Boulder, CO.: Westview P.

Schramm, Wilbur. (1983). The Unique Perspective of Communication: A Retrospective View. Journal of Communication, 33(3), 6-17.

Schramm, Wilbur, J. Lyle and E. Parker. (1961). Television in the Lives of Our Children. Stanford, CA.: Stanford UP.

Schroder, Kim. (1987). Convergence of Antagonistic Traditions? The Case of Audience Research. European Journal of Communication, 2, 7-31.

Schwanen, Daniel. (2001). A Room of Our Own: Cultural Policies and Trade Agreements. Choices, 7(4), Montreal, PQ.: Institute for Research on Public Policy.

Seiler, Robert. (2002). Selling Patriotism/Selling Beer: The Case of the "I Am Canadian!" Commercial. American Review of Canadian Studies, 32(1), 45-66.

Shao, W. Ming. (1995). Is There No Business Like Show Business? Yale Journal of International Law, 20, 105-150.

Shoyer, Andrew. (2000, March 27). Remarks made at WTO Dispute-Settlement Symposium, Ottawa, ON.

Simon, Herbert. (1958). Models of Man, Social and Rational. New York: Wiley.

Sinclair, John, Elizabeth Jacka, and Stuart Cunningham. (1996). Peripheral Vision. In New 
Patterns in Global Television (pp. 1-32). New York: Oxford UP.

Skidelsky, Robert. (2003, March 13). The Mystery of Growth. [Review of the books The Spirit of Capitalism: Nationalism and Economic Growth and Lectures on Economic Growth.] New York Review of Books, 50(4), 28-31.

Slack, Jennifer and Martin Allor. (1983). The Political and Epistemological Constituents of Critical Communication Research. Journal of Communication, 33(3), 208-218.

Slotkin, Richard. (1973). Regeneration Through Violence: The Mythology of the American Frontier, 1600-1680. New York: HarperCollins.

----. (2000, November). The Fall Into Guns. [Review of the book Arming America: The Origins of a National Gun Culture.] Atlantic Monthly, 286, 114-118.

Stabile, Carol. (1995). Resistance, Recuperation, and Reflexivity: The Limits of a Paradigm. Critical Studies in Mass Communication, 12, 403-422.

Straubhaar, Joseph. (1991). Beyond Media Imperialism: Asymmetrical Interdependence and Cultural Proximity. Critical Studies in Mass Communication, 8, 39-59.

Smadja, Daniele. (2002, April 18). Remarks at Ties that Bind conference, Ottawa, ON.

Smith, Allan. (1976). The Continental Dimension in the Evolution of the English-Canadian Mind. International Journal, 31, 442-469.

----. (1990). Canadian Culture, the Canadian State, and the New Continentalism. CanadianAmerican Public Policy Occasional Paper \#3. Orono, ME.: U Maine P.

-.--. (1994). Canada - An American Nation? Montreal: McGill-Queen's P.

----. (2000). Doing the Continental: Conceptualization of the Canadian-American Relationship in the Long Twentieth Century. Canadian-American Public Policy Occasional Paper \#44. Orono, ME.: U Maine P.

Smith, Anthony. (1971). Theories of Nationalism. New York: Harper \& Row.

-----. (1994). The Problem of National Identity: Ancient, Medieval, and Modern? Ethnic and Racial Studies, 17(3), 375-399.

(1995). Nations and Nationalism in a Global Era. London: Polity.

----. (1998). Nationalism and Modernism: A Critical Survey of Recent Theories of Nations and Nationalism. London: Routledge. 
----. (2002). National Identity, rev. ed. Reno: U Nevada P.

Smith, Marilyn L. (1999). Cultural Carve-Out Versus Cultural Cohesion: The Canadian

Exemption for Culture in the MAI. Unpublished M.A. thesis, Carleton University.

Smith, Martin. (1994). Policy Networks and State Autonomy. In Stephen Brooks \& Alain-G.

Gagnon (Eds.), The Political Influence of Ideas: Policy Communities and the Social

Sciences (pp. xx-xx). NY: Praeger.

Sparkes, Vernon. (1977). TV Across the Canadian Border: Does it Matter? Journal of

Communication, 27(4), 40-47.

Sproule, J. Michael. (1994). Progressive Propaganda Critics and the Magic Bullet Myth. Critical

Studies in Mass Communication, 6(3), 225-246.

Steger, Debra. (2000). The World Trade Organization: A New Constitution for the Trading

System. In Marco Bronckers \& Reinhard Quick (Eds.), New Directions in International

Economic Law (pp. 135-154). The Hague, Netherlands: Kluwer.

----. (2002). Afterword: The "Trade And..." Conundrum - A Commentary. American Journal of International Law, 96(1), 135-145.

Stewart, Gordon. (1992). The American Response to Canada Since 1776. East Lansing:

Michigan State UP.

Stuart, Reginald. (1997). Anti-Americanism in Canadian History. American Review of Canadian

Studies, 27(2), 293-310.

----. (2001). Death of the Nation State? American Review of Canadian Studies, 31(3), 427-440.

Stursberg, Richard. (2000, November 25). Trade and Culture. Remarks made at Canadian Institute of International Affairs, Montreal.

Sui-nam Lee, Paul. (1995). A Case Against the Thesis of Communication Imperialism: The Audience's Response to Foreign TV Programs in Hong Kong. Australian Journal of Communication, 22(3), 63-81.

Swanson, Roger. (1977). Canadian Cultural Nationalism and the U.S. Public Interest. In Janice Murray (Ed.), Canadian Cultural Nationalism (pp. 55-84). New York: NYU P.

Tichenor, P., G. Donohue and C. Olien. (1970). Mass Media Flow and the Differential Growth of Knowledge. Public Opinion Quarterly, 34(2), 159-170. 
Tilly, Charles. (1975). Reflections on the History of European State-Making. In Charles Tilly (Ed.), The Formation of National States in Western Europe (pp. 3-83). Princeton, NJ: Princeton UP.

Thompson, John and Stephen Randall. (1997). Canada and the United States: Ambivalent Allies, $2^{\text {nd }}$ ed. Athens, GA.: U Georgia P.

Thompson, John. (1995). Media and Modernity: A Social Theory of the Media. Stanford, CA.: Stanford UP.

Thompson, Kristin. (1985). Exporting Entertainment: America in the World Film Market, 19071934. London: British Film Institute.

Throsby, David. (2001). Economics and Culture. Cambridge: Cambridge UP.

Tomlinson, John. (1991). Cultural Imperialism: A Critical Introduction. Baltimore, MD.: Johns Hopkins $U$.

-.-.-. (1999). Globalization and Culture. Chicago: U Chicago P.

Tracey, Michael. (1985). The Poisoned Chalice? International Television and the Idea of Dominance. Daedalus, Fall, 17-56.

Trebilcock, Michael and Robert Howse. (1999). The Regulation of International Trade, $2^{\text {nd }}$ ed. London: Routledge.

Truehart, Charles. (1994, December 2). Culture Clash: Canadian Nationalists Decry American Infiltration. Washington Post, A2.

Twiggs, Joan. (1987). The Tokyo Round of Multilateral Trade Negotiations: A Case Study for Building Support for Diplomacy. Washington, DC.: Georgetown University Institute for the Study of Diplomacy.

Varan, Duane. (1992). The Costs and Benefits of Television: Applying the Emerging Paradigms of Development Communication to the Cook Islands Experience. Unpublished Ph.D. dissertation, Austin, TX.: U Texas.

-----. (1998). The Cultural Erosion Metaphor and the Transcultural Impact of Media Systems. Journal of Communication, 48(2), 58-85.

Vidmar, Neil \& Milton Rokeach. (1974). Archie Bunker's Bigotry: A Study in Selective Perception and Exposure. Journal of Communication, 24(1), 36-48. 
Vipond, Mary. (1977). Canadian Nationalism and the Plight of Canadian Magazines in the 1920s. Canadian Historical Review, 58(1), 43-63.

Wall, Irwin. (1991). The United States and the Making of Postwar France, 1945-54. Cambridge: Cambridge UP.

Warner, Donald. (1960). The Idea of Continental Union: Agitation for the Annexation of Canada to the United States, 1849-1893. Lexington, KY: University of Kentucky Press.

Warner, L. and W. Henry. (1948). The Radio Daytime Serial: A Symbolic Analysis. Genetic Psychoanalysis, 37, 3-71.

Weaver, John. (1973). Imperilled Dreams: Canadian Opposition to American Empire, 19181930. Unpublished Ph.D. dissertation, Duke University.

Weintraub, Sidney. (1994). Current State of U.S.-Canada Economic Relations. American Review of Canadian Studies, 24(4), 473-488.

Wernick, Michael. (2001, November 28). Remarks at the Trade and Culture Conference, Ottawa, ON.

Wheeler, Mark. (2000). Globalization of the Communications Marketplace. Harvard International Journal of Press/Politics, 5(3), 27-44.

Wildman, Steven and Stephen Siwek. (1988). International Trade in Films and Television Programs. Cambridge, MA.: Ballinger P.

Wilhoit, G. Cleveland \& Harold de Bock. (1976). "All in the Family" in Holland. Journal of Communication, 26(4), 75-84.

Williams, Raymond. (1974). Television: Technology and Cultural Forum. New York: Schocken.

----. (1983). Culture. In Keywords: A Vocabulary of Culture and Society, rev. ed. (pp. 87-93). New York: Oxford.

Winks, Robin. (1998). The Civil War Years: Canada and the United States, $4^{\text {th }}$ ed. Montreal: McGill-Queens P.

Winseck, Dwayne. (1997). Contradictions in the Democratization of International Communication. Media, Culture, and Society, 19(2), 219-246.

Wise, Sidney. (1962). The Origins of Anti-Americanism in Canada. In Fourth Seminar on Canadian-American Relations (pp. 297-306). Windsor, ON. U Windsor P. 
Wise, Sidney and Robert Brown. (1967). Canada Views the United States: $19^{\text {th }}$ Century Political Attitudes. Seattle: U Washington P.

Wolfe, Robert and Matthew Mendelsohn. (2002). "Values, Interests, and Globalization: The Continuing Compromise of Embedded Liberalism." Paper presented at the Canadian Political Science Association annual conference, in Toronto, May 29-31.

Wonnacott, Paul. (1965). The Canadian Dollar, 1948-1962. Toronto: U Toronto P.

World Trade Organization. (1997). Canada - Certain Measures Concerning Periodicals. WT/DS/31/R. Geneva.

Zemans, Joyce. (1994). "And the Lion Shall Lie Down with the Lamb": U.S.-Canada Cultural Relations in a Free Trade Environment. American Review of Canadian Studies, 24(4), 509-536. 